
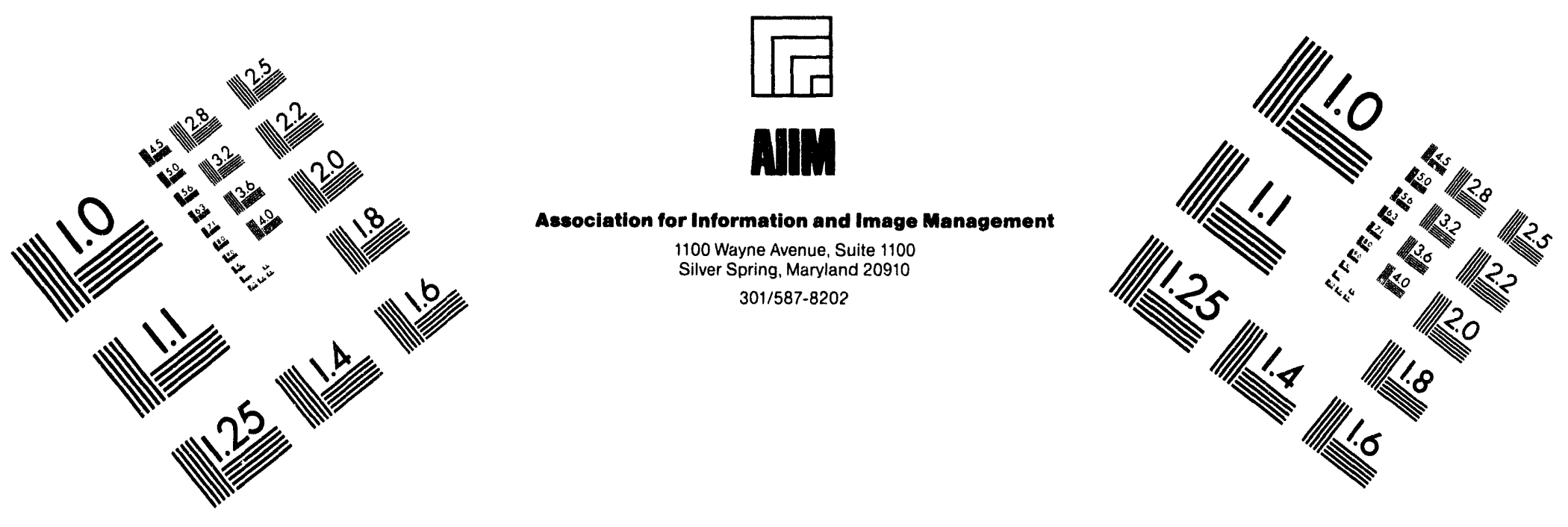

\title{
Centimeter
}

$\begin{array}{llllllllllllllll}1 & 2 & 3 & 4 & 5 & 6 & 7 & 8 & 9 & 10 & 11 & 12 & 13 & 14 & 15 & \mathrm{~mm}\end{array}$ Inches

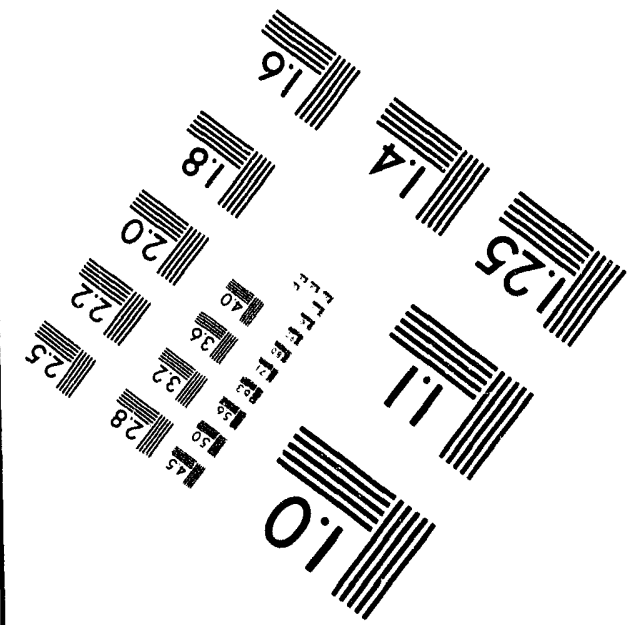

MANUFACTURED TO AIIM STANDARDS BY APPLIED IMAGE, INC.

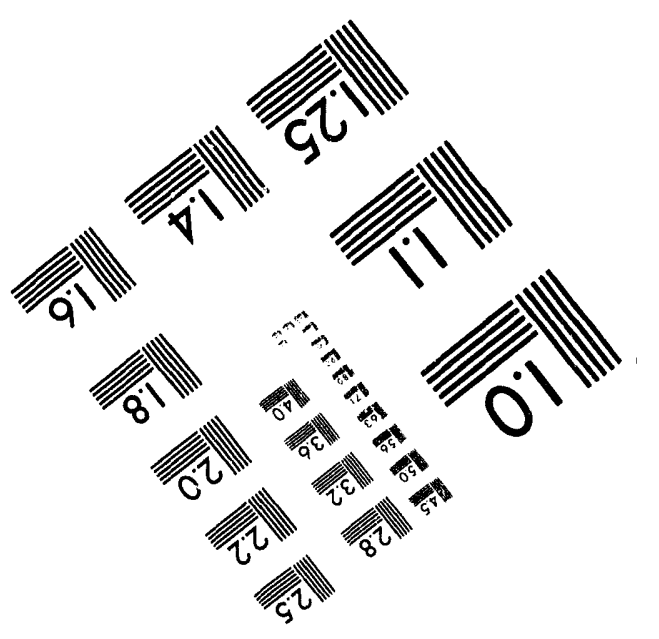



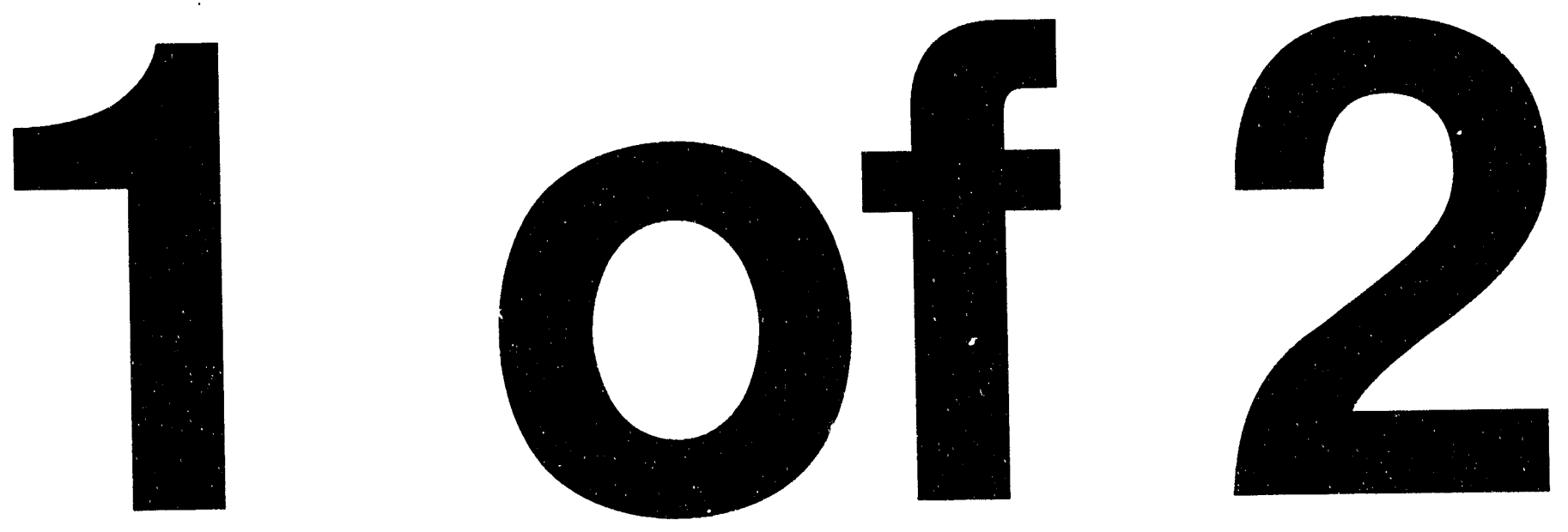


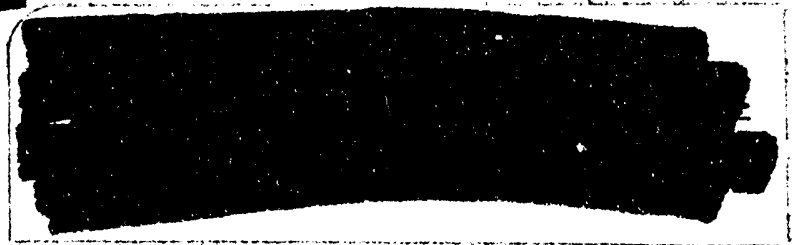

\section{DESIGN STUDY INTERIM REPORT}

\section{RMA BUTTON LINE RADIATION REDUCTION}

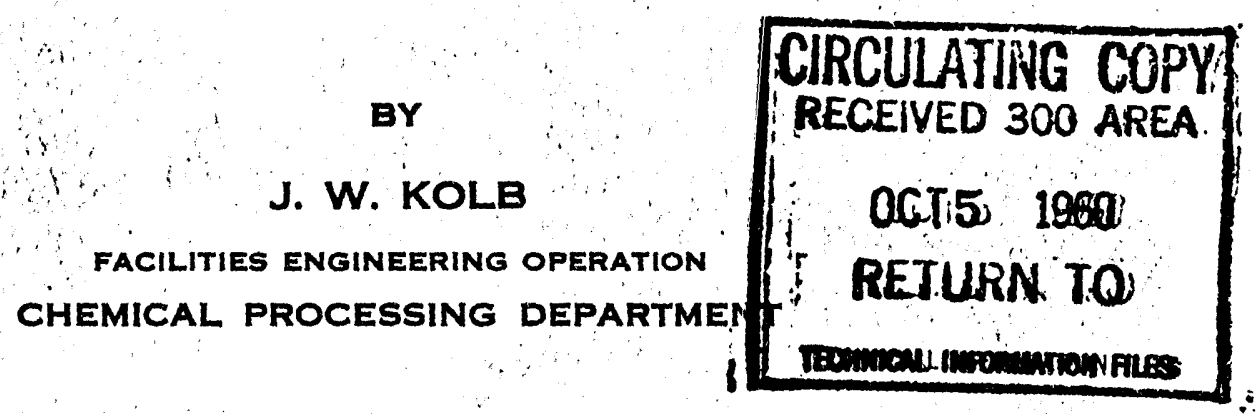

H. J. BELLARTS

DESIGN ENGINEERING OPERATION

CONSTRUCTION ENGINEERING AND UTILITIES

APRIL 1, 1960

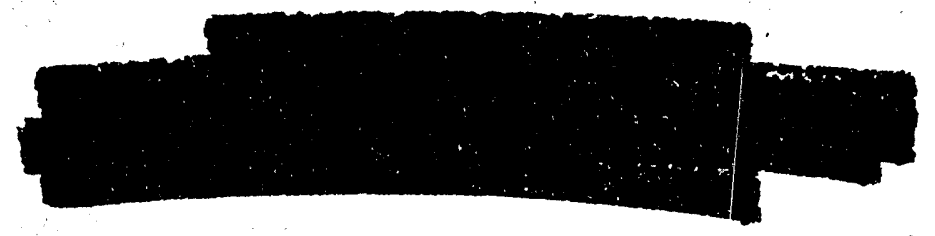

HANFORD ATOMIC PRODUCTS OPERATION RICHLAND, WASHINGTON

\section{GENERAL (G) ELECTHE ISSIFIED}

A.E.C. - G.E. - MKCHLAND. WASH.

....... GROUP 1

DEXELUDED FROM AUTOMATIC ONWNA

AND DECLASSIFICA,

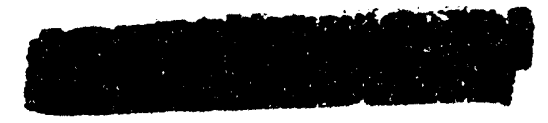

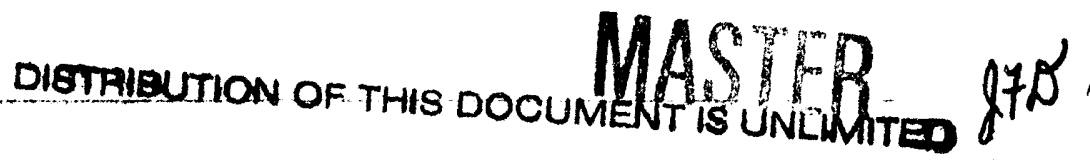


This document consists of

101 nages. No.

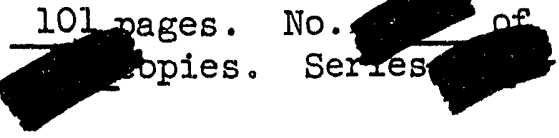

DESIGN STUDY INTERIM REPORT RMA BUTTON LINE RADIATION REDUCTION

By

J. W. Kolb

Facilities Engineering Operation CHEMICAL PROCESSING DEPARTMENT

H. J. Bellarts

Design Engineering Operation CONSTRUCTION ENGINEERING AND UTILIflyedisication Cancolind and Chanoed To

April 1, 1960

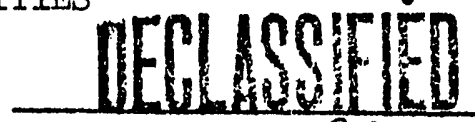

B) Authority of $C G P R-2$

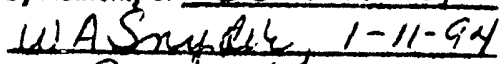

$8 y-217$ aley, $1-26-44$ HANFORD ATOMIC PRODUCTS OPERATION Verifed by of 5 Saesey $2-4-94$
Richland, Washington
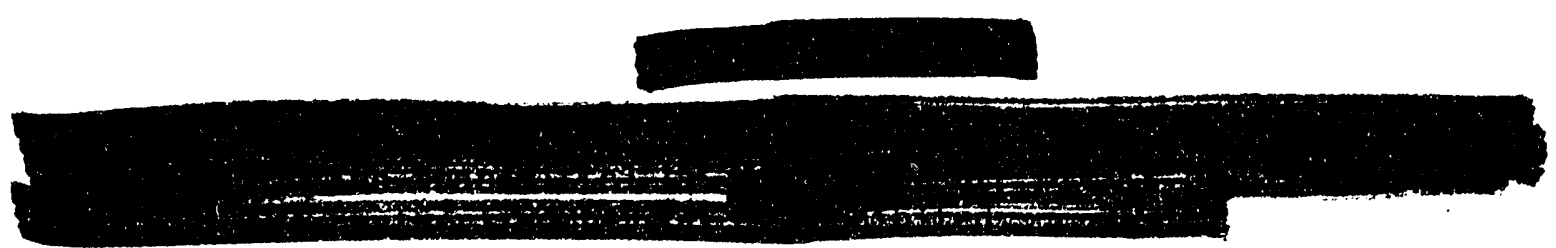

\begin{tabular}{c|c|c||c|c|c} 
Route To & Read By & Date & Route To & Read By & Date \\
\hline ph feut & 236 & $271 T$ & & & \\
\hline & & & & & \\
\hline & & & & & \\
\hline & & & & & \\
\hline
\end{tabular}




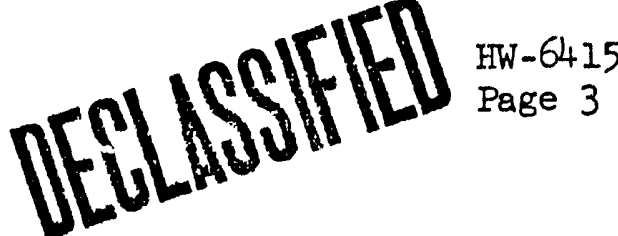

$\underline{\text { Page }}$

I. INTRODUCTION

II. PURPOSE

III. SUMMARY AND CONCLUSIONS

IV. DISCUSSION

A. Need For New Facilities $\quad 7$

B. Design Philosophy 8

C. Processing Equipment - General 10

D. Maintenance Procedures 11

E. Plastic Bag Techniques 12

- STUDY DRAWINGS

SK-2-18256 Wet and Dry Chemical Equipment 14

SK-2-18257 Reduction Equipment 15

SK-2-17974 Process Flow Diagram 16

SK-2-18211 Process Sequence Schemat1c Mod. $2 \quad 17$

SK-2-18255 Building Arrangement 18

SK-2-17978 Maintenance Hood Arrangement 19

SK-2-18224 Double-Sleeve Bag-Out Procedure 20

APPEIDIX I

INTRODUCTION 21

GENERAL PROCESS DESCRIPTION 21

DESIGN BASIS

STUDY DRAWINGS

SK-2-18231 PR Can Unloading Station and RC Can Loading 53

SK-2-18232 Arrangement and Piping PR Hood and Killed 54 Filtrate Hood

SK-2-18218 Typlcal Shielding Mod. 2 - Wet Chemistry 55 Vessels 


\section{- VEULLSSIFED}

HW -64156

Page 4

\begin{tabular}{|c|c|c|}
\hline & & Page \\
\hline SK $-2-18235$ & $\begin{array}{l}\text { Remotely Operated Unloading Head for } P R \\
\text { and RC Can }\end{array}$ & 56 \\
\hline SK-2-18242 & Positioning Cart For PR Can - Mark III & 57 \\
\hline SK-2-18237 & PR Can and Container & 58 \\
\hline sK $-2-18234$ & Remote Sampler Arrangement & 59 \\
\hline$S K-2-18233$ & PR Hood and Killed Filtrate Hood Details & 60 \\
\hline SK-2-18226 & Wet Chemistry Arrangement - Mark 2 & 61 \\
\hline $\begin{array}{l}\text { SK-2-18212 } \\
\text { Sht. } 1 \& 22\end{array}$ & $\begin{array}{l}\text { Equipment Arrangement Wet and Dry Chemistry - } \\
\text { MK II }\end{array}$ & $62-63$ \\
\hline SK-2-17976 & Reactor Vessel & 64 \\
\hline SK-2-17975 & $\begin{array}{l}\text { Proposed Modifications to Bird Mfg. Co. - 6" } \\
\text { Centrifugal }\end{array}$ & 65 \\
\hline SK-2-17977 & Screw Reactor and Housing & 66 \\
\hline SK-2-17979 & Gas Tight Powder Valve & 67 \\
\hline SK $-2-18245$ & $\begin{array}{l}\text { Non-Vibrating Reactor Low Frequency Heating, } \\
\text { MK } 3\end{array}$ & 68 \\
\hline $\begin{array}{l}\text { SK-2-18207 } \\
\text { Sht. } 1-3\end{array}$ & Dispenser and Storage Station MK II & $69-71$ \\
\hline SK-2-17986 & Biological Shielding Arrangement & 72 \\
\hline SK-2-17990 & Piping Arrangement & 73 \\
\hline $\begin{array}{l}\text { SK-2-18210 } \\
\text { Sht. } 1-5\end{array}$ & $\begin{array}{l}\text { Material Transfer Tube Plan, Elev, and } \\
\text { Sections }\end{array}$ & $74-78$ \\
\hline$S K-2-18208$ & Material Transfer Tube Typical Details & 79 \\
\hline SK $-2-18060$ & Pressure Vessel Lifting and Centering Device & 80 \\
\hline SK-2-18215 & Pressure Vessel MK III & 81 \\
\hline SK-2-18247 & Crucible MK II & 82 \\
\hline SK-2-18041 & Sand Loader, Small, Task III & 83 \\
\hline SK-2-18057 & Crucible Insertion Station & 84 \\
\hline SK-2-17989 & Sand Loader & 85 \\
\hline SK-2-28205 & Chemical Addition Station Mod. 2 & 86 \\
\hline SK-2-18250 & Mixing Station & 87 \\
\hline SK $-2-18058$ & Gasket Dispenser Station & 88 \\
\hline SK-2-18047 & Reduction Furnace Station Mark I & 89 \\
\hline SK-2-18246 & Gasket Cover Remover MK III & 90 \\
\hline SK-2-18052 & Crucible Grinder & 91 \\
\hline
\end{tabular}




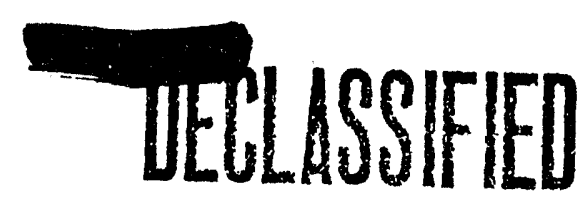

$\mathrm{HW}-64156$

Page 5

Page

SK-2-18244 Crucible Dumper and Screen Mark 292

SK-2-18222 Pickle and Wash Station Off-Set; Vertical 93 Drive

SK-2-18214 Button Finishing Operation Assemb1y 94

SK-2-18251 Numbering Station MK II 95

SK-2-18252 Sampling Station MK I 96

SK-2-18249 Wire Brusher for Groove and Top of Pressure 97

SK-2-18254 Pressure Vessel Exit and Dead Storage Station 98

SK-2-18248 Vacuum Cleaning Station : 99

SK-2-18217 Toggle "C" Clamp for Eguipment Flanges . 100

$\begin{array}{ll}\text { SK-2-17987 Crane Arrangement } & 101\end{array}$ 
III. SUMMARY AND CONCLUSIONS

The design approach followed in this study is that of handing and processing plutonium solution and powders within tightly sealed but readily replaceable units of processing equipment, each one of which will do one step in the overall process. The presently used method is to use open equipment enclosed in glove boxes attached to a transporting device. Elimination of the glove box enclosure and 1ts replacement by tightly sealed and detachable equipment provides the accessability necessary for equipment repair and reduction of down time, thereby reducing costs.

Most of the primary functions for the entire button line have been studied and no insurmountable design problems have been encountered. Studies of the pre-reduction and filtrate treatment functions and the PR can unloading and RC can loading equipment have been summed up and complled into a design criteria. Design concepts for ali of the equipment for processing from the nitrate through the button stage have been worked out and appear to be acceptable approaches, except for the vacuum arum filter and the vibrating tube reactor. The latter two components have been studled and drawlngs prepared; however, the concepts developed are not considered entirely acceptable from the operation and maintenance standpoint. Because of these shortcomings, alternate approaches are being considered for both components. Present plans cali for investigation of a newly developed 6-inch continuous centrifuge to replace the vacuum drum filter, and a ribbon screw-type reactor to replace the vibrating tube. Both substitutions are to be verified by a testing program.

Longer-range plans include investigations of a direct calclnation unit to replace both the vacuum drum filter and the calciner; a fluid bed halogenator to replace the ribbon screw-type reactor; and a continuous Task III. If these processes are developed in time, they will have considerable impact on the equipment designs now being worked out. Most of the equipment used in the present process will be eliminated, and new and different equipment will have to be studied and designed for production. Iine application; however, no insurmountable design problems are foreseen. Other components needing further study and evaluation are the overhead handling and exhauster system whlch is necessary for maintenance of this new production line, and the mainte.sance and decontamination glove boxes.

The overall potential of this new design approach looks favorable. The malntenance procedures are conslderably different; however, the operating procedures are much the same and no insurmountable difficulties are anticipated as long as: (I) components are tested and debugged before installation; (2) all integrated functions are tested and debugged before hot startup; and.(3) operators and malntenance personnel are given adequate training.

IV. DISCUSSION

A. Need for New Facilities

Radiation exposure to operating and maintenance personnel in the 234-5 Building is a problem in the present Task I, II, and III facilities. 
Present information and estimates indicate that the annual exposure rates are near the maximum allowable. Radiation levels of production feed materials will increase substantially in the future due to an increase in present production reactor exposure levels, and the significantly higher exposure levels of the proposed new production reactor. Non-production reactor fuels from off-site may also be processed at HAPO. These non-production reactors w1II be operated at exposure levels many times greater than production reactors, and feed materials will have high radiation levels corresponding to the increased fraction of higher isotopes of plutonium present. In the future, existing Hanford reactors are expected to operate at around $800 \mathrm{MWD} / \mathrm{T}$, the new production reactor at $2,000 \mathrm{MWD} / \mathrm{T}$, and non-production reactors as high as $10,000 \mathrm{MWD} / \mathrm{T}$. At the same time, greater emphasis is being placed on reduction of personnel exposure to radiation. A working limit of $5 \mathrm{rems} / \mathrm{year}$ has been adopted at Hanford. W1th this low working limit, utilization of the present process equipment for processing future production and non-production material as separate streams would result in either excessive radiation exposure to operating and malntenance personnel or unrealistic rotation control to prevent overexposure. Addition of shielding to existing glove boxes would probably produce the desired reduction in total body exposures; however, it would not control hand exposures and it would make it virtually imposstble to repair and replace equipment in the glove boxes due to inaccessibility. In some cases, thick shielding would make it impossible to even operate the equipment.

Data taken from the existing production line indicates that the majority of the exposure recelved is due to the product build-up on the walls of the glove boxes and equipment rather than direct exposure from the material in process. It is well known that appreciable quantities of product ashere tenaciously to the walls and collect on the floors of glove boxes. This belng the case, recycling of the product in process to clean it up would not in itself produce any great reduction in radiation levels at the glove box wall. Numerous attempts at removing the materlal from the glove box walls have falled. A new approach is needed which will eliminate the undesirable features of a glove box yet will prevent spread of contamination, permit heavy shlelding to protect the operators, and allow fast changeout of equipment to prevent overexposure to maintenance personnel.

B. Design Philosophy

As stated previously, the re is firm evidence to support the contention that the majority of exposure to personnel results from the process material which adheres to the walls of the glove boxes. Several attempts at developing techniques for cleaning the interior of the glove box have falled to produce the desired results. Although this might be possible in a laboratory glove box, it is felt that any future attempt to control exposure by this method on a production 
Iine will be totally unreliable. Since the glove box ls the primary source of radiation, and addition of the shielding to glove box walls is not a practical approach to the problem, some means must be devised for elluinating the glove boxes.

The first question that is ralsed when considering the elimination of a glove box $1 \mathrm{~s}$ the risk of contamination spread. Actually, in most cases the elimination of glove boxes around the process equipment does not involve a great deal of risk. For example, in the present glove box approach, rotary shaft seals are employed in the sides of the glove box to transmit rotary motion from the external drive motor to the process equipment inside. Flanges and glove ports are attached to the walls for iperation and malntenance. All of these penetrations and appurtenences are potentlal points for contamination spread, not to mention the fact that the integrity of the glove box proper as ' $a$ ' shielded unit is not too high because of the many points of contamination spread due to leaks around the windows, gasketed jolnts; etc. Very soon after hot startup, the process materlal works its way out into the glove box and adheres to the walls, the gloves, and the seals much the same as it does to the internal walls of the equipment. In effect, the situation which exists inside of the glove box a few weeks after startup is very little different than if the equipment itself provided the confinement. In either case the greatest potential for spread of contamination outside is the shaft seal. Certain types of seals have been employed on glove boxes very successfully in the past. If the process equipment is designed to be as tight as the present glove boxes and if simliar shaft seals are used, then there should be little or no difference in the risk of contamination spread with or without the glove box. If ganma shielding is added directly to the walls of the equipment and portable neutron shlelding is stacked around the equipment in such a way that it can be easily removed by an overhead crane, then the objectives of contamination confinement, reduced operator exposure, and maintenance accessibility can be met.

This obvious change in a production line concept suggests a probable change in operation and maintenance techniques. In general, however, the operation of the line would be quite similar to that presently employed. As shown on SK-2-18256 and SK-2-18257, attached, most of the operation is performed from the Zone I operating gallery which is separated from Zone III by a thick water wall. Full control of the entire line is raintained at this point and exposure limits are expected to be approximately .I mrem/hour. On the Zone III side a minor amount of operator support is needed to load crucibles, gaskets, chemicals, and perform certain viewing operations. The exposure in this zone is expected to be held to approximately I mrem/hour. During normal operation the operator in Zone III would be protected by the gamma shjelding on the equipment and the portable neutron shielding located around the equipment. There should be little or no occasion for the Zone III operator to perform operations inside of the neutron shielding. 
The malntenance techniques will be considerably different from those presently employed, so much so, that special attention, if not complete preference, must be given to maintenance consideration in equipment designs. A typical maintenance procedure is as follows: To repalr or replace a plece of equipment, the malntenance personnel would (I) by use of the overhead crane remove a section or sections of the neutron shlelding; (2) employ a plastlc bag procedure to remove the faulty equipment from 1 ts place in the line; and (3) Immediately after the faulty equipment is removed, insert a spare plece of equipment in it place. During the time of removal and replacement the overhead exhauster would be employed to reduce the chance of contamination spread. The faulty equipment would then be removed to a decontamination unit where it would be cleaned up for subsequent transfer and repair in a maintenance glove box. It will be noted that durling the time for removal and replacement of the equipment the malntenance man is belng exposed to the full fleld of neutrons plus a slight amount of gamma radiation. It is, therefore, desirable that the techniques for removal and replacement be fast and systemized. The same incentive for fast and systemized techniques exists at the maintenance glove boxes. Although equipment is decontaminated prior to Insertion in the glove boxes, material will accumlate over a period of time and the same undesirable effects would be realized here as would be in the present process glove boxes. The exposure at this polnt can be minimized by customizing maintenance glove boxes for quick removal and replacement of equipment and replacement of parts. Essentially, all maintenance and repair would have to be performed in the maintenance glove box since in-line maintenance would be eliminated for all practical purposes. Only minor amounts of rejair could be made in open-faced type maintenance hoods. The plastic bag techniques and maintenance procedures are of spectal significance in this new design approach. Existing knowhow and procedures are generally not adequate. For this reason separate paragraphs $D$ and $E$ have been included in this report to discusa the proposed new concepts.

C. Processing Equipment - General

The discussion of button line equipment designs, in Appendix I, is divided into four general groups: (1) PR can unloading and $R C$ can loading; (2) pre-reduction and filtrate treatment equipment; (3) precipitation processing, wet and ary chemistry; and (4) reduction equipment. Within the groups, each process function or equipment component is discussed with respect to the required furctional criteria, the most promising design approach, neede for further design study or testing required, and technological improvements that would simplify or Improve the design where applicable. Process flow diagrams SK-2-17974 and SK-2-18211 attached, have been included to show the present process on which this study has been based.

The first two groupe are made up of all the equipment which handles IIquids in process and the third group is made up of equipment which 


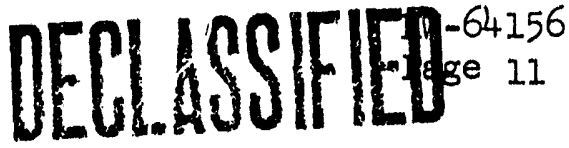

converts the liquid to a dry powder. A pictorial representation of these first three groups is given on SK-2-18256, attached. This drawing shows only the main features of the assembled equipment and is not intended to be mechanically correct or dimensionally accurate. The fourth group is made up of reduction equipment for converting the powder to a metal. A pictorial representation of this group is given on SK-2-18257, attached. An arrangement of the ent1re button Iine located in the 234-5 Building is shown on SK-2-18255, attached.

It can be seen from the above sketches that operation of the entire button line is from the Zone I side of the water wall, similar to the present operation. On the backside of the water wall in Zone III the equipment is located near the wall to permit good visiblilty. Except for the glove boxes housing the valves and pumps (potential leakers) assoclated with the liquid handing portion of the line and the maintenance glove box, equipment is shown without glove boxes. The Task III tunnel which is an enclosure for transferring the pressure vessel between operations is only large enough in cross-section to permit passage of the pressure vessel. Shielded viewing windows are located on the Zone I side of the tunnel to permit observation while handling of the pressure vessel for the varlous loading, firing, positioning, and unloading operations. Portable neutron shielaing is stacked around the equipment to permit frontside viewing and removal by the overhead crane. An exhauster which moves with the crane is used during equipment removal and replacement. Two or more maintenance glove boxes are located in the Zone III area near the equipment. A decontamination unit (not. shown) is located nearby for removal of excess product from equipment needing it to lower radiation levels.

D. Maintenance Procedures

When the glove box is eliminated and the equipment proper becomes the contamination enclosure, the maintenance and replacement of parts becomes a very special problem. The inside of the equipment is contaminated and the outside clean. Some of the external parts are clean entirely, and others are contaminated one end and clean on the other. All parts inside are contaminated. It must be assumed that at one time or another, any one of the parts on a piece of equipment may need replacement. Parts that are completely external can usually be handled by conventional means. Internal parts and parts such as shafts, bearings, and seals which are likely to be contaminated on only one end, are the real problem. The answer is in the design of the section of equipment where these parts are mounted, and in the maintenance glove box.

If the equipment is designed so that the section which houses these parts is detachable and bagable from the remainder of the equipment and can be attached to a glove box with the contaminated parts extending instde and accessible through gloves, then the parts can be repalred and replaced. Removal or replacement of parts prior to 
detachment from the equipment proper would probably be impossible in most cases because of inaccessibility. Once the section is mounted on the maintenance glove box, internal parts are easily replaced by conventional hot maintenance techniques. Special design consideration must be given to the assembly of partially contaminated parts if they are to be replaceable at the maintenance glove box." First, the housing in which these parts are assembled must be flanged in some manner so that when it is detached and bagged from the equipment proper, the parts are accessible from both sides of the flange. A good example of this. Is the way the agitator. drive assembly for the reactor on Hood $9 \mathrm{~A}$ is mounted on a flange outside the hood with the shaft extending through the flange and down into the vessel mounted on the inside top of the hood. When the flange is removed, the drive, shaft, bearings, and seals come with it exposing the contaminated end or side of these parts to the inside of the plastic bag. If this flange is attached to a maintenance glove box, then the parts are accessible through rubber gloves. The second design requirement is that the assembly of these parts in that section be such that defective parts can be displaced into the malntenance glove box by inserting a new one in. its place from the outside. This principle is quite similar to inserting ice cream cartons through a sphincter segl.

In order for this approach to be workable, special design consideration must also be given to the maintenance glove box. Flange ports must be located and sized to accomodate the various size flanges and the equipment needs. The location of glove ports with respect to the flange port opening is also particularly important. At the same time, standardization of flange sizes is desirable. A representative maintenance glove box arrangement is shown on drawing SK-2-17978, attached.

\section{E. Plastic Bag Techniqües}

In many cases, the removal and replacement of equipment secttons cannot be handled conveniently by present plastic bag techn'iques. This is particularly true for sections that require sealing off at both ends. Here the situation would be much the same as removing a section of pipe from a contaminated pipe line. The absence of a free end to slip the plastic sleeve over effectively, rules out present techniques. Because of radiation effects on personnel and temperature effects on the plastic, bags or.sleeves should not remain on the flanges. A green house would normally be used in this case; however, this would not be acceptable for routine maintenance because of the time, cost, and exposure involved. Conventional bolt-up flanges are not acceptable because of the contamination spread when the bolt is removed. An acceptable scheme must: (1) employ flanges which fasten together without bolts; (2) allow application of the plastic material to the flanges on elther or both ends of the section while still attached to the 
equipment proper; (3) allow removal of the section without damaging the bags; and (4) allow removal of the bag or bags after the section has been replaced. A plastic bag procedure and flange design which meets these requirements is shown on SK-2-18224, attached. Conventional "C" clamps or toggle "C" clamps similar to those shown on drawing SK-2-18217, in Appendix I, would be used for fastening the flanges together. 


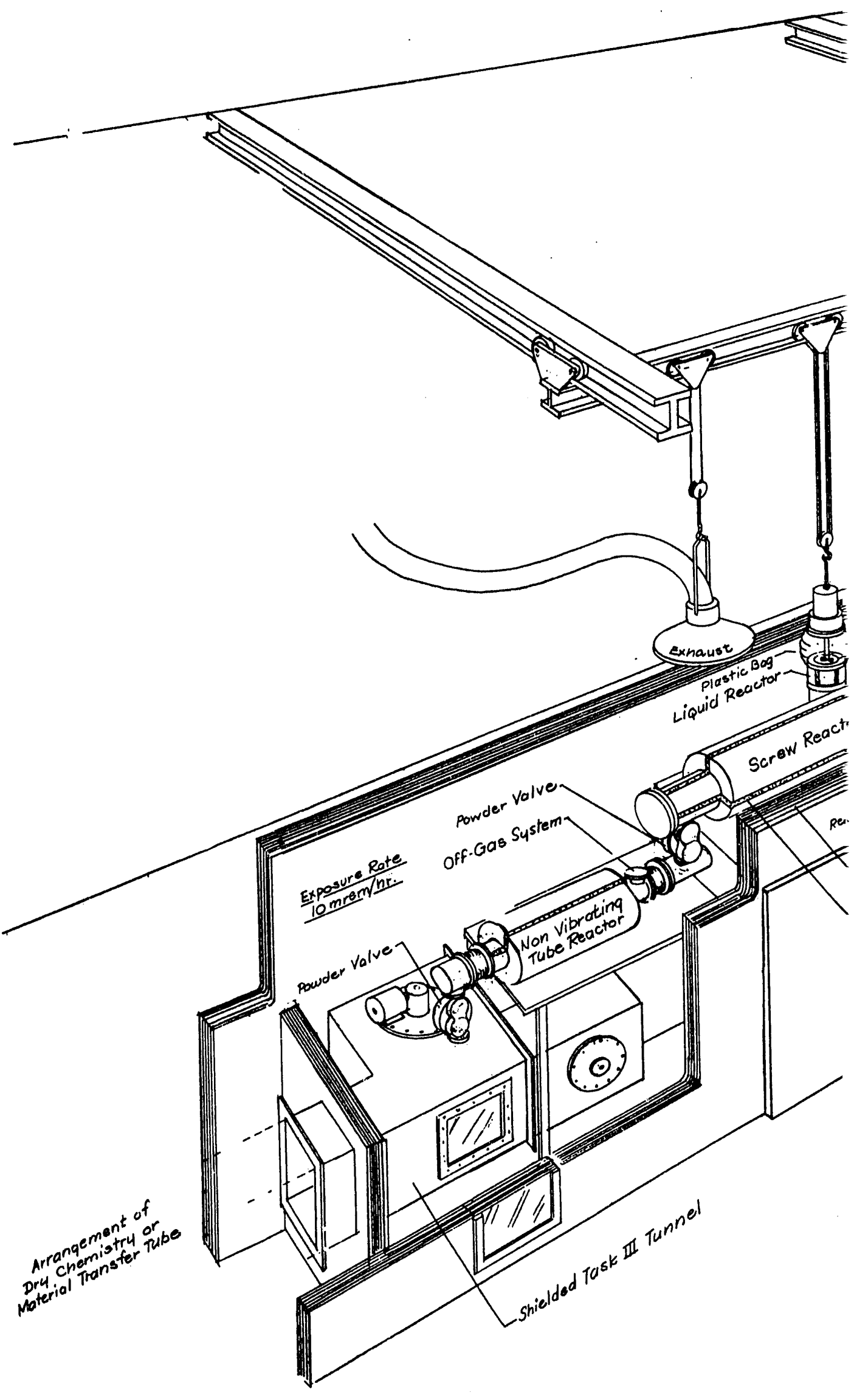




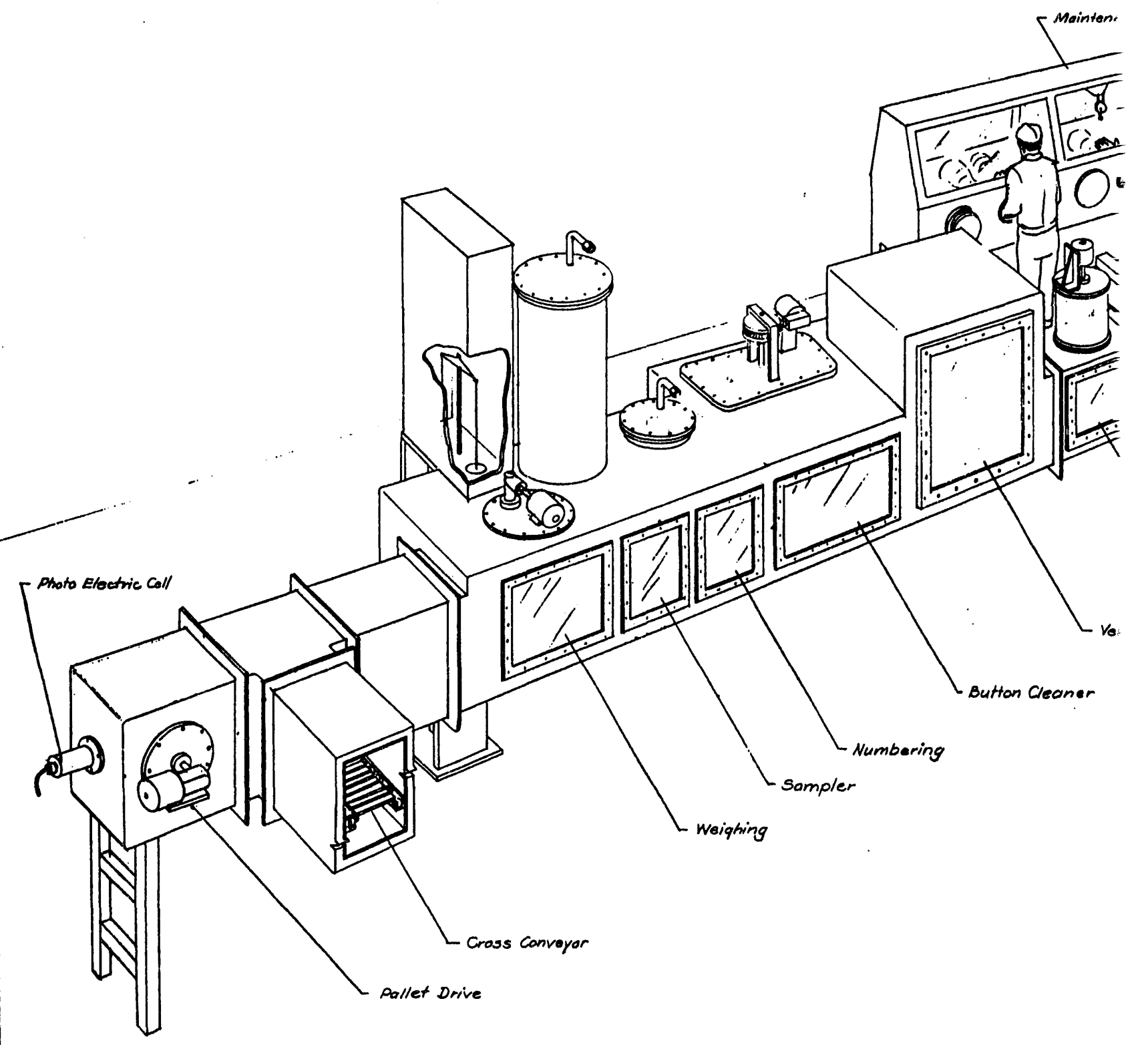



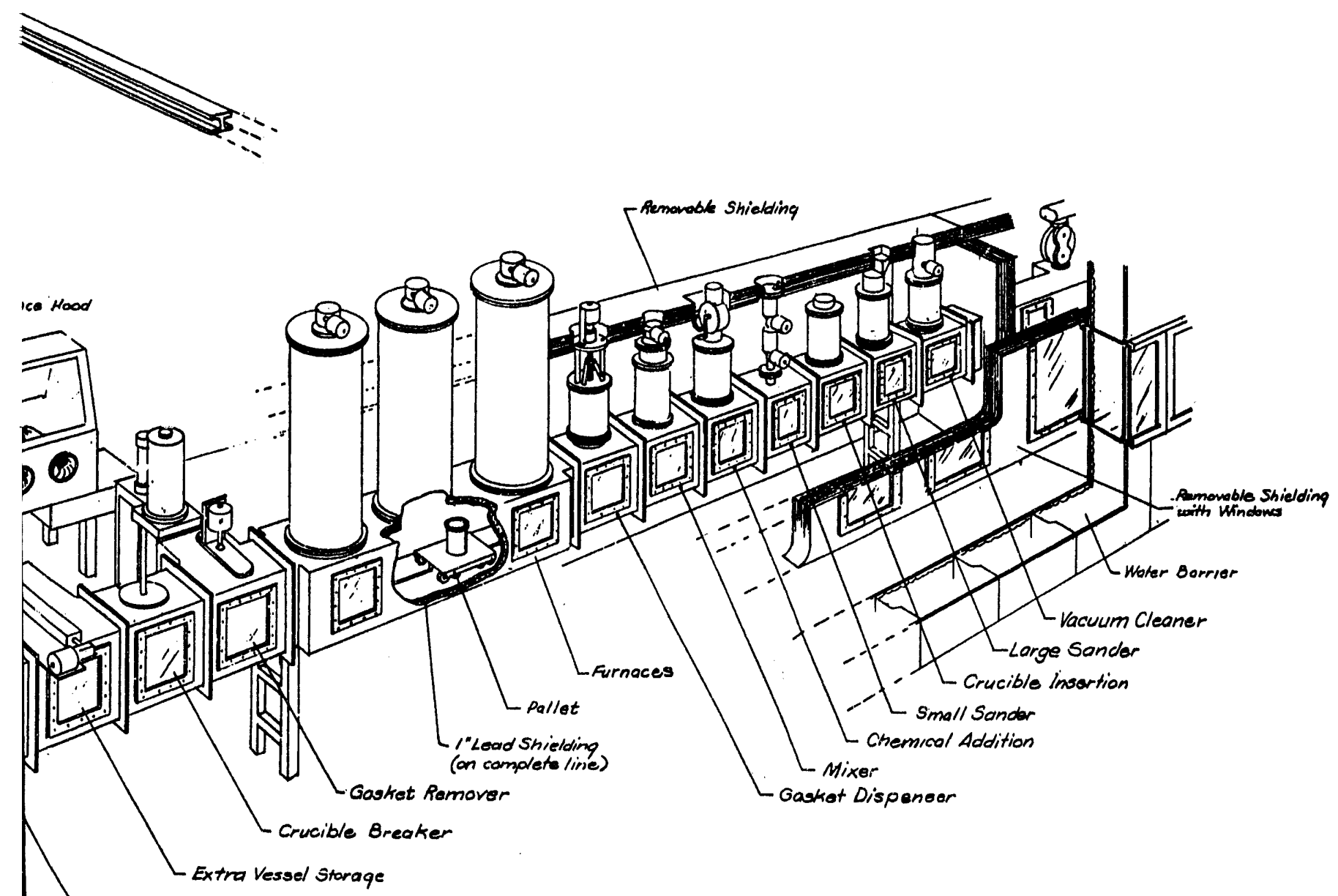

Groove Brusher

I Dumper
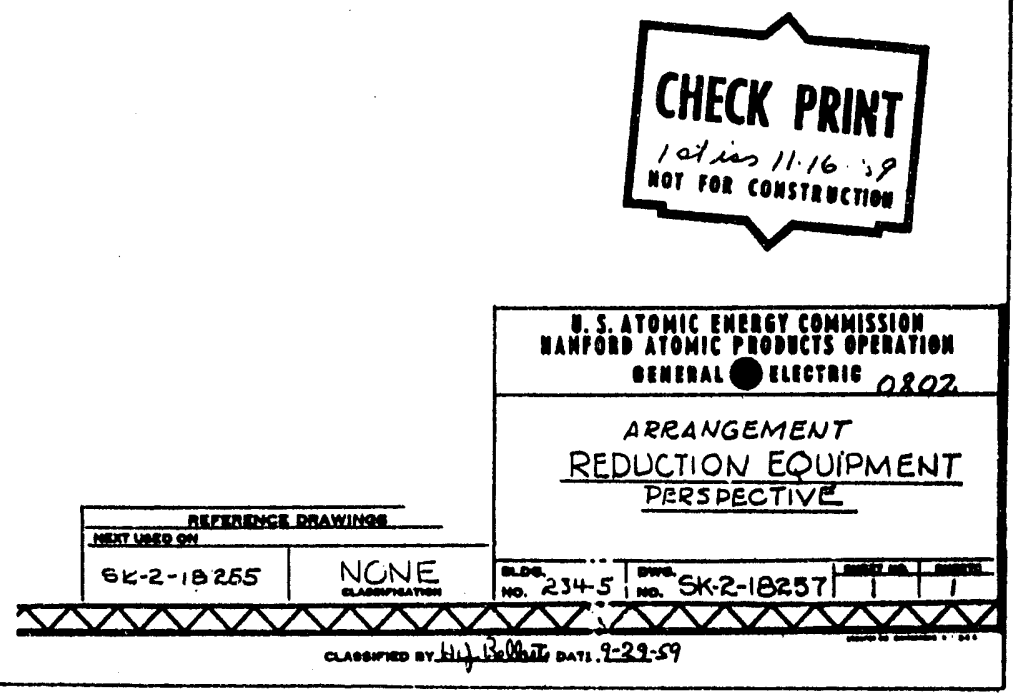


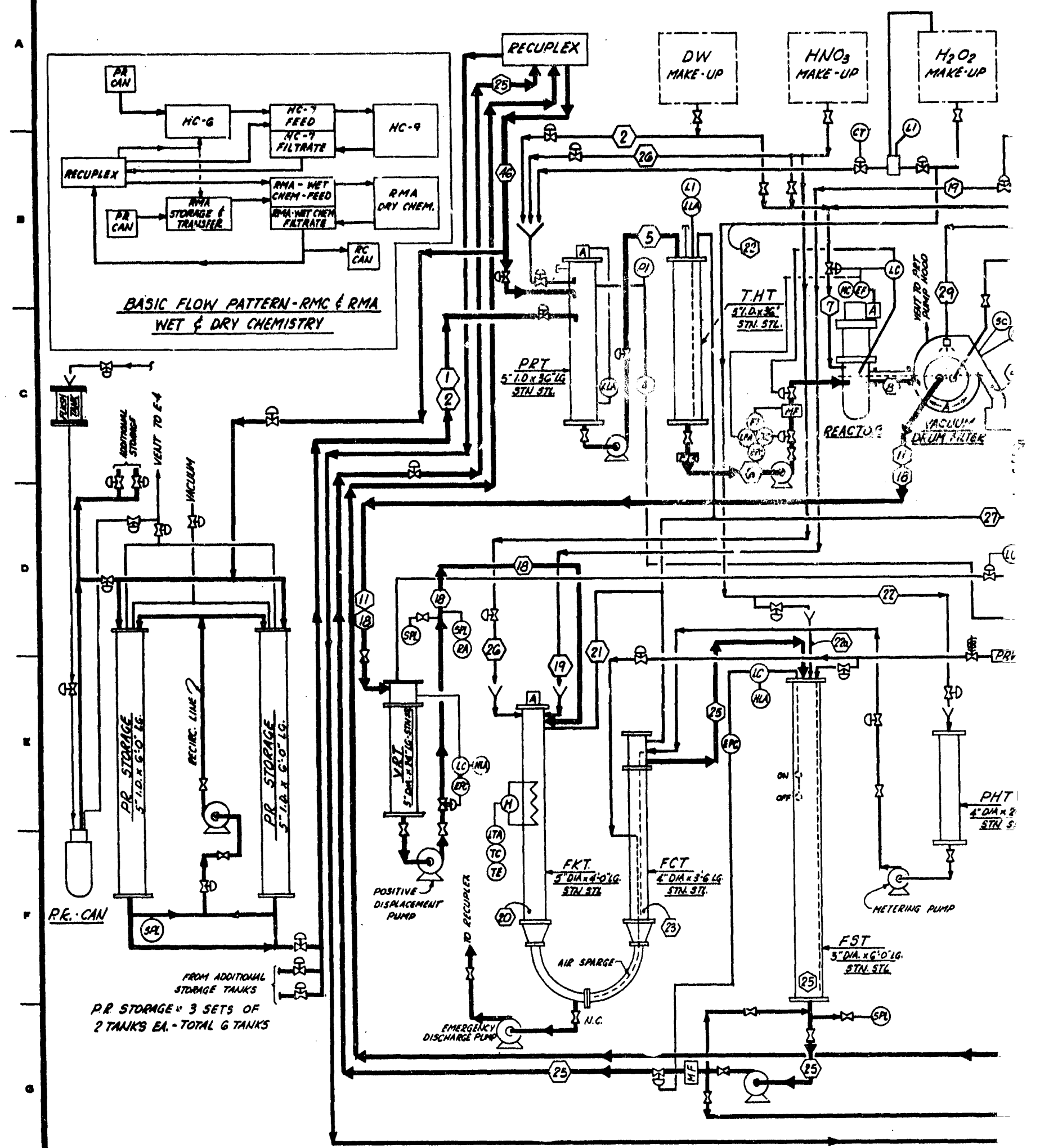




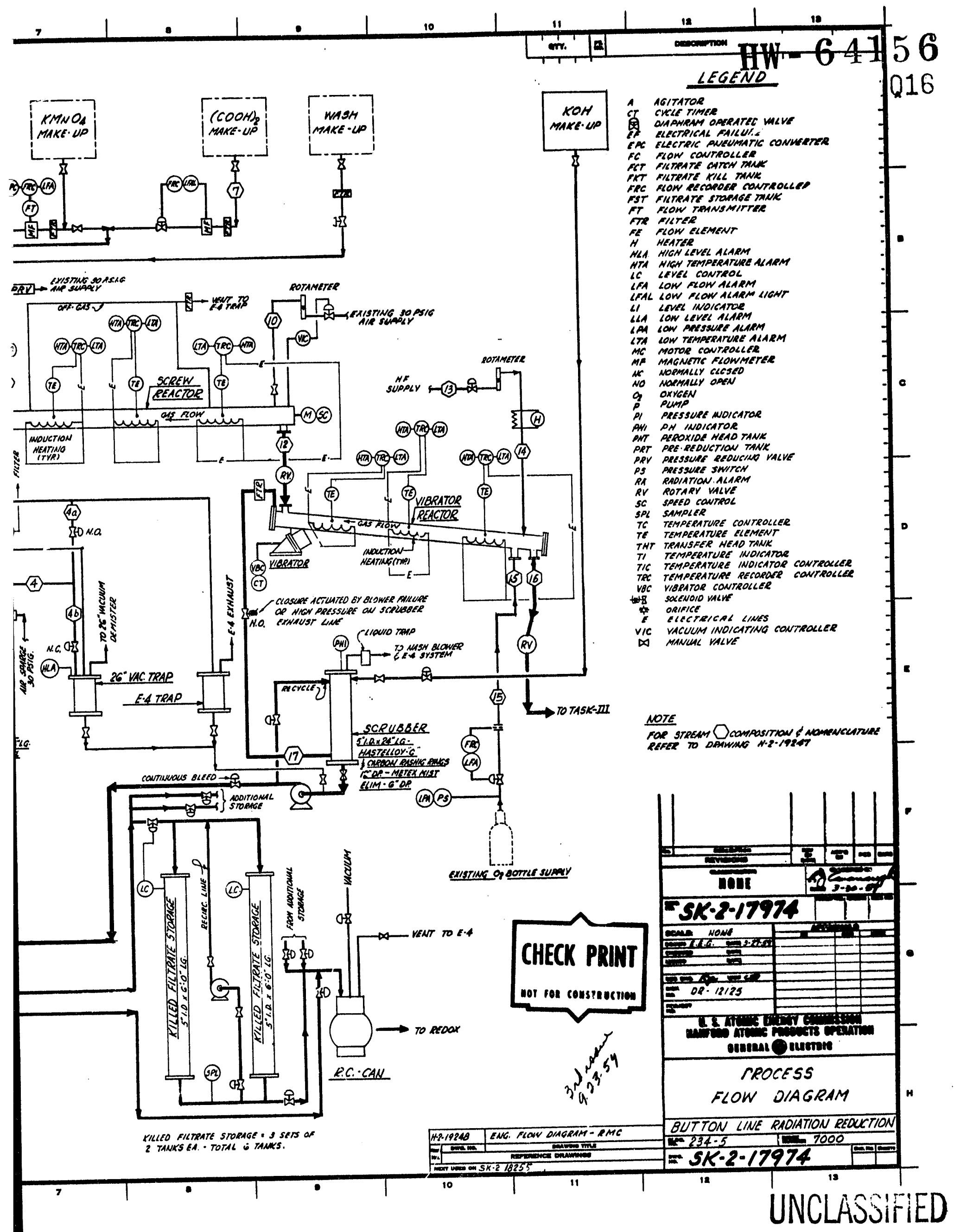




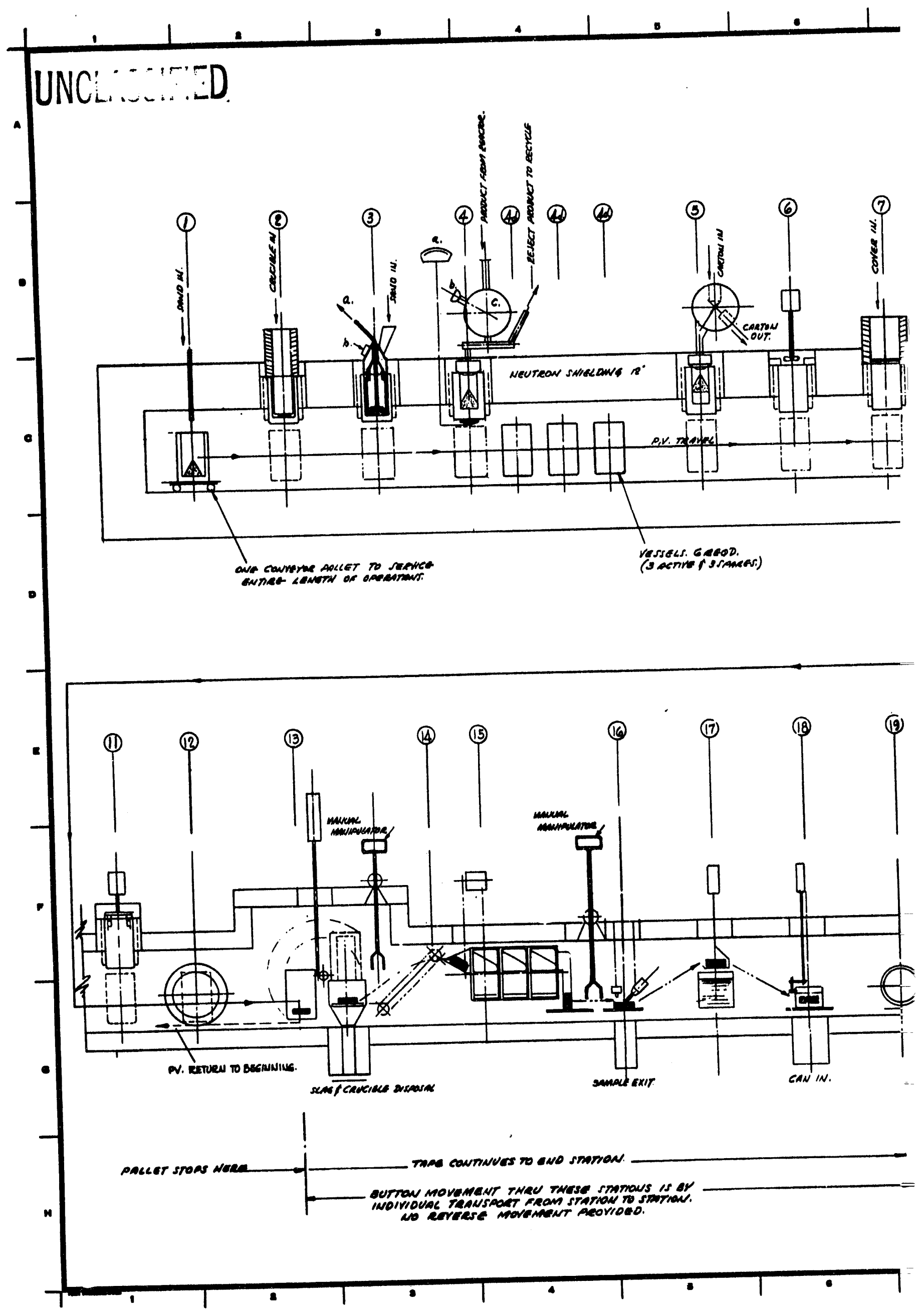




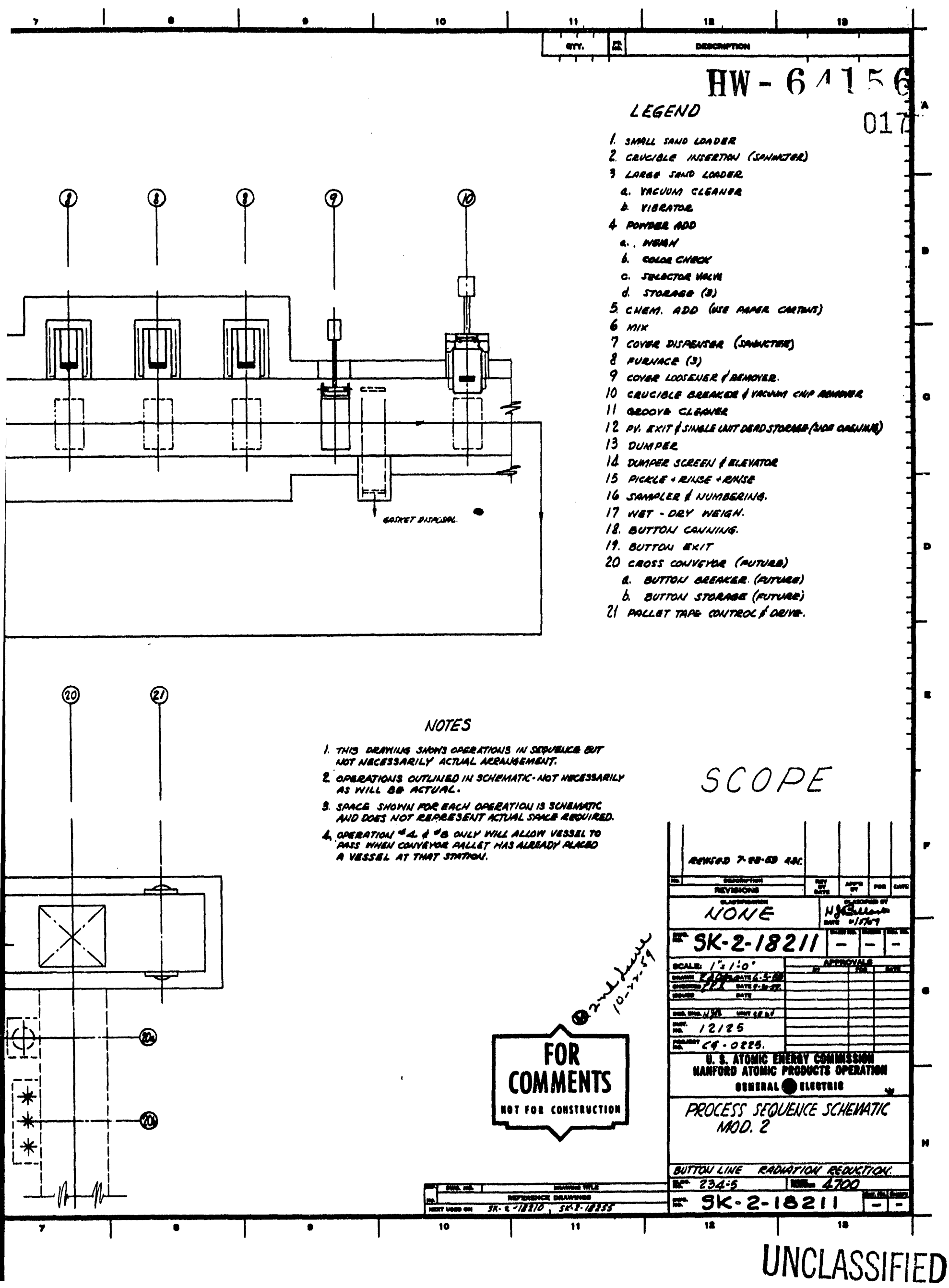




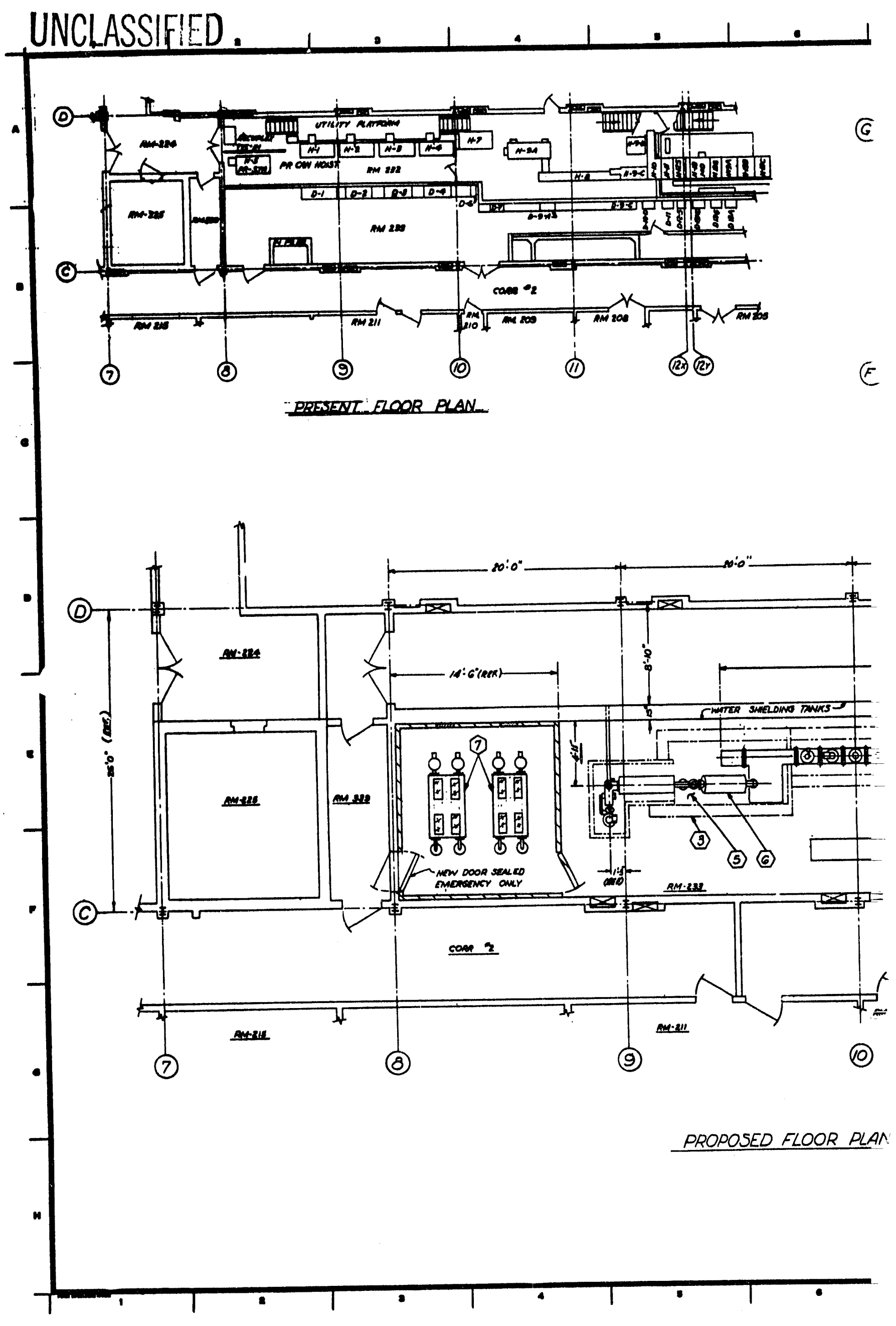




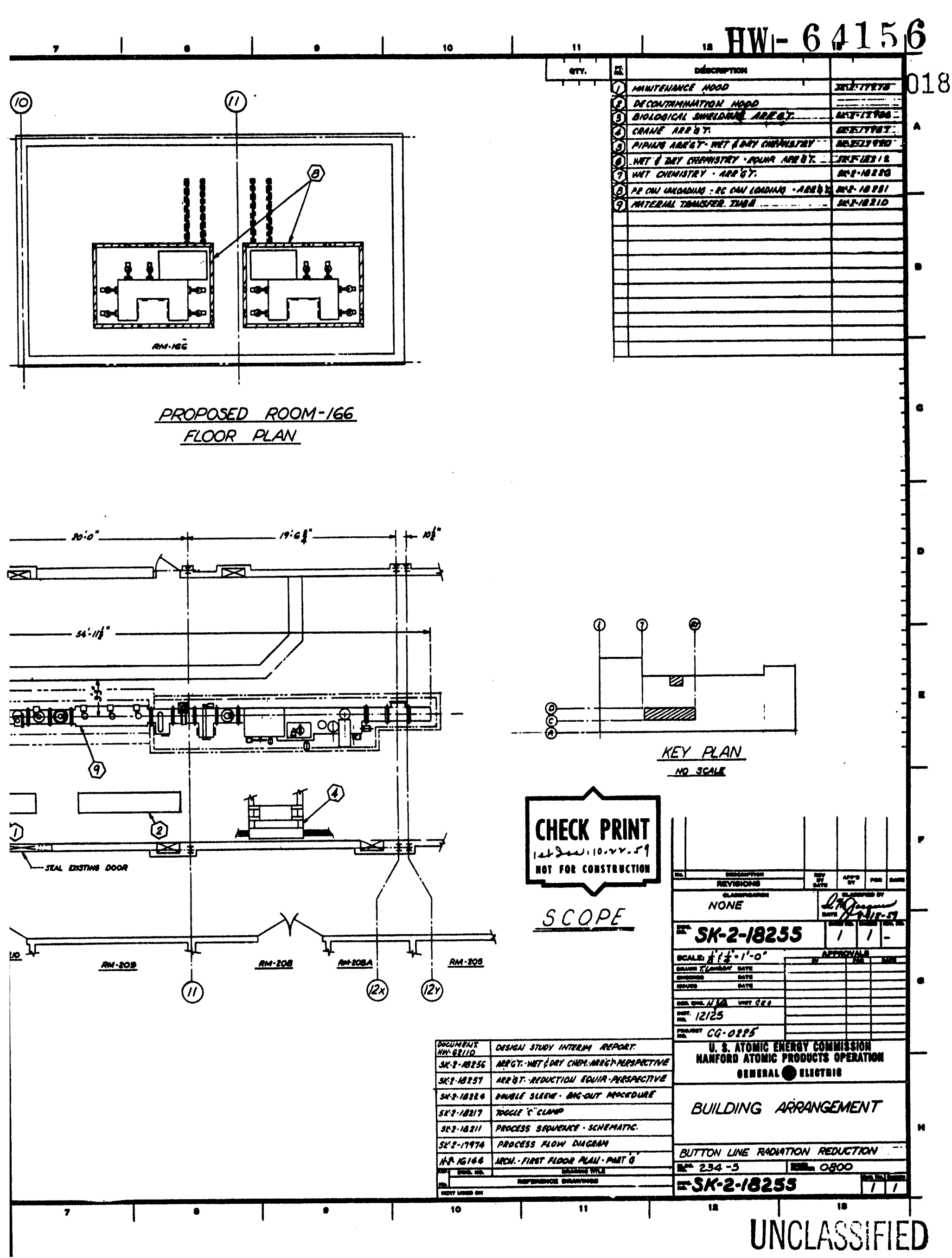




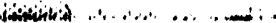

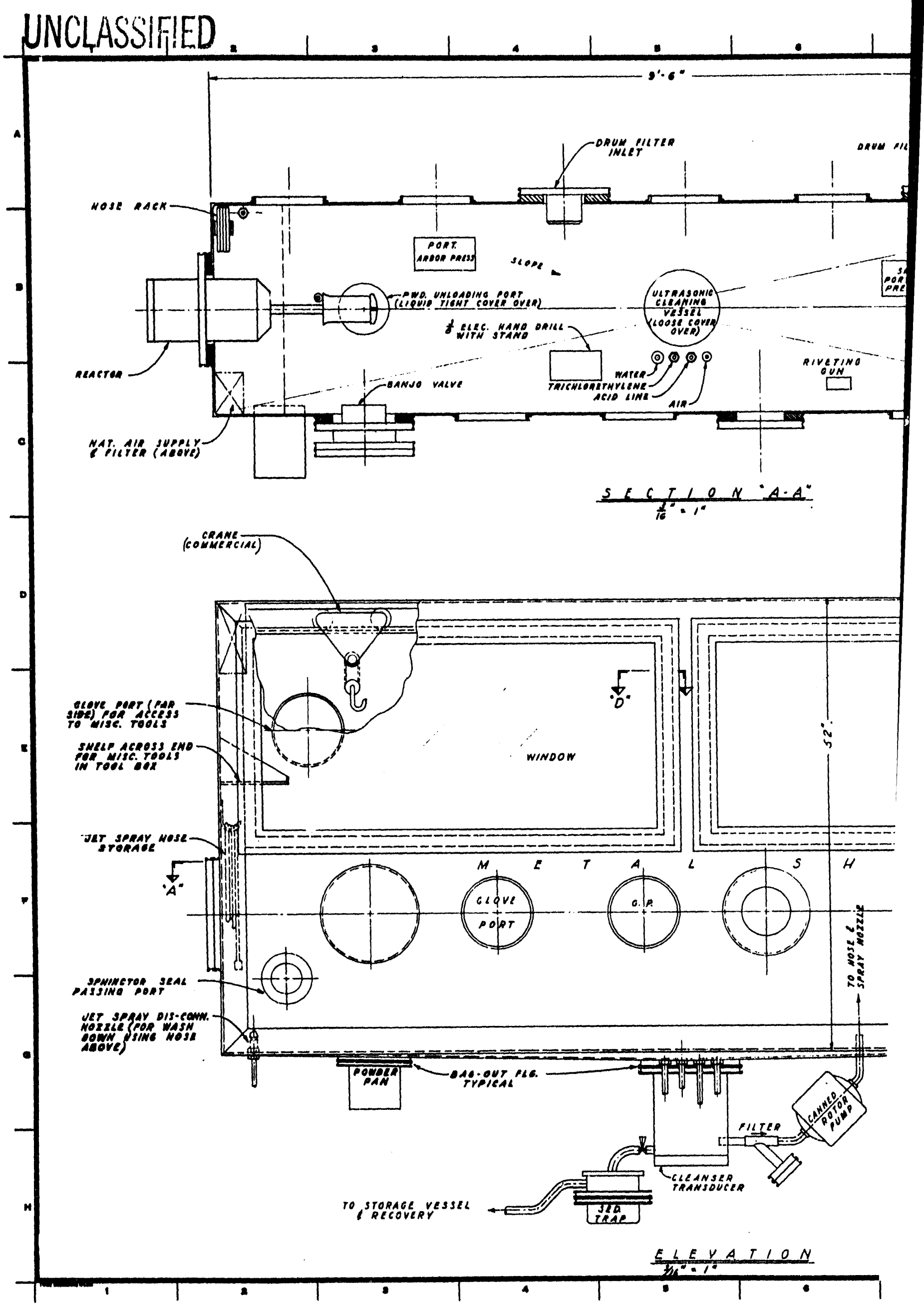




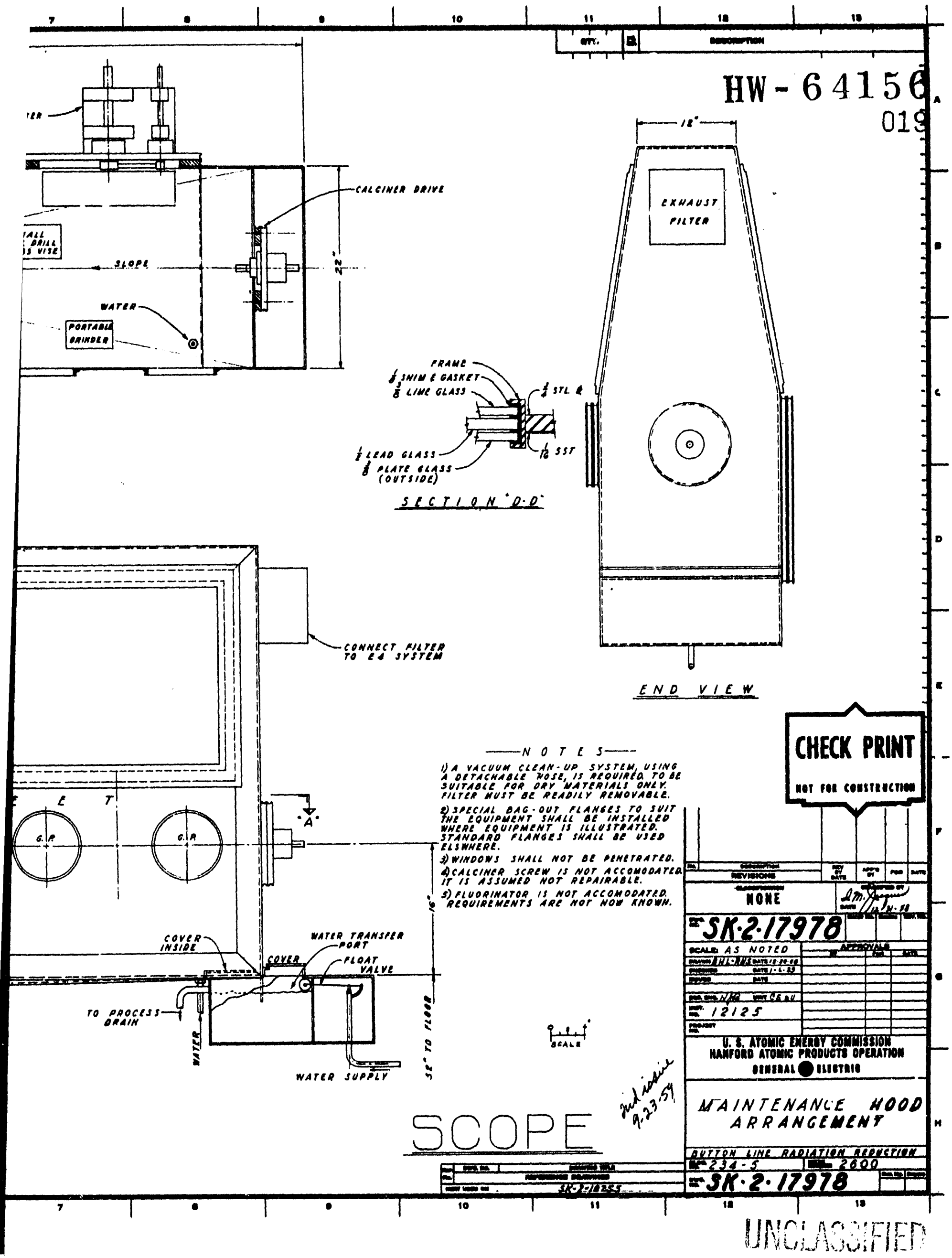




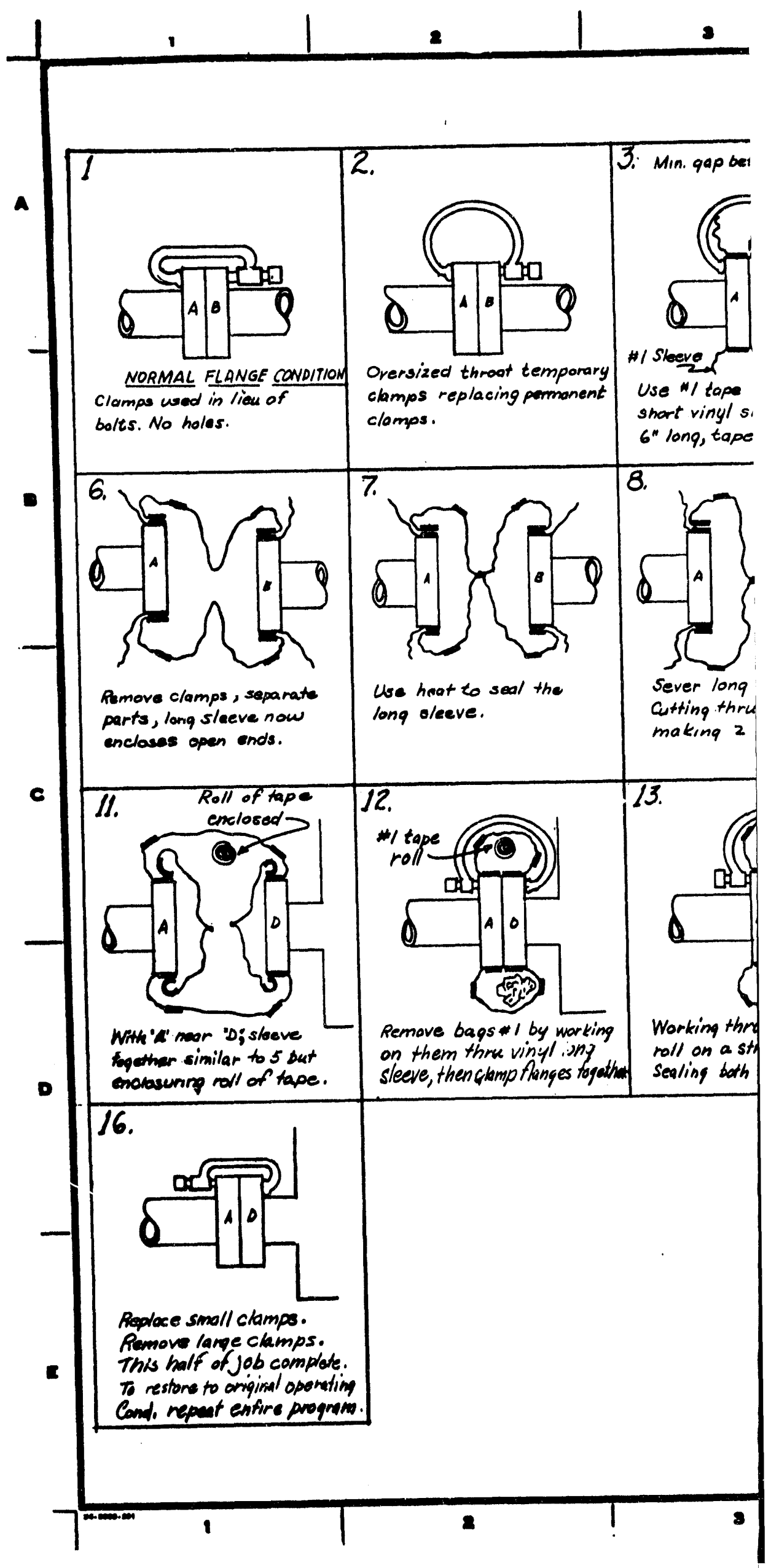




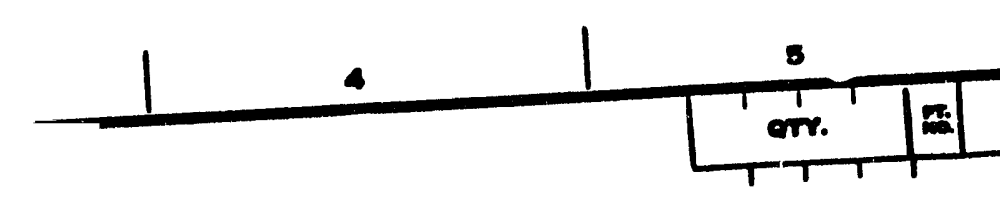

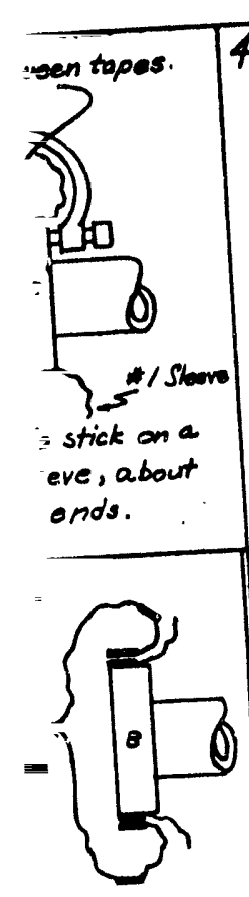

$\because$ seve by heat seal

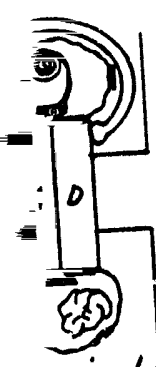

$\because$ viny/ sleeve, Tip of tape ipes tagethen separate bags.

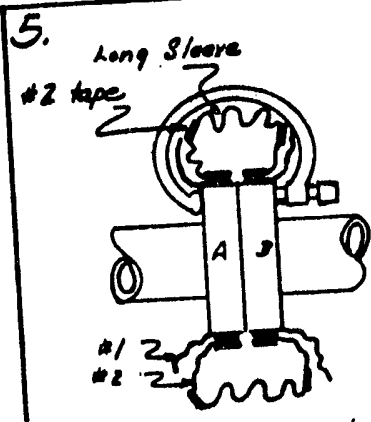

Connect both 2 short sleeves with 22 tape forming a tire. Tape on a second vinul sleeve same as panel 3

9.
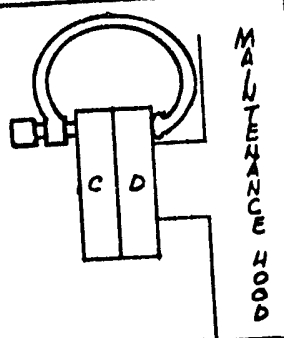
of maintenance hood

(or similar location) Then perform operation 3 thres o

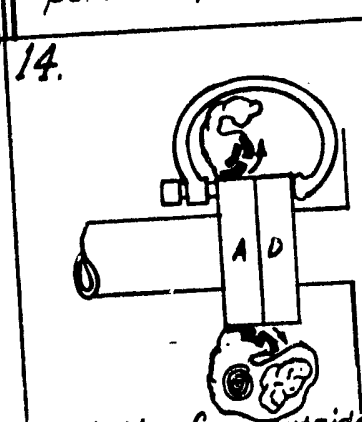
"Tire" roll it off carefully
Normal flange condition

Working from dutside of to ane side, off Manges
10.

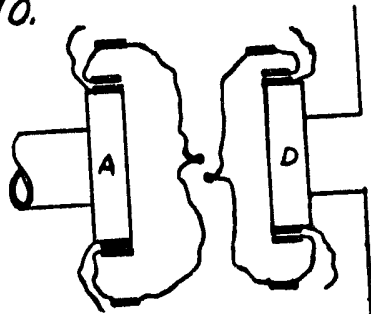

Remove flange " $C$ " to storage. Bring flange "A" into place. notes...

(1) "1 Tape is Scoteh "33-1k"wide, "2 Tape is

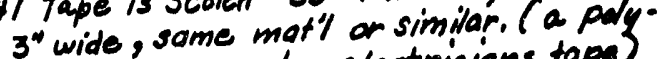
ethylene or mylar electricians topes

(2) $A, B, D, C$ represent flanges or covers of the same Size. Letter designotions is for accountability.

(3) Short sleeves are long strips of heary $(18,0,000)$ Vinyl urapped around, with overlapping ands tape seaked to form a tube.

(4) Long sleeves are of such width vinyl to permit separation of the flange pair. This wiath may be inches to many feet.

(5) Where a spool section must be removed, the operation must be performed twice, once at each place of separation.

(2) Panel 8 completes separation of one flange pair. Panel: 9 begins iristallation elsewhere.

(7) Where tape is used to join vinyl to Vinyl, use wide tape.

\section{5.}

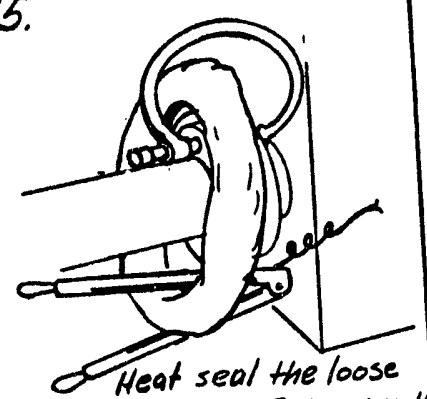

"Tire". Cut as in 0 to open th circle, remove the severed tire.

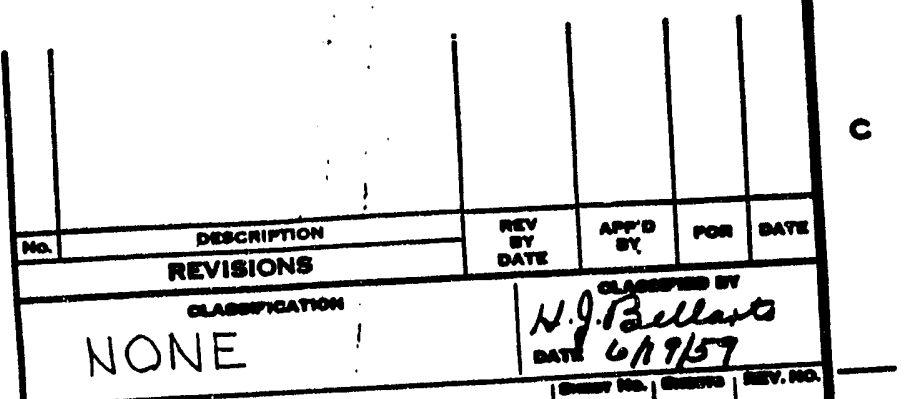

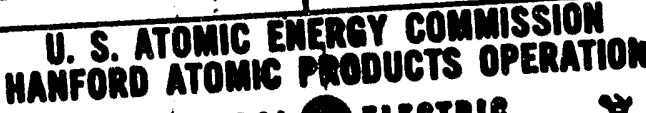
ómenal Elestalo o PROCEDURE 


\section{APPENDIX I}

\section{INTRODUCTION}

The following paragraphs and attached drawings describe and disucss the various process and handling functions which make up the new button line design concept. The process being followed and the design basis used is given followed by a detall description and discussion of the most promising approaches developed.during the study. The discussion of the button line equipment designs is divided into four general groups:

\section{PR Can Unloading and RC Can Loading;}

2. Pre-Reduction and Filtrate Treatment Equipment;

3. Precipitation Processing, Wet and Dry Chemistry; and

4. Reduction Equipment.

Within the groups each process function or equipment component is discussed with respect to the required functional criterla, the most promising design approach, needs for further deslgn study or testing required, and technologicsl improvements that would simplify or improve the design where applicable. A. pictorial representation of the four general groups of equipment is shown on the two perspective drawings attached to the body of the report.

\section{GENERAL PROCESS DESCRIPTION}

The process being followed is essentlally the same as that for the RMC Button Line which is outlined in Document $\mathrm{HW}-47655$, RMC Line Flowsheet Task I, II, III, by W. G.? Browne: Two incomplete flow diagrams included in the body of the report, SK-2-17974 and SK-2-1821I reflect some minor changes in the flowsheets.

In brief, the process consists first of a batch reduction of plutonium nitrate solution reducing the plutonium (VI) to the plutonium (IV) valence state by the use of hydrogen peroxide. The reduced solution is batch transferred from the pre-reduction tank to the transfer head tank where it is led continuously into the reactor vessel. In the reactor, oxalic acid is added continuously to form a plutonium oxalate slurry. The resultant slurry overflows or is pumped into a centrifugal æeparator or vacuum drum filter where the oxalate precipitate is continuously separated. The separated precipitate is processed in a continuous calciner while the filtrate solution is transferred to the filtrate recelver tank.

The plutorium oxalate preclpitate in passing through the continuous calciner is maintained at a temperature of $350^{\circ} \mathrm{C}$ to $400{ }^{\circ} \mathrm{C}$, and is converted to plutonium dioxide. The plutonium dioxide is transferred to a continuous fluorinatior which is maintained at a temperature of $450^{\circ} \mathrm{C}$ to $500^{\circ} \mathrm{C}$. The plutonlum dioxide under the action of the gaseous hydrogen fluoride is converted to plutonium tetrafluoride. The plutonium tetrafluoride powder 


\section{DECLLSSFFEED \\ Page 22}

is batch transferred to Task III where it is mixed with the reducing gigent, metallic calcium, lodine crystals and in some cases chemical 70-58 when delta phase plutonfum is desired. The mixture is placed in a pressure vessel contalning a magnesium oxide cruclble and is heated in an induction furnace to the point where an exothermic reaction ensues. Molten plutonium settles to the bottom of the crucible and is separated from the lighter slag. Upon cooling, the crucible and slag is broken and ground up and the solidified metal button is removed for cleaning, plckling, sampling, welghing, and further processing in the fabrication ilne or shipment off-site. The slag and crucible fragments which contain small amounts of plutonium are removed and sent to the recovery process. The filtrate solution from the centrifugal separator contains approximately one percent of the plutonium inducted into the system. This solution is transferred from the filtrate tank for continuous treatment to dissolve oxalate solids.

There is some chance that advances in technology will take place prior to the time funds are authorized to design and construct a new button line. Isboratory effort is now being directed toward the development of a direct calcination process, an improved halogenation process, and a continuous Task III. If these processes are developed in time, they will have considerable impact on the equipment designs now being worked out. Most of the equipment used in the present process will be eliminated and new and different equipment will have to be studied and designed for production line use.

\section{DESIGN BASIS}

The new equipment has been designed to process plutonium at a rate of $1 \mathrm{Kg}$ per hour nominal; $2 \mathrm{Kg}$ per hour maximum, on the precipitation process and wet and dry chemistry portions of the production line. Throughput rates on the reduction line are based on handling one to two $\mathrm{Kg}$ charges in pressure vessels at the rate of one per hour. When operating three shifts and seven days/week at 80 percent overall efficiency, the capacity of the system will be approximately 6,990 Kgs per year nominal. Equipment will be designed to permit operation within a working limit of $2 \mathrm{R} /$ year total exposure. This working limit has been set so that the line can be operated at its maximum capacity without the necessity of special rotation control. Frontside operation in Zone I w1ll be limited to an exposure rate of .I mrems/hour and on the backside in Zone III, I mrem/hour.

\section{PR Can Unloading and RC Can Iarding - SK-2-1823I}

Product feed solutions are received from Redox and Purex in PR cans, and filtrate solution from the Wet Chemistry process is frequently shipped back to these plants in RC cans. The unloading of PR solution into storage and transfer tanks, and the loading of the filtrate into RC cans is accomplished at the same location to simplify can handing and transportation procedures.

The PR cans in a Redox or Purex batch are emptied by vacuum transfer into twin, interconnected storage tanks with a combined volume of approximately four PR cans. The cans are rinsed with a small quantity of wash 
which is then transferred to the storage tanks. The volume transferred to the tanks is read. by the operator on a callbrated liquid level gauge glass in the tanks and recorded. The solution is then recirculated in the tanks and a representative sample taken. Figures for accountability are obtained from volume and concentration analysis figures. The batch is then ready for admission to the process. A vacuum transfer from the storage tanks to the pre-reduction tank is then made. The capacity of one set of tanks is sufficlent for more than one shift operation. Tnree sets of tanks are provlded so that PR unloading need be done only on day shift.

Killed filtrate is transferred from the filtrate storage tank in the process line to one of six storage tanks in the can loading area and is sampled prior to loading. $R C$ cans are filled by vacuum transfer from these tanks and sent to Redox for further processing.

The PR can unloading and RC can loading station is located in Room 166 adjacent to Hood HC- 6 . The proposed arrangement of this equipment is shown on SK-2-18231. The loading and storage glove boxes are 1solated from the Hood HC-6 operating area by a four-inch wall of neutron shielding (masonite enclosed by $1 / 4 "$ steel plate).

The feed solution storage tanks are external to the glove box containing the assoclated valves, pumps, samplers, and $P R$ can unloading heads as shown on SK-2-18232. The PR storage tanks shown are type 304-L stalnless steel construction 5" I.D. with opposing sight glasses built into the walls of the tank per SK-2-18218. The over-all tank lengths are 6'-9" tapering at top and bottom from 5" I.D. to 2 I/2" I.D. The straigint center length is to be $5^{\prime}-6^{\prime \prime}$. The taper is to prevent a heel of liquid from remaining in the tank upon draining and producing an error in future. volumetric measurements.

One-inch thick removable lead shielding encased in stainless steel is used to jacket the tanks and high density lead glass will be incorporated over the sight glass area. The sight glasses are calibrated for visually reading volume of solution in the tanks. A typical cross-section of this construction is shown on SK-2-18218.

The remote attachment unloading head mechanism for the PR can is shown on drawing SK-2-18235. For unloading the shlelded container is placed on a locating cart and moved into place under the glove box attachment port. The locating cart is then positioned above an elevating mechanism which ralses the PR can and presses the gasketed top flange of the PR can against the hood port in such a position that the PR can plug surface mates with the hood port cover surface. The locating cart is as shown on $\mathrm{SK}-2-18242$.

The operator then remotely unlatches the PR can plug by operating a crank mechanism on the PR can contalner. An electromagnet contained in the glove box port cover energizes and the port cover and the magnetically 
attached PR can plug are remotely lifted into the glove box. Both the normally clean mating surfaces of the PR can piug and the port cover are sealed one against the other and are not exposed to contamination while in the glove box.

The PR can is fabricated with an integral dip tube. The dip tube, rinse and vent connections terminate in a plate lmmediately below the PR can plug and contaln normally closed check valves. The PR can is shown on SK-2-18237. Check valves are simllar to Bruning Company "Slip-Joint" self-sealing quick disconnect couplings. This is not called out on the drawing.

A matching unloading head plate whlch is connected to the tank 1111 , rinse and vent lines within the hood are lowered by screw drive to seat against the PR can connection plate. Upon seating, the mating connection check vaIves will open, allowing passage of solution from the PR can through the storage tank f1II lines as well as passage of rinse solution Into the PR can.

Following unloading of the PR can, rinsing, and evacuation of rinse solution the unloading head 18 ralsed and the check valves close. The operator then actuates closing of: the port cover, thus reseating the PR can plug, latches the plug and de-energizes the lifting magnet. The locating cart mechanism can now be lowered and the empty PR can moved away from the glove box.

Remote sampling of the solutions in the tanks is accomplished by use of the remote sampling mechanlsm shown on drawing SK-2-18234. The shielded sample bottle contalner is attached to the glove box by an interrupted thread connection. The lid is unlatched and then lifted into the glove box in the same manner as the PR can plug. The sample head is remotely lowered into the sample bottle and a sample pulled from the tanks by use of a vacuum trap. The sample head is then raised and the lid reseated and latched. The operator may then remove the sample container.

Recirculation of the solution prior to sampling is accomplished by use of a canned rotor magnaflow pump. Plping is shown on drawing SK-2-18232. All vacuum vent and liquid valves in the hood require on-off control and are remotely actuated diaphragim operated valves.

The PR can unloading facility and RC can loading facility glove boxes are shown constructed of type 304-L stalnless steel plate and are shlelded with one inch of lead encased in stalnless steel. Glove ports are provided for malntenance access; but should normally be covered with shlelded port covers during operation. Viewing windows are constructed of $11 / 2$ "thick high density lead glass. The glove box is vented to the E-4 system. Bag-out type blank flanges are provided for equipment entry and removal. Glove box construction is shown on SK-2-18233.

Storage tanks to recelve kllled flltrate and a loading station for recycle cans are provided in the same area. A quick disconnect loading head 


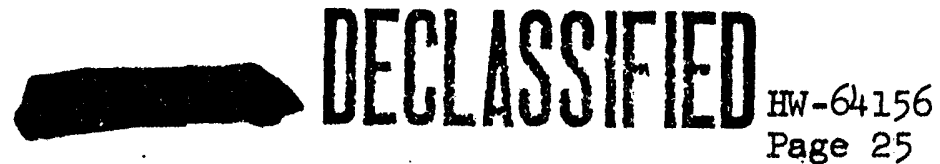

similar to the PR can unlcading head is provided. The killed filtrate tanks are also shown outside of glove boxes and are removable utilizing bag-out procedures.

Killed filtrate storage tanks are shown 5" I.D., 7' high, constructed of I/2" thick type 304-I stainless steel wall. Removable one Inch lead shlelding is to be provided per SK-2-18218. A high level control in the tanks closes the inlet control valves. All valves and the sampler are enclosed in a glove box. The killed filtrate facility arrangement is shown on SK-2-18232. Construction is shown similar to the PR can facility so that conversion to PR can unloading could be easily accomplished at a " later date.

2. Pre-Reduction and F1ltrate Treatment Equipment - SK-2-18226

The high exposure product feed must be pre-reduced and pumped to the reactor from a transfer head tank as in the present process. The filtrate recovered from the drum filter must be killed prior to further recovery processing.

The wet chemistry process is essentlally the same as the process presently in operation with the exception of the addition of a KOH scrubber for treatment of the fluorinator off-gas. The process flowsheet is shown on SK-2-17974.

Feed solution is transferred from the storage tanks at the PR can unloading station in Room 166 by means of vacuum transfer to the prereduction.tank. $\mathrm{HNO}_{3}, \mathrm{H}_{2} \mathrm{O}_{2}$ and distilled water are added for pre-reduction and aclitity control of the feed solution.

The pre-reduced feed solution is then pumped to the transfer head tank. Feed solution is pumped continuously from the transfer head tank to the reactor vessel for oxalate precipitation.

Filtrate from the vacuum drum filter must be chemlcally treated with $\mathrm{KMnO}_{4}$ and the solution subsequently reacted with $\mathrm{H}_{2} \mathrm{O}_{2}$ prior to pumping to Recuplex or return to Redox for further recovery operations.

Filtrate is recelved continuously by vacuum transfer from the drum filter to the vacuum recelver tank. The filtrate is pumped by a positive displacement pump from the vacuum recelver tank to one side of a U-tube reactor to which $\mathrm{KMnO}_{4}$ is added (filtrate kill tank). The solution moves down the U-tube and up into the other side (filtrate catch tank) where it is reacted with $\mathrm{H}_{2} \mathrm{O}_{2}$ and then overflows into the filtrate storage tank.

The killed filtrate is then pumped from the filtrate storage tank to the RC can load out facility in Room 166 or to Recuplex.

The high exposure feed materlal to be processed through the RMA replacement line established a requirement that both gamma and neutron shielding

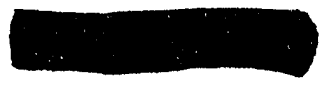


be provided. The basic shlelding figures to be used for the wet chemistry process are the equivalent of one inch of lead for gamma shlelding and four inches of masonite or plexiglas for neutron shielding; however, this is subject to change as actual radiation level data becomes avallable.

The wet chemistry process vessels and piping include the pre-reduction tank and the transfer head tank in the feed system. Also included are the vacuum receiver tank, filtrate caich and kill tanks, filtrate storage tank and peroxide head tank in the filtrate treatment system, an off-gas scrubber, 26" vacuum trap and E-4 exhaust system trap. Arrangement of this equipment is shown on SK-2-18226.

Elimination of glove boxes around the process vessels is to be accomplished. to provide ease of accessibility, viewing and removal utilizing bag-out procelures. Lead gamma shielding is installed as removable jacketing around the process vessels. Vessele are constructed of $1 / 2^{\text {" thick type }}$ 304-I stainless steel walls and have a maximum I.D. of 5". Vessels requiring visual observation of the contalned liquid are constructed with opposed sight glasses in the walls. The removable shlelding is constructed with lead glass incorporated at the sight glass area. The vessels requiring sight glasses are the pre-reduction tank, transfer head tank, filtrate kill and filtrate catch tanks. The process vessels are removable utilizing bag-out procedures. Typical vessel and shielding construction is shown on $\mathrm{SK}-2-18218$.

All pumps, control valves, manual valves, flowmeters, and fllters associated with the vessels are located in glove boxes to provide containment for possible leakage at pipe connections and seals. One-inch thick gamma shielding is provided in the construction of the glove box walls. Covered shlelded glove ports are provided for access for operation of manual valves and for malnterance, and viewing windows are constructed of $11 / 2 "$ thick high density lead glass. A bag-out type blank flange is provided for equipment removal and entry.

The wet chemistry area is shown enclosed within neutron shielding walls constructed of four-inch thick masonite within a $1 / 4$ " steel plate case. Access is by shielded door normally, however, some sections of shielding are removable by bridge crane if a larger access area is required. Plexiglas windows are provided at the water wall so that the Zone I operator may observe the liquids in the pre-reduction tank, transfer head tank and the filtrate catch and kill tanks.

Plutonium bearing process piping between process vessels and glove boxes is run inside shielded ducts and is permanently secured in a common bagout flange at each end of the duct. These flanges are to mate with bagout flanges at the glove box or vessel. Process piping connections will be broken inside the glove box prior to the removal of the tanks. Arrangement of process vessels, glove boxes, and interconnecting shielded process piping is shown on SK-2-18226. 


\section{DEELLSSSFIFD}

Material of construction for the fluorinatior off-gas scrubber is Hastelloy "C". Removable lead shlelding 1s used to jacket the scrubber. The scrubber is exhauated by a Nash blower. A pump will be provided to pump the liquid discharge to Resuplex.

All vessels requiring venting will vent into a common header through a trap to the E-4 system. A vacuum trap is provided for vacuum ines from process tanks.

The plping arrangement in the hoods is shown on SK-2-18226. Canned rotor magnaflow pumps are uililized wlth the exception of the vacuum recelver tank discharge where a positive displacement pump is used to pump from an evacuated tank and the peroxide head tank discharge where the flow quantity is so small that a metering pump rather than a centrifugal pump is better.

The basic instrumentation and flow control scheme is shown on SK-2-17974. The wet chemistry control system will essentially duplicate the RMC Iine control system. An exception is the use of magnet1c flowmeters for flow measurement and control algnal. Diaphragm operated valves will be ut1lized for flow control. Metering pump flow control will be utilized for pumping filtrate from the vacuum recelver tank and $\mathrm{H}_{2} \mathrm{O}_{2}$ from the peroxide head tank.

\section{Precipitation Processing, Wet and Dry Chemlstry - SK-2-18212}

This portion of the button Iine recelves the feed solution as a liquid in a continuous nitrate stream and converts it to a dry fluoride powder. A reactor vessel is used to $\mathrm{mix}$ the nitrate feed with the various reagents which forms an oxalate slurry. This slurry overflows from the reactor into a vacuum drum filter or centrifuge where the solids are separated from the liquid in the form of a cake. The cake is then fed into a calciner to convert it to an oxlde powder. The oxide is then passed through a halogenator to convert it to a fluorlde. The liquid separated at the vacuum drum filter is fed back into the wet chemistry portion of the line for recovery and disposal.

The proposed design for the various components mentioned above, and the particular problems associated with each, are discussed below. In the design of each component, parts and assemblies of parts have been scrutinized for adherence to the maintenance and bag-out requirements mentioned previously. All parts which are likely to need repair or replacement have been installed in such a manner that they can be removed by the aforementioned bagging procedure, transferred to the maintenance hood, repalred or replaced at the hood, and subsequently be installed in their original locstion.

\subsection{Reactor - SK-2-17976}

The reactor receives the product and make-up chemicals in a continuous stream, mixes them, and allows the newly formed compound to overflow 
Into the next operation as a unfform siurry. The precipitate produced in this reaction, beirig much heavier than the suspendine Ilquid, requires continuous agltation to keep it from setting and forming a hard mass in the bottom of the vessel. The very high settling rate and the very low flow rates involved makes design of liquid hanaing components critical. A balance must be reachea between small diameter lines which give high velocity, but result in plugging tendencies unier no flow conditions and larger diameter lines with lower velocities and plugging tendencies due to settlir.g in the absence of sufficient turbulence.

The unformity of the discharge stream is a function of the residence or reaction time in the vessel, the mixing, and the feed rates to the vessel. Consequentiy, accurate control of these variables is necessary. An accurate and dependable liguid level control is also needed since the liguid level in the vacuum drum filter and protection against overflow of trie solution into the calciner is controlled by the liquid level in the reactor. Overflow of liguld into the calciner coulo have serious consequences. Another important consideration is the design of the agitator. Complete mixing without expulsion of liquid from the interface is cesirable. It la also desirable that feeds be introduced at the bottom of the vessel to assure adequate reaction time prior to the time the liguid overflows into the next operation.

The reactor vessel shown on the above drawing consists of a vertical stainless steel bowl surroundea by removable lead shielding. Attached to the top of the ressel, by a bae-out flange, is the agitator and drive assembly. Inis essembly is removable ond beggable to permit transfer of this section to the maintenance hood for repair or replacement of the necessary bearings, shafts, and seals. Wherever possible piping has teen located to gvold interierence with the removal and repair of the seitator and arive assembly. The level control shown on the drawing is not recessarily the proposed design. It is shown merely to indicate that such a device is necessary. The unusual agitator blade design attempts to achleve two objectives:

(1) to agitate the liquid without disturbing the interface; and (2) to break up and disperse any solids that tend to form on the bottom of the vessel. Baffle plates are located radially around the bowl to aid in achieving these objectives. The usual drain line from the bottom of the vessel has been eliminated with the thought that should it become necessary to clean out the reactor, it would be easier to remove the whole bowl assembly by bag procedures than to provide for the plugging problems which are normally associated with small lines and valves in a drain of this type. Rod out provision has been made wherever possible on other lines leading to and away from this vessel. 


\section{IFCLLSSFFED}

HW -64256

Page 29

\subsection{Centrifuge - SK-2-17975}

Th1s component recelves the slurry from the reactor, separates the precipltate from the 11quid, washes 1t and dries 1t, and empties the ary cake into the calciner. In the early stages of this study, a vacuum drum filter was thought to be the only plece of equipment which would satisfactorliy perform this function. Recently, however, it has become evident that a continuous centrifuge can probably also be used, Because of the many maintenance difficulties of the existing vacuum drum filter in the RMA and RMC IIne, and the relative simplicity of the centrifuge, study on the vacuum drum filter was discontinued and efforts were placed on the design of a centrifuge which would be compatible with the maintenance and bag-out procedures described earlier. Equally important in the decision to switch from the vacuum drum filter to the centrifuge was a series of tests run by the Hanford Laboratorles Operation and the B1rd Machine Company, which Indicate that a much drier and unfform cake could be attained using a small six inch centrifuge than could be attained with elther a drum fliter or a disc 11lter. The importance of a dry cake cannot be over-emphasized, in that fallure of this component to produce a dry cake regults in plugging problems in the calciner, the powder valves, the fluorinator, and the exit discharge valve. In effect, it can be said that if wet cake is allowed to go into the calciner over an extended period of time, within an hour or so the entire system will probably plug up and the unit must be shut down and cleaned out. On the other hand, it should be expected that there may be very short perfods of time during startup in whlch the cake is not absolutely dry. For this reason, it is important that components recelving this cake be capable of handling small quantities of wet cake, otherwise it would be impossible to get the unit started up.

The centrifuge shown on the above drawing is that proposed by the Bird Machine Company. All moving parts, bearings, and seals are removable and replaceable at the maintenance glove box. The unlt amounts to a horizontal drum in which is located a rotating bowl and a rotating flight conveyor. The rotation of the outer bowl and the accompanying centrifugal force throws the heavier material, the solids, to the outside and the flight conveyor or screw which moves at a slightly lower rpm, scrapes the solids from the moving bowl, and forces them out the cake discharge opening. The separated liquid beling lighter than the solids floats on top of the solids and drains out over a dam and into the filtrate outlet pipe. Feed is introduced through the center of the rotating components and is vigorously agitated as it is thrown into the rotating bowl. The two rotating components are ariven through concentric shafts by a single drive motor. The relative speeds of these two components is controlled by a hydraulically operated planetary gear arrangement.

Since this component constitutes a considerable departure from past practice, a unit is being designed and will be bulit and tested by 
Bird Machine Company on stand-In powders or slurry after which time it w1ll be tested in the 234-5 Bullding by the Chemical Development Operation or Hanford Laboratorles Operation. Timing of this work with respect to other work being carrled out by Chemlcal Development, such as the direct calcination unit may eliminate the need for a centrifuge or a vacuum drum fliter. If the direct calcination process is developed, it would not only eliminate the above two components, but also the reactor and a good part of the liquid processing systems assoclated with these components.

\subsection{Calciner - SK-2-17977}

The calciner recelves the cake from the filter, dries it in an atmosphere of oxygen and air, thus converting the cake to an oxide powder, and discharges it into the powder valve for metering into the fluorinator. One of the most important considerations in the calciner is that it be capable of handling a slightly wet cake produced by the centrifuge for a short perlod of time. Aside from this special requirement, the calciner essentially amounts to nothing more than a screw located inside of a critically-safe tube for moving the powder and tumbling it as it is being exposed to the oxygen atmosphere. Conversion to the oxide is enhanced by heating the calciner tube to the temperature of approximately $350^{\circ} \mathrm{C}$.

Because of the plugging difficulties that normaliy occur at the inlet end of the calciner, it was felt that some special device should be provided to eliminate the need for operator attendance to force the cake 1nto the calciner screw. Hand feeding of the calciner would not be permissible while processing high exposure plutonium.

As shown on the above drawing, the calciner consists of a stainless steel tube, approximately six feet long with an internal screw, which is driven from one end through the necessary seals and bearings. The seal, bearling, and screw assembly is removable and maintainable at the maintenance glove box. A low frequency induction coil is used to. heat the calciner tube. Low Inftial cost and infrequent maintenance are the primary reasons for selection of this heating unit rather than high frequency induction unit or a resistance heating unit.

Not shown on this drawing, but included in the design, is a thin wheel or gear located at the head end of the screw and driven by it to prevent clogging of the screw when damp cake is received from the centrifuge. In effect, this wheel while rotating cleans the flutes of the screw as it rotates thus making certain that there is always a space for the new cake to be introduced Into the screw. This accomplishes the same thing as an operator forcing the cake Into the screw with a spatula. On drawing SK-2-17977 an arrangement of this feeding device is shown on the discarded vacuum drum filter design. A design of this type w1ll be incorporated on either the centrifuge drawing or on the calciner. 


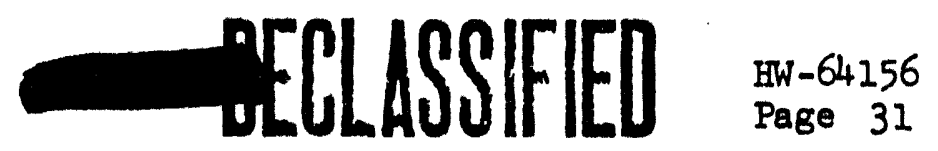

As mentioned in the previous section, work is underway on the development of a direct calcination unit. Th1s unit would replace the calciner shown on the above drawing and would probably be much smaller and more compact. If there is any difference in the relative design difficulty, the new direct calciner unit would probably be easier to adapt to the new malntenance and bagout requirements.

\subsection{Powder Valve - SK-2-17979}

The powder valve serves as an alrlock as well as a feed hopper and dispenser for the fluorinator tube. It also acts as an accumulator to make up for slight differences in the flow rates of powder in the calciner and fluorlnator. These three criterla are relatively simple unt1l it is realized the nature of the powder that is handled. If the oxide 1s wet when recelved from the calciner, it will stick tenaclously to the walls of the feed hopper and to the flutes in a rotary valve. Also past experience indicates that the slight amount of HF that is introduced or transferred from the fluorinator to the upper hopper in the powder valve causes the powder to partially fluorinate and form a hard solld with a consistency almost like drled concrete. Under normal conditions the powder has a very hlgh angle of repose perhaps up to even $90^{\circ}$.

With these factors in mind, the valve has been designed to force the powder from the hopper into the rotary valve by continuously breaking any bridges that might form in the hopper and by scraping the powder from the sldes, and to scrape the powder from the flutes of the rotor on the under side so that it can fall directly into the fluorinator tube. There has been some operating experlence with this type of valve which has been satisfactory. Some improvements are needed, however, and the design shown on the above drawing attempts to solve these difficulties as well as make it possible to repair or replace the many bearings, seals, shafts, and rotors according to the new maintenance philosophy. Unt1l such time as 1t w1ll be possible to discharge the cake from the calciner directly into the fiuorinator, some type of device, similar to the powder valve, w1ll be required.

\subsection{The Fluorinator - SK-2-18245}

The fluorinator recelves the oxide powder from the powder valve, heats it in an atmosphere of $\mathrm{HF}$ and oxygen, agitates 1t, and converts It to a dry fluorlde powder. The powder is then discharged into a second rotary valve and hopper arrangement for subsequent loading in to the pressure vessel. The extremely corrosive nature of the IF gas and the extremely h1gh temperature $\left(500^{\circ} \mathrm{C}\right)$ makes the design of the fluorinator tube difficult. In order for the powder to be in intimate contact with the HF gas, it must be agitated so that all of the material is exposed to the HF for approximately one to two hours. At the present time, a vibrating tube is used to move the powder. Because of critical mass limitations and the reaction time involved, a long thin tube is used. Heating is by a resistance coil. 


\section{DECLASSIFIED}

Maintenance of the units now in service has been a serfous problem. Frequent plugging of the off-gas system, rupture of the bellows attached at both ends of the fluorinator, and plugging of the fluorinator tube at the powder inlet have made it clear that some other approach should be considered. In princlpal, the vibrating tube conveyor is quite aimple; however, when the tube is long and small in cross-section, the relative flexibility of the system causes It to vibrate like a reed rather than a rigld member. The net effect is that under certain conditions there is a phase shift in the amplitude of vibration over the length of the tube. Too high a phase shift over this length can cause dead spots which represents a barrier to the passage of powder and in a short perlod of time the tube w1ll become plugged. Adalng further to the difficulty of analyzing and designing an acceptable and dependable vibrating tube are the many fixtures which are attached and which represent indeterminate forces on a system which already has three degrees of freedom. Past experlence has already borne out the fact that two vibrating tubes built from the same drawing do not behave 1dentically under operating conditions. Each tube must be debugged independently, essentially by trial and error. This procedure has been costly and In the long run performance is questionable, since changes in frequency, amplitude of vibration or extraneous forces can upset the balance and the debugging procedure must be performed again.

The fluorinator shown on the above drawing consists of a long cylindrical tube with an internal ribbon screw conveyor driven through a hermetically sealed magnetic coupling on one end. All parts are constructed of Hastelloy "C" for corrosion resistance to the HF gas. The off-gas system is attached rigialy to the tube so that vibration by an air vibrator mounted on the off-gas stack will cause the powder which collects on the filters to fall back into the fluorinator tube. In this design there are no bearings and seals as such, and damage or excessive wear to the screw would necessitate changing the entire unit. A low frequency induction coil is used for heating the tube. The advantages of low initial cost and infrequent maintenance apply here as in the case of the calciner.

Work now underway in the Chemical Development Lab may simplify the design requirements or even eliminate the screw reactor entirely. Considerable work has been done on the chloride process which, if adopted, would make the material requirements less stringent. Work is also underway on a fluid bed halogenization unit. If this process is adopted, the entire fluorinator tube assembly would be eliminated and an entirely jifferent equipment concept would have to be designed for production line use.

\subsection{Dispenser and Storage Station - SK-2-18207}

At this point the powder is collected in the second hopper and rotary valve located at the discharge end of the fluorinator. The rotary 
valve and hopper assembly and a dispenser and storage station working together have several. functions. First, storage at this point acts as an accumulator to make up for the difference in instantaneous rates between the continuous feed from the fluorinator tube and the batch operation in Task III. Second, the powder is checked for quality at this point. A light pink color denotes that the powder has been fully processed in the fluorinator tube. Third, the powder 1s collected and carefully welghed into batches for charging with the pressure vessel.

The best procedure for operating this station has not been fully determined at the present time, nor is the design shown on the above drawing completely acceptable. In general, however, the operation would be as follows: Powder recelved in the fluorinator discharge hopper would be continuously fed into the dispenser hopper Immediately below 1t. The volume of the dispenser hopper is calculated to be approximately that of the pressure vessel crucible. During the time of filling, a visual observation would be made of the powder to determine 1ts color. After the dispenser hopper is filled and if the color is right, the screw feeder immediately below the hopper would be actuated and powder fed into a pressure vessel cructble. The pressure vessel is located by a turntable 1mediately beneath the dispenser assembly. If the powder is out of process, the screw feeder would be actuated in the opposite direction which feeds it Into a small chamber for vacuum transfer back to the head end of the fluorinator for reprocessing. The off-gas system on the fluorinator is designed to handle the additional flow required for this vacuum transfer. The chamber used for the transfer is essentially a reversed cyclone which excelerates the particles to a velocity sufficient to carry them back to the fluorinator without plugging the lines. Tests on this device indicate that lumps as large as $1 / 4$ " square, can be successfully transferred.

As mentioned previously, a turntable immediately below the dispenser assembly is used to index the pressure vessels into position for the addition of powder. This arrangement is also equipped with a weighing device to weigh the pressure vessel as the powder is being added. Flexibility has been provided by making the table large enough to hold three pressure vessels, in addition to the one being loaded.

The accuracy of the welghing device is quite critical since it must detect a welght variation of 5 to 10 grams in the charge out of a total welght of approximate Ly $3 C \mathrm{Kgs}$. A device of this accuracy is not known to exist on the market at the present time, however, discussions with instrument vendors indicate that such a weighing device can be developed using strain gauges. The pritmary reason for using such a device, is that by doing so the need for a powder pan is eliminated. About the only justification for a powder pan on the existing button lines is the fact that an adequate weighing device has not been found for weighing the charge in the pressure vessel directly. Except for cases where the product is alloyed, the weighing station is probably unnecessary. Other means of assuring accurate charges are avallable. 
Work underway in the Chemical Development Laboratory can eliminate the need for this entire assembly. The new process is a continuous Task III which would recelve the fluoride directly from the fluorinator tube in a semi-continuous stream and alscharge a metal rod or billet in a continuous stream. Viewing of the powder prior to entry into the continuous unit might still be necessary; however, some other means of determining the quality of the powder would greatly simplify the design. If viewing is necessary, about the only satisfactory remote device for accomplishing this is a colored TV set or periscope. Neither is entirely satisfactory.

\subsection{Shieldirfs Arrangement - SK-2-17986}

This portion of the button line emits alpha, gamma, and nelitron radiation. The alpha radiation does not constitute a serious problem, since it can be shielded out with relatively thin shielding materials.

The gamma cadiation on the other hand, which covers a large range of energy levels, does create a problem and requires considerable lead or lead glass shielding. Neutron radiation is due to spontaneous fission and in the case of the fluorinstor tube, an alpha-n reaction. Although the neutron field generally does not increase directiy in proportion to the increase in higher isotopes of plutonium as dc the gamma fields, the shieldins requirements are considerably more difficult to handle design-wise because of the much greater thicknesses required. For example, one inch of lead will shield out most of the gamma energies anticipated in the future, while in the order of 12 " to 16" of neutron shielding is needed to shield the fluorinator tube. If both of these shlelding thicknesses were attached directly to the equipment, it would be virtually impossible to repair and replace parts. Viewing of certain operations would also be difficult if not impossible.

Several levels of personnel exposure are expected on an operating line of this type: (1) the operator who stands for a full shift and recelves exposure by the hour each day; (2) operators who perlodically make adjustments in the equipment, add make-up, and inspect the product; and (3) the maintenance operator who is exposed only during equipment outages. Since the \#l operator is in the field of radiation the greatest length of time, it is desirable that he be provided with the greatest possible amount of shielding. Because of the nature of the \#2 operator's function, it is necessary that he be protected by a iosser amount of shielding because viewing, inspecting, and adjusting operations are frequently required. The third type of exposure, the maintenance man, requires an even smaller amount of shielding, since he has to replace parts and remove and replace equipment.

In view of tine above requirements and conditions, it was decided. that the best approach would be to provide as much protection for the maintenance man as possible by fixing permanent gamma shielding 
to the walls of the equipment or making it integral with the walls. Protection against neutrons auring equipment replacement did not appear to be feasible because of the shielding thickness involved, thus making it necessary to provide portable shielding which could be removed for free access to the equipment diring replocement. In this way, the \#2 operator is protected against both gamma and neutron radiation during normal operation, in that the neutron shielding is removed only for maintenance purposes. The \#I operator is further protected by the water wall whlch completely isolates him from the button line area.

The design of the shielding shown on the above drawing is not firm; however, it represents a reasonable approach to the problem. Portable sections made up of masonite or lucite are stacked around the varlous components in thicknesses proportional to the shielding required in such a way that they can be removed and replaced by the overhead crane. Gamma shlelding in some cases is integral with the walls and equipment, and in other cases, a lead wrapping. Where visibllity is necessary, lead glass is used for gamma shlelding and lucite for neutron shielding. The exact thicknesses of materlal have not been determined at the present time, however, the designs have been guided to permit the use of the maximum thicknesses that could be anticipated.

\subsection{Piping Arrangement - SK-2-17990}

The three major objectives of the piping arrangement are: (1). that pipes be located in such a way that they cause a minimum of interference to removal and replacement of equipment; (2) that pipes requiring shielding be routed to minimize the amount of shielding required; and (3) that piping runs be bundled and in some cases encased to minimize the surface area that would have to be decontaminated, if contamination were spread within the area. As can be seen from the above drawings, piping runs extend down into the equipment supporting structure where longer runs can be bundled as well as runs to equipment at other locations. The equipment supporting structure is totaliy enclosed with removable panels. This semi-enclosure serves two purposes: (1) it protects the contents from a contamination spread in the area thus minimizing the amount of surface area needing cleaning and decontamination; and (2) it provides a convenient location for valves and connectors needed to tie-in the various equipment components. This approach is more or less a matter of compartmenting wherever possible to isolate and control spread of contamination. For example, if a contamination spread were to occur whlle removing the powder valve for maintenance ur repair, the many pipe lines associated with the remainder of the equipment is not exposed. Only the portion of the line extending above the floor of the equipment mounting platform and the duct encasing the bundled lines extending into the next area are involved. A better feeling for the practicability of this approach will undoubtedly be developed during detail design stages. 
4. Reduction Equipment - SK-2-18211

This portion of the button line recelves the dry fluoride powder from the wet and dry section of the Iine and reduces it to a metal button. First, the powder is loaded into a crucible contained in a stainless steel pressure vessel. During loading, welght measurements are made and recorded. Second, make-up chemicals are added and the pressure vessel is transferred to a reduction furnace where the contents are heated and the metal button is formed. Immediately following, the slag and crucible are separated from the button and the button is then pickled to remove any small amounts of crucible adhering to the surface. The pickled button Is them welghed, sampled, and marked and transferred to a storage station for subsequent use in the casting operation on the fabrication line. The remainder of the equipment associated with the reduction process is used to prepare the pressure vessel, cruclble, gaskets, etc., needed for the reduction operation. Since the greatest percentage of operations involve the handling of the pressure vessel, the design of the handing system has been slanted in that direction. Nearly all of the operations require some operation or manipulation through the top of the pressure vessel. It remains in the upright position during all operations except removal of the slag and cruclble and button. These conditions led to the conclusion that if a tunnel were provided for the pressure vessel to move through, the varlous loading, unloading, and firling operations could be located at intervals along the top of this tunnel thus providing free access on boib sides of the tunnel and providing a convenient means of overhead supporting of the equipment during removal procedures. This makes it possible to have viewing windows on one side of the tunnel free of obstructions and clear access on both sides of the tunnel for maintenance accessibility. The equipment located on top of the tunnel is flanged for easy removal and transfer to the maintenance glove box. To conserve on materlal and shlelding costs the cross-section of the tunnel is only large enough for the pressure vessel to pass under the various operating steps. A pallet connected to steel tapes driven from both ends of the tunnel indexes the pressure vessel under the various operations.

Draw1ng SK-2-i8210 shows the arrangement and typical details of this equipment. Process sequence diagram SK-2-182II, is included in the body of the report to show the various operations to be performed on the product. The number of operations and the number of stations are not necessarily the same, since the reasonable number of operations to be performed at a particular station is largely a matter of design judgment.

\subsection{Material Transfer Tube - SK-2-18210 and SK-2-18208}

As stated previously, the material transfer tube is used to transfer the pressure vessel to the varlous loading, unloading and firing operations which are located along the top of the tube. The bottom and sldes of the tunnel are free of penetrations which permits: (1) movement of the pallet alons the bottom; (2) viewing windows on the Zone I sIde; and (3) free access on the backside for maintenance purposes. Maintalning a uniform cross-section free 


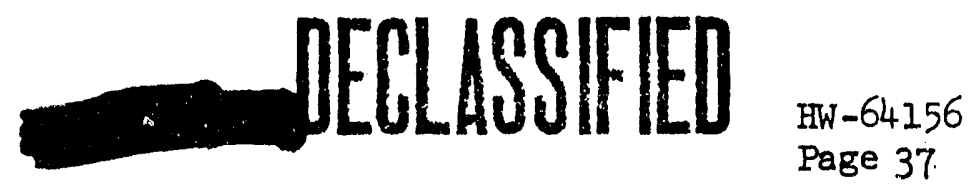

of obstructions makes sweepling and cleaning of the tunnel feasible. This may be done by attaching a broom or swab to the pallet and pulling the assembly the full length of the tunnel.

The pallet is driven from both ends by a steel tape wound on motor driven spools. Movement in one direction is driven by one spool and movement in the other alrection by the other. Flanged openings are located along the top of the tunnel for the various operating functions. Rough positioning of the pressure vessel under the various operation is by visual mears and exact location by an indicator system.

Since fluoride powder is handled within the tunnel, it is desirable to minimize dusting and splilage of powder wherever possible to lessen the need for frequent sweeping and cleaning. The movement of the pallet from one enu to the other would tend to spread any spill that might occur, which would result in excess neutron exposure for operating and maintenance personnel. For this reason it was declded to seal off the pressure vessel from the tunnel during each operation which would tend to spill or in any way dump fluoride powder into the tunnel. This is done at various stations by an overhead positioning and centering device, which lifts the pressure vessel from the pallet, seals it against the top of the tube, and locates it vertically in the position needed for the operating function. A description of this device is given in Paragraph 4.2. Identical devices are used at each of the operating stations, thus proviaing interchangeability. Operating functions which are mounted on top and operate through the device are designed to mate with this standard unit.

The best means of fabricating the Task III tunnel has not been resolved at the present time. The above drawings show the tunnel made up in sections connected by bolt-up flanges with an operating component mounted ontop of each section. The main advantage of this approach is that the operating component and the section of tunnel to which it is attached can be tested completely independent of any of the other operating functions and tunnel sections. In this way, alignment of the operating component with the pallet, pressure vessel, viewing window, etc., can all be done during fabrication and prior to the time the assembly is installed on the production line. If during fabrication or testing modifications are required, they can be handled easily without affecting adjacent sections. In this way, installation of the already debugged sections is merely a matter of setting them in place and bolting them together.

An alternate approach would be to make the tunnel all in one piece. The most obvious advantage of this, of course, is that the tunnel could be of all-welded construction without gasketed joints providing an extremely tight system. The major disadvantage is that final 


\section{DECLLSSFFIED}

adjustment and alignment of the various components and testing could not be made until after they were installed in position on the tunnel. Errors in fabrication and interferences might not be picked up or correctable until after the entire line has been assembled. Tunnel modifications at this stage would be much more difficult and expensive.

4.2 Pressure Vessel Lifting and Centering Device - SK-2-18060

As stated in the previous section, this device is used to lift and center the pressure vessels at the various operating stations. After the pallet has located the pressure vessel roughly within $+1 / 4 "$, the lifting and centering device picks it up and locates it precisely under the operating function, and at the same time seals it from the tunnel.

As shown on the above drawing, this device consists of a threaded sleeve mounted inside of a flanged container which, when rotated, raises or lowers lifting fingers that clamp to the upper end of the pressure vessel. Normally the fingers are extended out and against the top of the tunnel to allow passage of the pressure vessel beneath them. Once in position under the station, the fingers rotate down and contact the rim of the pressure vessel. Further rotation of the internal sleeve causes the entire assembly to move up against the top of the tunnel. At this point the operating function is performed. Upon completion of the operation the threaded sleeve is rotated in the opposite direction, the pressure vessel lowers to the pallet, and the fingers swing out once again against the top of the tunnel. The pressure vessel can now be moved to the next station. When it is necessary to clean or sweep the tunnel, the fingers can be withdrawn up into the centering device shell by driving the sleeve all the way to the top.

Approximately seven operating stations use this device. These are the crucible insertion, chemical addition, mixing, gasket dispenser, vacuum cleaning, cruclble grinder, and large sander stations. As stated previously, all of these operating components have been designed to operate through the center. of the lifting and centering device.

4.3 Pressure Vessel and Crucible - SK-2-18215 and SK-2-18247

Since the pressure vessel is involved in every operation along the Task III tunnel, its design deserves special consideration. The internal contour must be shaped to fit the crucible, its external configuration compatible with the heating system requirements, and it must be stable so it will not tip over as it is moved along the tunnel on the pallet. The upper end must be shaped to fit a gasket and mate with the centering and positioning device fingers. The thickness and type of materials used must be of sufficient strength

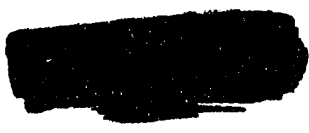


to withstand the high temperatures and pressures involved in the reduction process and to resist the corrosive atmospheres. Since it is used repeatediy, the internal contour and the gasket seats must be cleanable. During the firing operations pressures as high as 20,000 pounds total thrust may be exerted on it at temperatures as high as $1500^{\circ} \mathrm{C}$. Perlodically, these severe opergting conditions cause the crucible to rupture or a gasket to blow. In some cases this requires cleaning or repair or even replacement of the pressure vessel.

The proposed design is fabricated from a special alloy material, 35H alloy-ASTM-A-296, to obtain the desired magnetic permeability and good heating properties. The high permeability of this materlal permits the use of a low frequency induction coll. A thin copper coating or lining is added to the outside surface to further aid in the heating effect. Flux, coupling with the high permeability material, causes a high current to flow tangentially around the surface of the pressure vessel in the copper jacket. The $I^{2} R$ losses in the copper generates the heat in the pressure vessel.

The crucible is designed to fit within the pressure vessel with a clearance of about $1 / 8$ ". The shape of the bottom is determined by the button form desired, and the total volume is determined by critical mass considerations. It is made from magnesium oxide by a slip casting process and is easily broken; consequently, handling systems must be designed to prevent cracking or chipping. Its resistance to impact and shock can be considered slightly greater than that of an egg shell.

To reinforce the crucible within the pressure vessel, a layer of sand is added around the sides and beneath 1t. This supports the crucible during the firing operation and if a break does occur, minimizes the amount of molten plutonium that comes in contact with the pressure vessel. If molten plutonium comes in contact with the walls of the pressure vessel, it is extremely difficult to remove and recover.

4.4 Sand Loader-SmaII - SK-2-1804I

The small sand loader is used to dump a small quantity of sand on the bottom of the pressure vessel prior to insertion of the crucible. This prevents damage to the crucible when it is lowered into the pressure vessel at the crucible insertion station. It also provides clearance around and beneath the crucible which is later filled with sand at the large sand loader station.

As shown on the above drawing, the loader consists of two commercially available powder measures which are mounted one above the other over the center of the lifting and centering device. Two are used in series to provide an airlock between the inside of the tunnel and the Zone III area where the sand is loaded into the top of the upper 


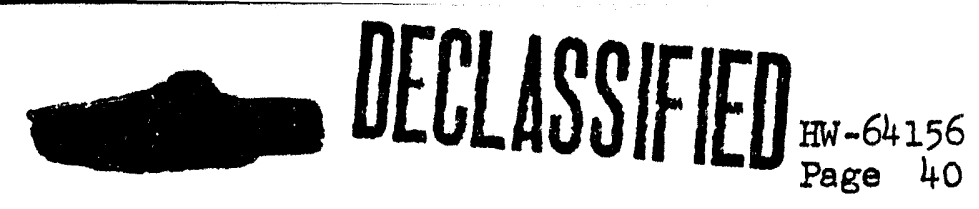

powder valve. Very accurate and minute quantities of material can be discharged with these powder measures. A long thbe is used at the lower end of the bottom powder valve to extend through the shlelding and into the pressure vessel.

In the operation of this device, care must be taken to make certain that the lower powder measure hopper is never completely empty. As long as sand remains in this hopper, an effective seal is maintained, and contamination spread from the lower valve to the upper valve is prevented. If the lower hopper is completely emptied, the action of the lower rotor will tend to spread contamination into the hopper and, subsequently, from the upper rotor on 1ts underneath side to the hopper above it. If the unit were operated continuously in this manner, eventually contamination would probably spread to the top cover and when the cover was opened, spread into the room.

\subsection{Crucible Insertion Station - SK-2-18057}

After the small sand loader has deposited a small quantity of sand on the bottom of the pressure vessel, the crucible can then be lowered into the pressure vessel. This is done at the crucible insertion station. After the pressure vessel is positioned, raised, and sealed against the top of the tunnel, the cruclble inserter which is located above and in the center of the positioning and centering device is actuated and a cruclble is pushed down and released allowing it to fall (approximately 1/8") to the bottom of the pressure vessel. The pressure vessel is then lowered and moved to the next station.

The cruclble inserter shown on the above drawing, consists of a long sleeve with a sphincter seal type internal configuration. Crucibles are shoved in from the top, one ahead of the other, much in the same manner as ice cream cartons are inserted through a sphincter seal. At least two crucibles must be in place at the time of charging, to prevent opening the inside of the tunnel to the outside Zone III. The upper crucible is pushed down, displacing the lower one, to the point where the sphincter no longer supports it, and it drops. An interlock is provided so that it is not possible to drop a crucible unless the pressure vessel is in place and sealed.

\subsection{Large Sand Loader - SK-2-17989}

The large sand loader is used to fill the remaining space between the crucible and the pressure vessel with sand. As stated previously, the sand supports the crucible during the firing operation, and prevents molten plutonium from reaching the walls of the pressure vessel should the crucible break. At the small sand loader station, a small amount of sand was placed beneath the crucible. This maintains the space between the bottom of the crucible and the bottom of the pressure vessel. In most cases, the amount of sand deposited will not completely fill the clearance between the crucible and pressure vessel at the bottom. It 1s, therefore, necessary for the large sand 


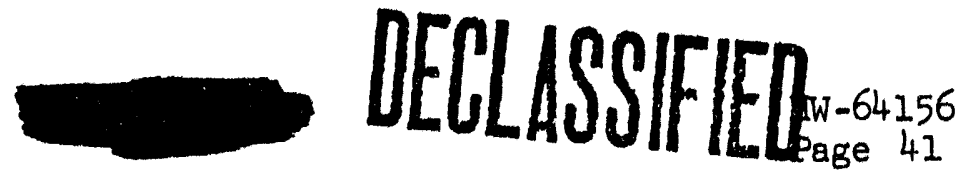

loader to not only fill the clearance around the sides of the crucible, but also the remaining space at the bottom. A further requirement is that the amount of sand or the thickness of sand around the outside of the crucible be unfform; consequently, it must be located and centered within the pressure vessel prior to the time that the sand is added.

As shown on the above drawing, the lifting and centering device ralses the pressure vessel against a seat at the lower end of the large sand loader. Thls seat centers the pressure vessel with respect to the lower head which extends down into the crucible. A vacuum-operated tube arrangement on the head is then actuated which centers the crucible with respect to the pressure vessel. Sand can now be introduced at the top of the loader and by use of a conical-shaped baffle and a vibrator, fed into the uniform clearance around the outside of the crucible.

At this point, the crucible pressure vessel assembly is ready for transfer to the dispenser and storage station for charging either with the plutonium fluoride or make-up chemicals. If the most desirable material flow sequence is to be followed, chemicals would be added prior to the addition of the plutonium fluoride. However, because of the possibility of pre-ignition when the hot fluoride is added on top of the chemicals, it may not be feasible to follow this procedure. If this happens to be the case, the assembly would have to be transferred to the dispenser and storage station first, the fluoride added, and then the assembly transferred back to the chemfcal addition station. Another factor involved which makes it desirable to load the fluoride before the chemicals are added is the possible necessity for welghing the plutonium fluoride out in precise batches. Since the fluoride is weighed in the pressure vessel crucible assembly, the additional weight contributed by the chemicals would only increase the accuracy required of the welght measuring device. If volumetric measure is permissible, then this would not be a factor.

When the button line is producing alpha phase material, it would probably be possible to charge the assembly by volume measurement, since enough chemicals for the maximum volume of fluoride could be added each time. A slight excess of make-up chemicals would not materially affect the reduction efficiency. If delta phase material is being produced, however, weighing would probably be required. Relatively accurate charges of fluoride would have to be measured out in order to determine the amount of alloying metal that is needed to stabilize the material in the delta phase. Alloying in the casting operation rather than in the reduction operation would be highly desirable because it would eliminate a considerable amount of complexity in the charging and chemical addition functions. For purposes of the discussion which follows, it will be assumed that the assembly is moved first to the dispensing and store ge station and after inspection, the powder charged into the pressure vessel and welghed. A discussion of this procedure was given under Paragraph 3.6, Dispenser and Storage Station. 


\section{- DECLLSSFIFED}

\subsection{Chemical Addition Station - SK-2-18205}

At this station calcium and lodine are added to the plutonium fluorlde to support the reaction and produce the metal button. If delta phase material is desired, an alloying element is also added at this point. All of the chemicals that are added are solids, however, they are not the type that are readily handled through conventional type rotary valves or powder measures.

Both chemicals are in the crystaline form and the calcium is ground and stored in an argon atmosphere. The lodone crystals have a noticeable tendency to stick together and form large lumps which are sometimes difficult to break up. Based on past experience, it has been concluded that the best means of adding these chemicals to the fluoride is to weigh them out accurately, place them in an ice cream carton, and then dump the contents into the pressure vessel. Metering of these chemicals by conventional rotary valves or powder measures does not appear to be practical.

As shown on the above drawing, the chemical addition station consists of a large rotor into which the lce cream carton containing the chemicals is inserted through a sphincter seal located at the top of the rotor. The loaded ice cream carton is pushed ahead of an empty ice cream carton into the cavity. In this way an empty carton is left in place in the sphincter seal, maintaining a seal between the rotor and the outside Zone III. At this point the large rotor 1s rotated approximately $120^{\circ}$ and the chemicals arop out through a long tube, which directs them into the loaded pressure vessel crucible assembly now located and sealed against the top of the tunnel. Location of the pressure vessel and crucible at this point is the same as at the previous stations. Once the lce cream carton has been emptied, the large rotor is then rotated approximately $60^{\circ}$ further in a counterclockwise direction and the carton drops from the rotor into a plastic bag. A rod port is located at the back end of the rotor to permit forcing the ice cream carton out of the rotor should it stick. After several cartons have been pushed into the plastic bag, they are removed by conventional plastic bag procedures.

If it should be found from experience that it is unnecessary to use the ice cream carton and sphincter seal principle for inserting chemicals, it is possible with this design to insert a sleeve open at both ends into the sphincter, thus allowing loading of the chemicals directly into the cavity of the large rotor. If after a period of time contamination spreads from the rctor to the outside, it would be possible to displace the sleeve and discharge it into the plastic bag in the same manner that an ice cream carton is handled. Operation of the unit thereafter could then be as was discussed in the first approach using the ice cream carton.

The drive for the large rotor shown on the drawing is by a manual handle and crank assembly. If eesired, the unit could be electrically powered, and sequenced to eliminate the manual operation. 


\section{DECLLSSFFIED}

\subsection{Mixing Station - SK-2-18250}

At this point the pressure vessel and crucible assembly has been sanded, the fluoride added, and the calclum and lodine added to the top of the fluoride. Mixing at this point is desired to give unfform high yields in the realuction step. At this station the pressure vessel is ralsed by the lifting and centering device and sealed against the top of the tunnel. A mixing head mounted centrally above this polnt rotates a hellcal-shaped screw as 1t lowers it to the bottom of the crucible, which continuously moves the contents and circulates them from bottom to top. The motor-driven device works on a principle quite similar to the level wind on a casting reel in that continuous movement up and down in the crucible is attained while the agitator is rotating. Hith a properly shaped screw, each increment of volume within the cructble is turned over during each stroke of the agitator. This device, like others along the Task III tunnel, is removable as a complete section for transfer and repair at the maintenance hood.

When the mixing is complete, the agitator drive is stopped and after a short time interval for dust settlement, the pressure vessel and crucible assembly is lowered to the pallet for transfer to the next station.

\subsection{Gasket Dispensing Station - SK-2-18058}

The mixing of the contents in the pressure vessel crucible assembly having been completed, the assembly is now ready for placement of a gasket on the top of the vessel. The pressure vessel is raised and sealed against the top of the tunnel and a gasket is. dropped into position from the stack located immediately above the opening over the pressure vessel. The dispensing of gaskets is much the same as that of the crucibles and chemical addition In that the stack of gaskets, perhaps as many as 10 , are pushed through a sphincter seal one ahead of the other. At each operation, one gasket is added to the top of the stack and a plunger actuates downward approximately the thickness of the gasket displacing one from the bottom of the stack.

As shown on the above drawing, the actuating device is nothing more than a small electric motor driving a lead screw which ralses and lowers a travelling nut driving against the gasket stack through a tripod-shaped framework. The ring fastened to the lower end of the tripod serves to keep the gasket square within the sphincter seal and prevents deformation of the edge of the gesket.

One obvious drawback of this design is the fact that gaskets have a small hole in the center. The gasket is made up of an 


\section{$\square$ DECLASSFFED}

HW -64156

Page 44

aluminum ring approximately 6" in diameter $\times 1 / 8$ " thick $\times 1 / 2$ " deep with a thin steel disk supported in the middle by grooves machined in the aluminum ring. If further study indicates that the small amount of alr leakage through the serles of holes in the gaskets becomes a problem, it may be necessary to insert the gaskets from the side in such a way that an air lock exists between the entry port and the stack of gaskets within the sphincter seal. Design-wlse, this should not present any particular problem.

4.10 Reduction Furnace Station - SK-2-18047

The pressure vessel assembly is now ready for the reduction firing operation. Since the overall time for reduction is somewhere in the order of two to three hours, and it is necessary to move other pressure vessels back and forth beneath this operation during that time, the pressure vessel must be lifted clear of the tunnel to provide clearance for passage at this point. This necessitates a iffing device different from that provided for the other operating functions. Another requirement for this lifting device 1s that it be capable of supporting a very high load and resist fairly high temperatures. Further, 1t must be capable of taking up on the pressure vessel as the reduction process ensues to make certain that the gasket maintains a seal during the entire operation.

In order for a tight seal to be maintained, the gasket must have sufficient force against it that it be deformed at room temperature. This force was calculated to be somewhere in the order of 20,000 pounds total force. As the reduction firing ensues, the temperature of the entire unit increases to somewhere in the order of $5000 \mathrm{C}$. At this high temperature, the aluminum gasket begins to yield and it then becomes necessary for the supporting hooks to take up on the gasket to compensate for Its deformation. The need for lifting and supporting the pressure vessel from above and the requirement that the pressure vessel be heated to high temperature creates another proilem. To get a rapid rise in temperature, induction heating $1 \mathrm{~s}$ desired and this results in heating of the components which support the pressure vessel which is undesirable. If conventional high frequency induction heating is used, another compl1cation is added in that some type of cooling must be used to prevent the colls from melting. Although water cooling is commonly used in applications of this type, and in some cases gas cooling has been used satisfactorily, netther is entirely satisfactory. In order to achleve the positioning requirements of this device, it would be necessary to use flextble lines for either type cooling system. For the above reasons and because of the inherent benefits, low frequency induction heating has been applied as in the case of the fluorinator and calciner. Another desirable feature is that the actuating system be powered by one drive motor to actuate all functions. For example, after a pressure vessel has been located underneath this station, the handing system is energized and a 
set of hooks lower, engage with the top of the pressure vessel, and then retract back up 1nto the overhead shell and seal the pressure vessel to the platen located at the top. The pressure vessel is then maintalned sealed against the top without-further control measures. Upon completion of the flring operation, the previously operated c1rcult is deenergized and another owltch actuated and the entire assembly moves back down Into the tunnel, the pressure vessel 18 released, and the hooks move back up into position above the top of the tunnel. At this point the pressure vessel is then ready to be transferred to the next station. The entire operation can be made entirely automatic without any great design difficulty.

The design shown on the above drawing cons1sts of a vertical lead screw and traveling nut to which is attached four arms that raise and lower with the traveliling nut and actuate four cam operated hooks at the bottom of the furnace unit. Also attached to the four arms is the low frequency induction coll which moves up and down with the arms and makes contact with terminals at the top of the stroke to actuate the heating system. In principle, the lead screw, travelling nut and arms work in much the same manner as the remote connectors used for piping in Purex and Redox Plants. Extremely high forces are attainable with a hook arrangement of this type.

Not specifically clarified before, but equally important, is the fact that the heating coll is automatically connected and disconnected as the assembly is moved up and down. This is made possible by the fact that the conductors and the entire electrical system is operated by 60 cycle 220 volt AC power and no cooling medium is needed.

As mentioned previously, the drive system for this device must be capable of taking up on the load as the temperature of the pressure vessel and gasket increases. This is done as follows: To the top of the lead screw ls attached a worm wheel. The worm wheel is driven by a worm attached to a magnetic clutch which is driven by a 3HP, three-phase AC motor. By running the motor cont1nuously a constant torque is applied to the lead screw and consequently, a constant force is applied agalnst the top of the pressure vessel. A power fallure would not effect the system, since the lead screw could not drive backwards through the worm wheel and worm assembly. Th1s same protection could not easily be provided by a hydraulic system.

4.11 Gasket Cover Remover - Mark 3 - SK-2-18246

The function of this station is to remove the gasket so that the contents within the pressure vessel can later be ground up and emptied for further processing. Experience has shown that in most cases the gaskets are not reusable; consequently, they are removed at the station and stored for subsequent disposal. Since there is little chance of spreading powder within the tunnel during this 


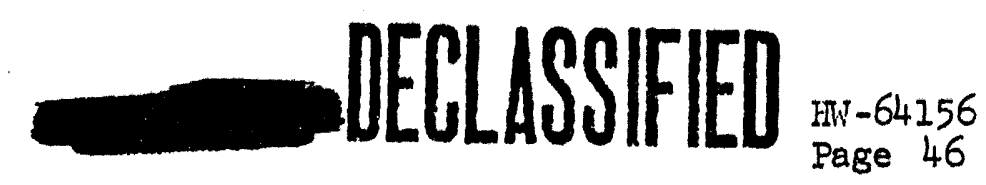

operation, the pressure vessel is not ralsed and sealed against the top of the tumnel es in previous operations. Instead, the gasket removing device lowers to the point necessary for plckup, grasps the gasket and transfers it to the disposal storage chamber.

Since the center section of the gasket is made of steel, an electromagnet is used to lift it from the pressure vessel. This magnet is positioned by an arm driven by a gear-driven shaft which rotates the magnets through approximately $140^{\circ}$. When the magnet and gasket have been rotated to the disposal port, a spring-loaded hammer automatically knocks the gasket from the electromagnet. The springloaded hammer is actuated by a cam, which is concentrlc with the driving shaft. Lifting of the gasket from the top of the pressure vessel is by the magnetic force of the electromagent ard actuation of the magmet is simultaneous with the energizing or loaling of the hammer. Attached to the disposal storage chamber is a bagout port which can be used for removal of the gaskets by conventional bagout procedures.

The design, as shown on the above drawing, is not entirely satisfactory. However, except for one relatively difficult problem, the remainder of the problems are of no design consequence. The most significant problem is the tendency for the gasket to stick to the top of the pressure vessel. No provision has been made in this design to take care of this. Also due to the configuration of the top of the gasket, there would be interference between the lower shoe of the magnet and the gasket rim when the hammer strikes the gasket to remove it and displace it in the disposal storage area. One possible solution to both of these problems is the use of the hamer to break the gasket loose from the top of the pressure vessel. For example, as the electromagnet is rotated into position, it would be possible to strike the gasket with the hamer just as the electromagnet is energized. In all probability this would break the gasket loose and the electromagnet would lift it free and clear of the groove in the top of the pressure vessel.

At this point the pressure vessel and its contents are ready for transfer to the slag and crucible grinding station for grinding and removal of the slag and crucible and transfer of the metal to the pickler.

\subsection{Crucible Grinder - SK-2-18052}

The function of this station is to grind up alz of the slag and crucible above the button and transfer this material and the sand around and below the crucible into a removable container for transfer to the slag and crucible dissolver in Recuplex. Ideally, when the pressure vessel leaves this station, nothing would remain in the bottom but the metal button. Since a considerable amount of dusting is likely to occur during this operation, a standard lifting and centering device is used to raise the pressure vessel to the top of the tunnel. 
The design shown on the above drawing incorporates many of the desirable features reguired at this station. A motor-driven rotary rock bit is used to grind the contents down to the level of the top of the button. The operation of this bit is much the same as that in drillins an oll well. The combined rotation and downward pressure on the bit causes the teeth to break up the surface of the slag in small chunks and these chunks are removed by a vacuum system as the bit moves f'urther down into the vessel. The vacuum system for removing this material into the center of the bit is not shown on this drawing. Also not shown on this drawing is the lifting and centering device which would be used for supporting and sealing the pressure vessel. Damage to the top of the button is prevented by a pre-determined stroke length on the bit shaft and by pre-determined crucible shape and volume which will produce a maximum button whose top surface clears the bottom of the rock bit at the end of. Its stroke.

Vendor's estimates on drilling rates and bit life for this type of bit on similar materials, indicate that this bit would last somewhere in the order of six months. The cost of replacement is somewhere around $\$ 80$. Although there is some small chance that the action of the bit would remove all of the sand and crucible and slag from the pressure vessel, it is only reasonable to assume that a certain amount of this materlal will remain after the rock bit has performed its function. For this reason, further provision must be made for separating these materials from the button. This is taken care of at the crucible dumper and screen.

4.13 Cruc1ble Dumper and Screen - Mark 2 - SK-2-18244

The function of this station is to make the final separation of the button from the loose solids that remain in the bottom of the pressure vessel. The loose solids and sand are collected for transfer to Recuplex and the button retrleved for transfer to the pickle station. It is at this point that the handing components make a departure from the concepts used in the previous stations. This was thought advisable because it is at this point that the pressure vessel must be lifted and inverted for dumping on the dumper screen. Also at this point the pressure vessel is recycled back through the line for preparation of the next reduction charge, and the metal button is handed from this point without the aid of a container.

Several study drawings have been made of this station and although the above drawing is not entirely satisfactory, it represents the latest thinking. It consists of a yoke which intercepts the pressure vessel on the pallet and rotates it into position over a lifting yoke. The lifting yoke assembly raises the pressure vessel and rotates it until it is upside down over a hinged grate. The hinged grate being motor-driven acts much like a shaker and allows small solids to fall through into a storage container but prevents the button from falling through and causes it to slide into a chute which leads to the

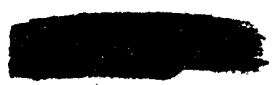


pickler. The pressure vessel is then transferred back to the groove cleaner and vacuum cleaner station by means of the tunnel pallet for preparation of the next reduction charge.

4.I4 Pickle and Wash Station Off-Set Vertical Drive - SK-2-18222 and SK-2-18214

The function of the pickle station is to remove any adhering crucible Iragments or slag by use of a nitric acid bath and then to rinse the button in a water bath. The time required for pickling varies with the amount of crucible and slag that has to be removed. It is, therefore, necessary that the button be inspected after passing through one pickling cycle and if it is not clean, it must be recycled before transferring it to the next station. Agitation of the pickle bath is desirable to speed up the chemical reaction and reduce the overall cycle time required for this process step. Since the pickle solutions emit highly corrosive fumes, It is desirable to isolate the entire pickling equipment as much as possible. Provisions must also be made for recovering the pickle solution for processing in Recuplex.

Out of the various study drawings made in an attempt to meet the criteria for this function, the above drawing appears to be the most promising. In principle, it is a rotary drum washing machine consisting of three separate chambers, one of which is for the pickle solution and two for wash solutions. Each of the three perforated drums rotate on a comon shaft within a sealed barrel. Openings at each end of the barrel are for entry and exit of the button. Within each perforated drum is a baffle which, when rotated through $360^{\circ}$ in one direction, dumps the button into the next drum. Oscillation of the drums without complete rotation causes the button to tumble in the bottom of the drum. Another baffle located in the drum causes the IIquid to be agitated. Rotation of the three drums in one direction causes the button to pass through the three drums in one direction whlle rotation in the upposite direction causes the button to move in the opposite direction. This feature permits the recycling of the button by simply changing direction of the rotation of the pickler. As shown on drawing SK-2-18214, at the exit end of the plckler is located a button inspection device. which permits looking at the button on both sides. The mechanism for dumping the button back into the pickler for recycle is not shown. Pickle and wash solutions are added to the barrel, as shown on SK-2-18222. It will be noted that the drum or enclosing barrel is segmented at the bottom to prevent intermixing of the wash and the pickle solutions. The use of a stepped shaft for driving the individual drums makes it possible to remove the drums through the top of the enclosing barrel using the new bagout procedure. The entire pickle and wash station can be removed as an assembly by bag procedure and transferred to the maintenance hood for repair.

After the button has been pickled, washed, and inspected, it is now readif for the final finishing operations. These operations are shown

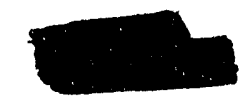




\section{- DECLLSSFFIED}

$\mathrm{HW}-64156$

Page 49

on SK-2-18214 and will be discussed independently in succeeding sections. It will be noted that transfer of the button from station to station beyond this point is by means of a lead screw and travelling nut which slides the button along the series of parallel rails.

\subsection{Numbering Station - Mark 2 - SK-2-18251}

For accountability and administrative purposes each button must be marked with a serial number and records kept of its location at all times. Because of the irregular surface of the button and the hardness in the case of alpha material, a considerable amount of force is reguired for this stamping operation. Consecutive numbering of buttons is required and in some cases it is also necessary to repeat a number.

The numbering head shown on the above drawing is a commercially available automatic numbering head with 1/16" numbers and provision for consecutive and repeat numbering. A Mead, model number AH65, Impact hammer is used for exerting force on the top of the button. The Mead hammer is actuated by an air system. The button is backed up underneath by an anvil which is attached to the floor. The anvil is recessed in the conveyor bed and flush with the top of it. The finger conveyor driven by the lead screw and traveling nut slides the button into position over the anvil. At this point the air supply is actuated and the numbering head is lowered and strikes the top of the button. Indexing of the numbering system is tied in with the stroke of the numbering head. After stamping the button is ready for transfer to the sampling station.

\subsection{Sampling Station - Mark 1 - SK-2-18252}

At this point a sample is taken from the button to determine the purity and the density. The desired shape of the button sample is best determined by the procedures used for analysis of the sample once it is transferred to the analytical lab. The best configuration has not been established at the present time; however, it has been assumed that a small cylinder approximately the size of a pencil eraser is satisfactory.

As mentioned previously in the section on crucible design, the button is cast or formed to have a thin section in the midale. The reason for this was to make it possible to punch through this thin section and displace a smaIl plug approximately the size previously mentioned. Kanufacturer's data indicates that an impact hammer using a $1 / 4$ " punch is capable of punching out a plug from a $1 / 4$ " plate of mild steel. A Mead impact hammer, model \#AH95, was selected for this button thickness. As in the case of the numbering station, an anvil is also needed with a hardeced die insert to back up the punching operation. This anvil is recessed in the conveyor bed much the same as in the stamping operation. 
The removal of this sample from the sampling operation is a special problem all of its own. Because of the high radiation levels of this material, it is not desirable to handle the button sample in a plastic bag. Nelther is it desirable to bagout each sample since this is time consuming. After considering several approaches, the one shown on the above drawing was selected as the most promising. A long copper or aluminum tube is inserted through the bottom of the enclosure through a sphincter seal directiy beneath the chute which directs the displaced sample to the temporary storage compartment. A funnel located in this compartment directs the sample into the tube and allows it to fall to the bottom. The bottom of the tube has been crimped so as to be air tight. Knowing the length of the sample it is now possible to crimp the tube above this point and remove this section which encloses the sample. The sample is now totally enciosed in a small aluminum or copper capsule and the tube above this point is ready for the next sample to be dropped in. Each succeeding sample is dropped into the tube and removed in the same manner. Eventually, when nearly all of the tube is used up, a new tube is pushed in behind, displacing the old through the sphincter seal into the enclosure. The displaced stubs are temporarily stored in this compartment until it becomes full, after which time all of them are bagged out and disposed of. A bagout flange in the bottom of this compartment is provided for this purpose.

If in the future it is found desirable to produce a sample which more nearly resembles a metal shaving or curl, a design has been worked out which incorporates a tool similar to a shaper and which can easily produce this type of sample.

At this point the button is readv for transfer to the weigh station where the final weight will be recorded and the button then transferred to storage or bagged out for shipment off-site. This design study does not make provision for a storage hood at the end of this line. It does, however, provide a button diverter and conveyor which can be used to transfer the button to a storage station which can be added later.

\subsection{Weighing Station - SK-2-18214}

A final weight check is made on the button at this point prior to transfer to the fabrication line or shipment off-site. Also in some cases a density check is made at this point. This weight measurement provides a good accountability check between the button and fabrication lines.

As shown on the above drawing, the button is transferred to the dry welght pan located in the cunveyor bed. The balance equipment used for making this weight measurement is identical with that presently being used on the RMA and RMC Button Lines. A complete scope drawing of this weigh station arrangement has not been prepared at the present time. 
4.18 Wire Brusher For Groove and Top of Pressure Vessel - SK-2-18249

The preceding paragraphs have dealt with the handling of the button after it has been removed from the pressure vessel and crucible assembly. At the point of separation (crucible dumper and screen), the pressure vessel is recycled for the next looding and firing operations. Before loading, several operations must be performed. The first operation required is that of brushing the inside and cleaning the groove on top. At the pressure vessel dumping station where the slag and crucible was removed the yoke transfers it back to the material transfer tube pallet, which positions it under the wire brusher station. At this point the lifting and centering device lifts the pressure vessel and seals it to the top of the tunnel. The main area needing cleaning is the groove directly on top of the pressure vessel and the internal contour shape immediately inside of the pressure vessel near the top of the cructble.

The device shown on the above drawing consists of a motor-driven shaft which extends down through a sleeve which is fastened to two brushes located at $90^{\circ}$ intervals around the diameter of the pressure vessel. The pressure exerted by the springs against the brushes and the rotation of the shaft assembly performs the cleaning operation.

It is not known at the present time if this approach is entirely satisfactory, and further study and evaluation w1ll be required for this component. Regardiess of the type of device used for this function, there will undoubtedly be times when the upper surface and inner surface will not be cleaned adequately. For this reason it is necessary to provide a pressure vessel loadout station for disposing of the defective vessels and inserting new ones.(SK-2-18254).

4.19 Vacuum Cleaning Station - SK-2-18248

In the preceding operation where the top of the pressure vessel was wire brushed, small particles of sand and miscellaneous solid particles will fall to the bottom of the pressure vessel. It is now necessary to vacuum clean the gasket groove at the top of the pressure vessel and the battom to make certain that the pressure vessel is clear of any obstructions to the insertion of the crucible and sanding.

The pressure vessel is transferred to this station by the pallet and positioned by the overhead lifting and centering device. The device used for vacuum cleaning shown on the above drawing consists of a long tube which can be lowered into the pressure vessel. A gear and rack assembly drives the tube up and down into position. A hose extending through the top connects to a vacuum and filter system for recovery of the contents. The entire assembly is removable by bag-out flange for transfer and repair at the maintenance hood. Not shown on the above drawing, but a feature to be 
incorporated, is a means of viewing the pressure vessel to determine that all the contents have been removed. At this point the pressure vessel is now ready for transfer back to the small sand loader station where the loading cycle begins.

\subsection{General}

In the discussion of components along the Task III tunnel and the Iinishing operations, it is evident that there has been very few applications of hydraulic cylinders for linear motion within the tunnel. Perhaps some explanation is in order at this point, since many of the functions could have been actuated by hydraulic cylinders. In almost every case, a lead screw and travelling nut assembly was used instead. There are two primary reasons for this. First, past experience in the building on the RMA and RMC button and fabrication lines has shown that rotary shaft seals confine contamination within the glove boxes. At the same time, there is hardly a case where a linear shaft seal has proven satisfactory over long periods of service even with the aid of a bellows seal. Hydraulic cylinders have been used for linear motion through the walls of the glove box, however, there is hardly a case where the hydraulic system has not become contaminated and the pumping system and valve racks eventually require masks, rubber gloves, and SWP clothing for maintenance and repair. This was not as objectionable when low level materlals were being processed. In the future, however, with the high radiation level anticipated, it is questionable that this could be tolerated. Further, since most of the linear motions required on the Task III tunnel are through the top, leaks would Inherently result in hydraulic fluid spreading along the bottom and sides of the tunnel. Penetrations through the bottom and sides of the tunnel by hydraulic cylinders would make it extremely difficult to provide a pallet transfer system, and would represent obstructions to cleaning and sweeping of the tunnel. The large number of cylinders sticking out in all directions would also make access to the tunnel extremely difficult.

Since the greatest rate of personnel exposure is recelved during equipment changeout, it is desirable that the time required for changing out any plece of equipment be reduced to an absolute minimum. Where power is transmitted through the tunnel by electric means rather than hydraulic, it is easy to see that disconnection of the power source would be much faster in an electrical system. Also the ease of routing unshielded electrical conductors makes the case for electrically-ariven lead screw and traveling nut transmitters of linear motion much more favorable. 


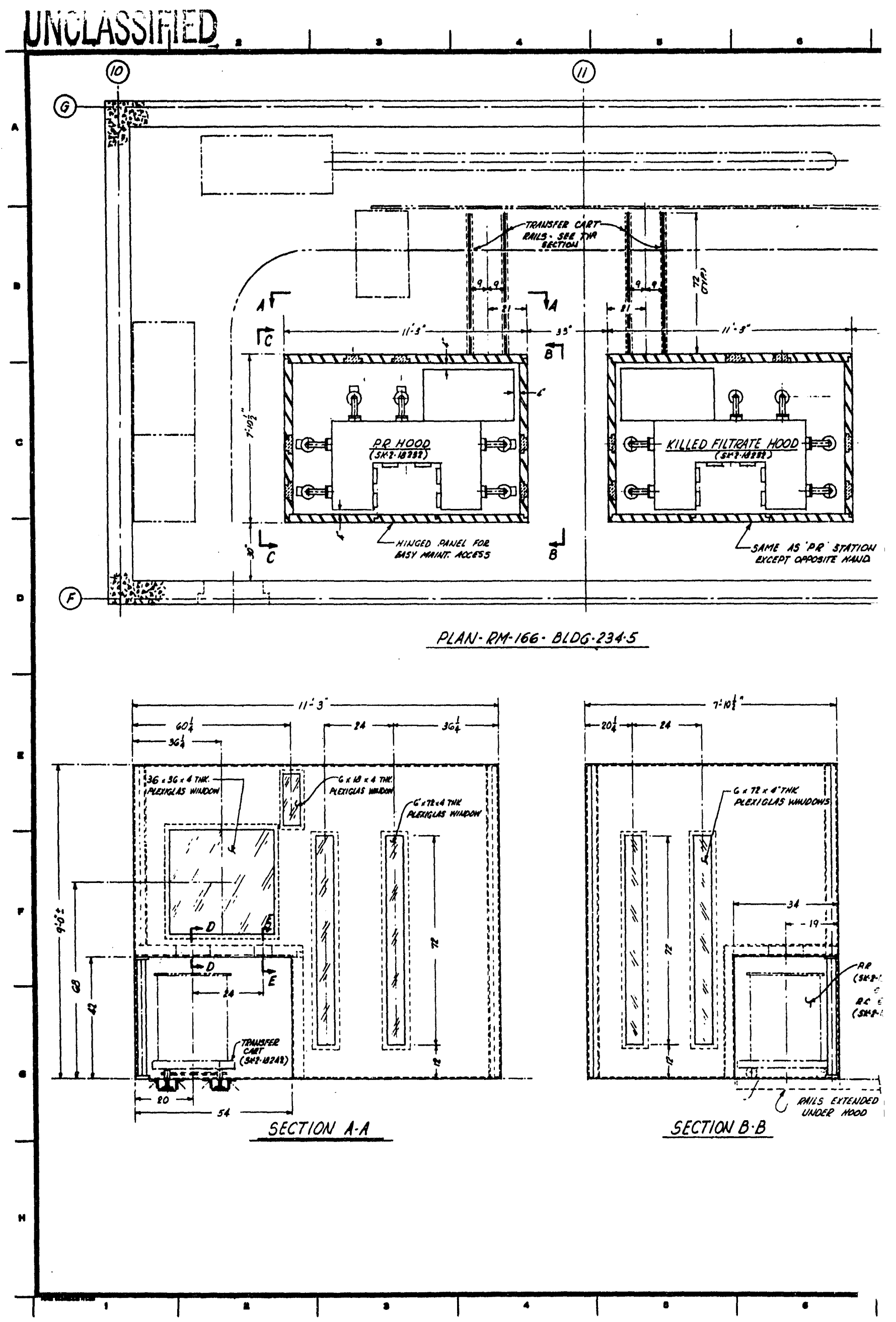




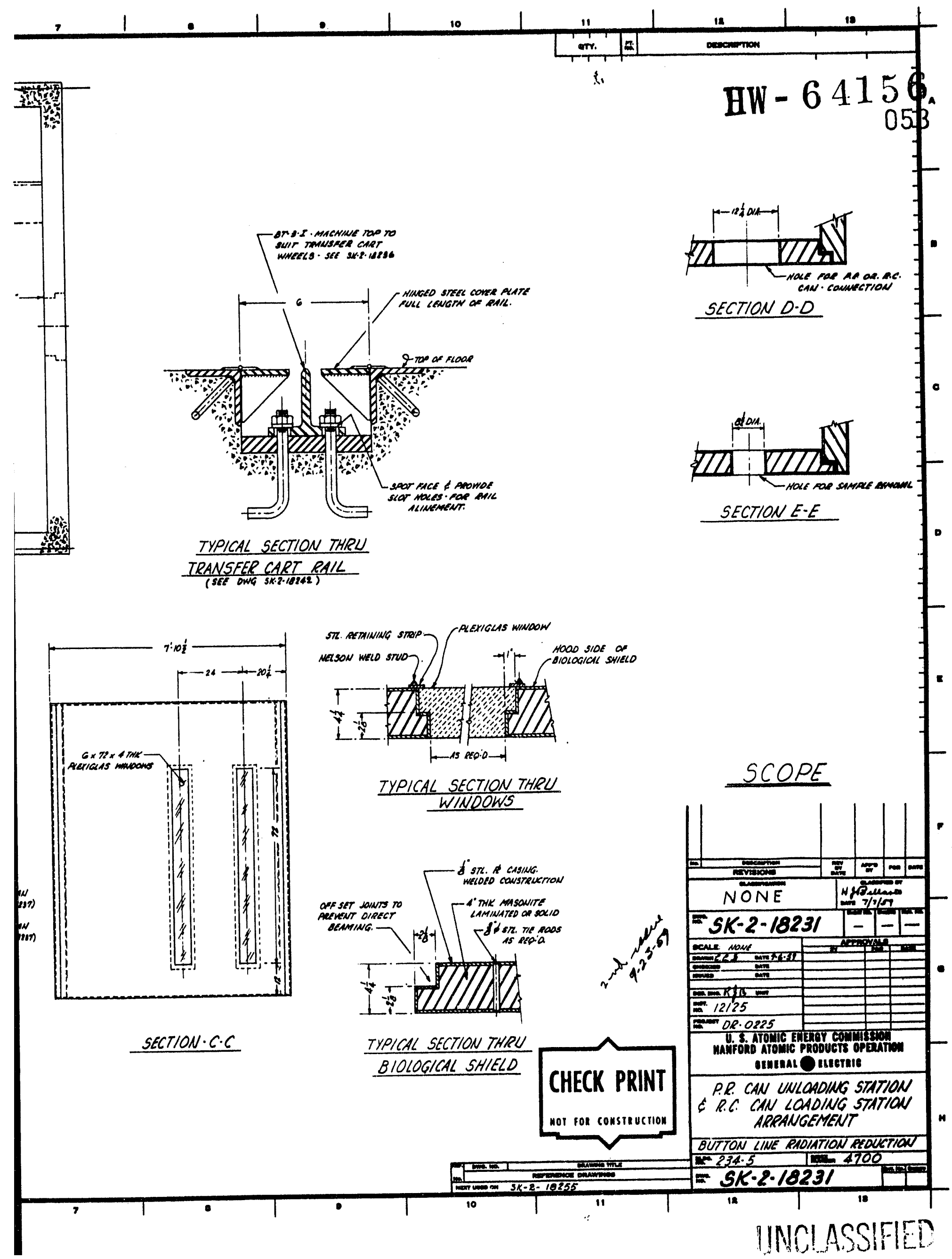




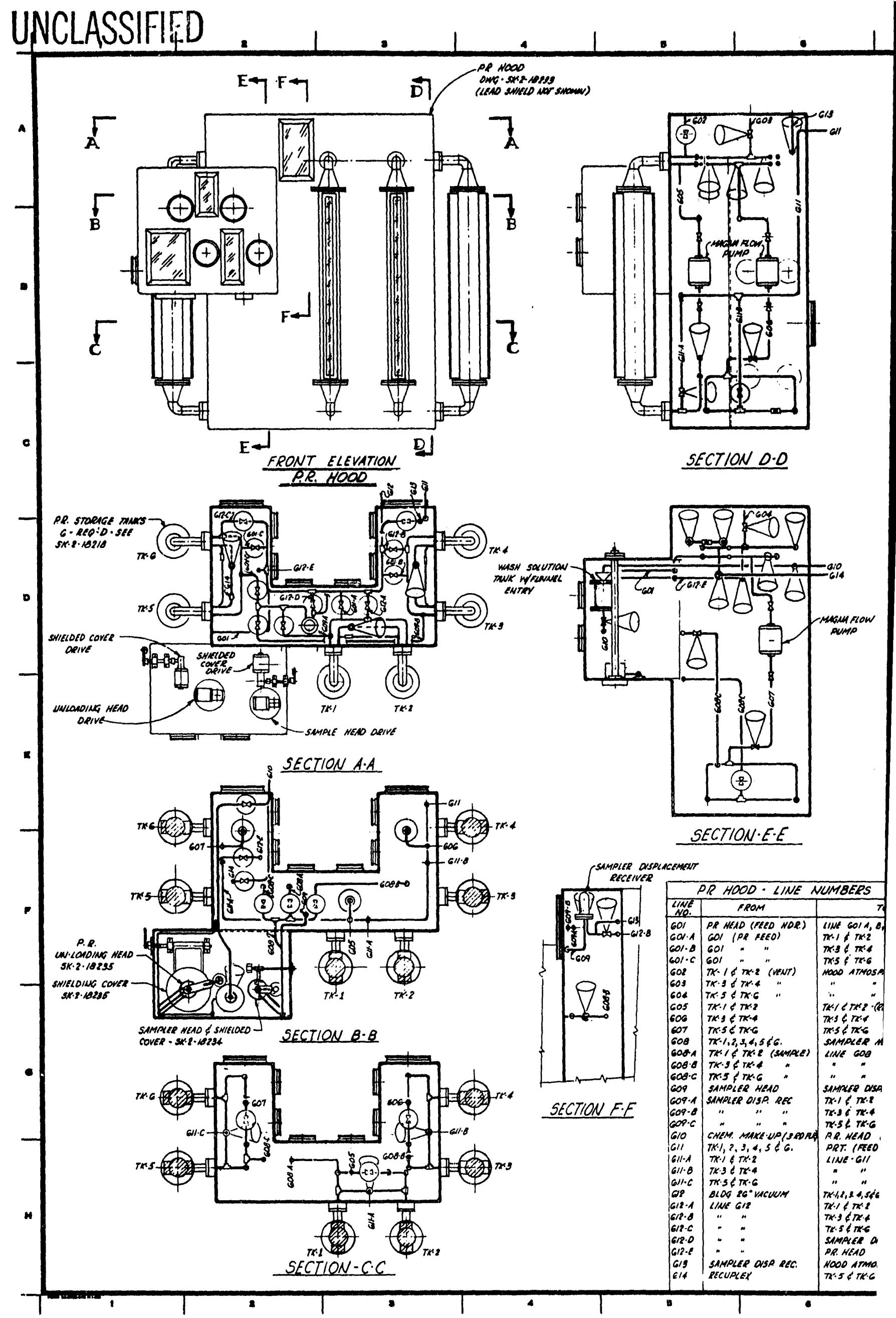




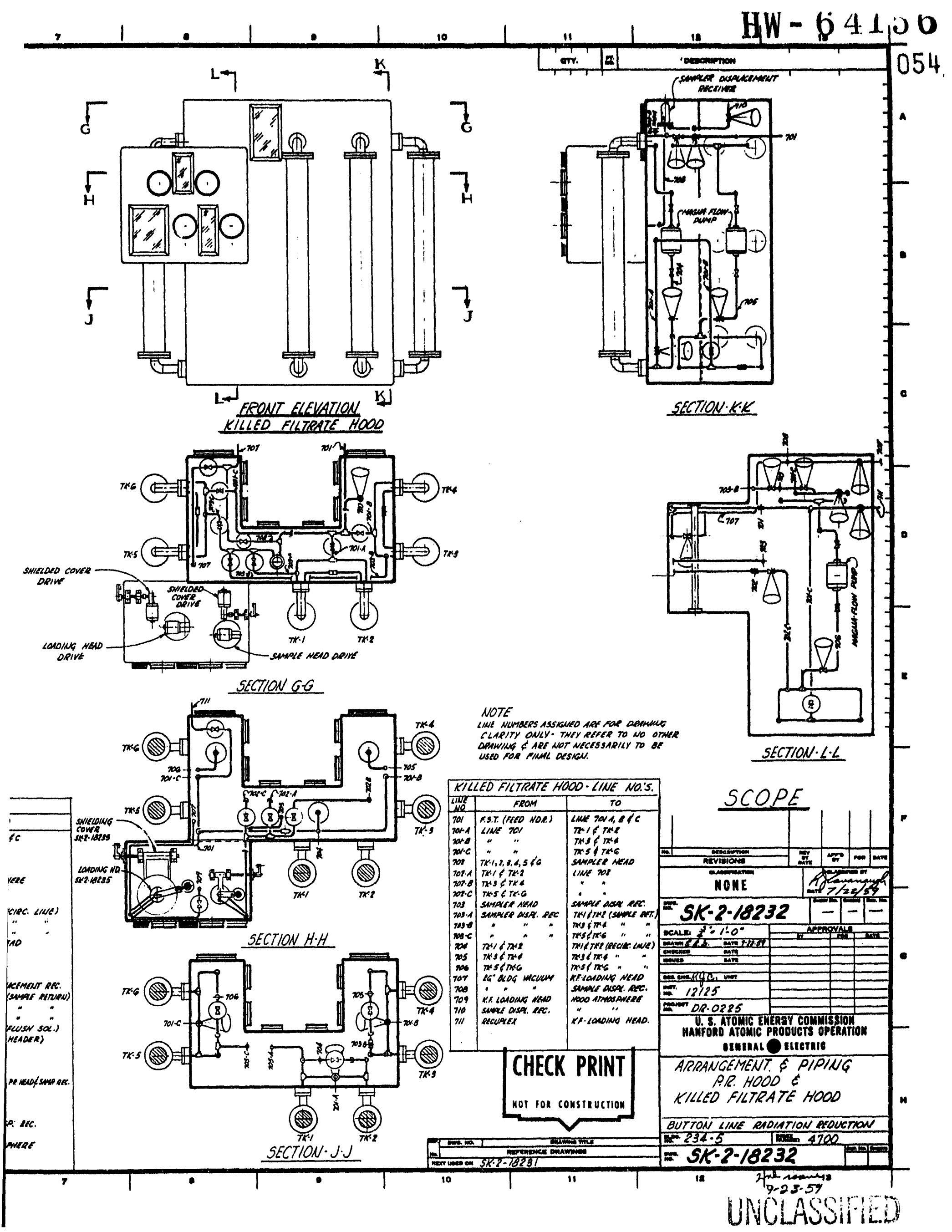




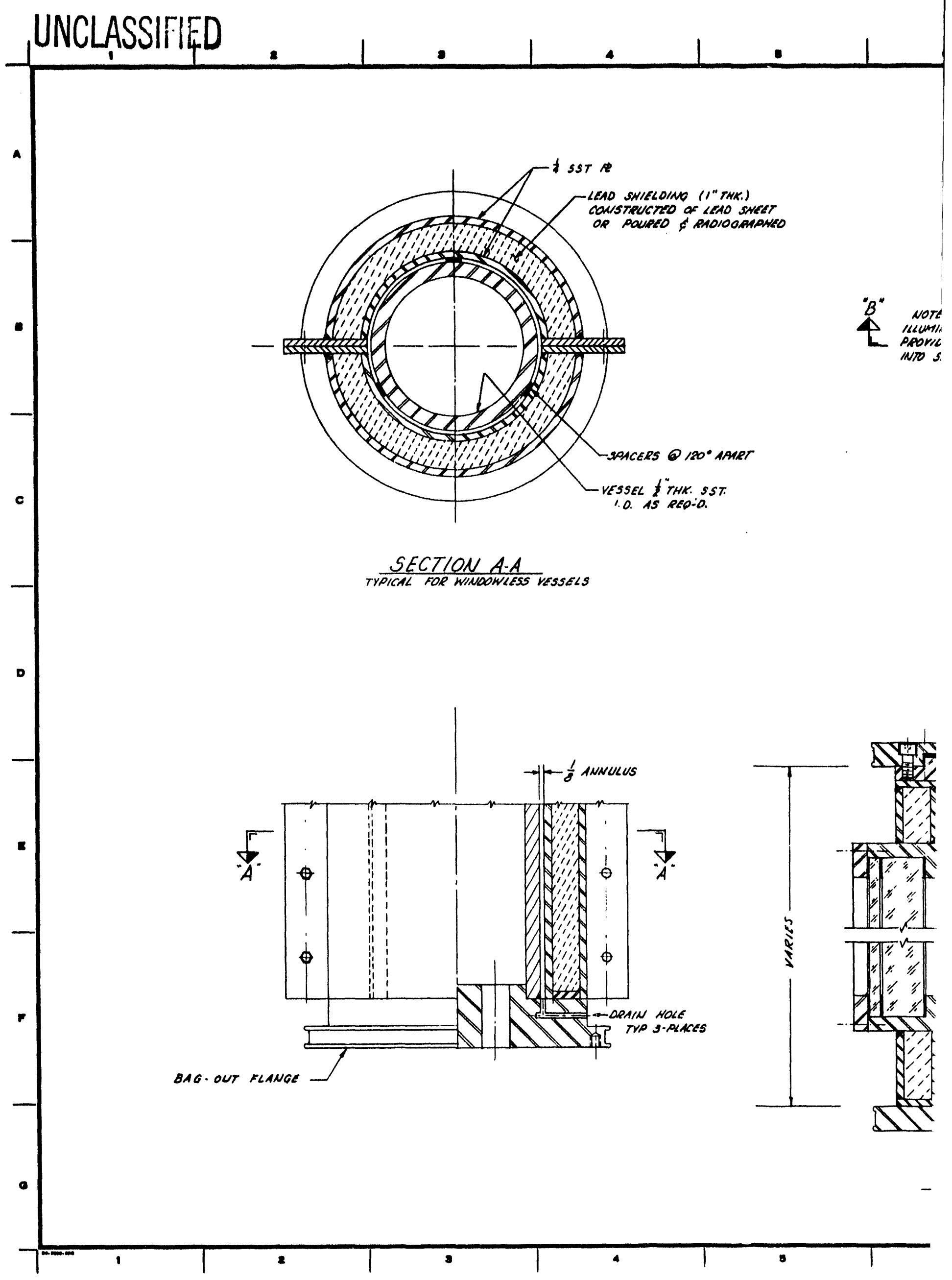




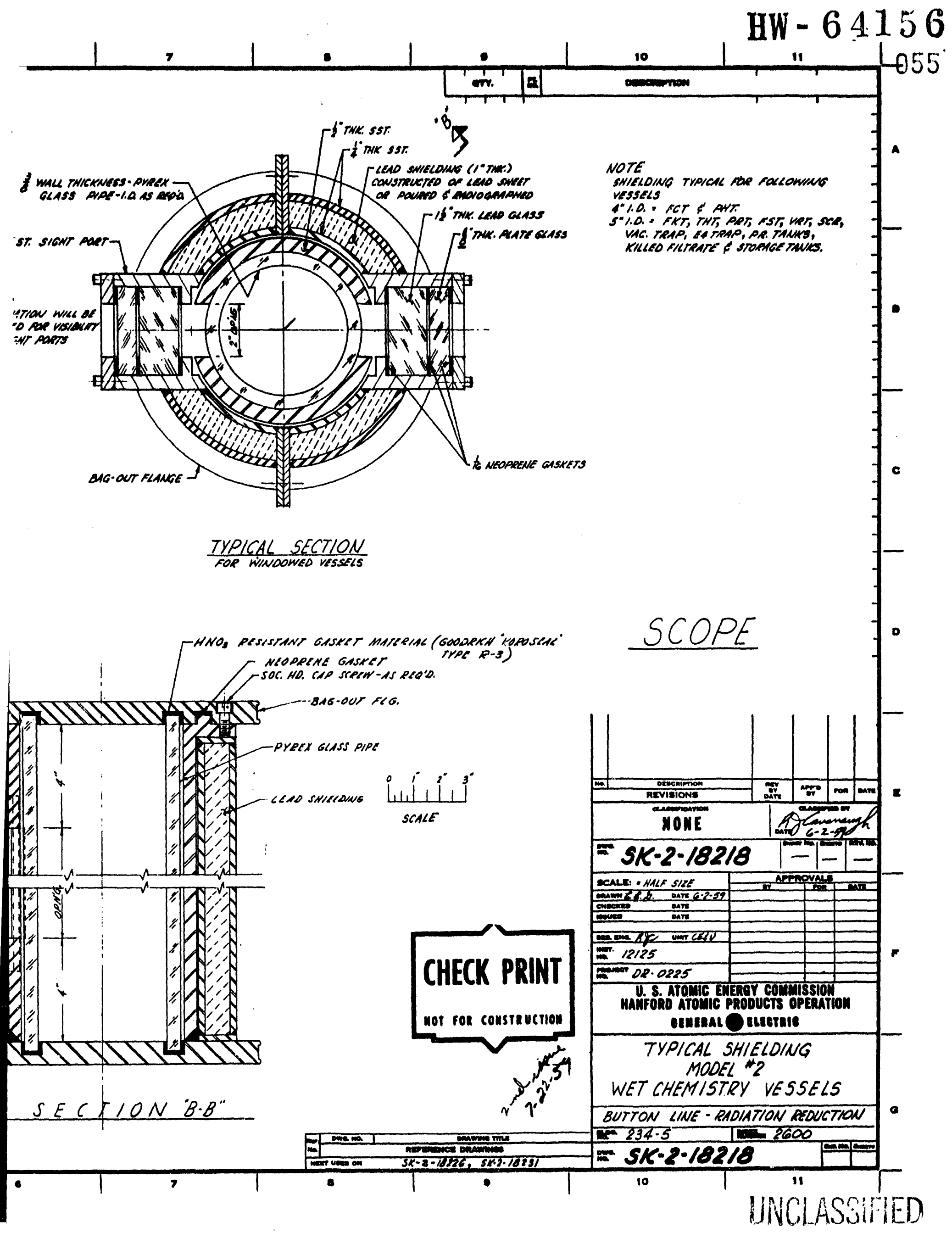




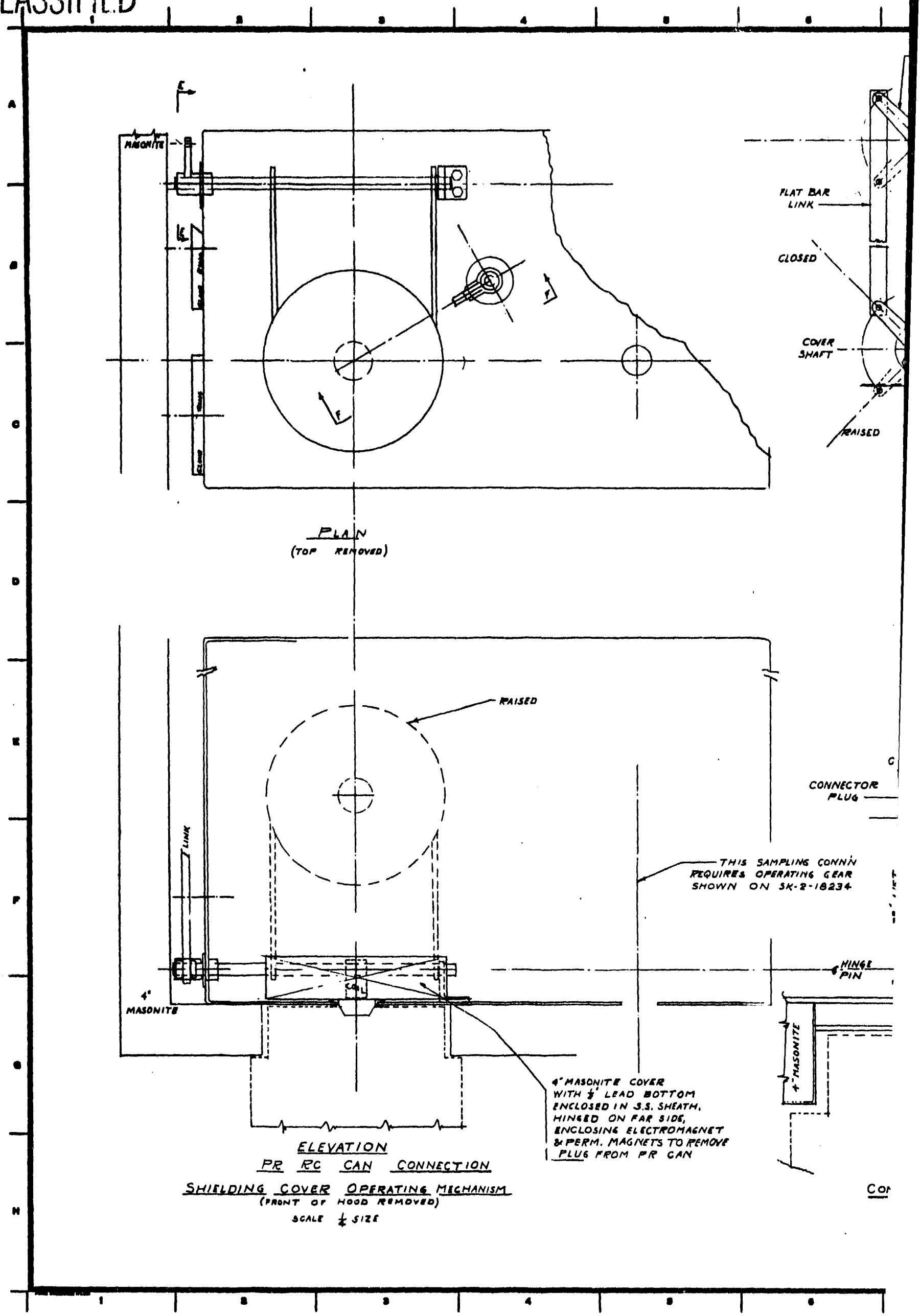




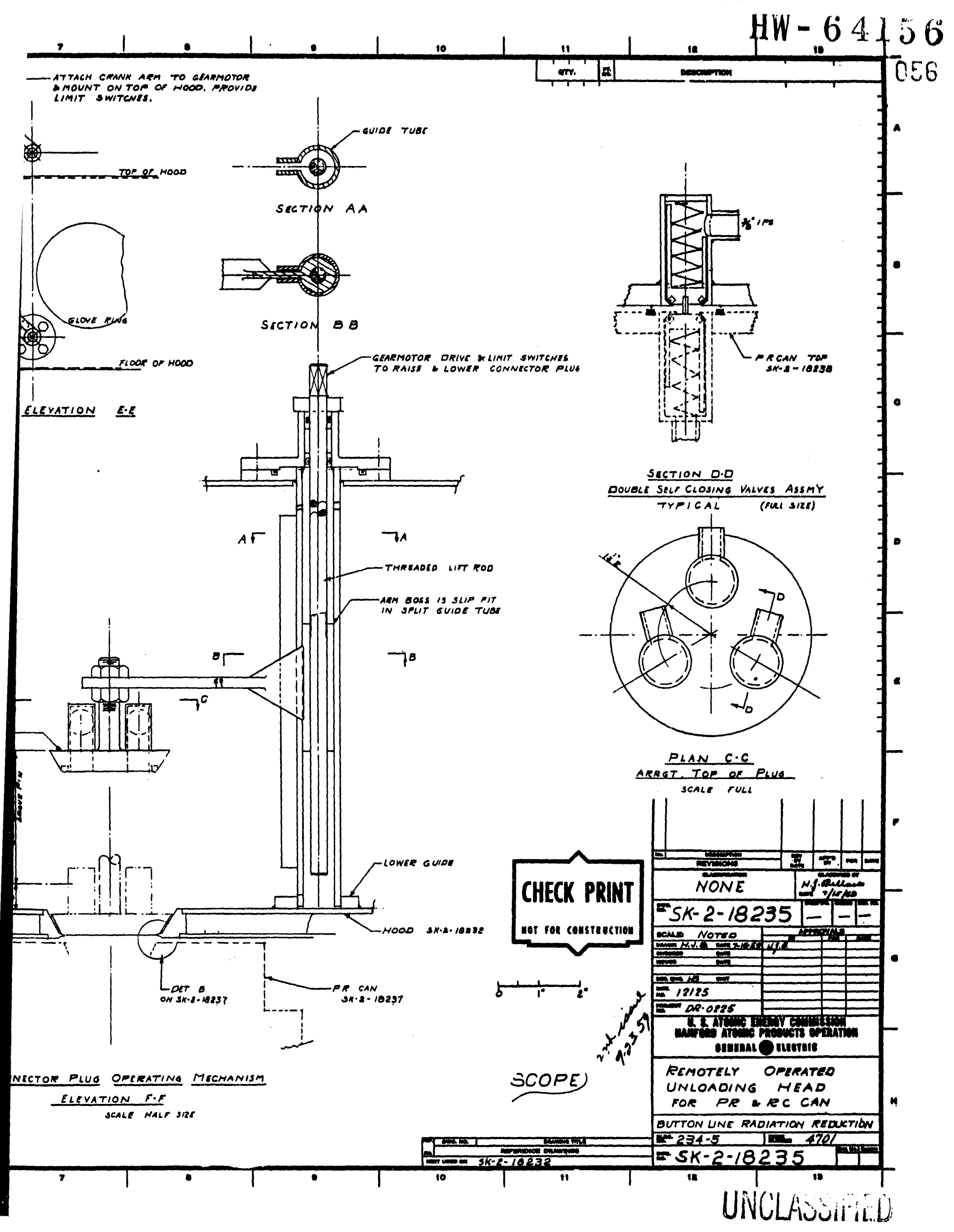




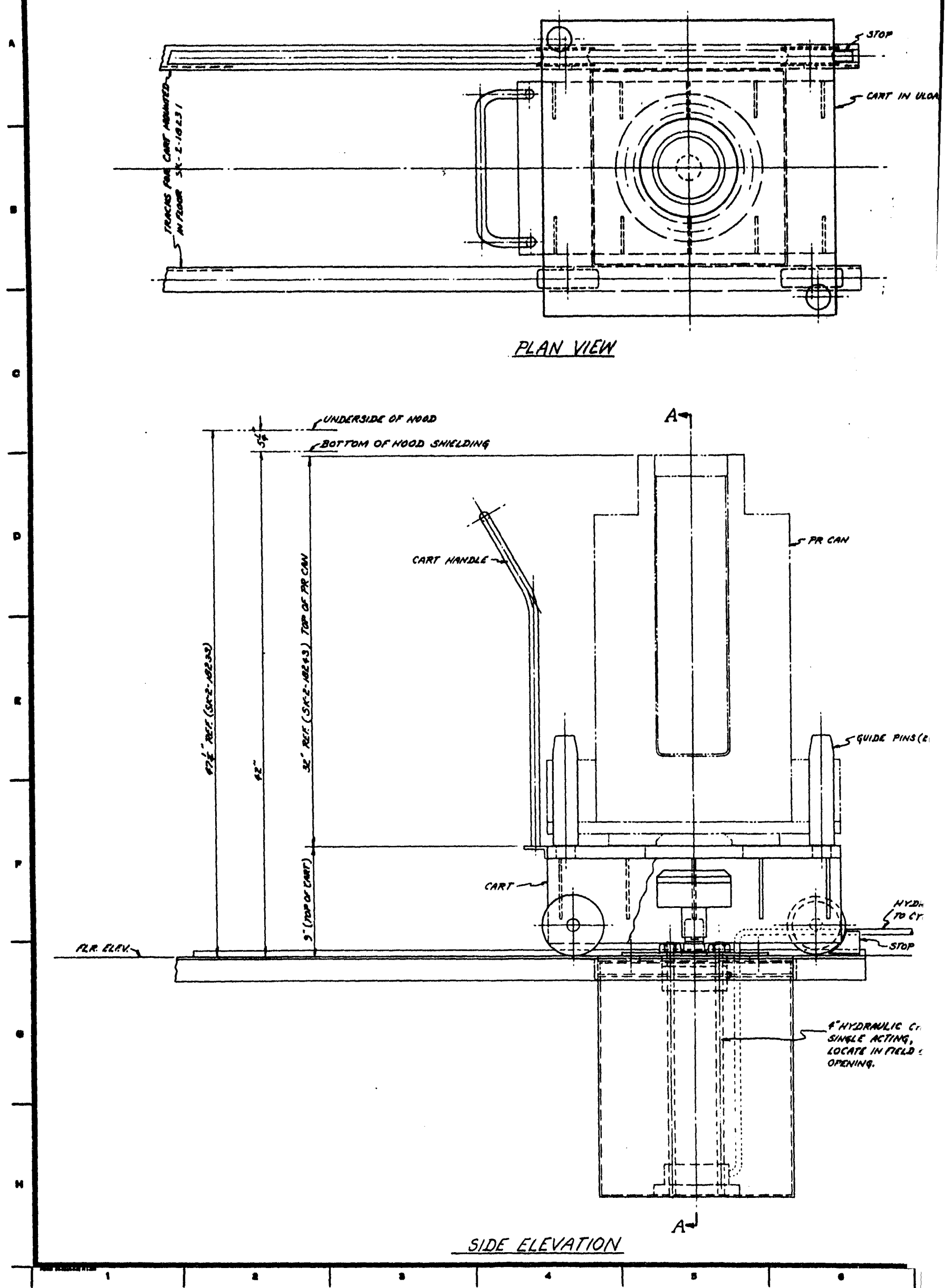


UNCLASSIFIED

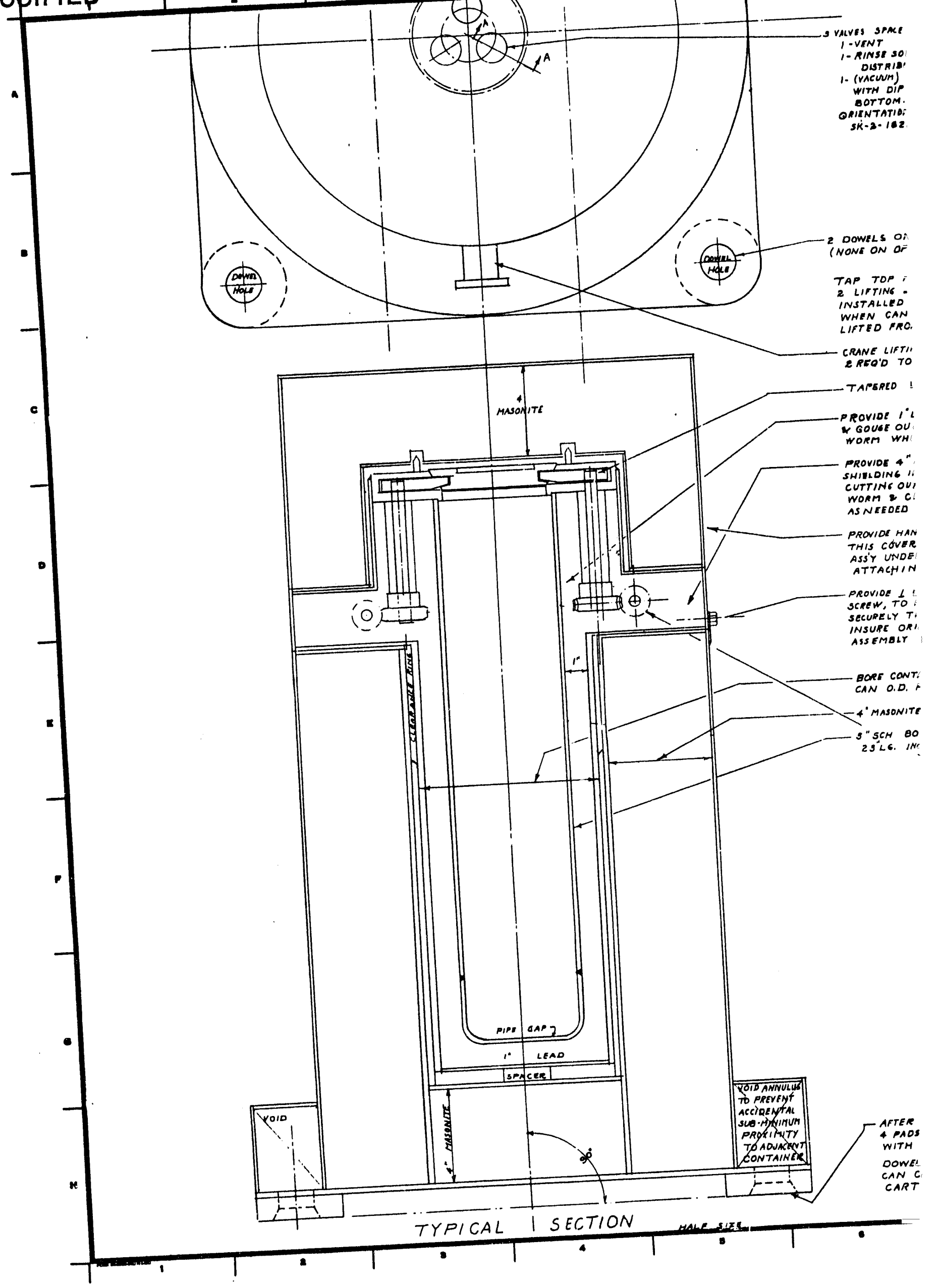




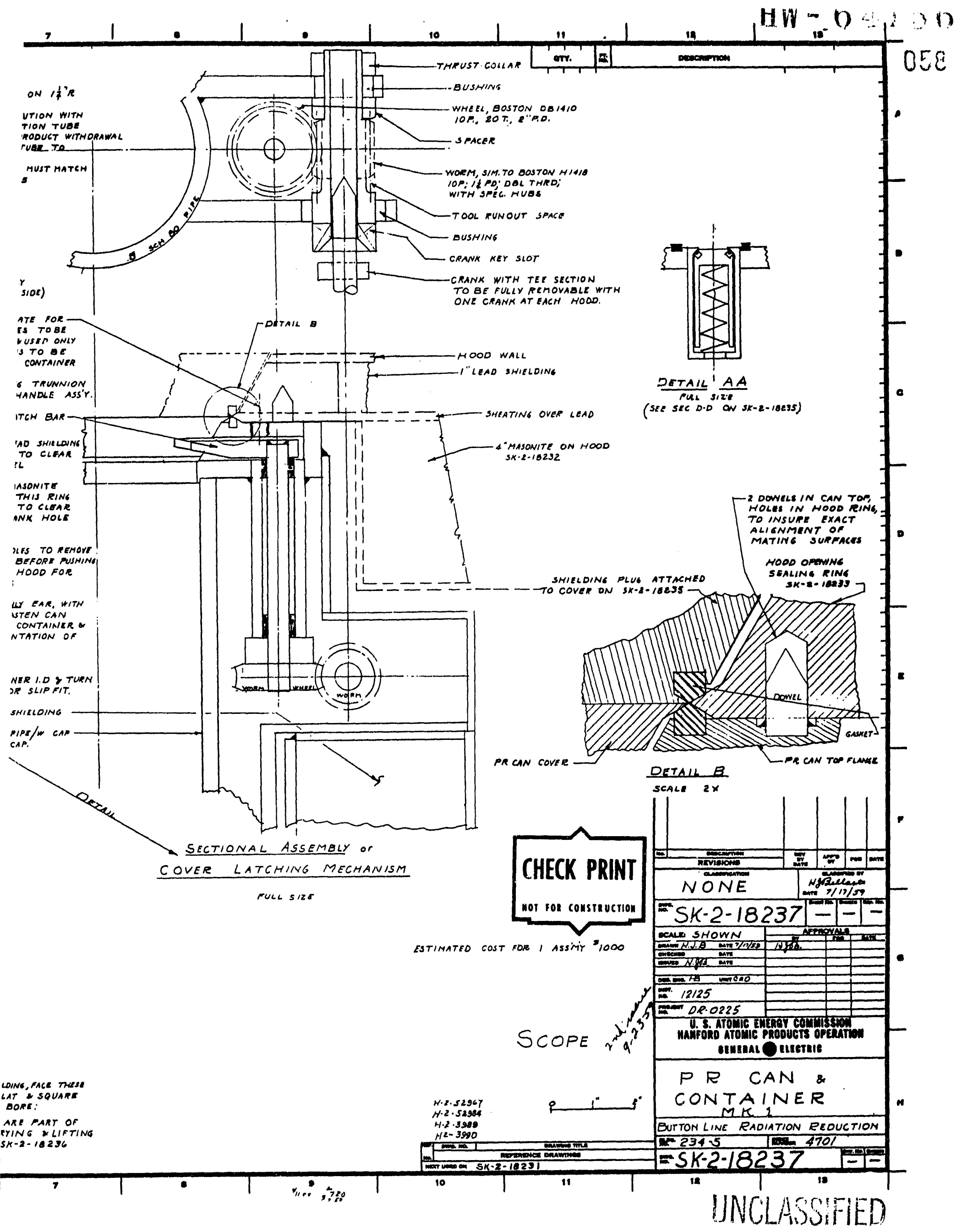




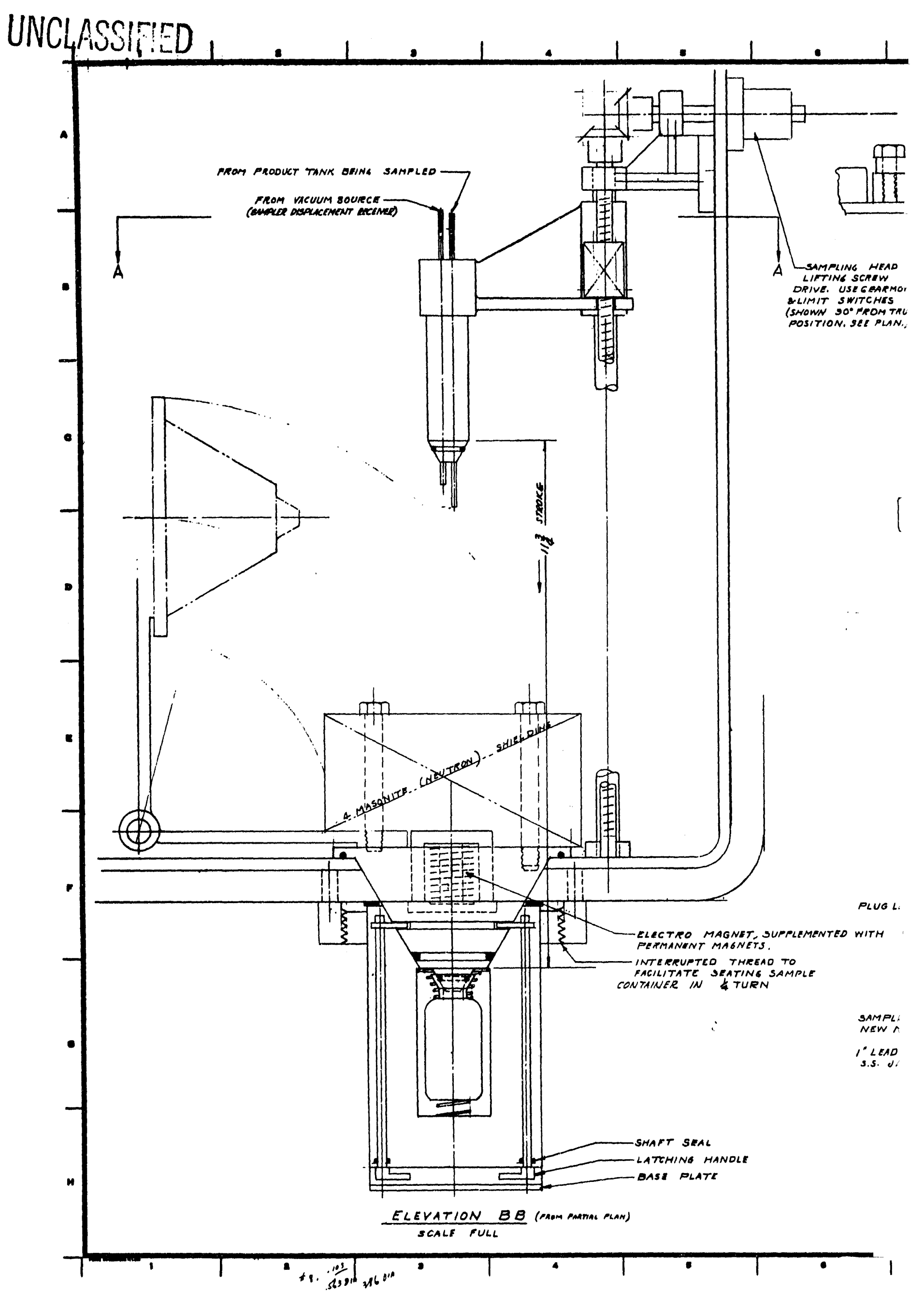




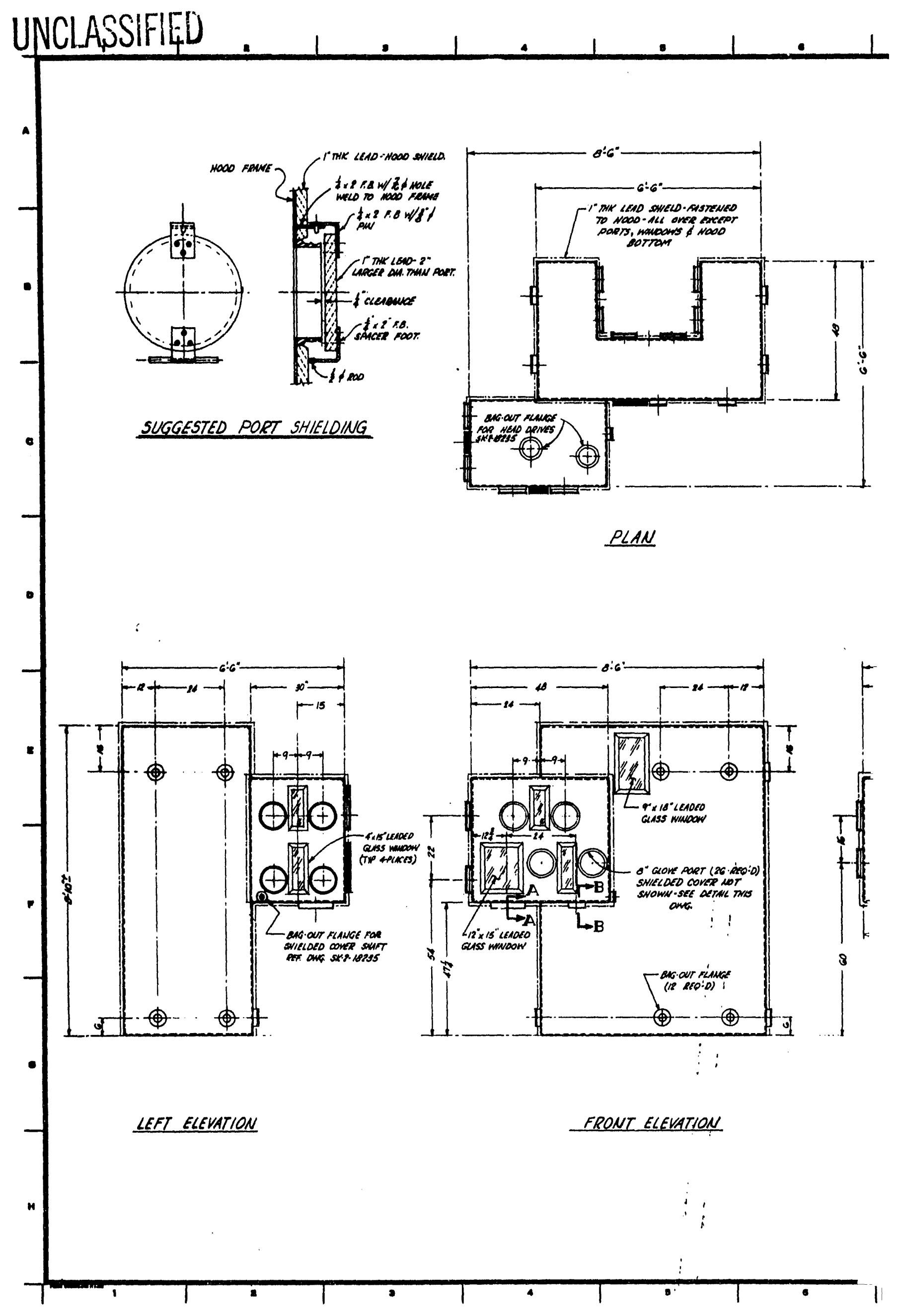




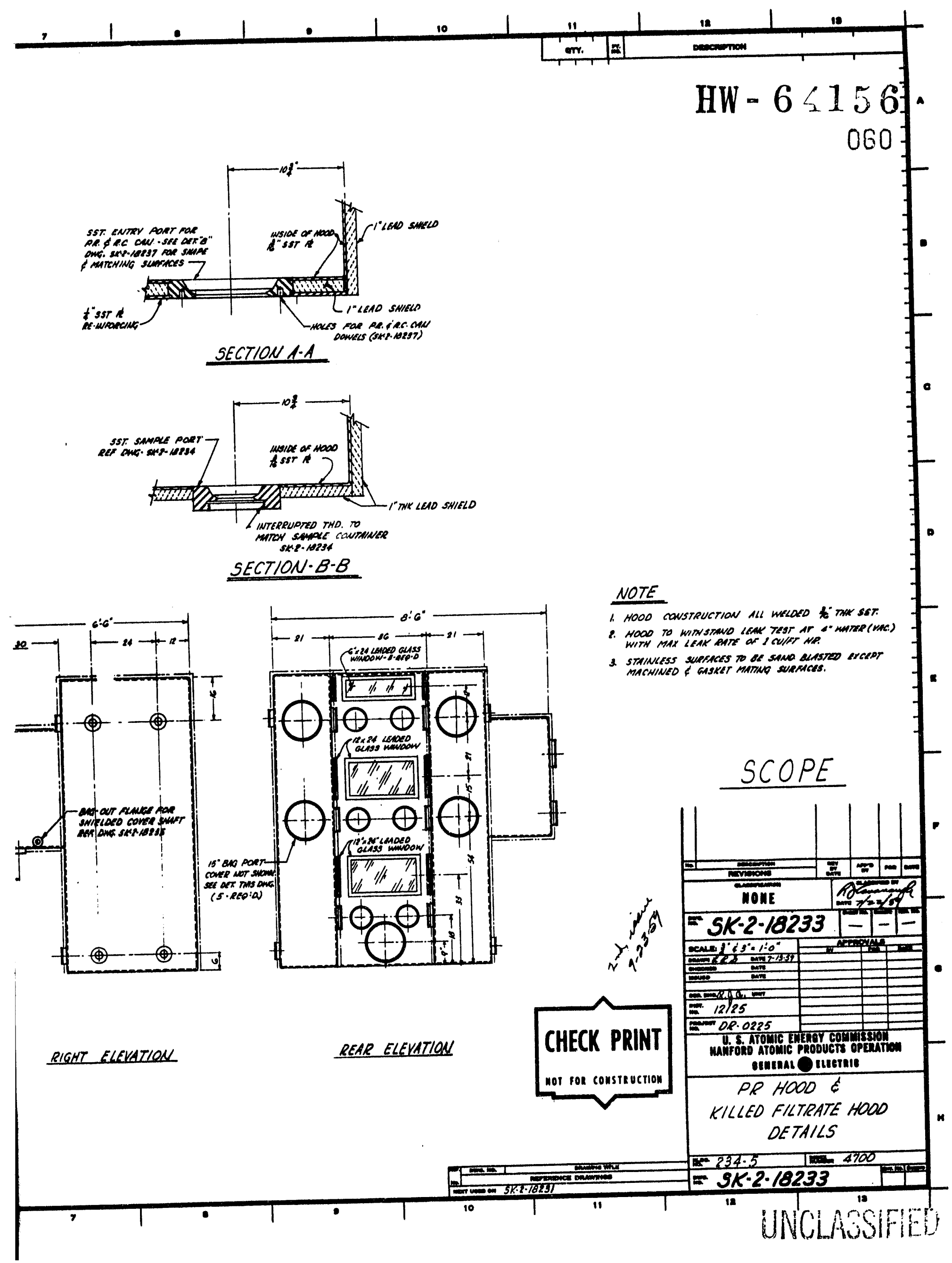




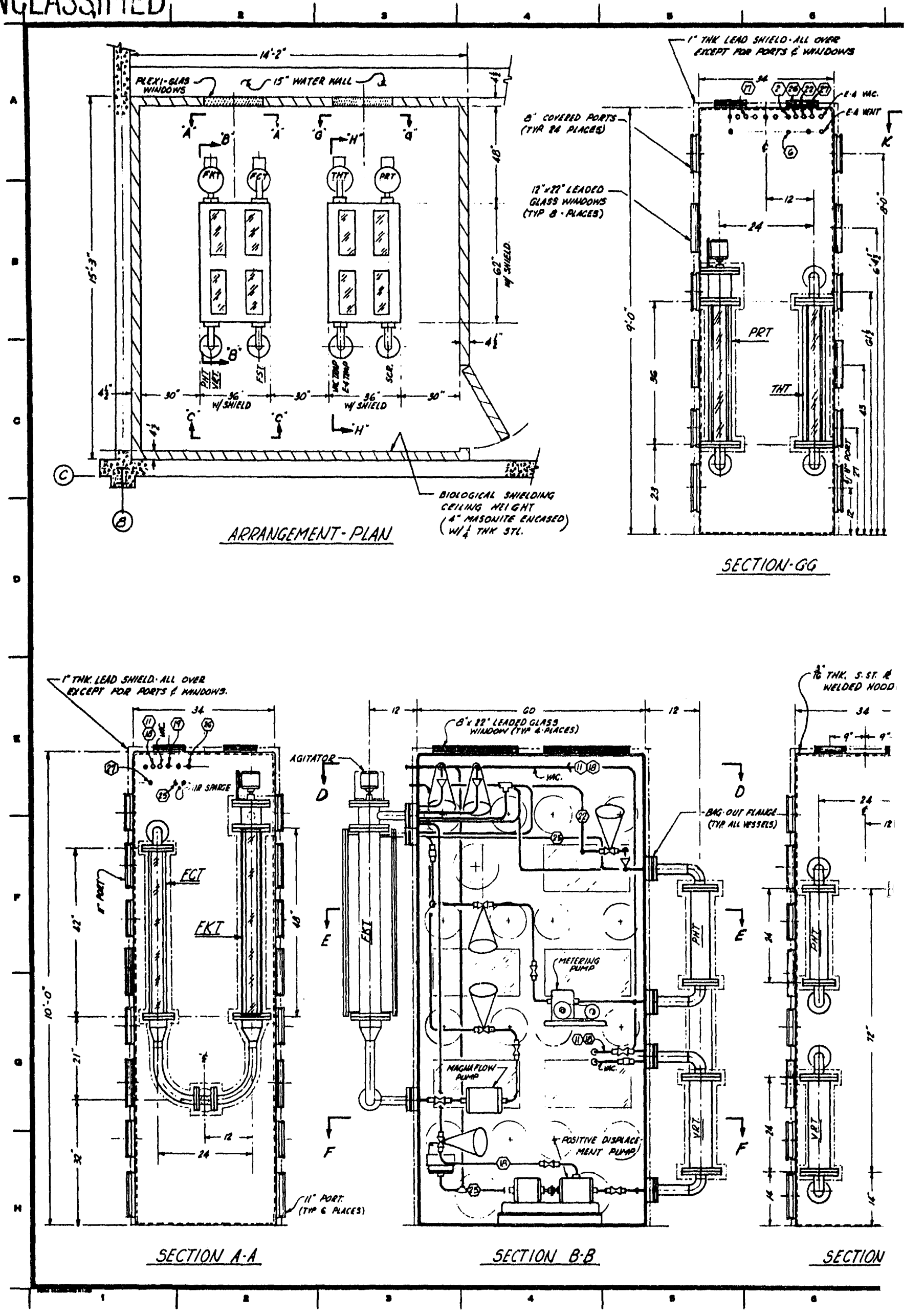




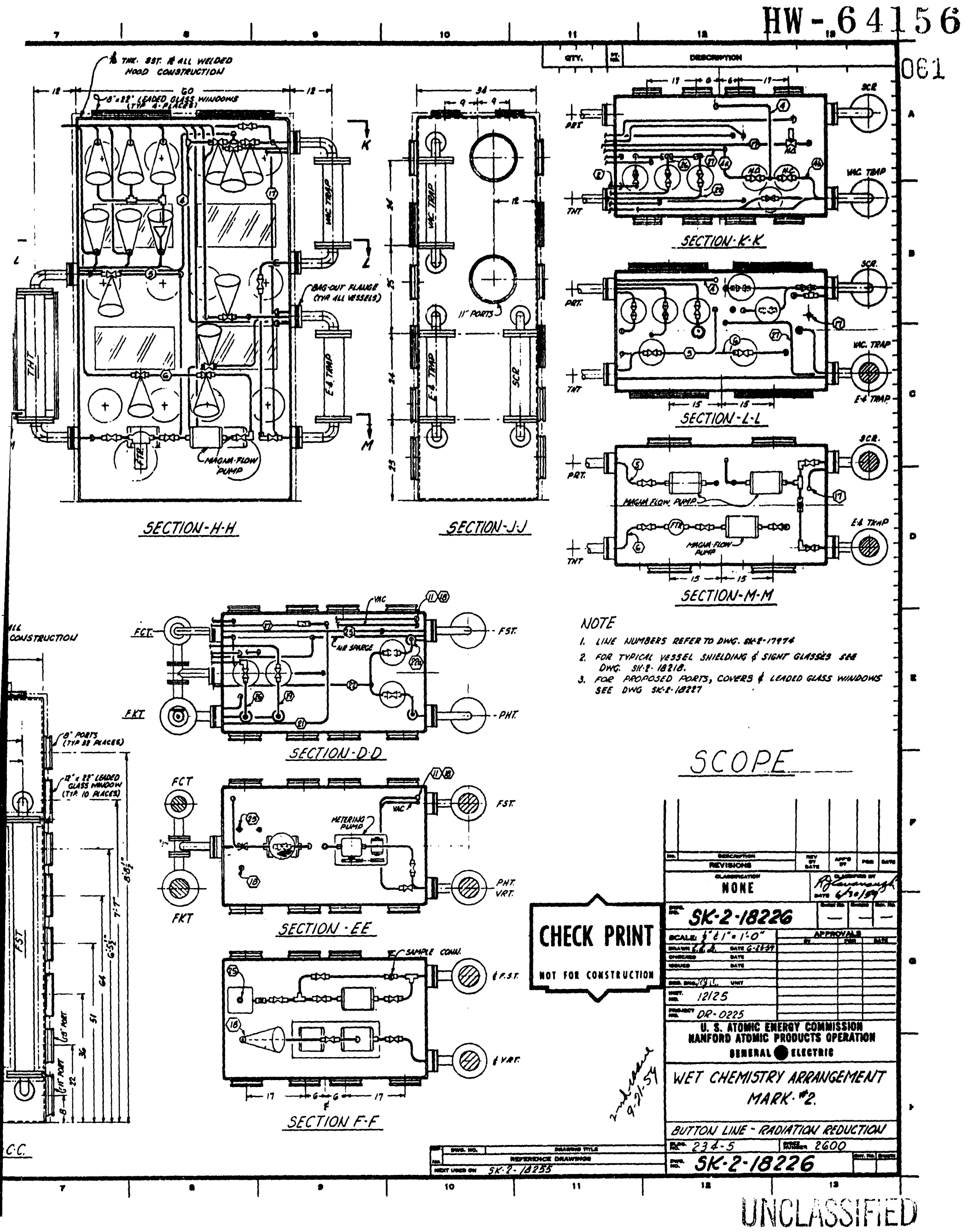




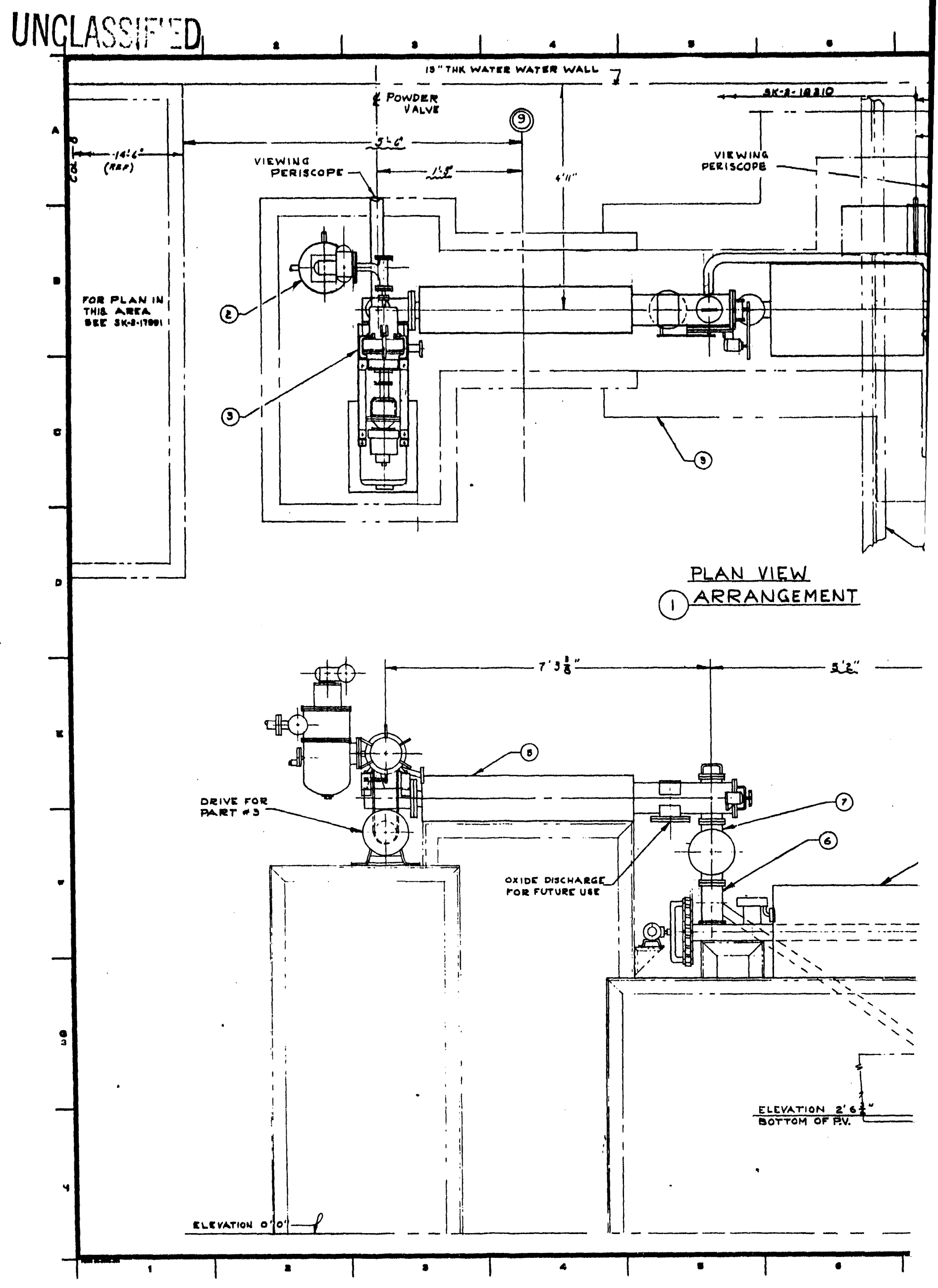




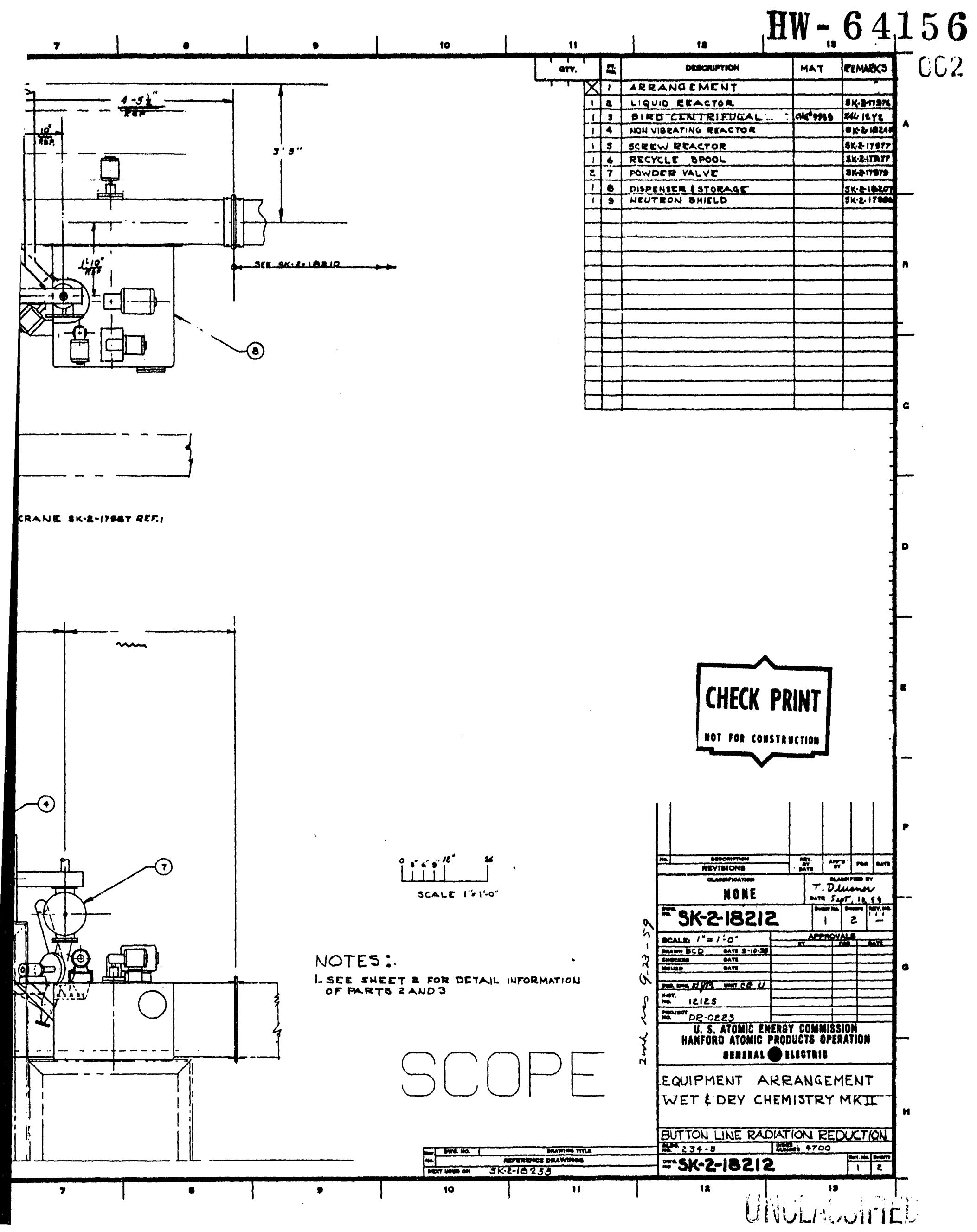




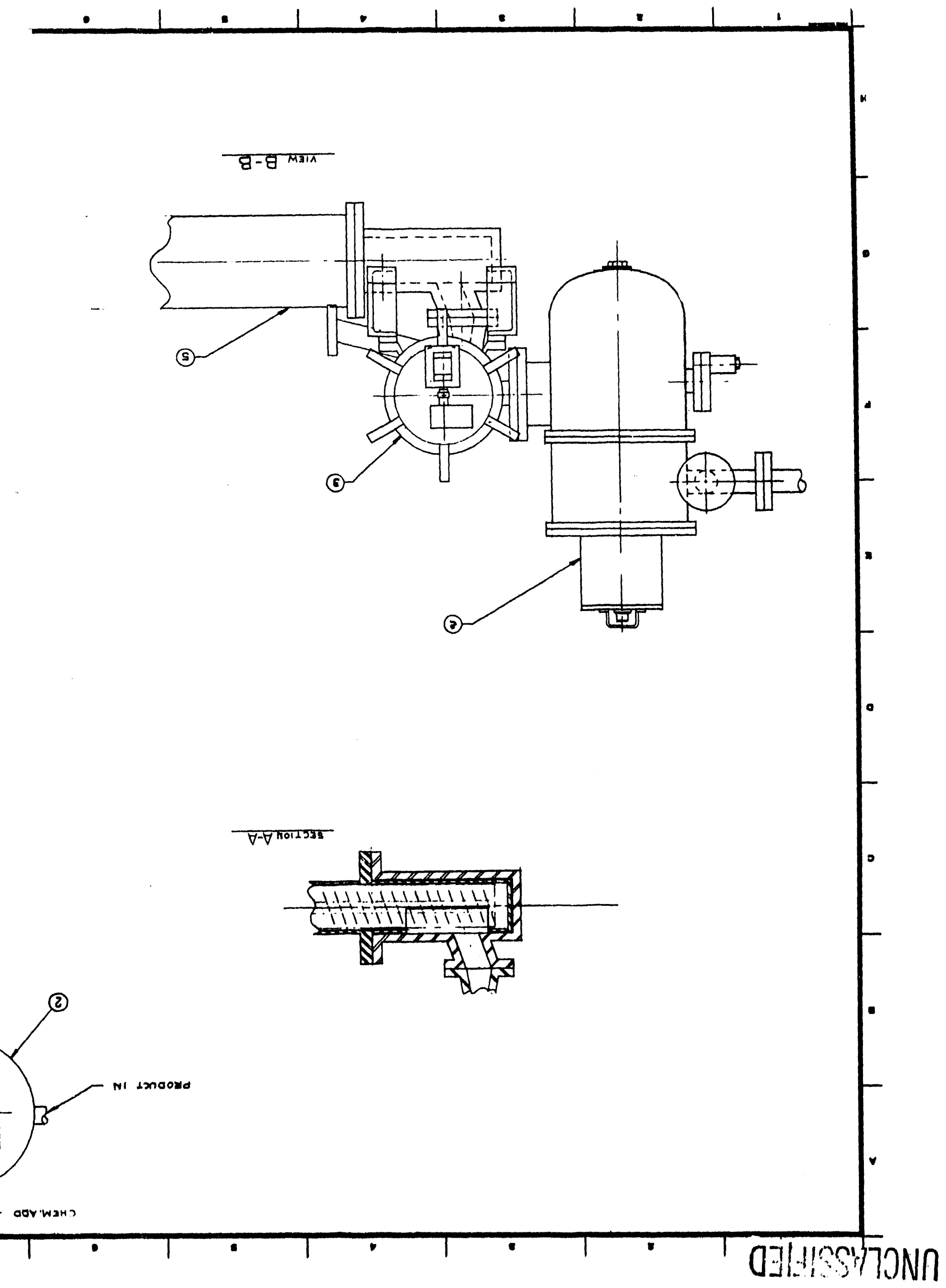




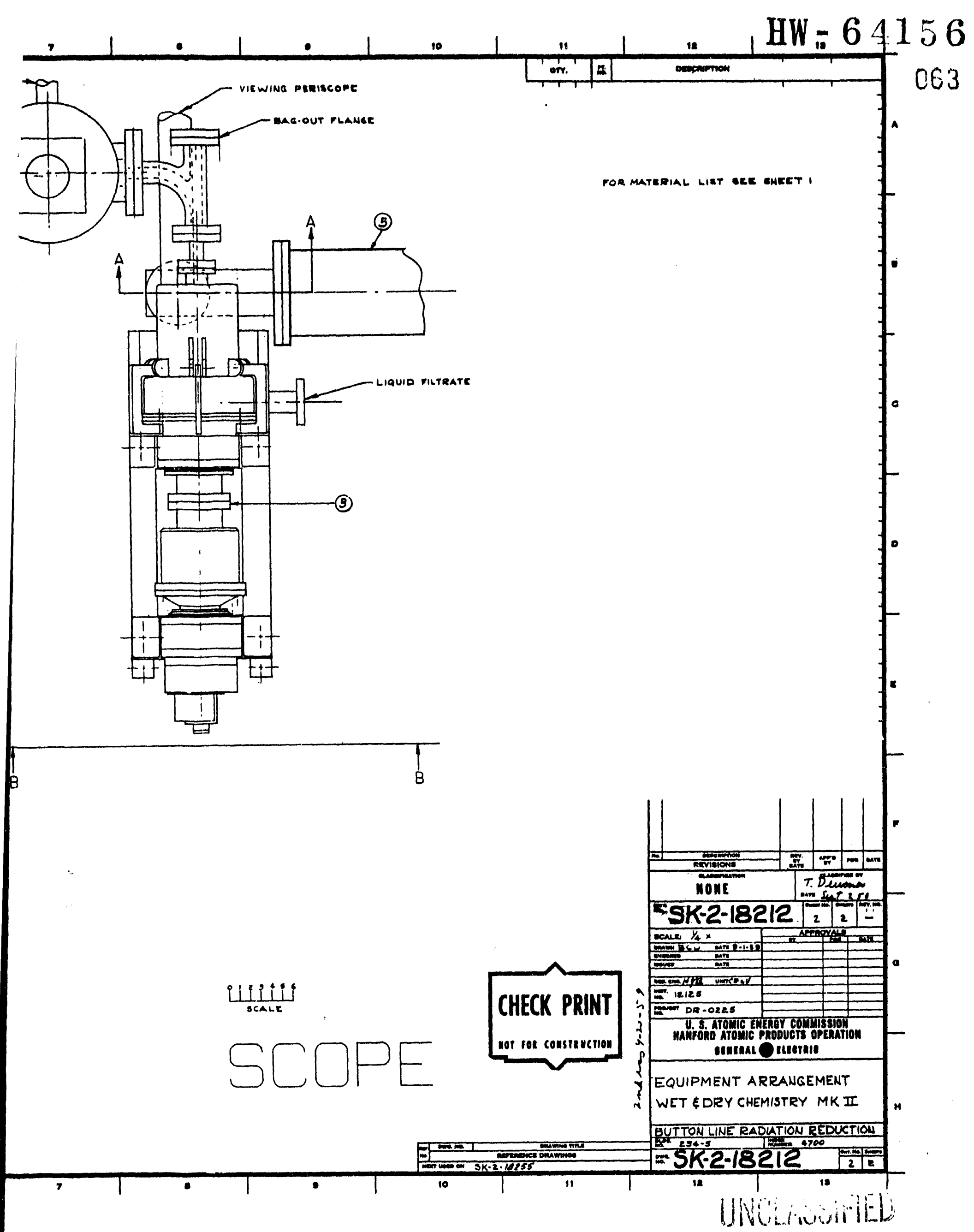


UNCLASBRIED

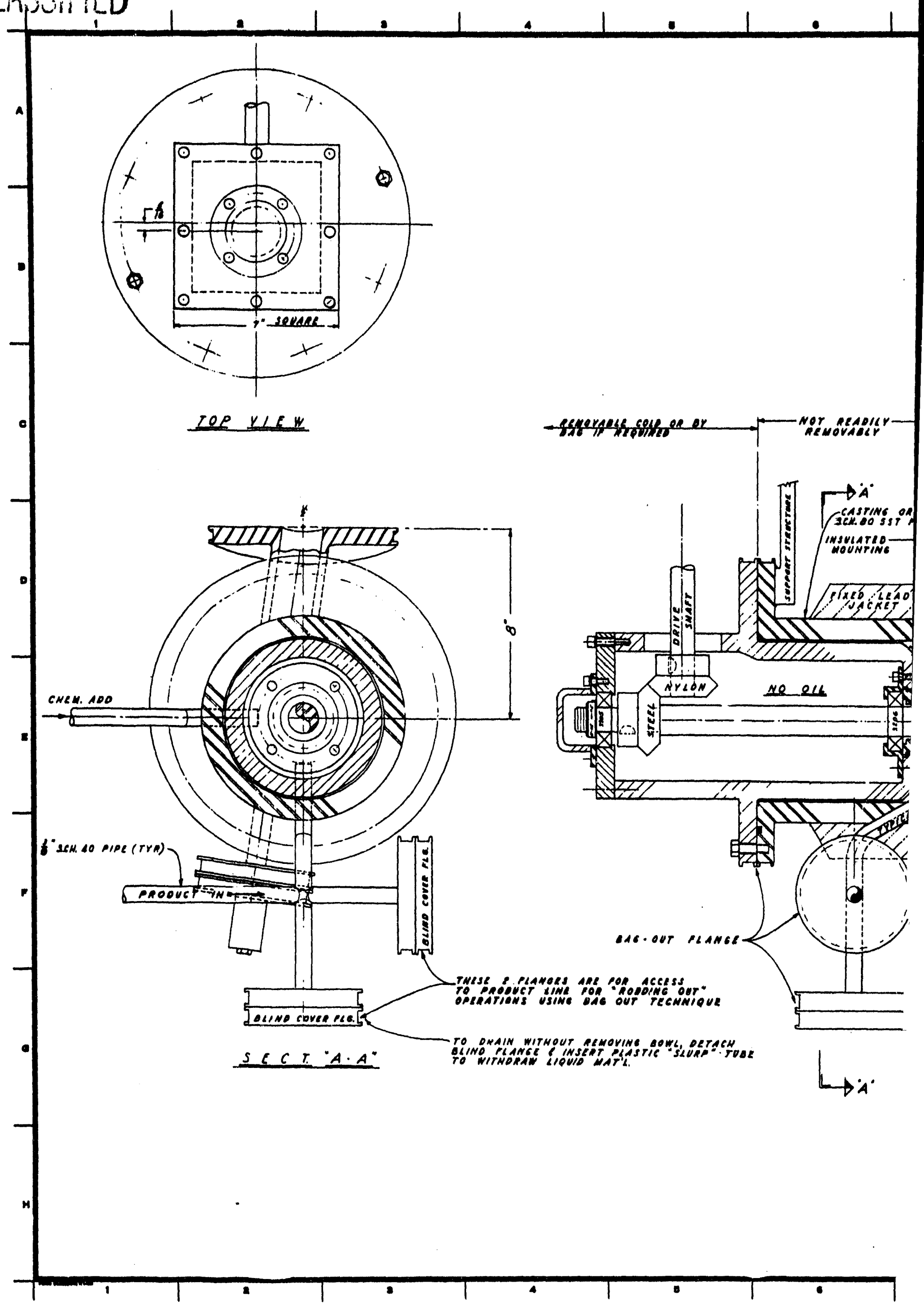




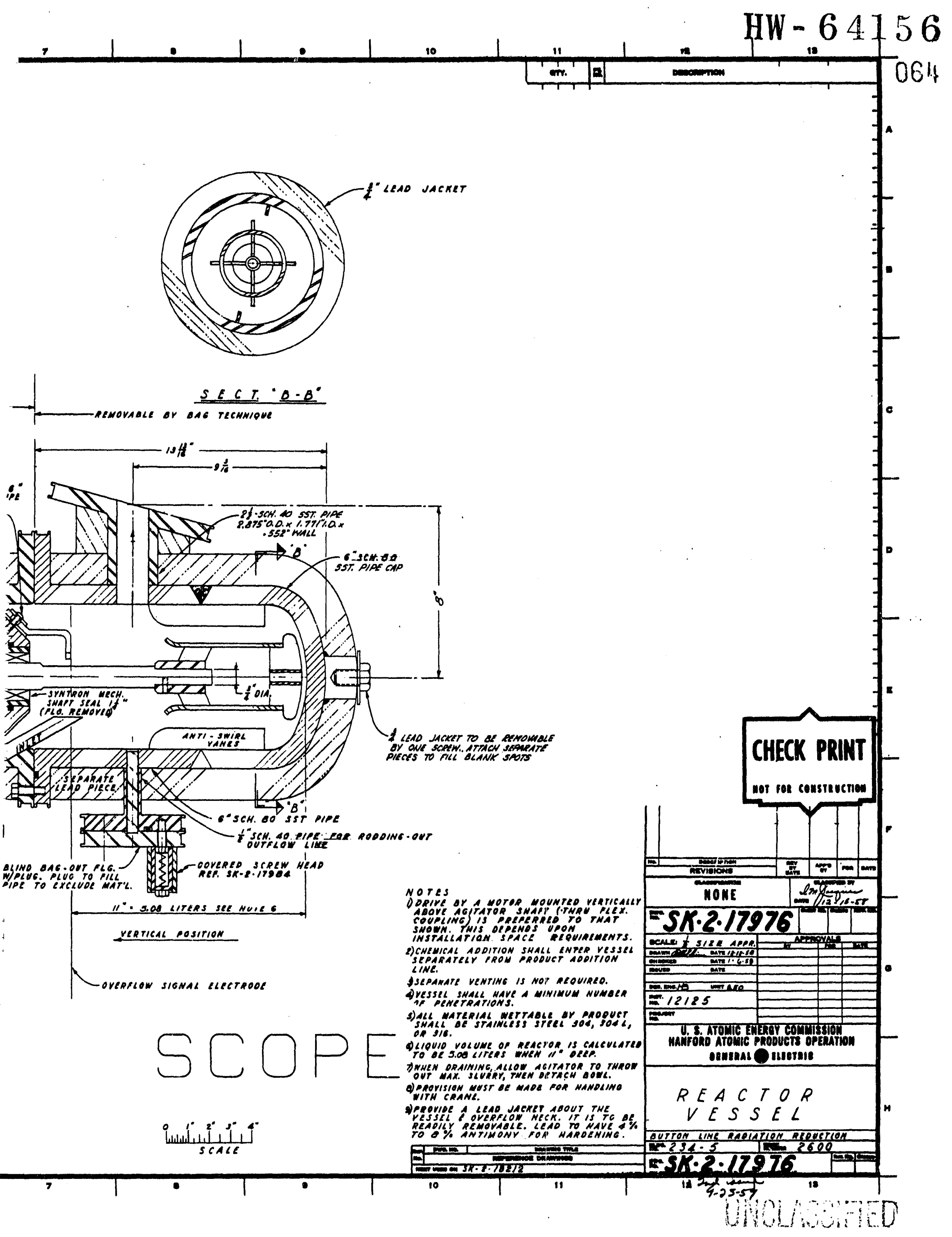




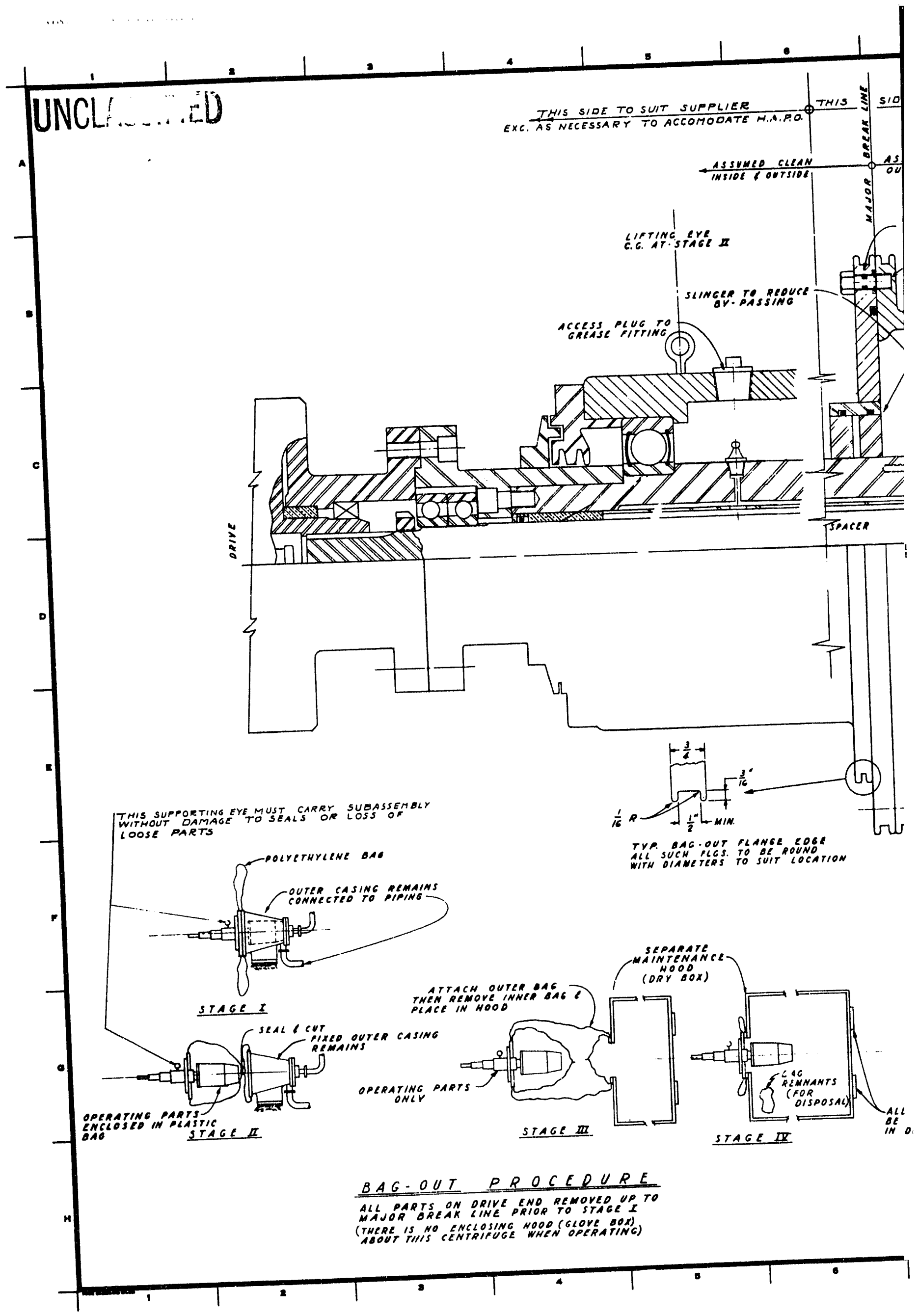




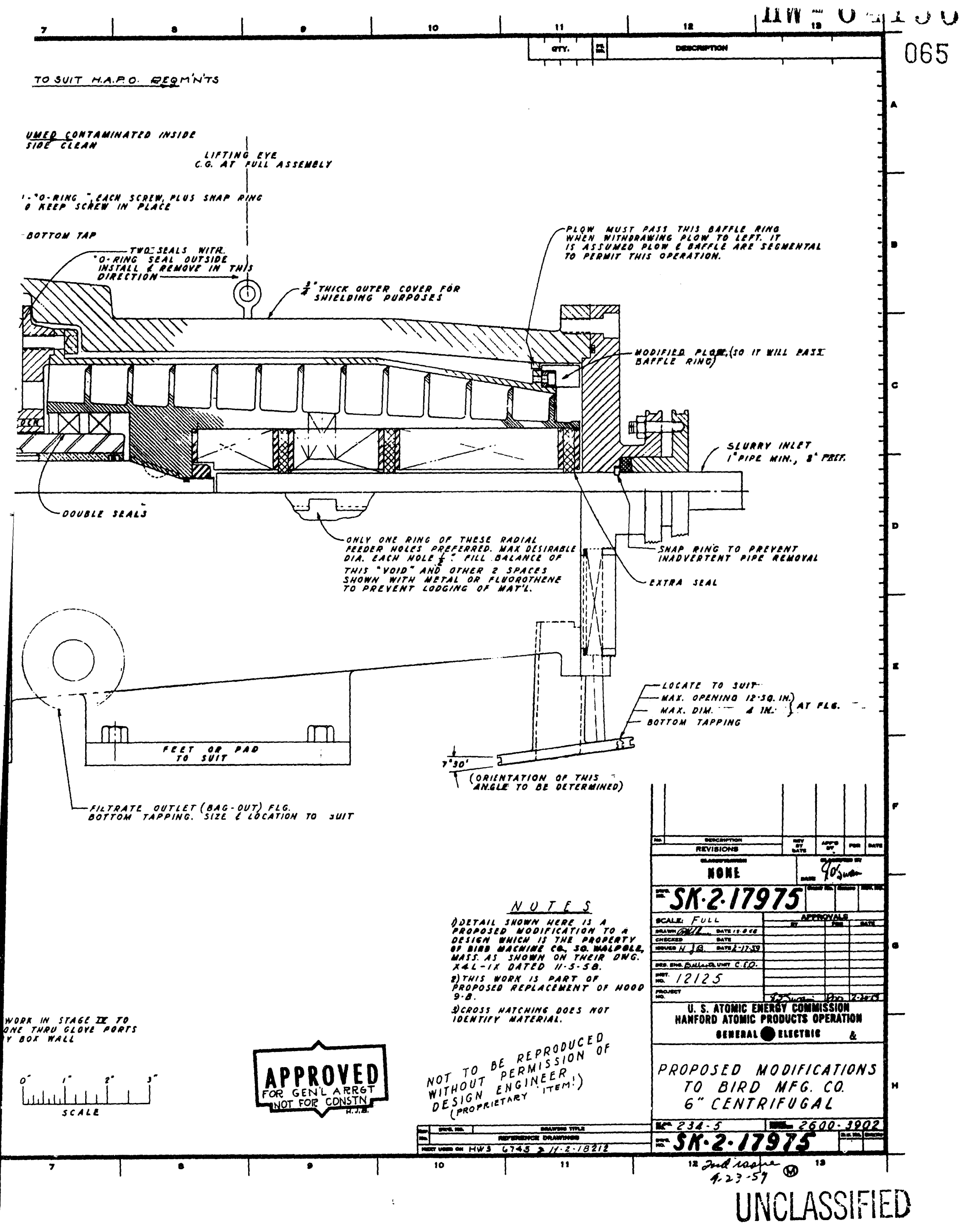




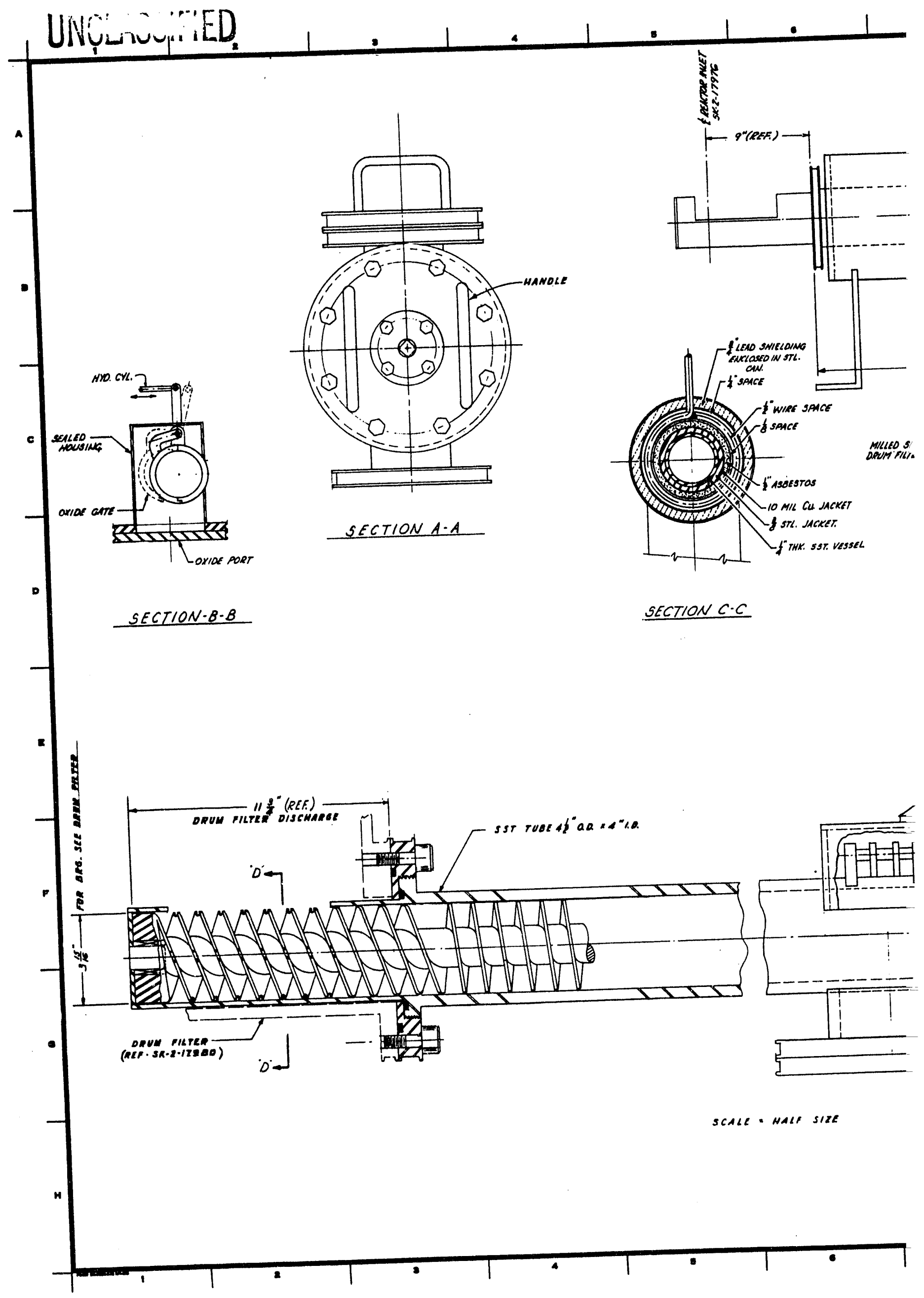




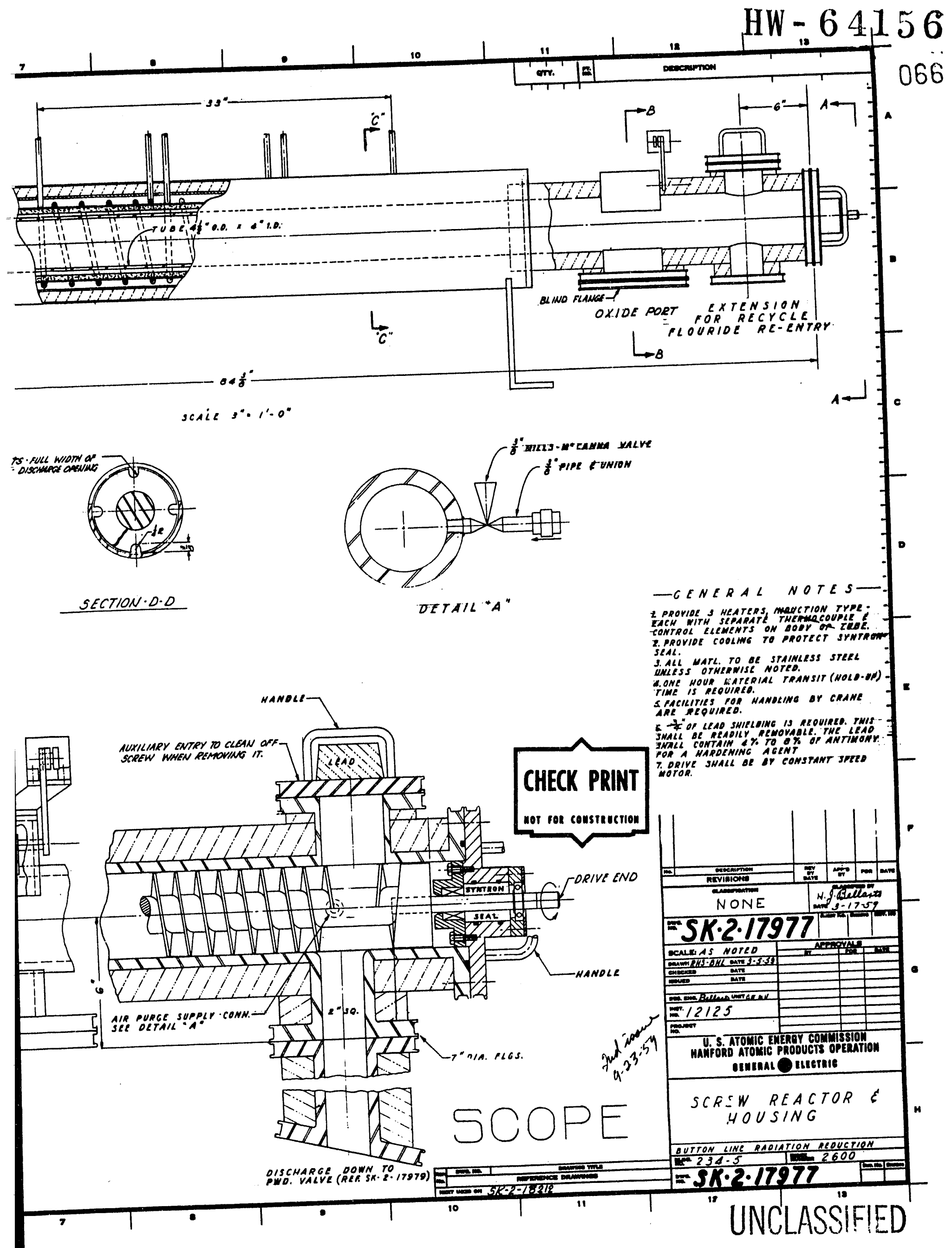




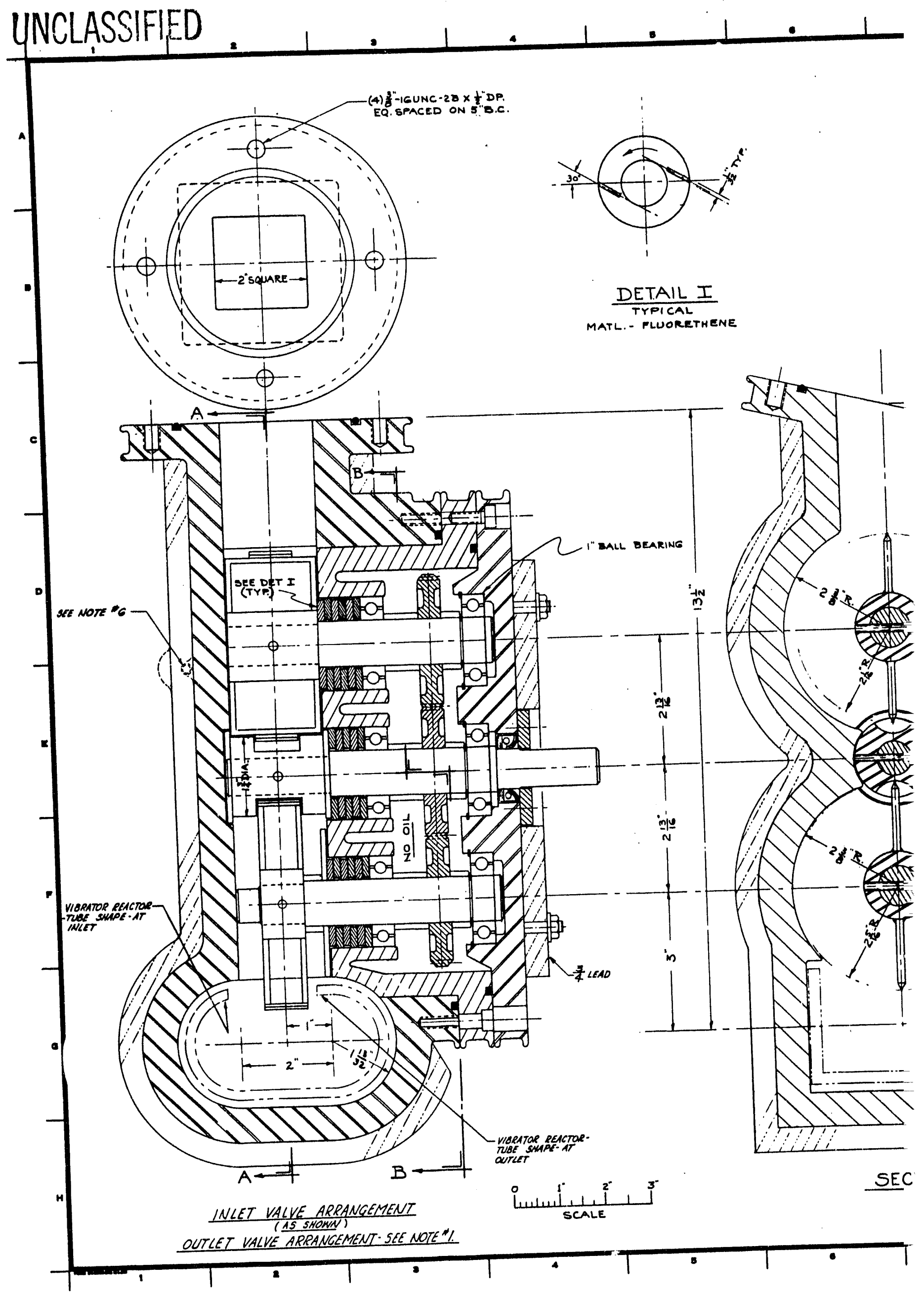




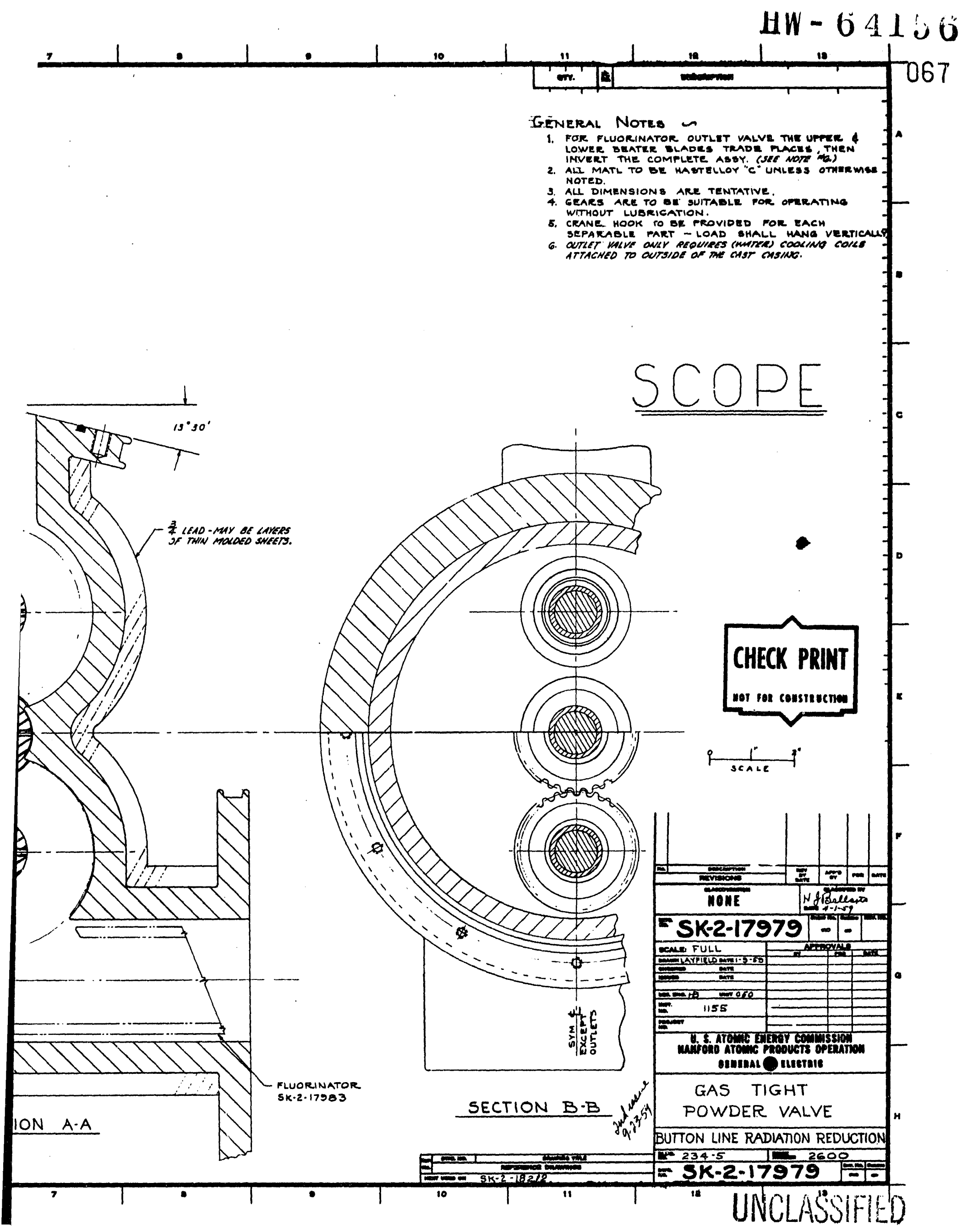




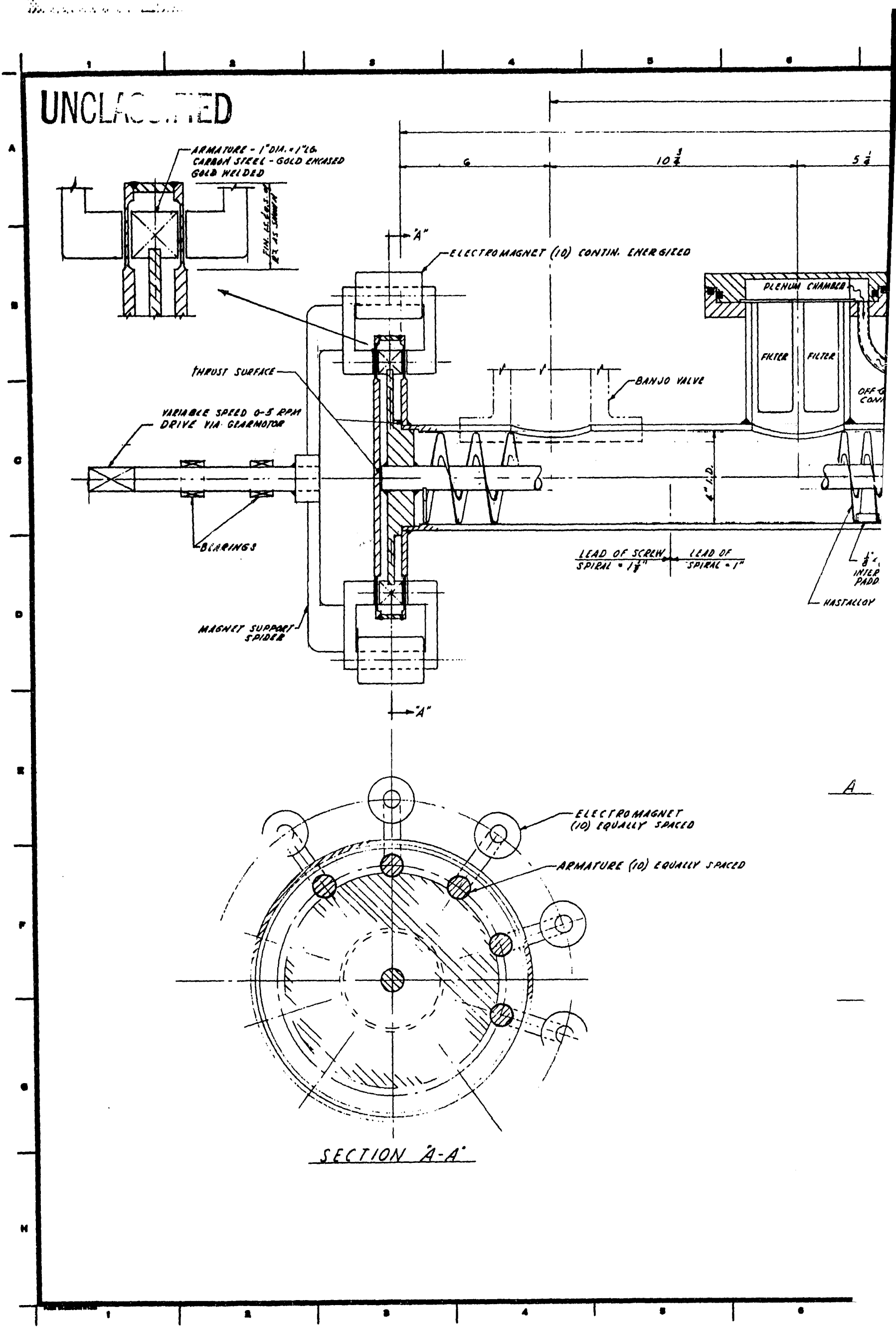




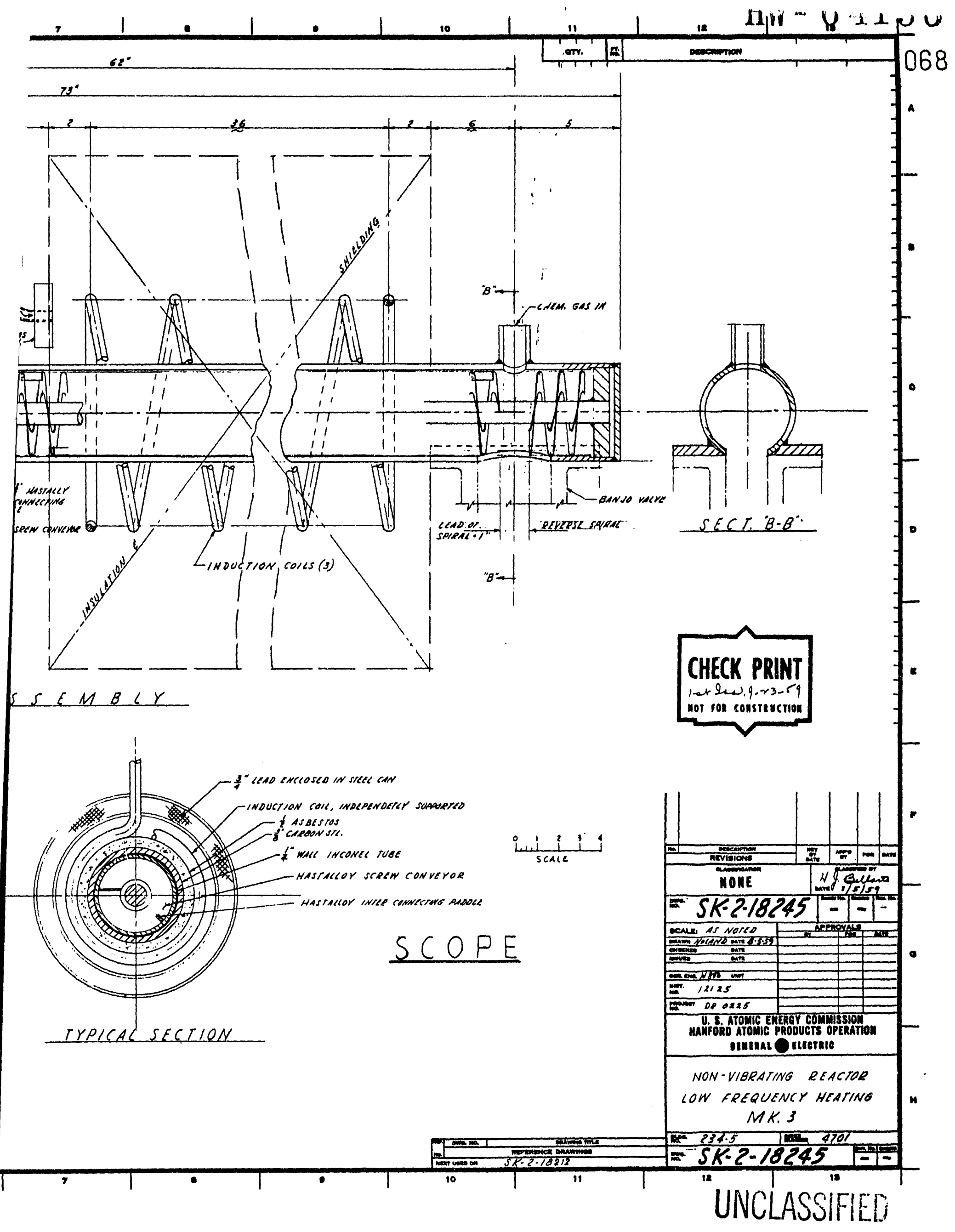




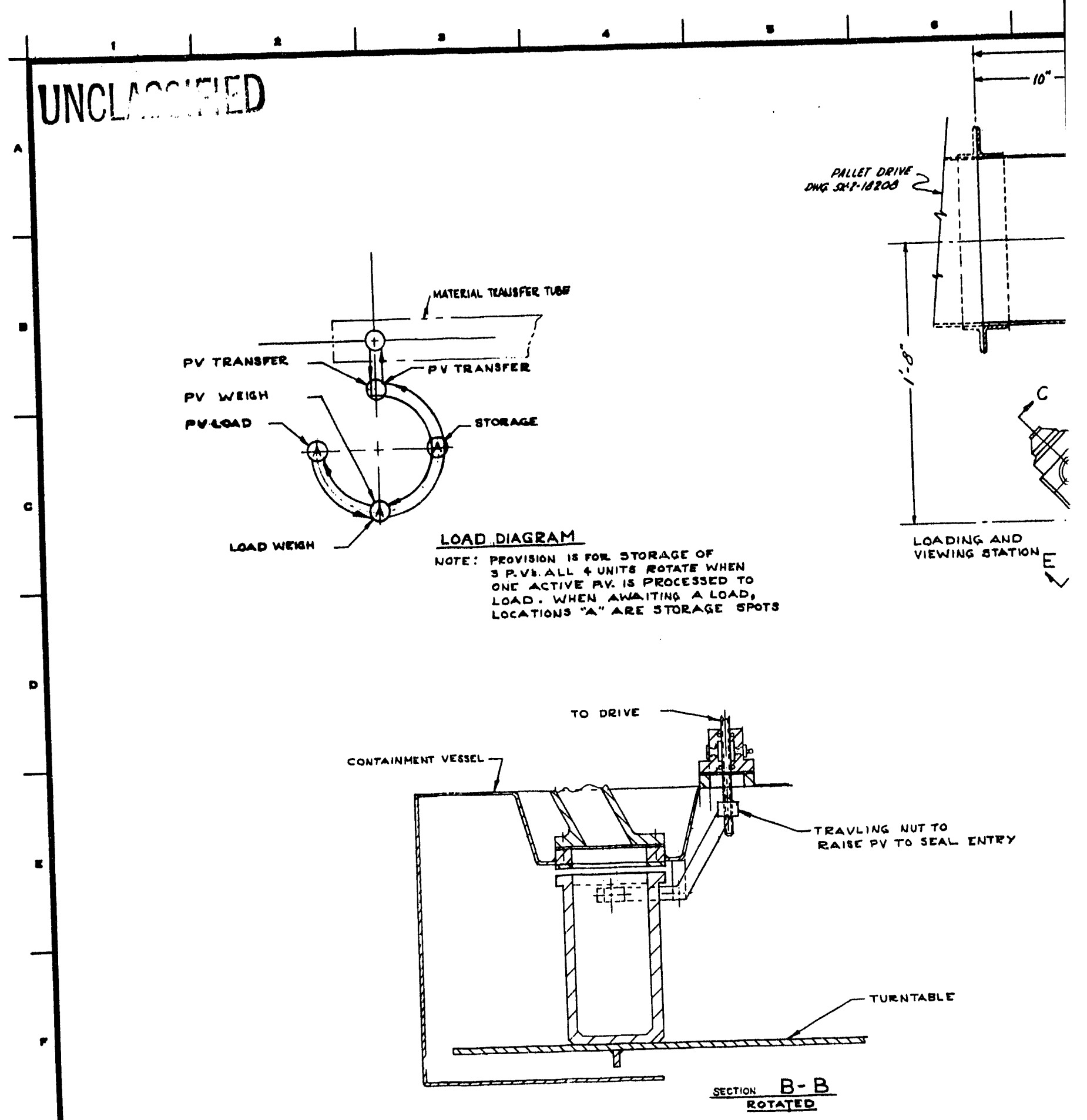

ELEV

- 


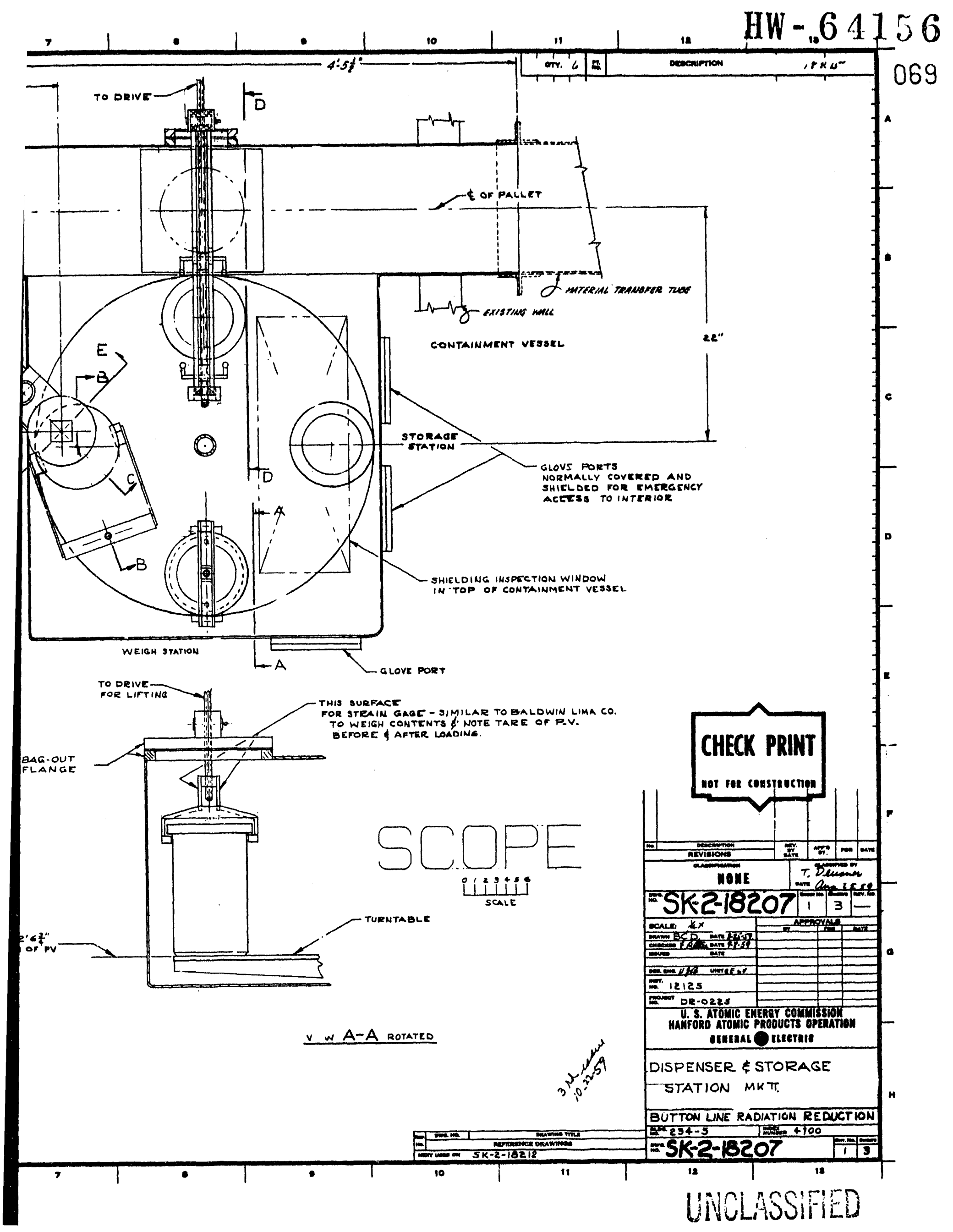




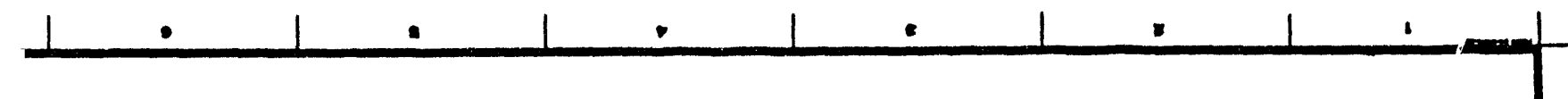

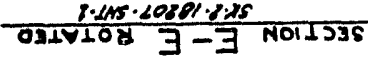

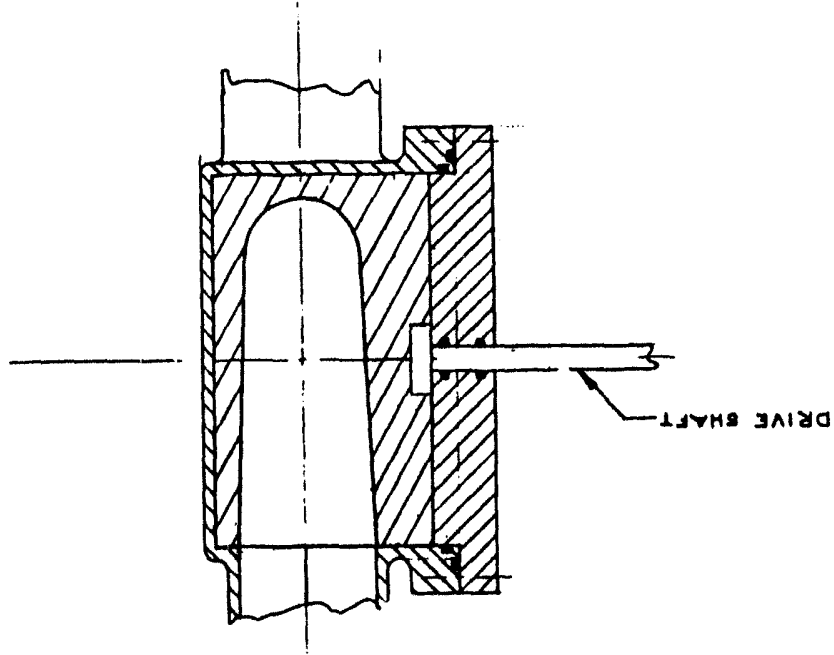

0]IISSG7DNก

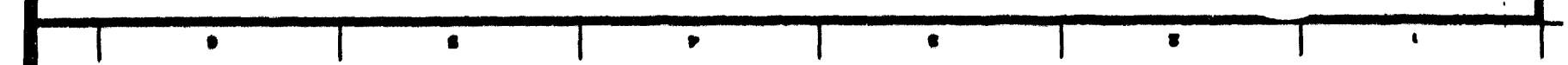




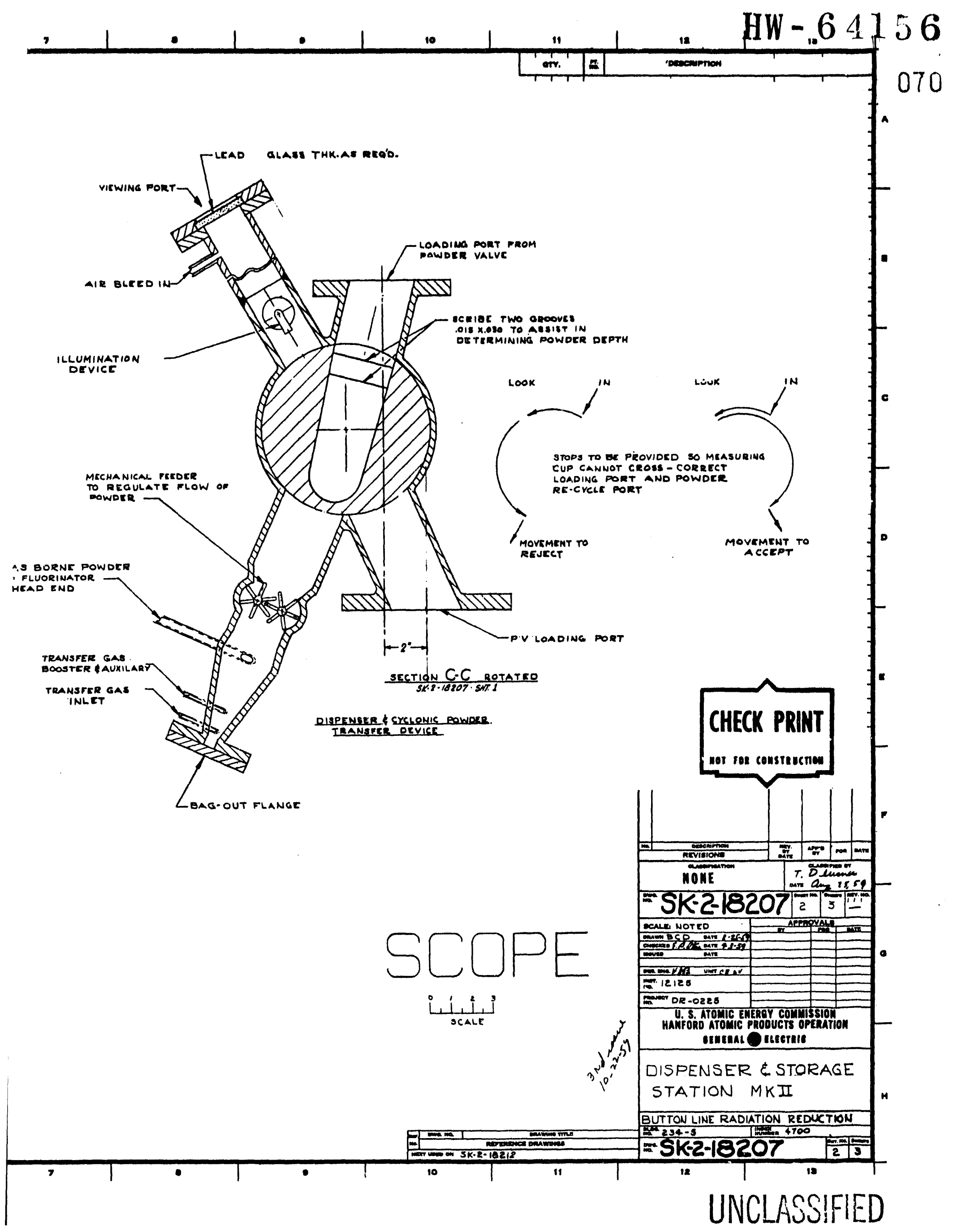




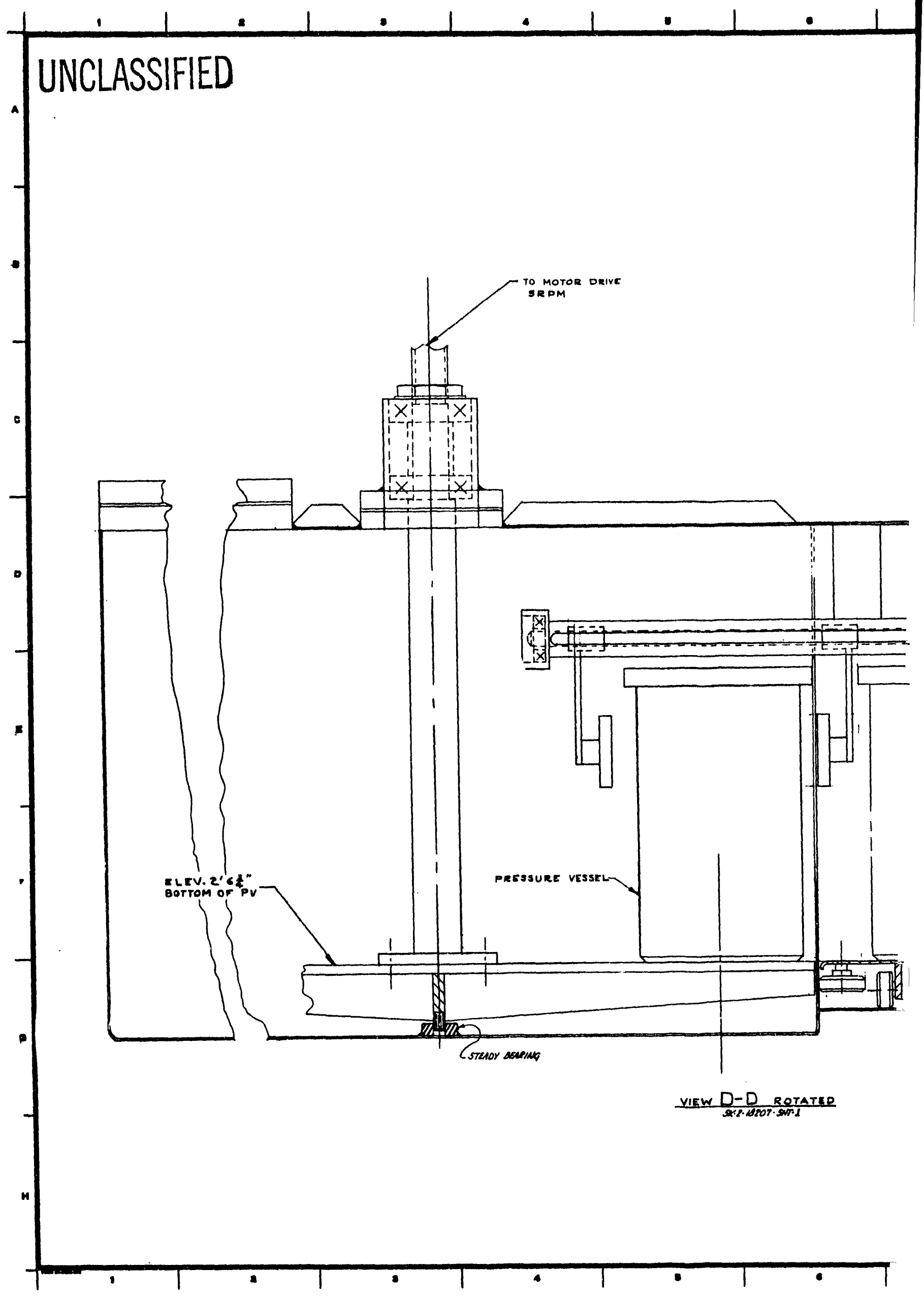



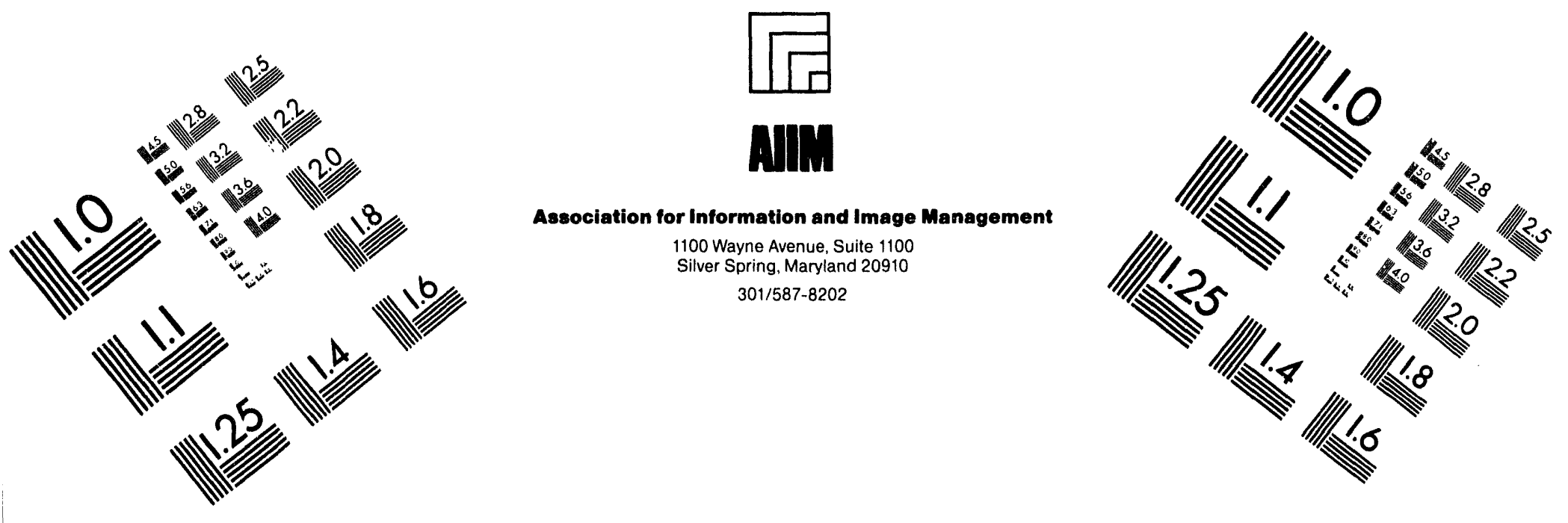

\section{Centimeter}

$\begin{array}{llllllllllllllll}1 & 2 & 3 & 4 & 5 & 6 & 7 & 8 & 9 & 10 & 11 & 12 & 13 & 14 & 15 & \mathrm{~mm}\end{array}$

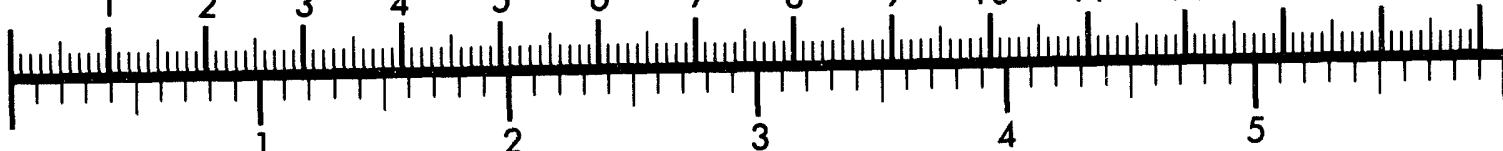
Inches

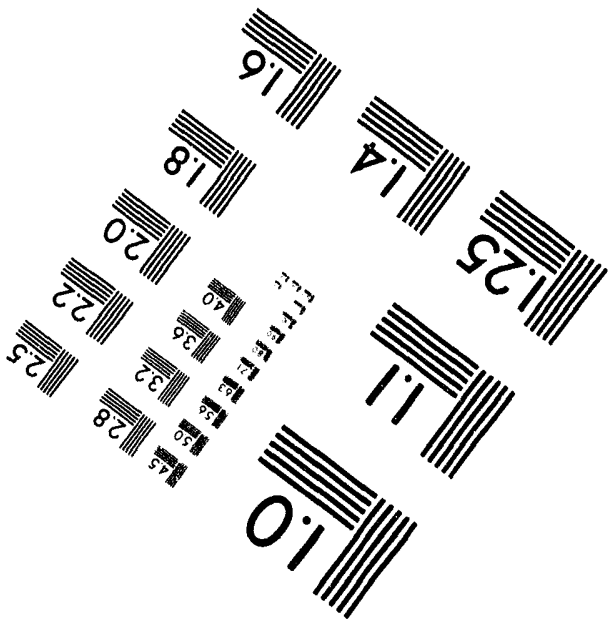

MANUFACTURED TO AIIM STANDARDS

BY APPLIED IMAGE, INC.

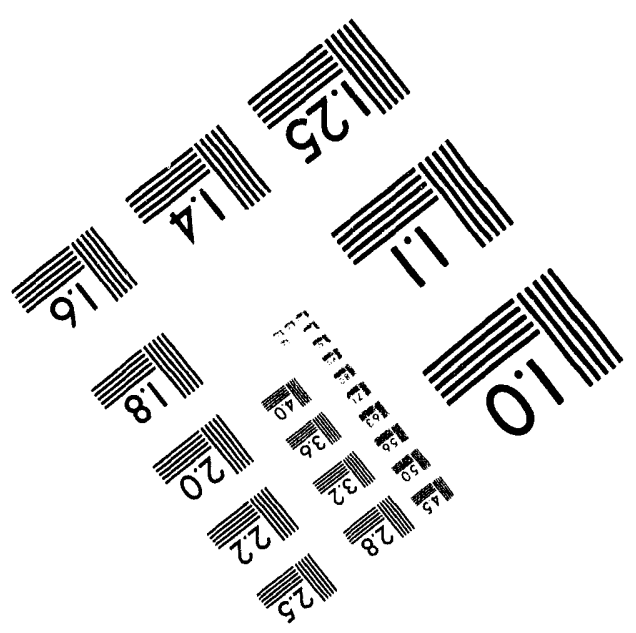



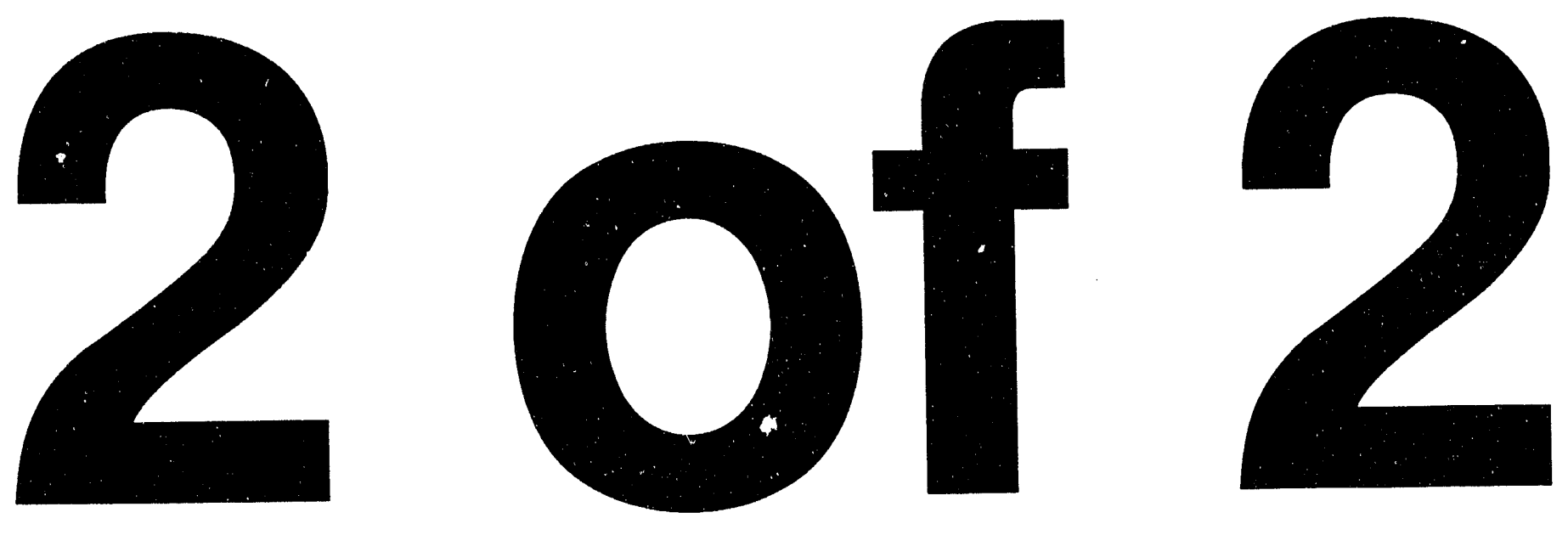

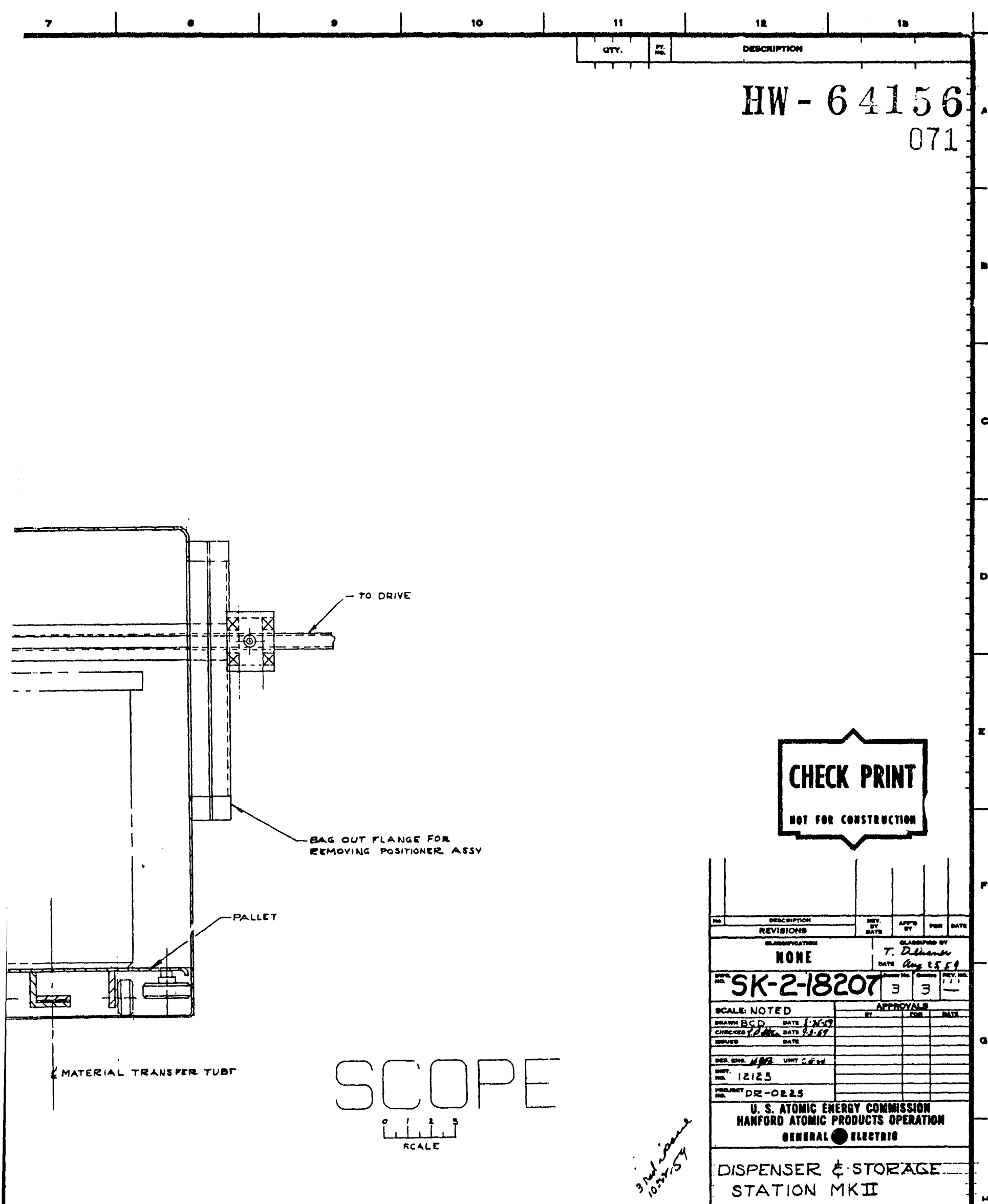

D

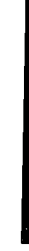




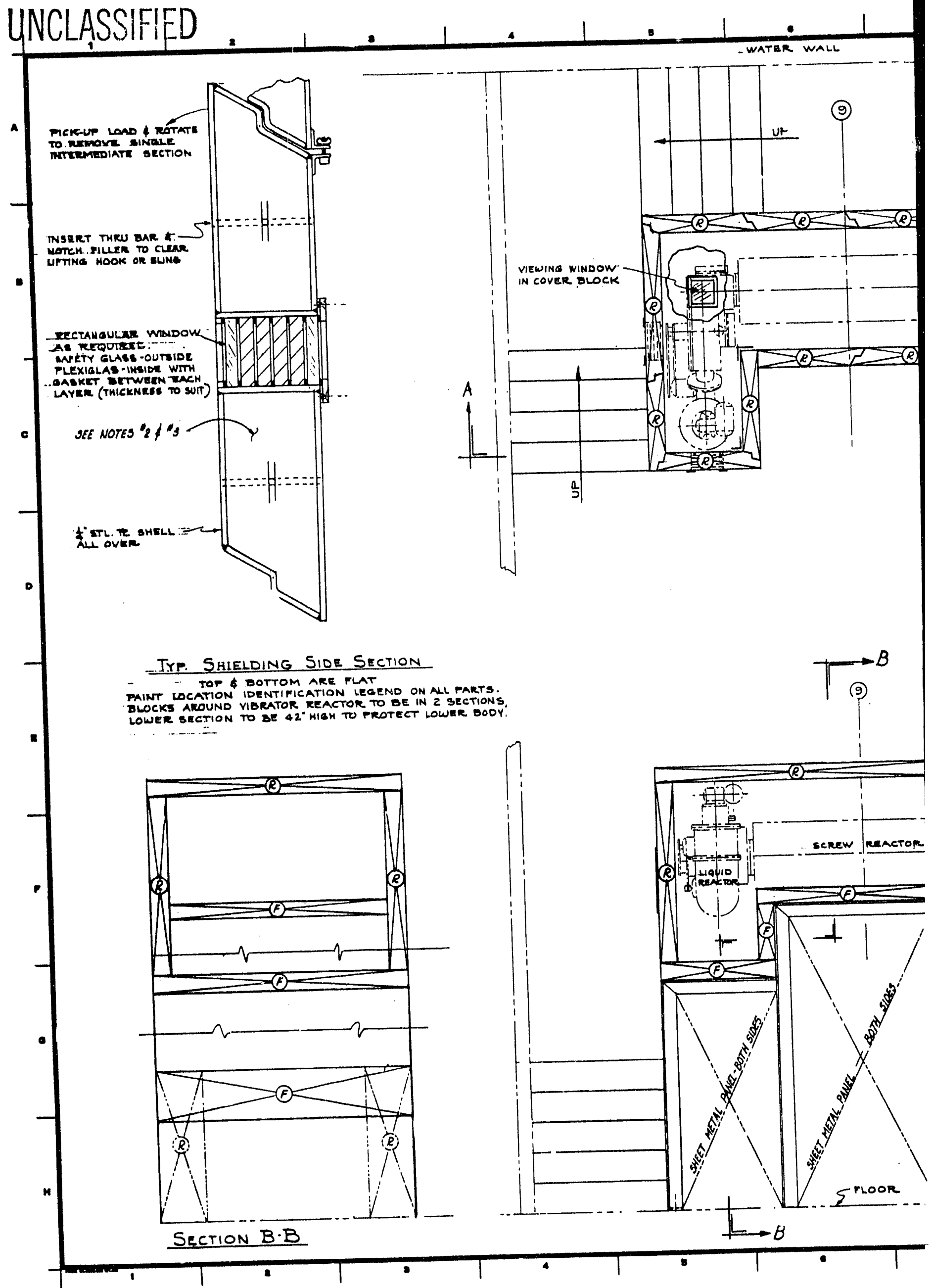




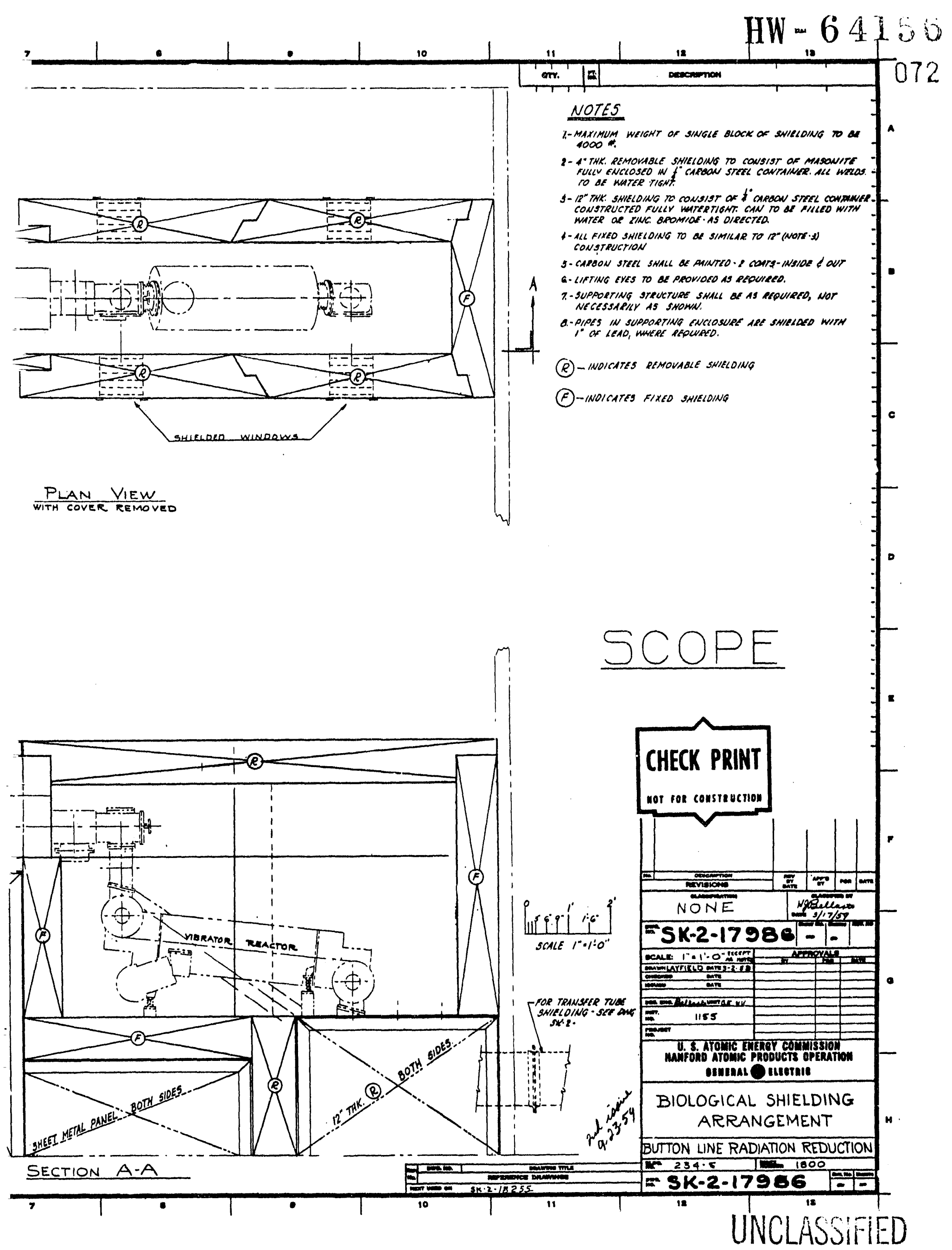




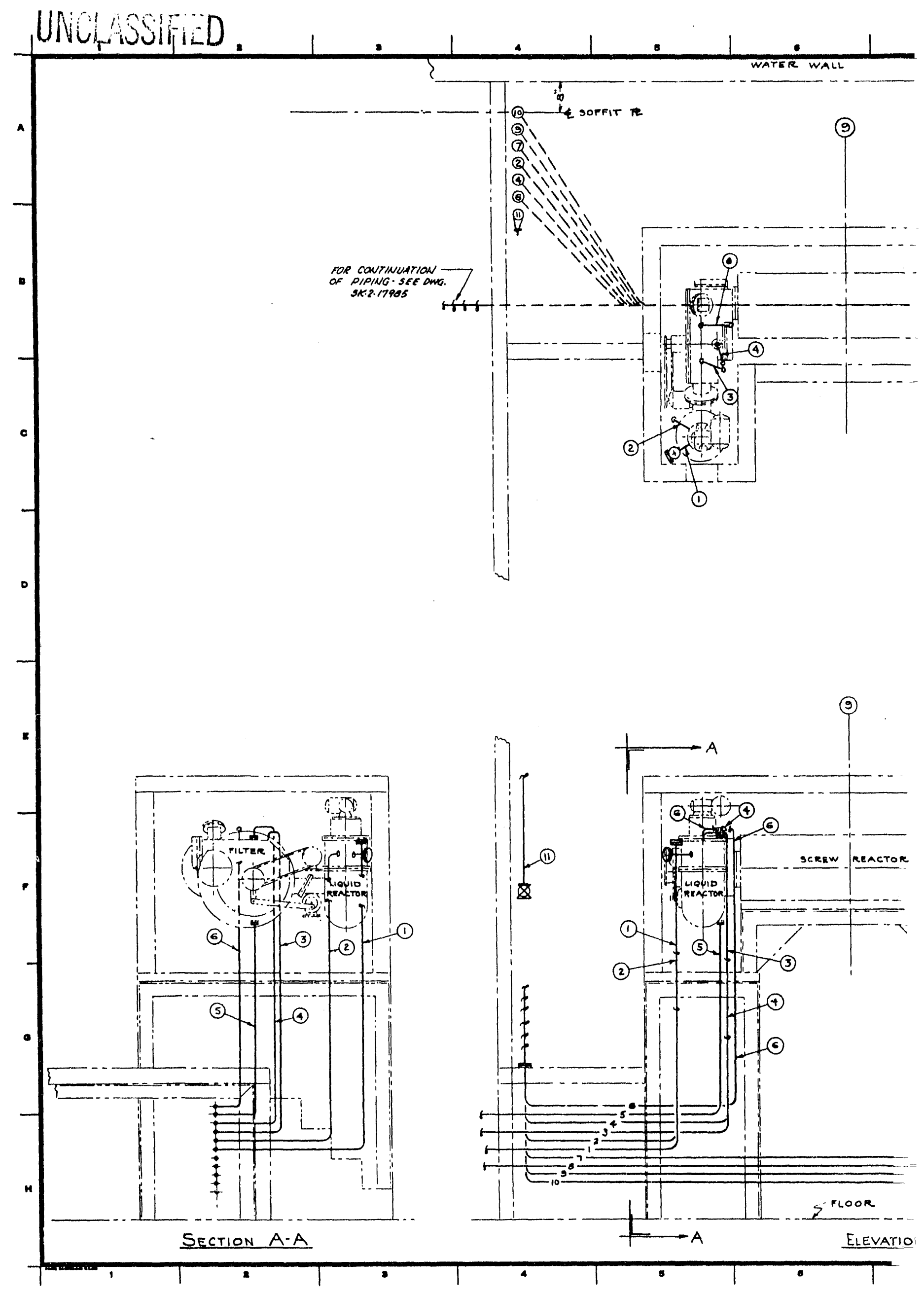




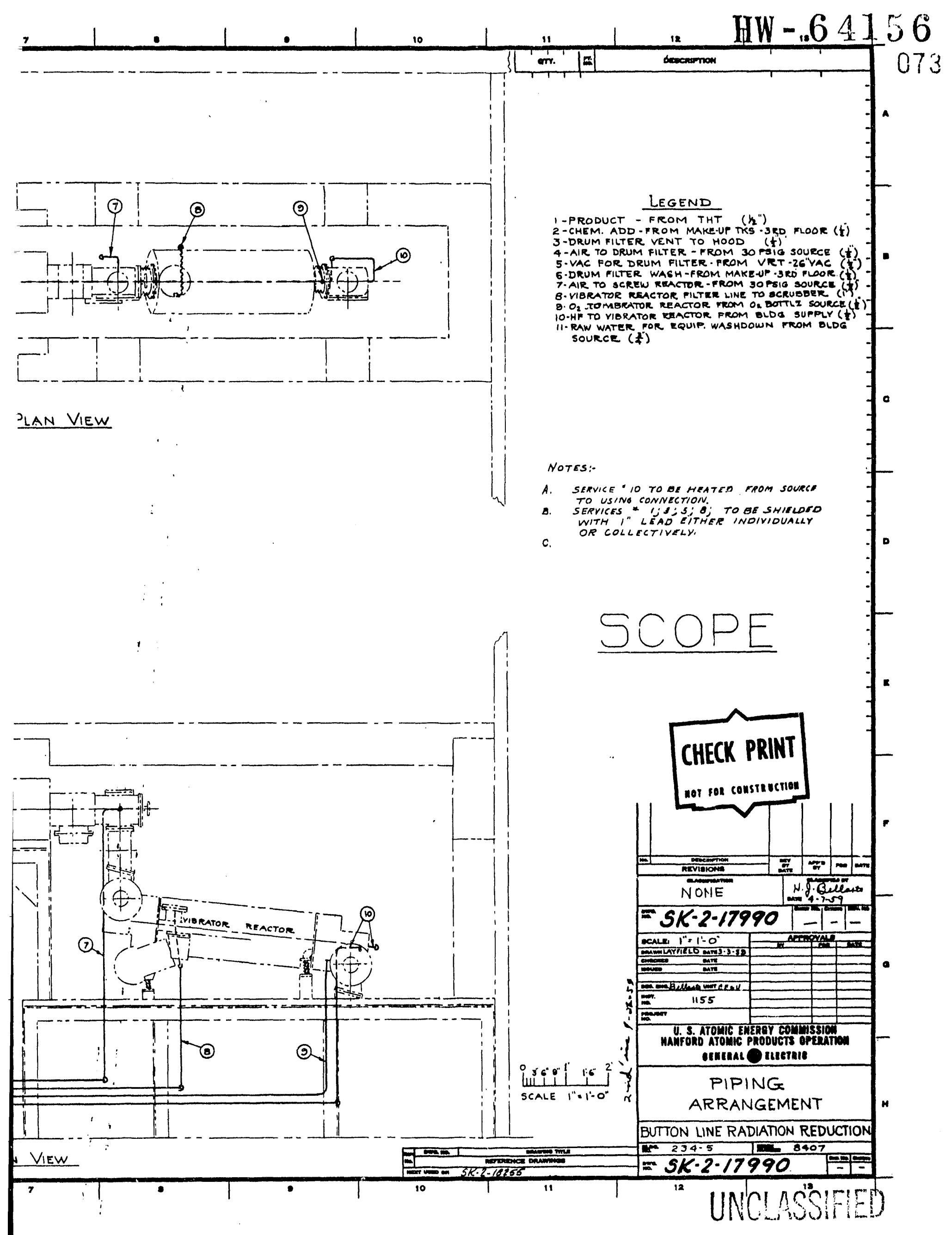




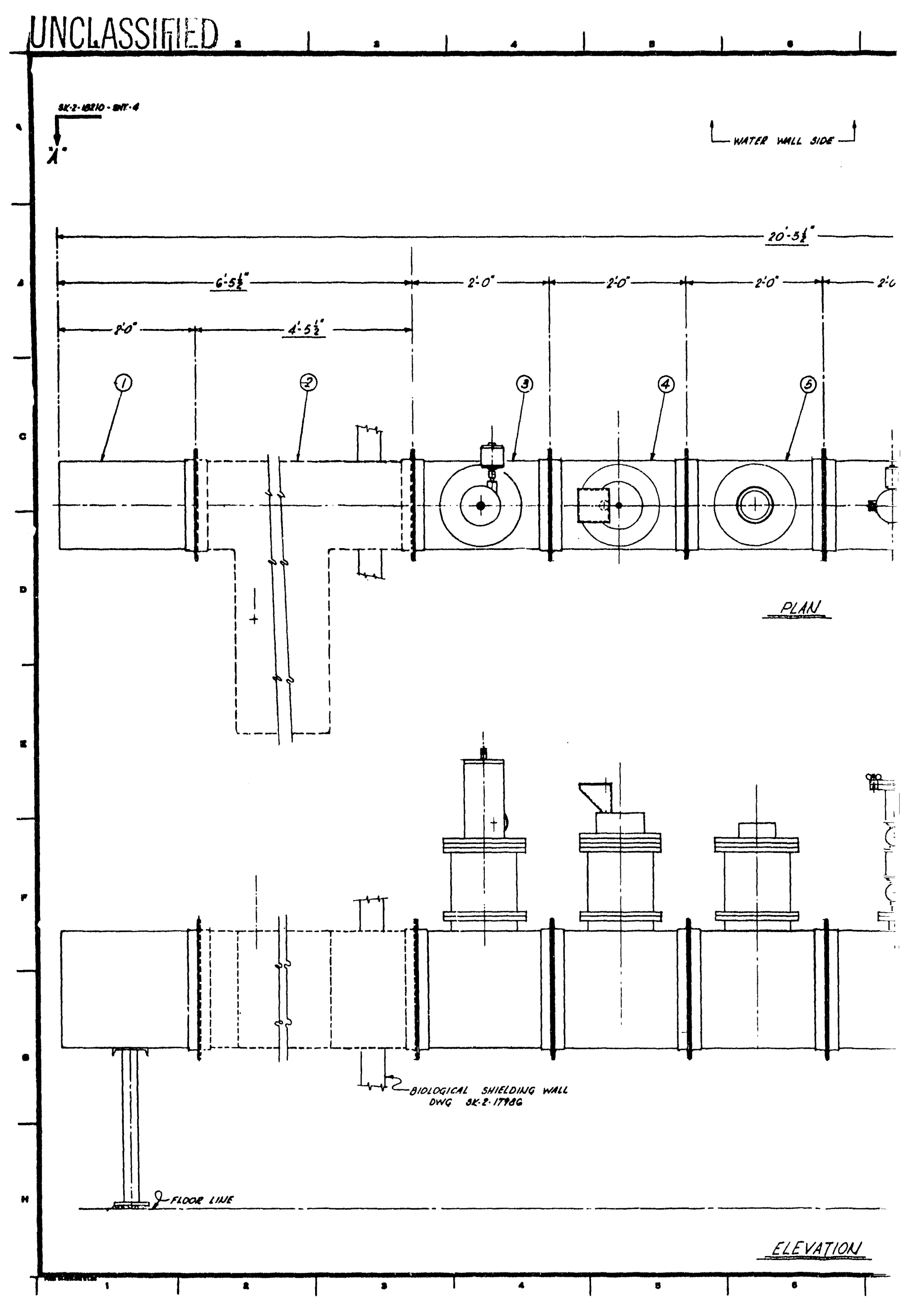




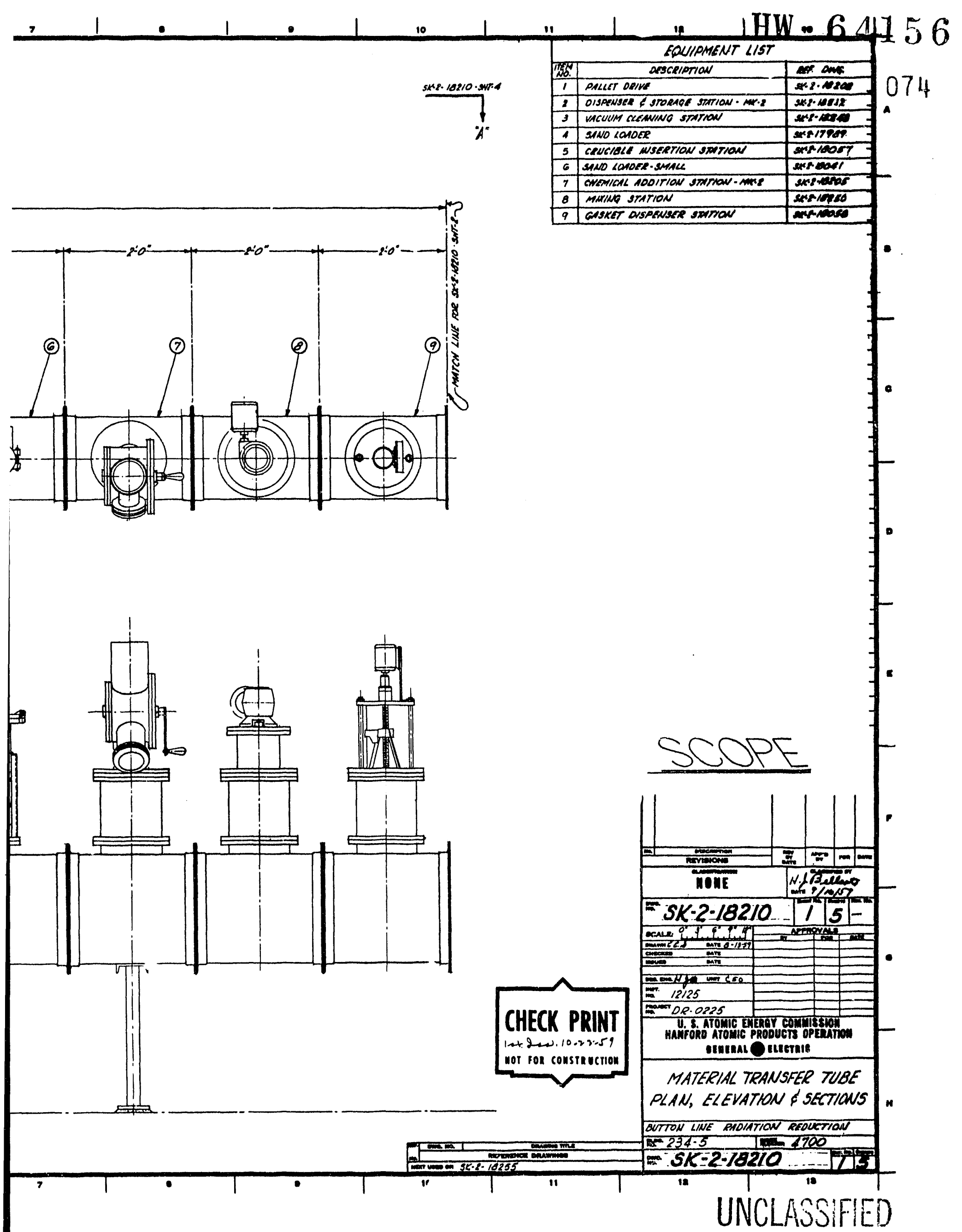




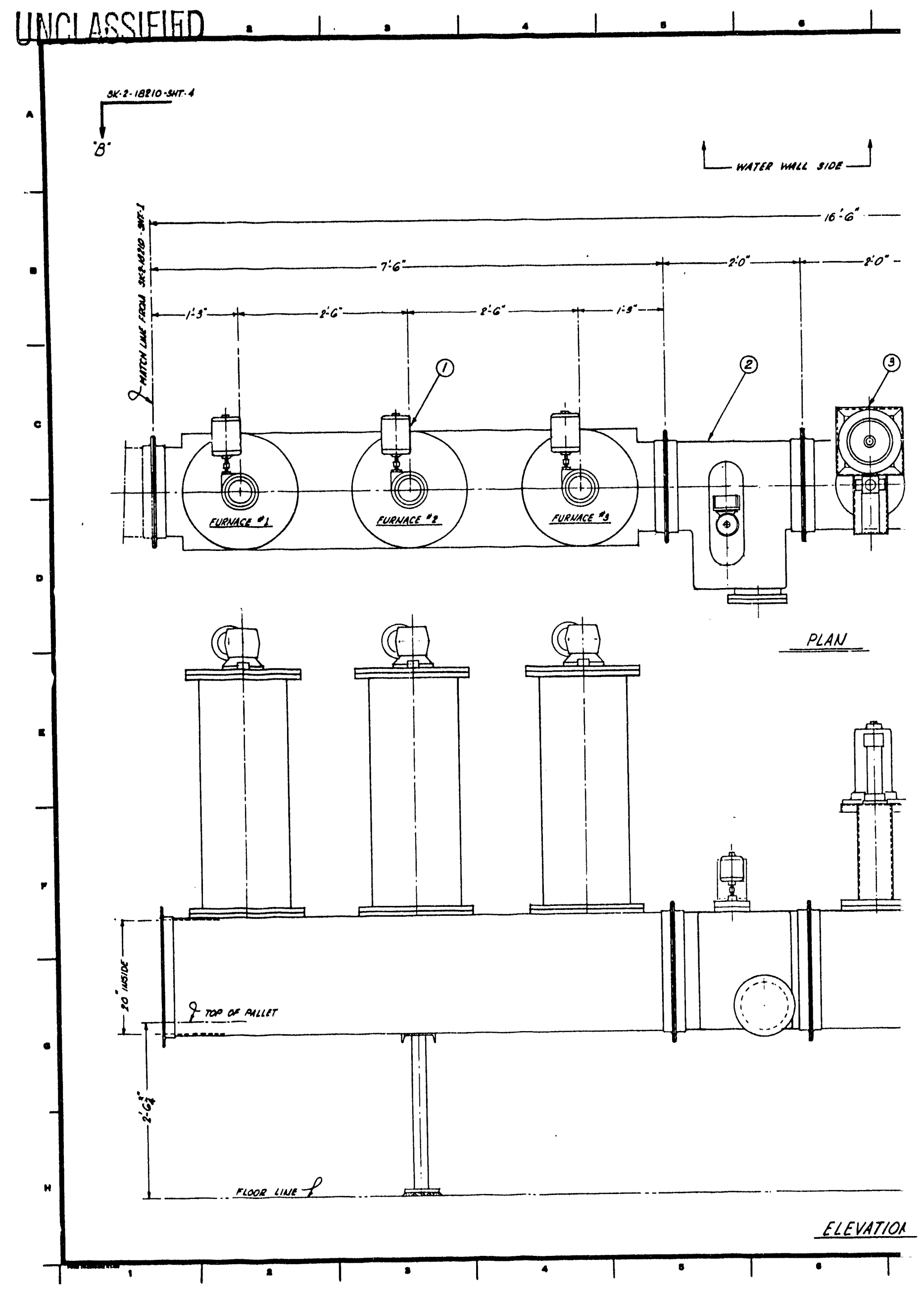




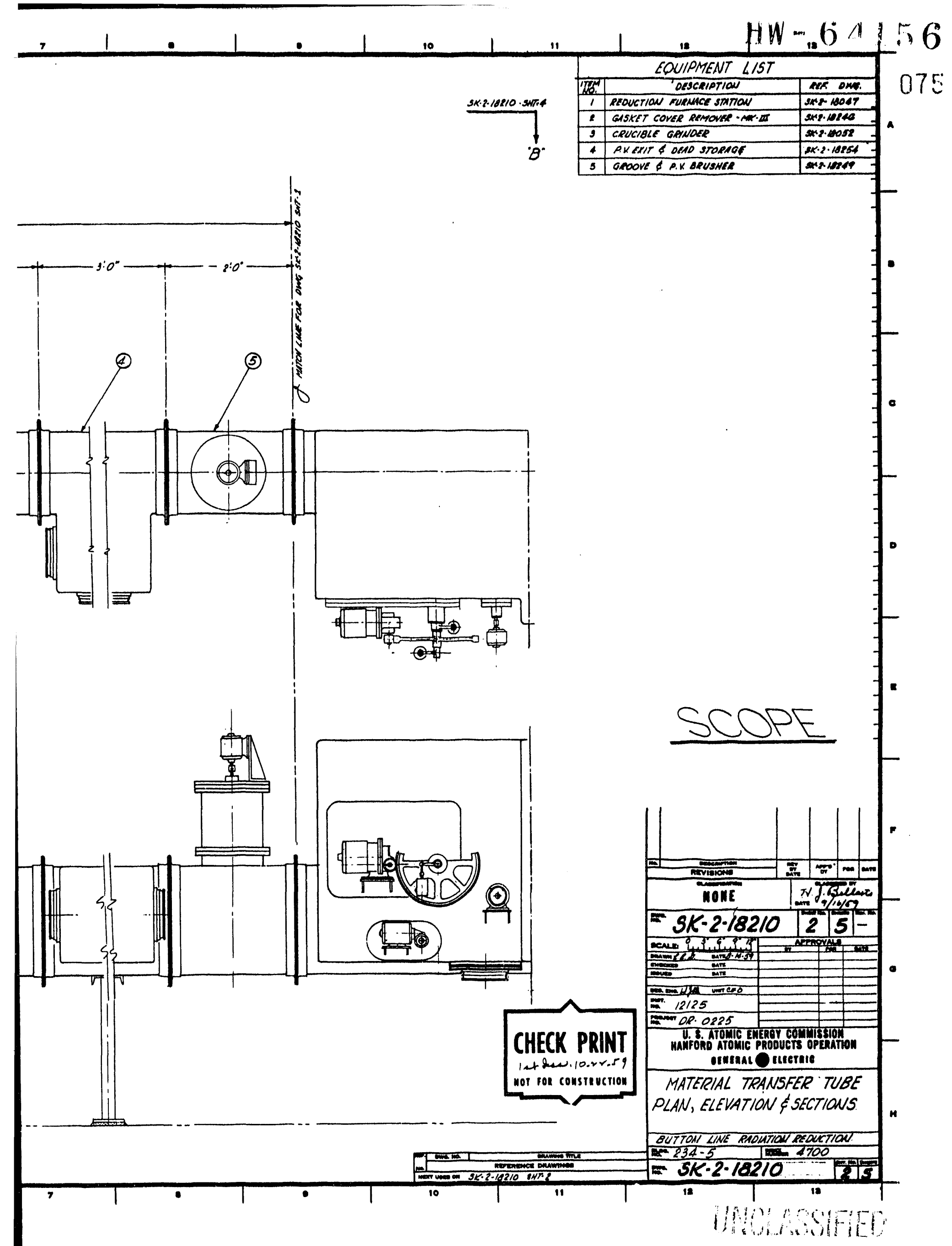


UNCLASSUEFD

rem

L water null solot

(18sumeo)

-

$-12: 0^{\circ}$

(1)

$-$

a)

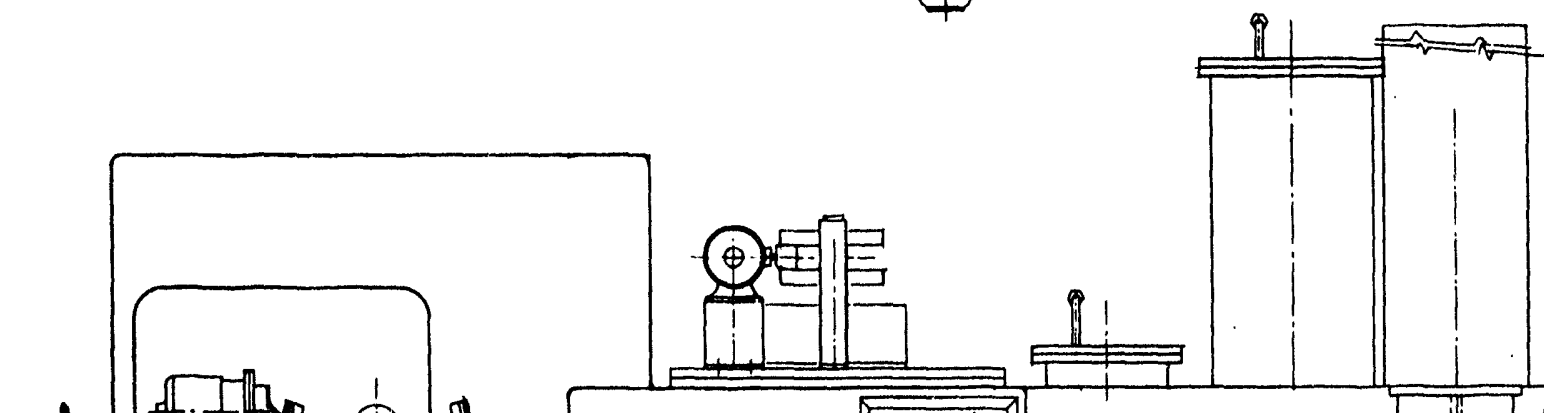

$\cdot$

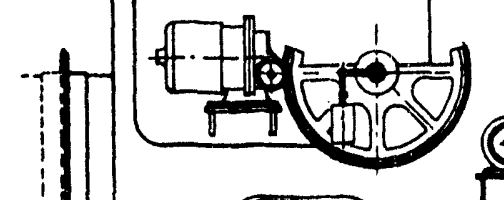

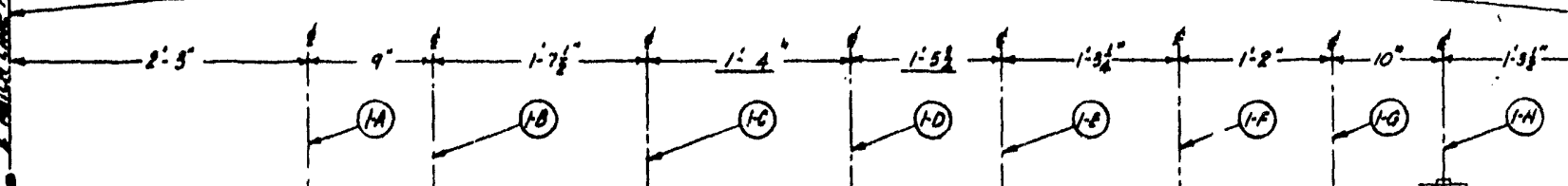

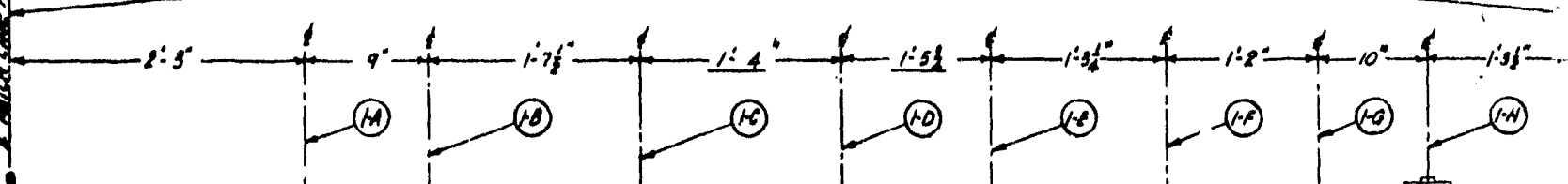

$\alpha$

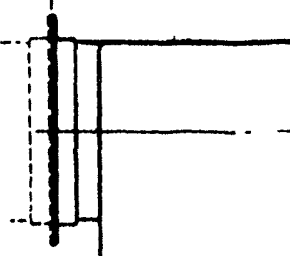

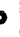
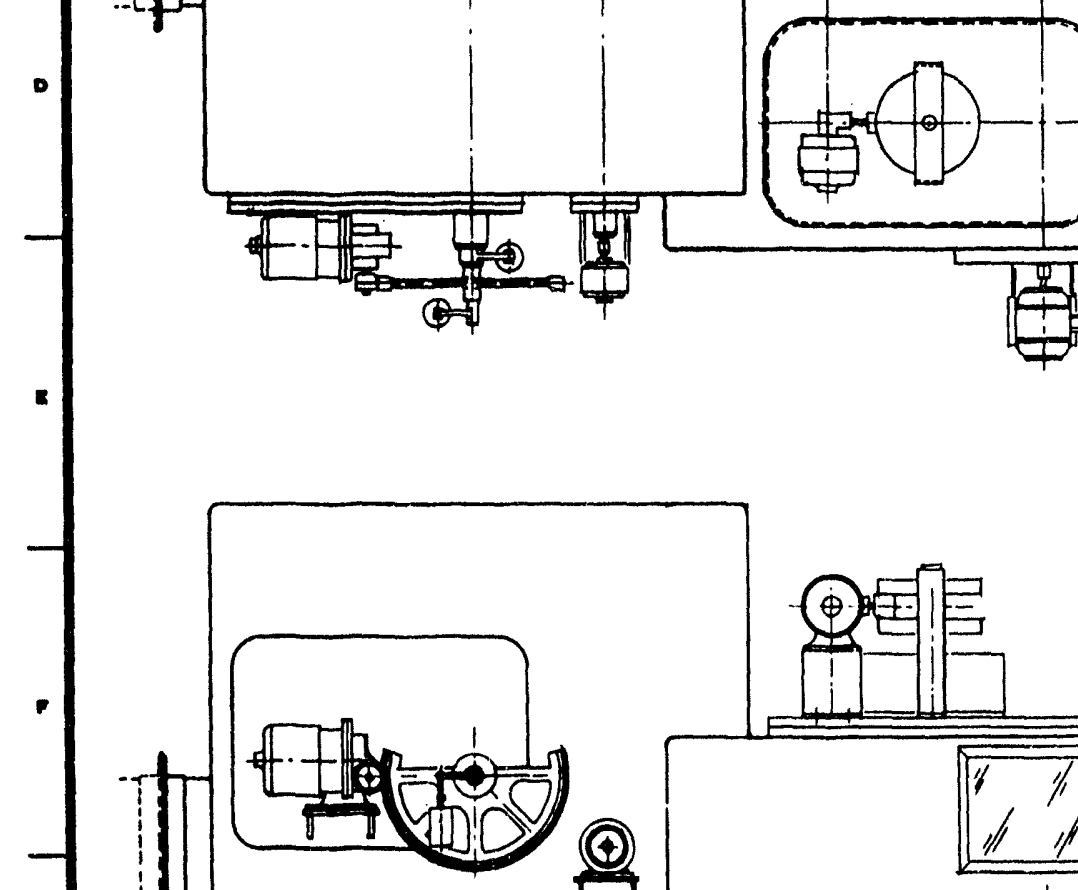

-

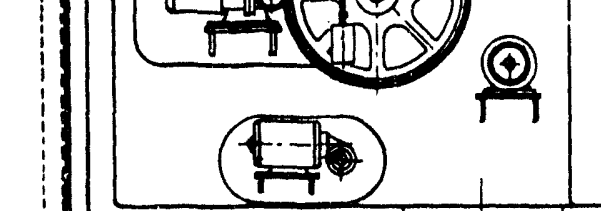

$+\infty$

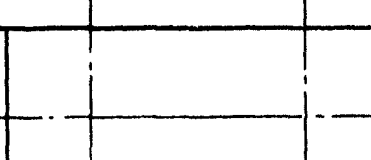



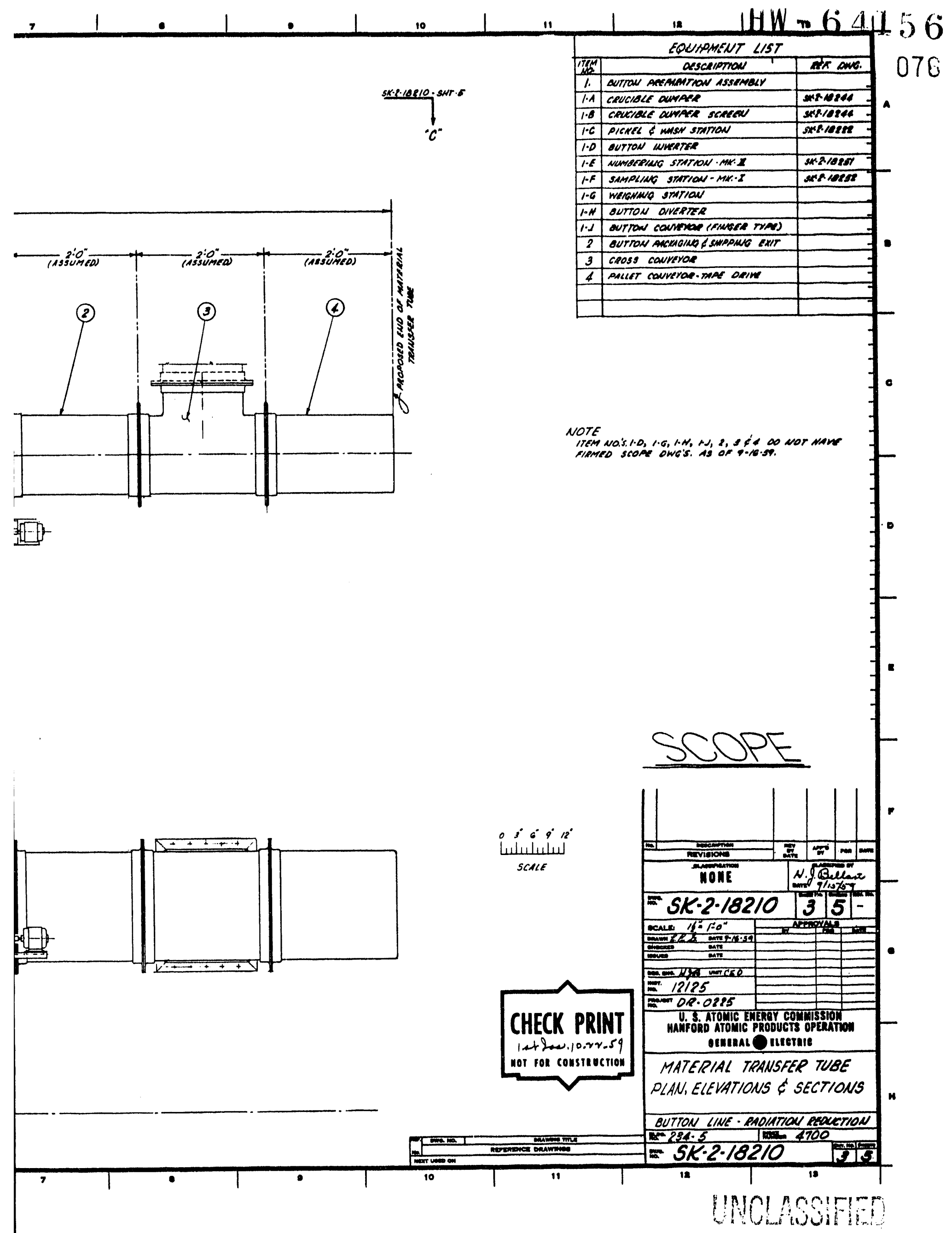

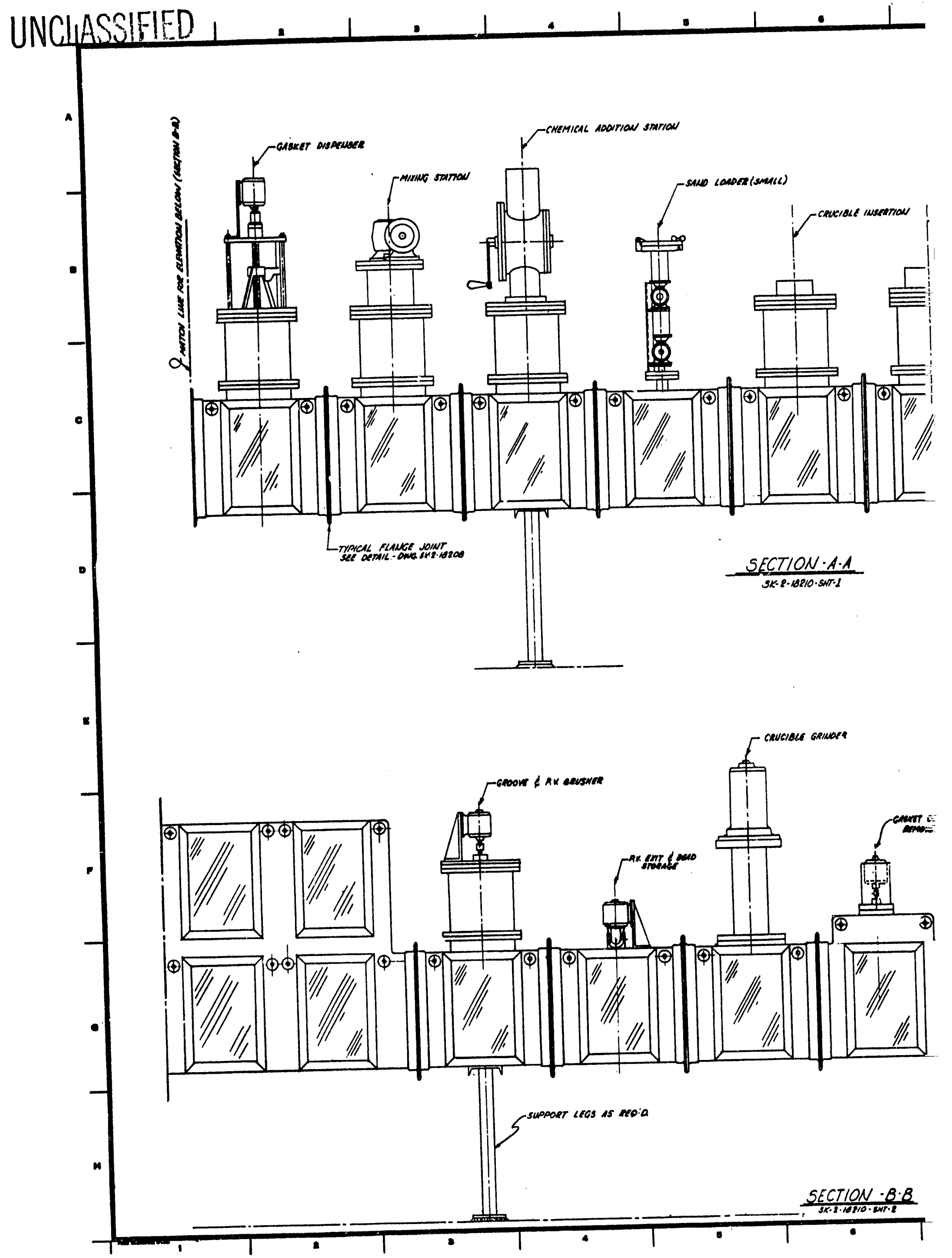


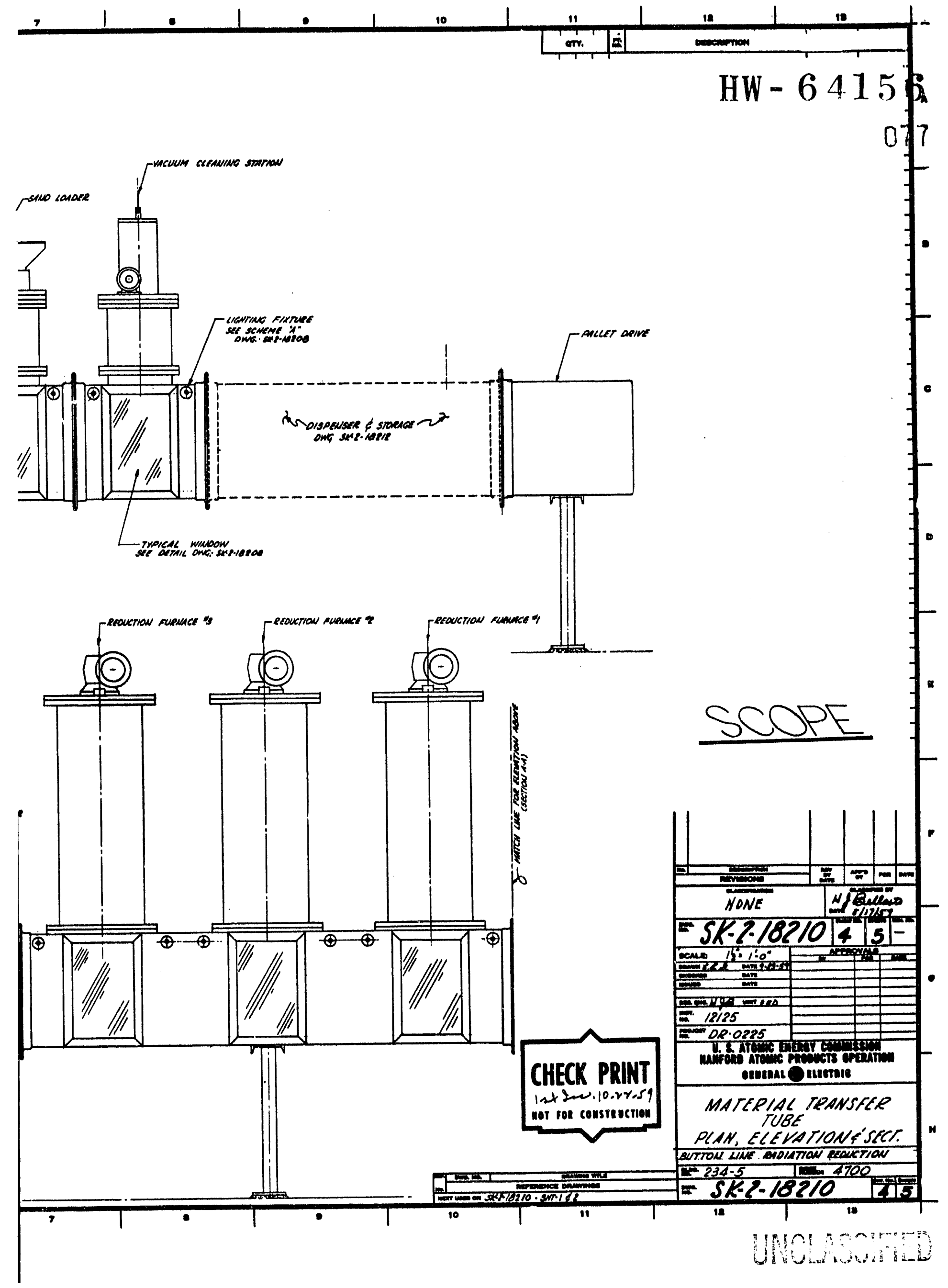




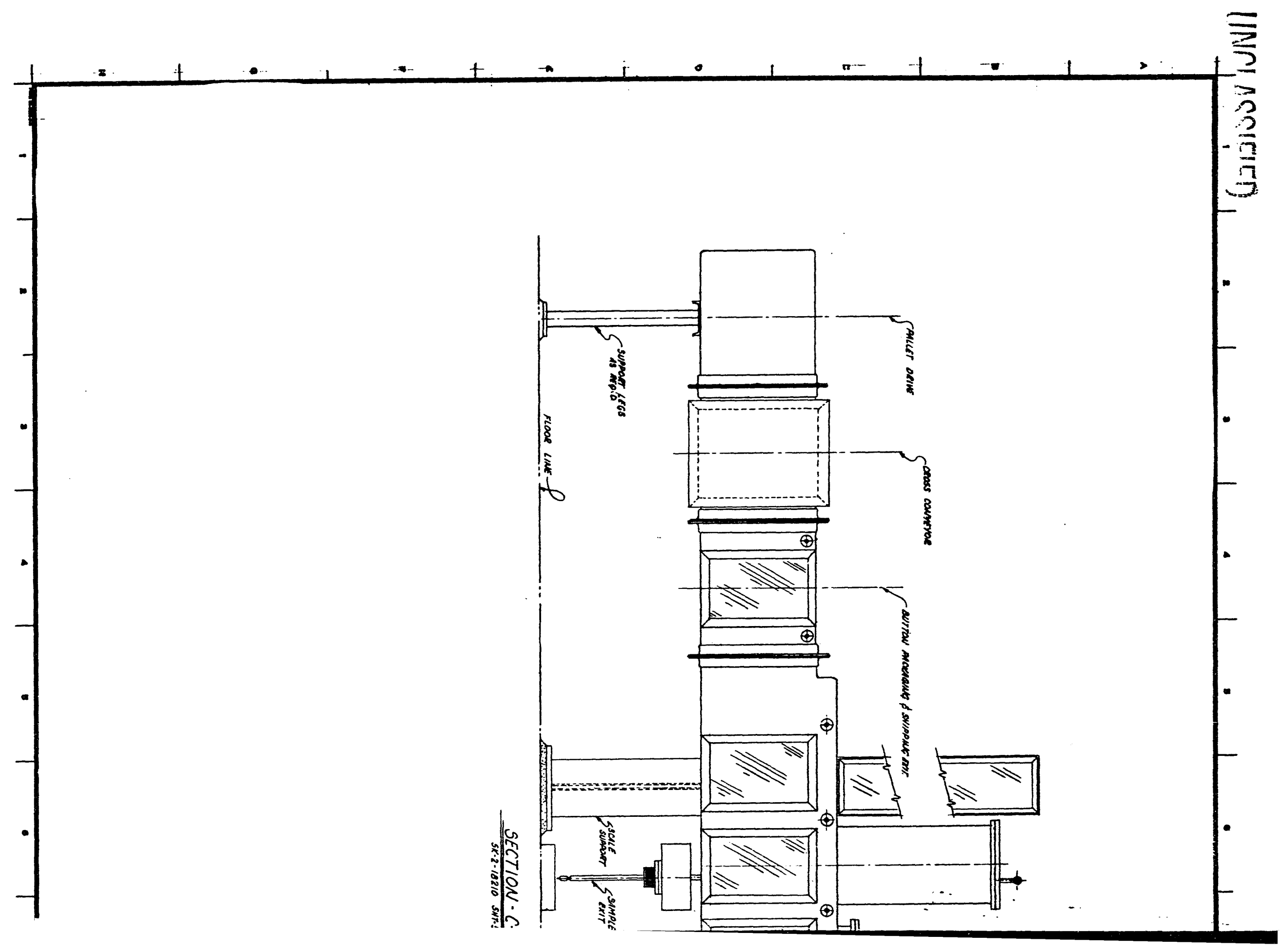




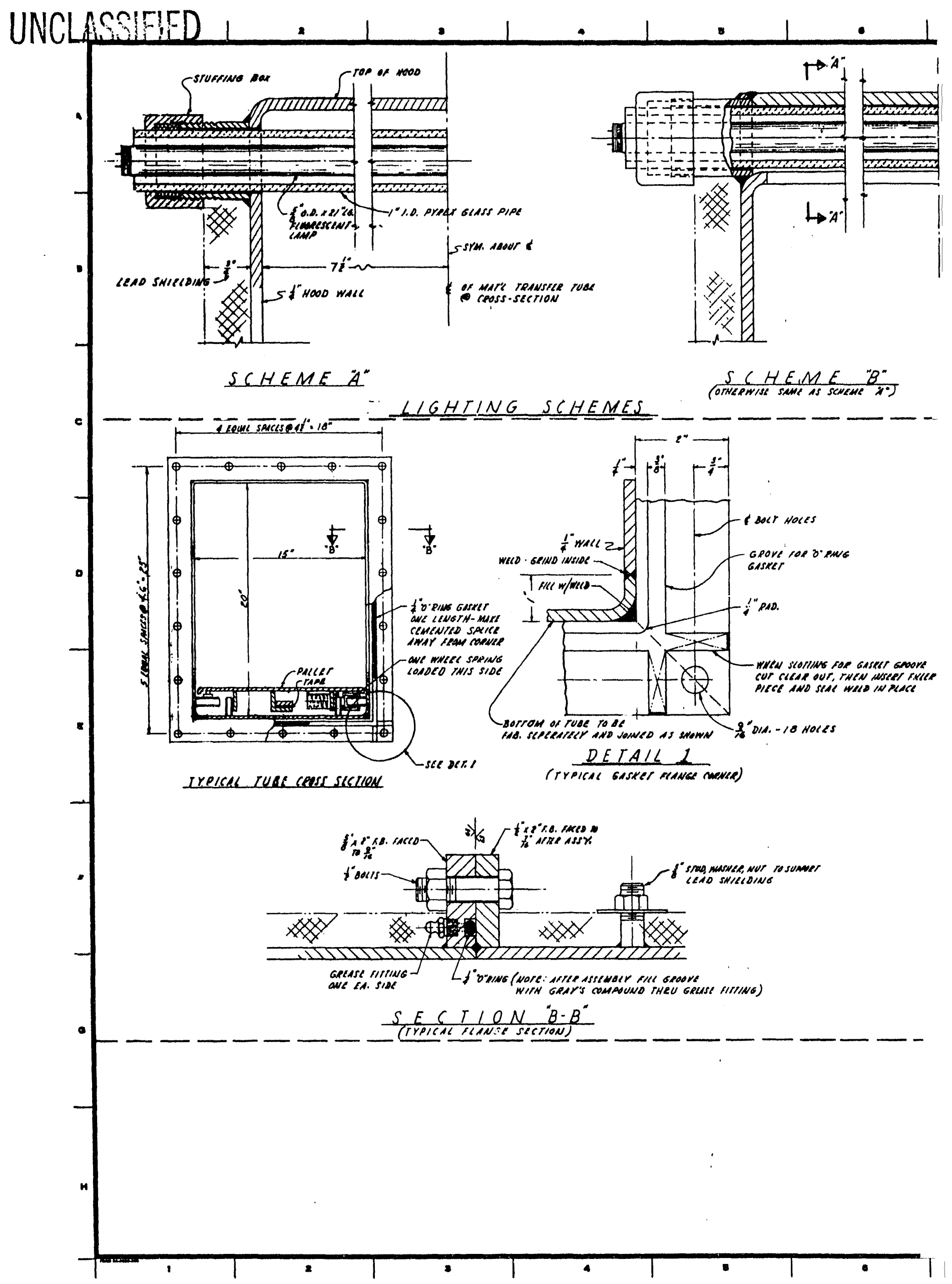




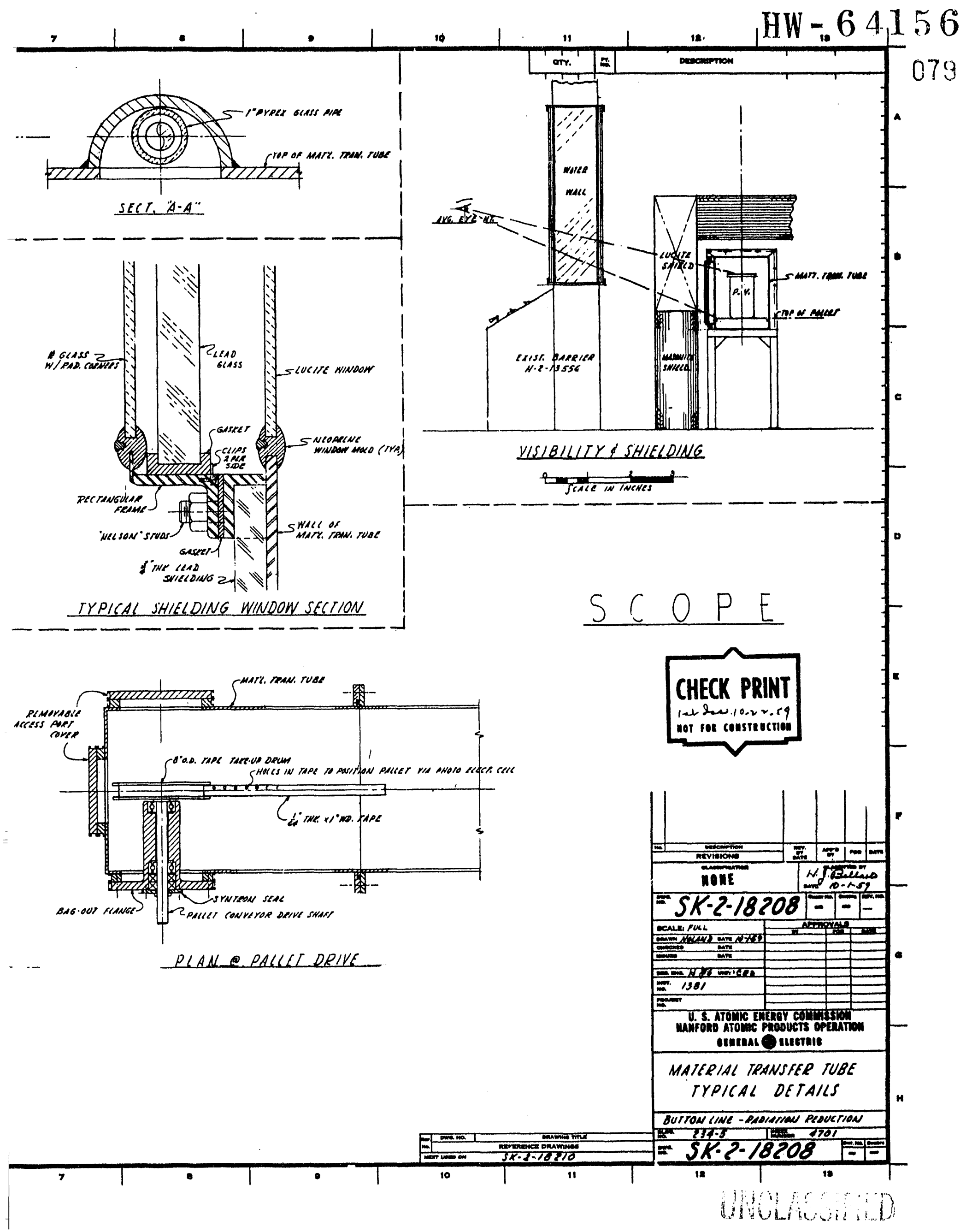




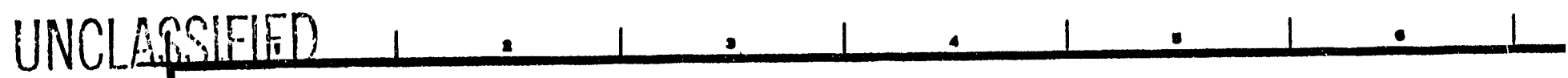

^

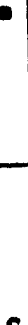

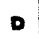

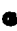

10.8 P.D - 108 TEETH ¿FACE 10 PITCH

.

$$
10 \text { PITCH }
$$

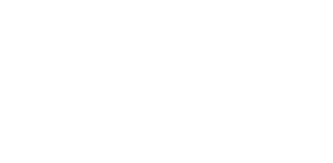

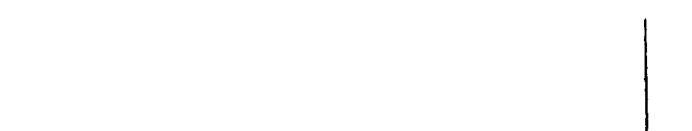

a

rop of TuBes?

DOWEL PIN

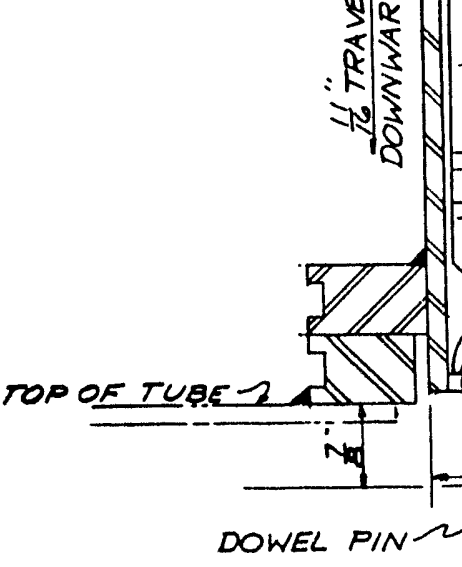

KAYDON BEARING

*KA-80, ENG.CAT. 54
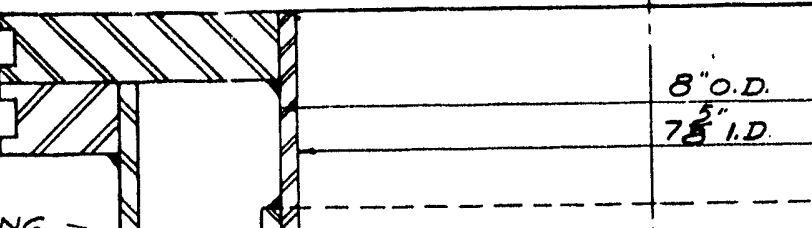

2

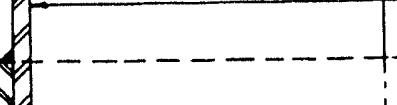




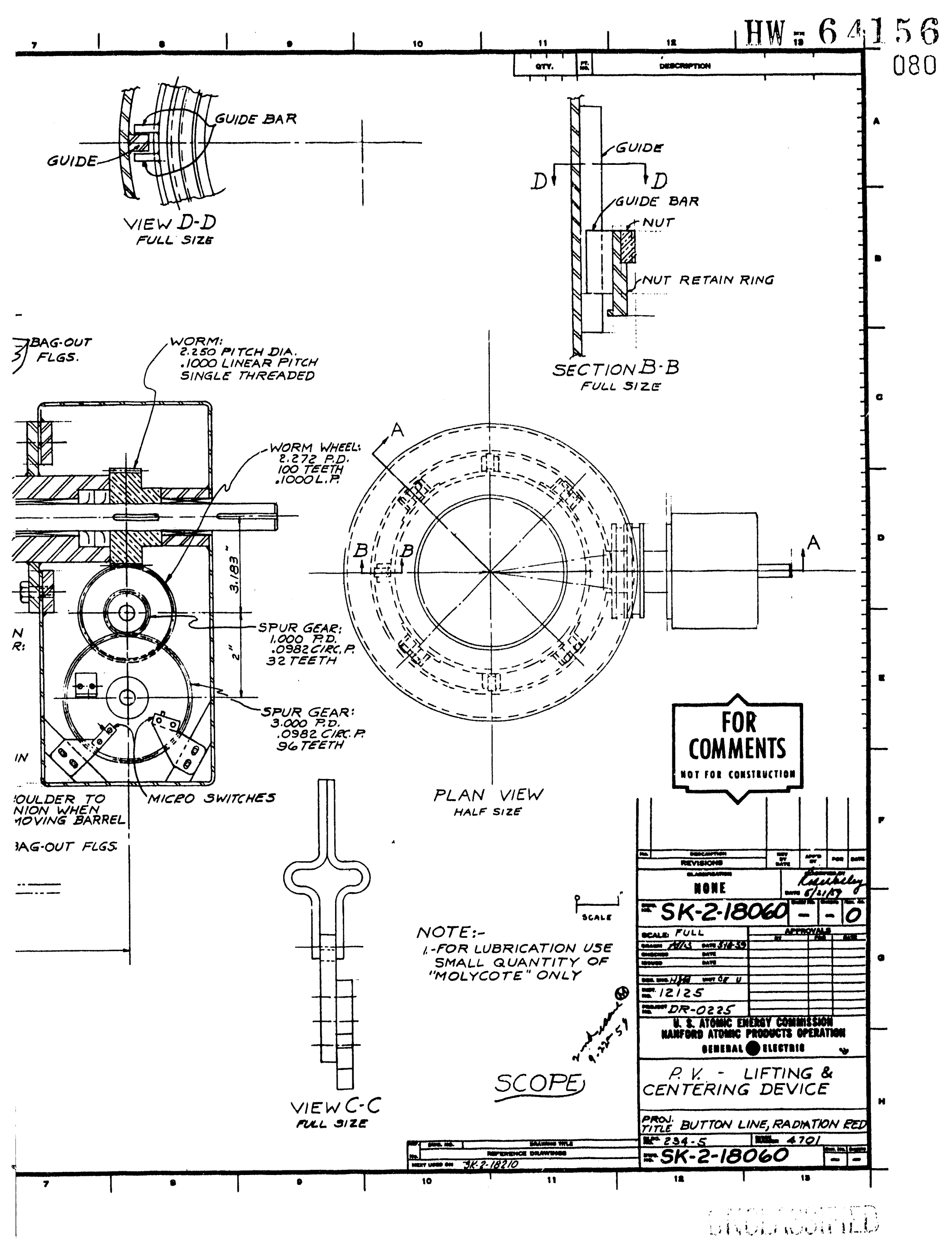




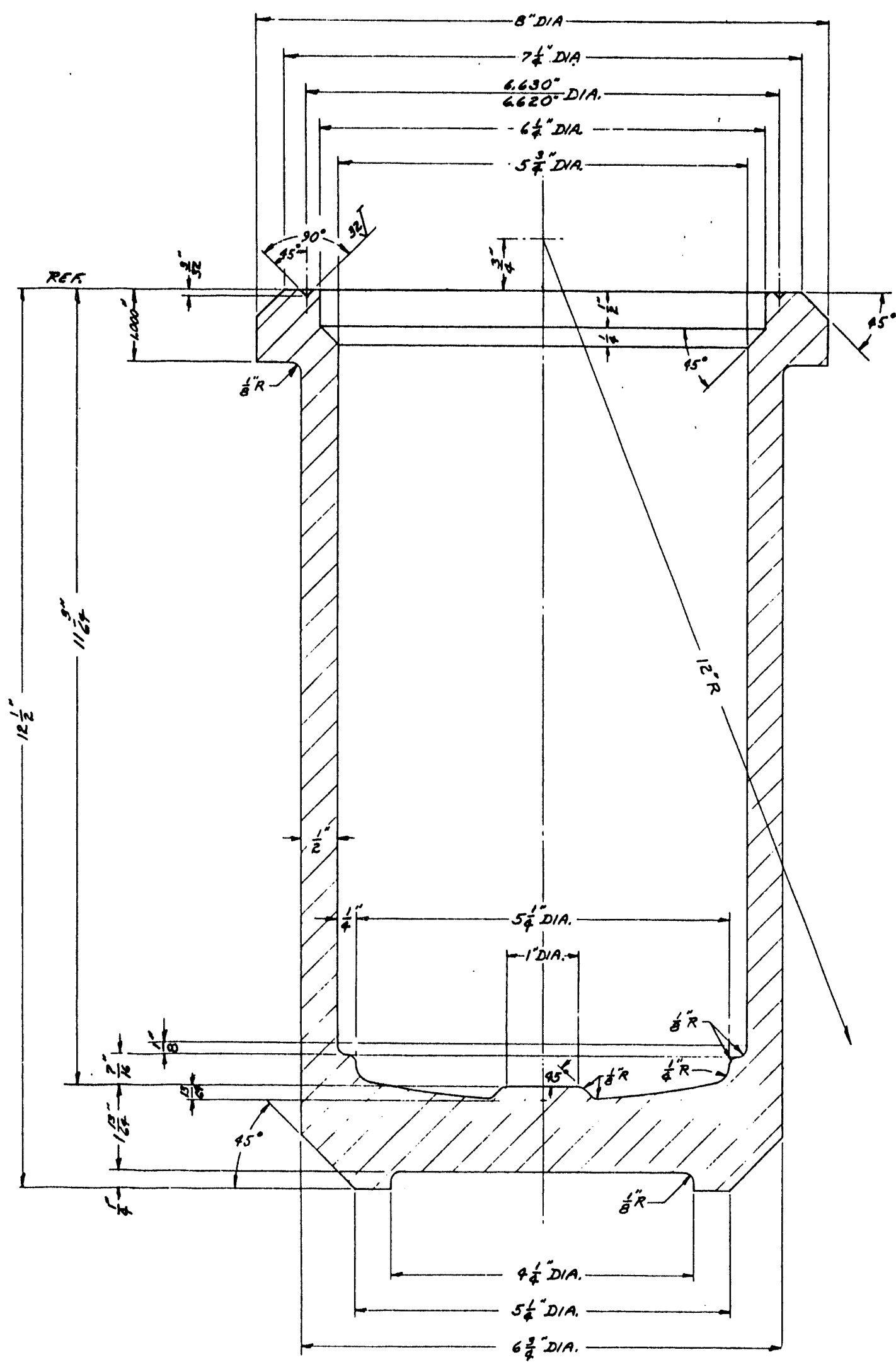

-

SECTION $\oplus \mathscr{L}$ 
UNCLASOSTED

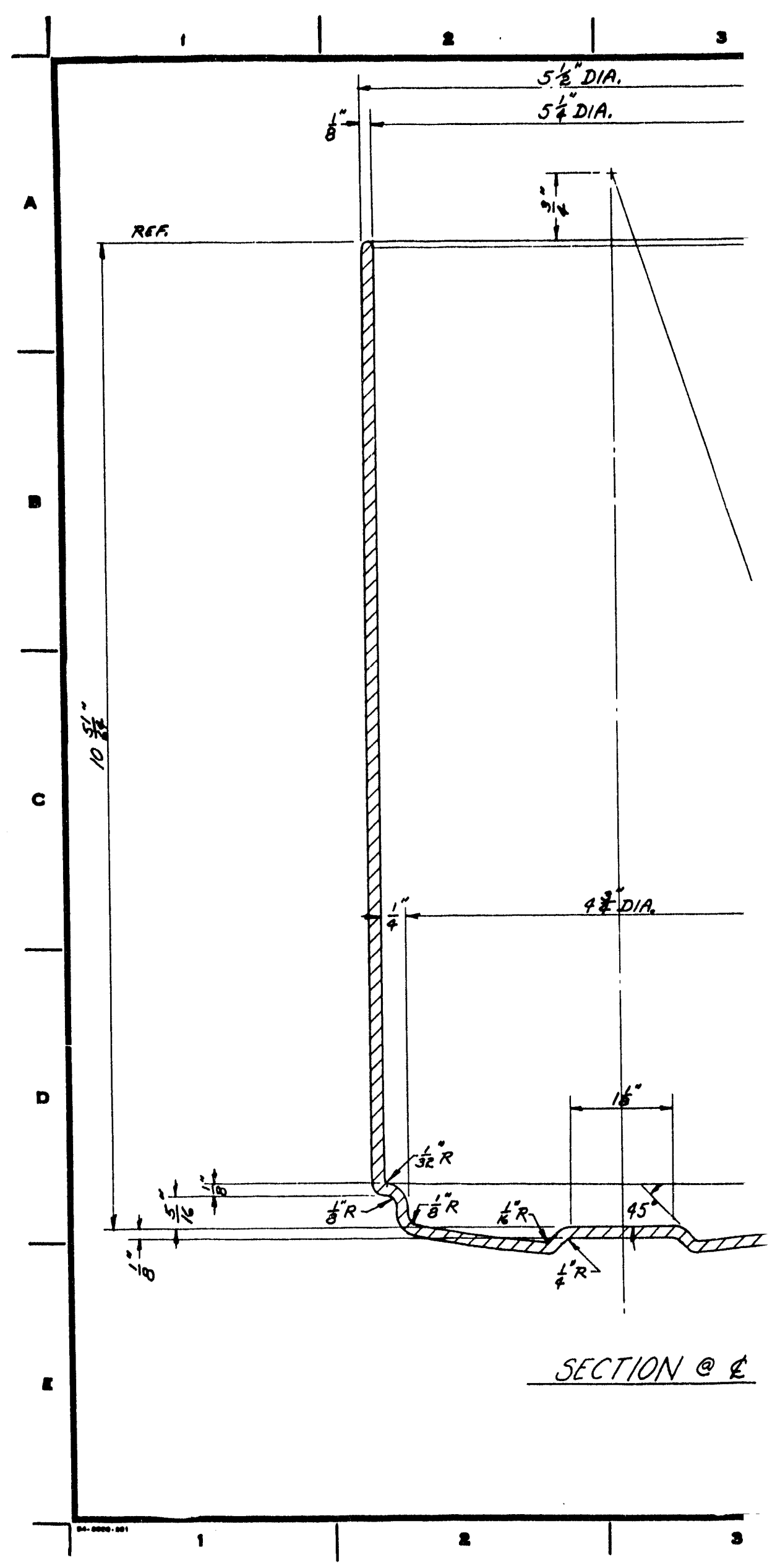




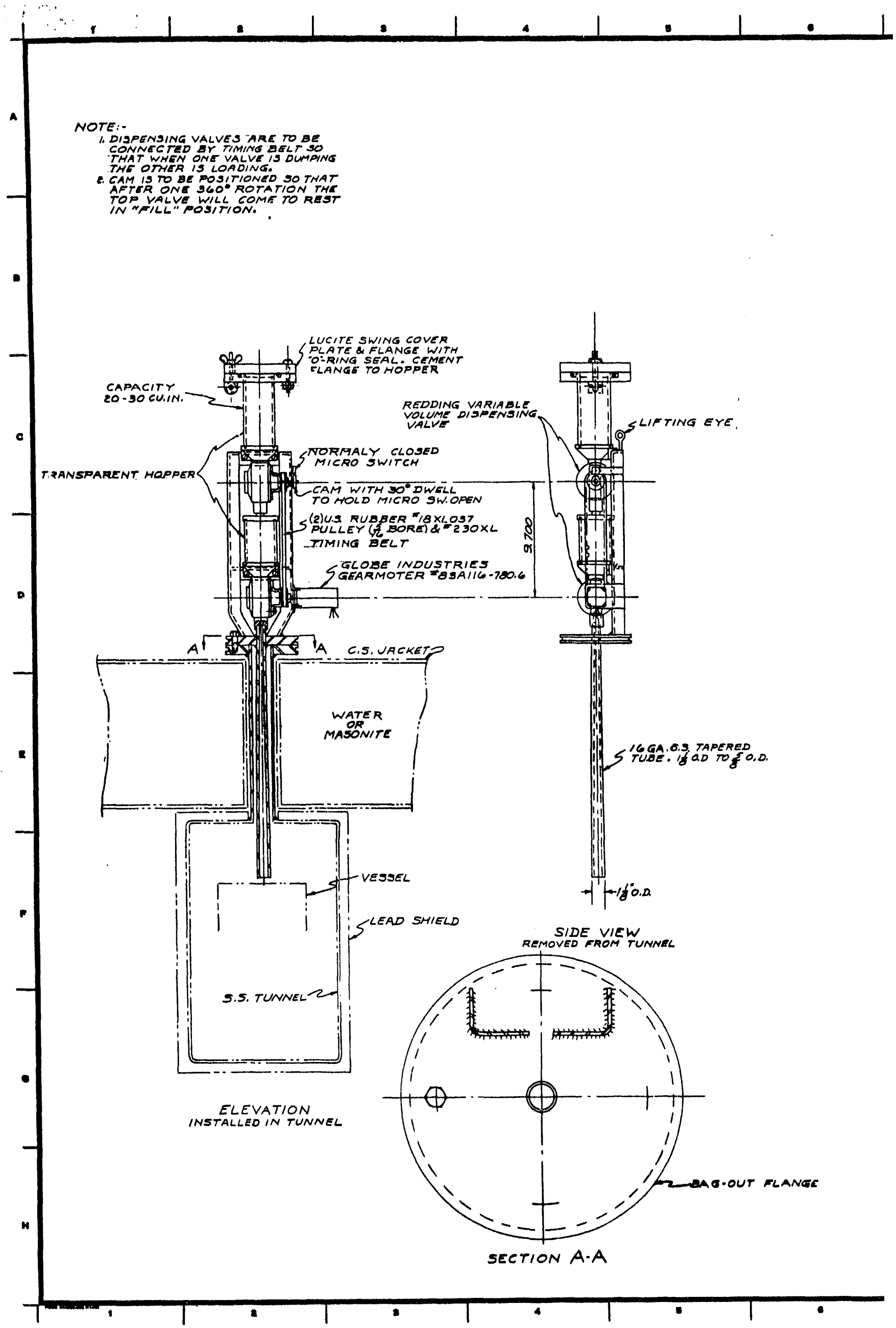




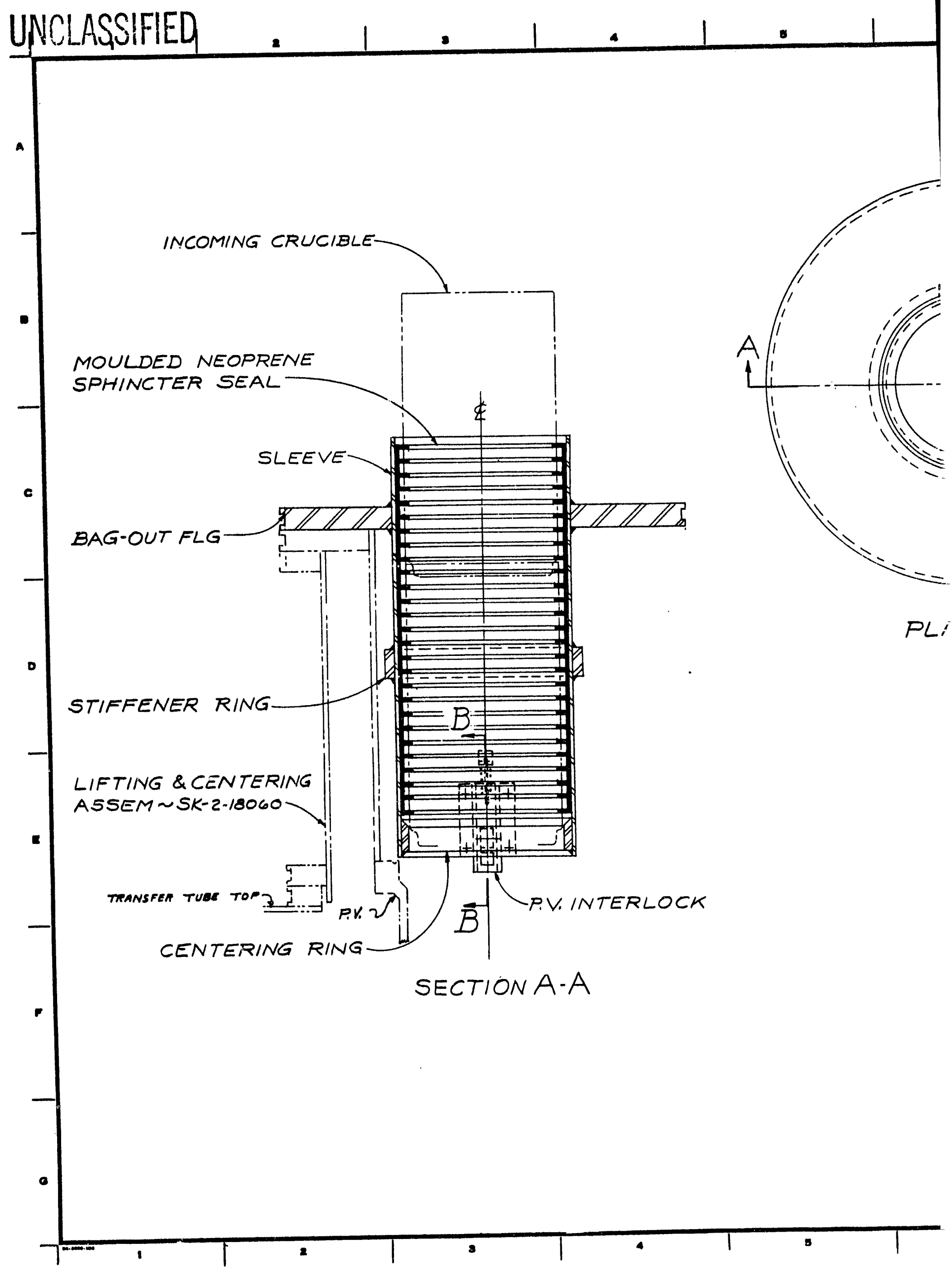




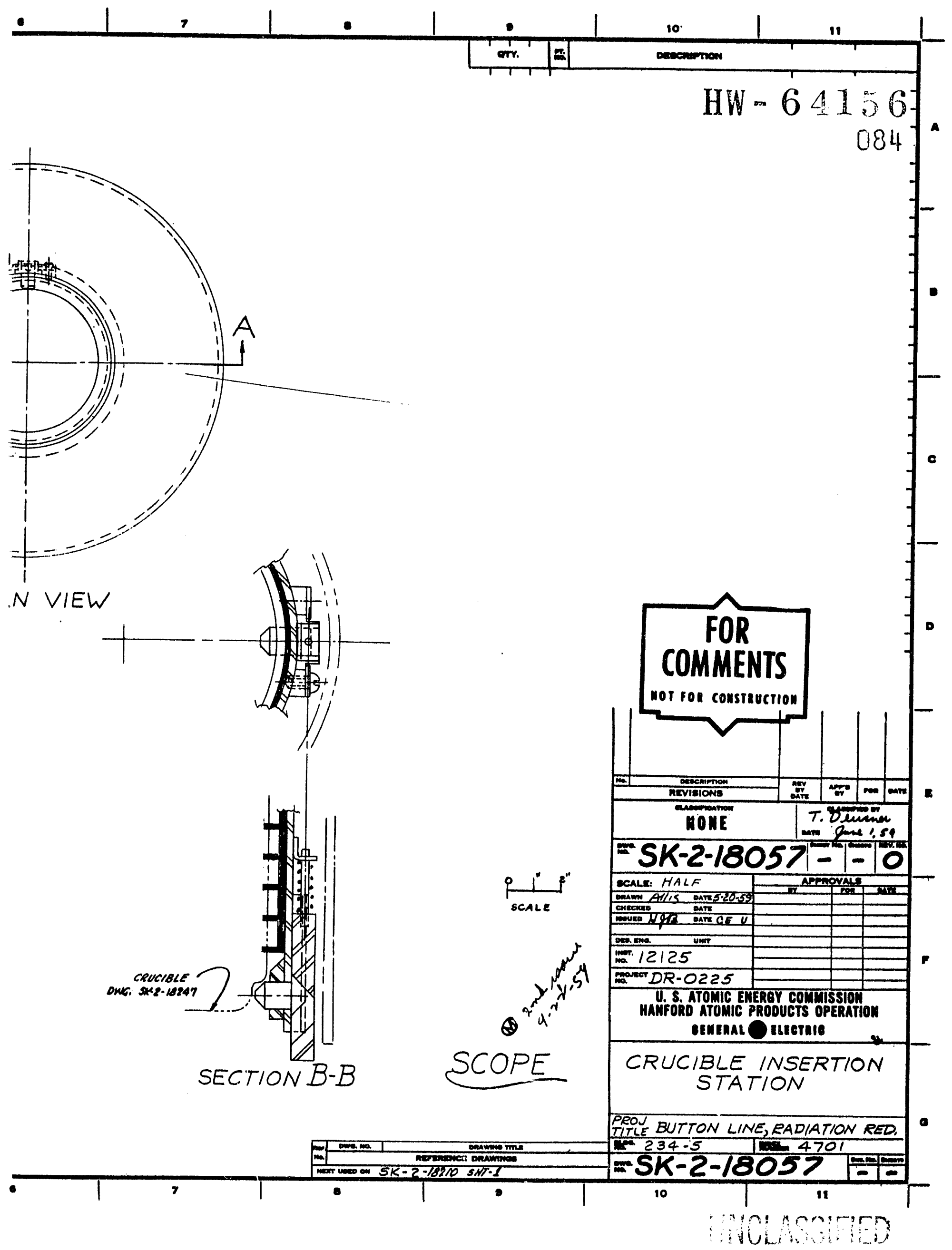




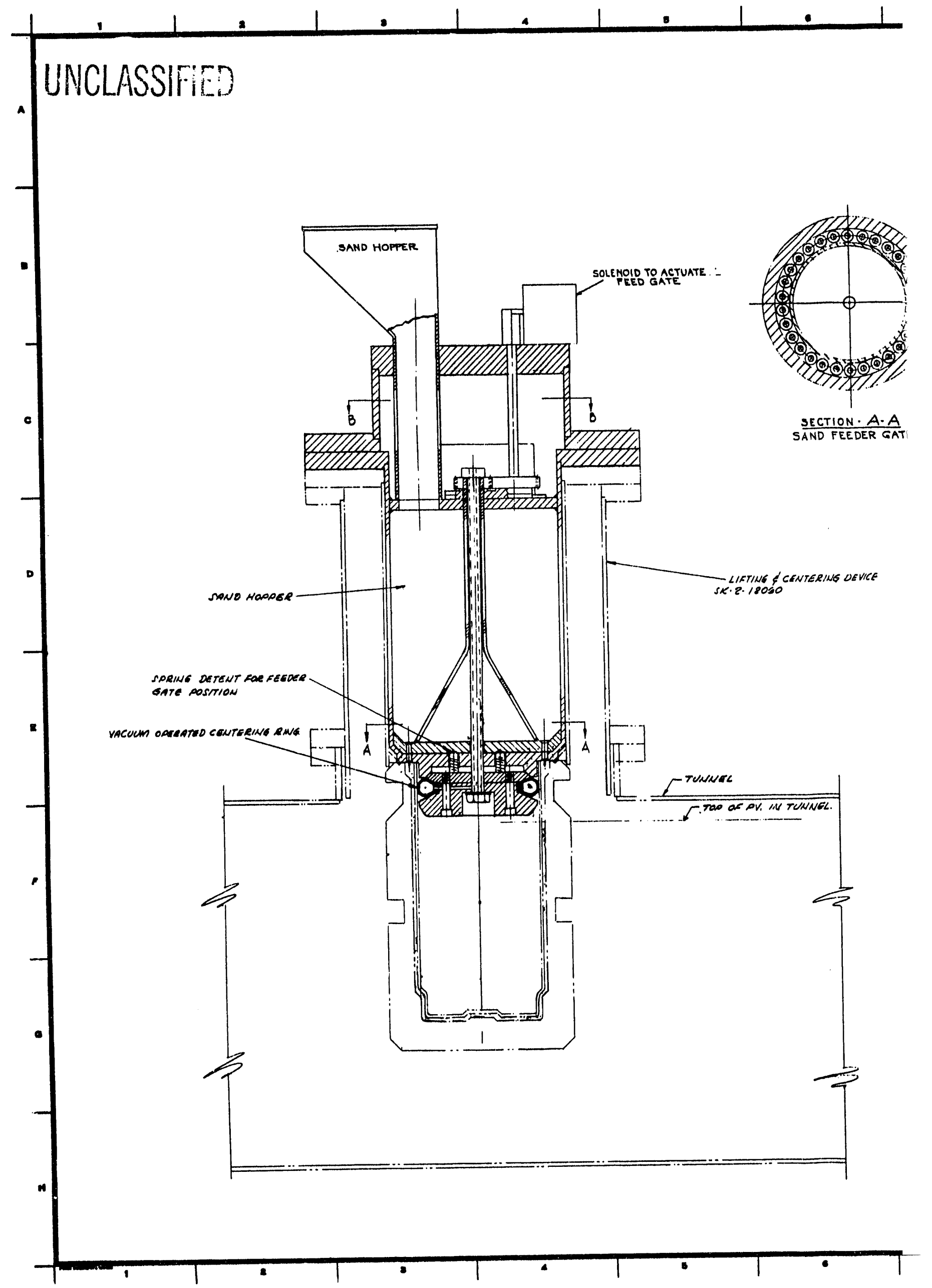




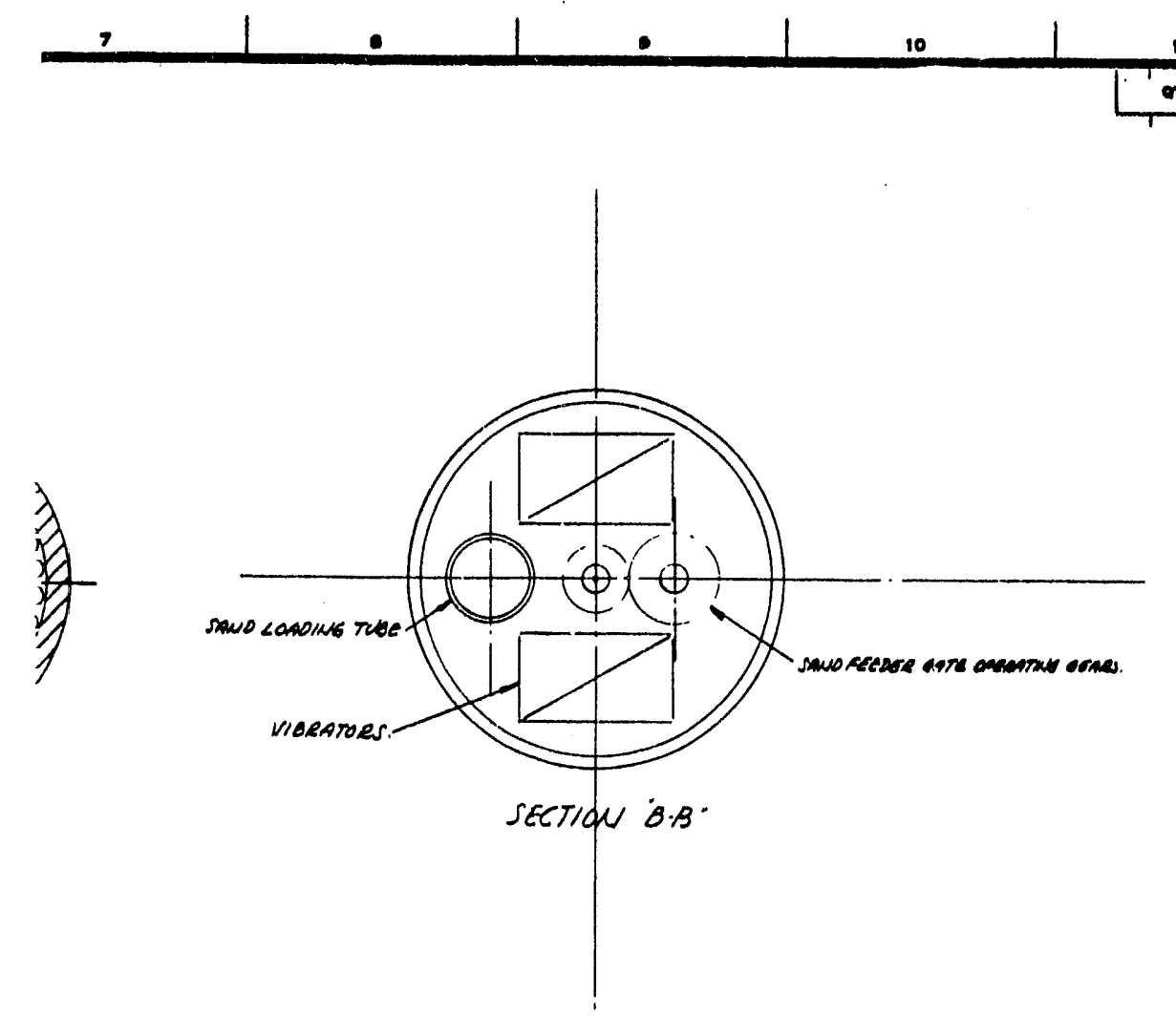

FOR DET'S NOT SHOWN SEE H.2.19235 2 H.8.19206.
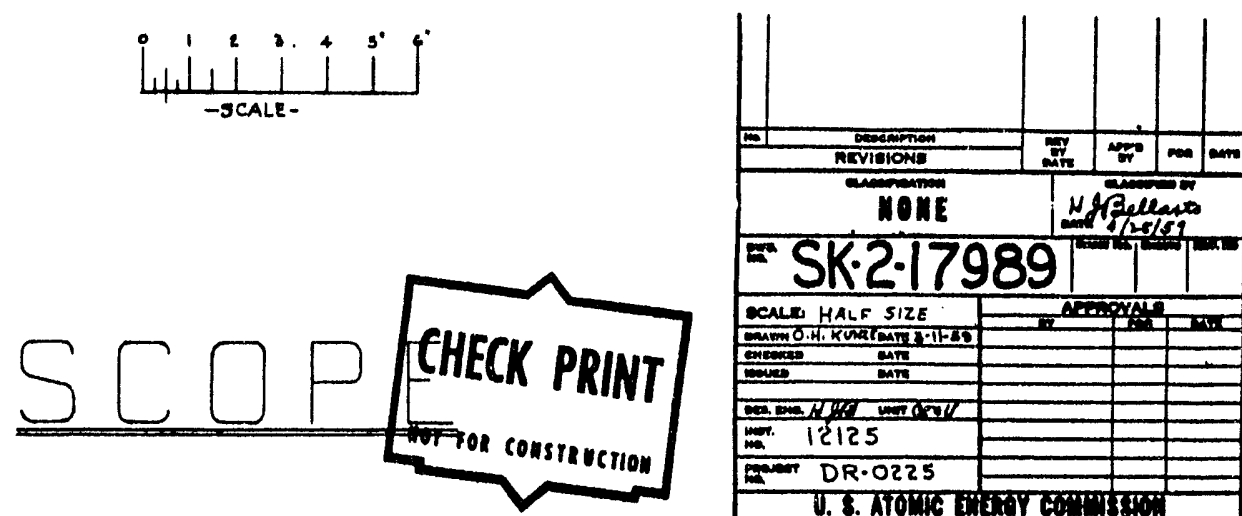

enLE HALF SIZE

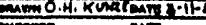

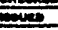

conting Con 125

DR.0225

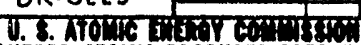

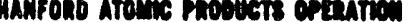
oruinal OLemane

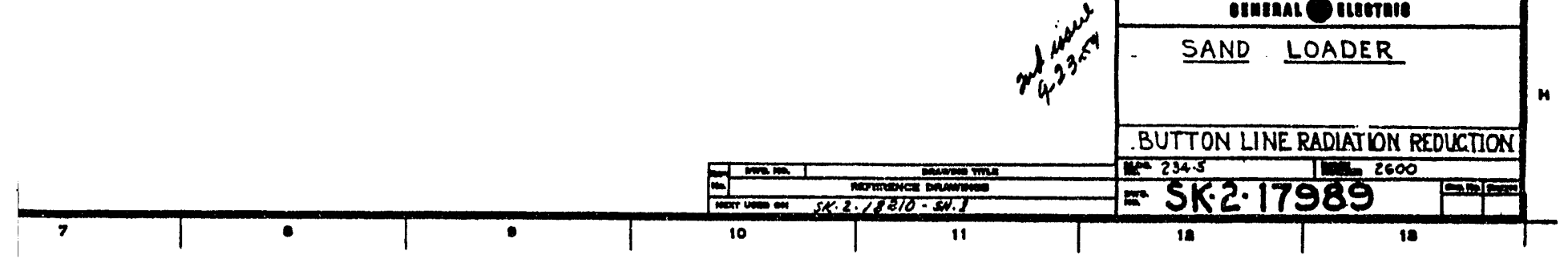




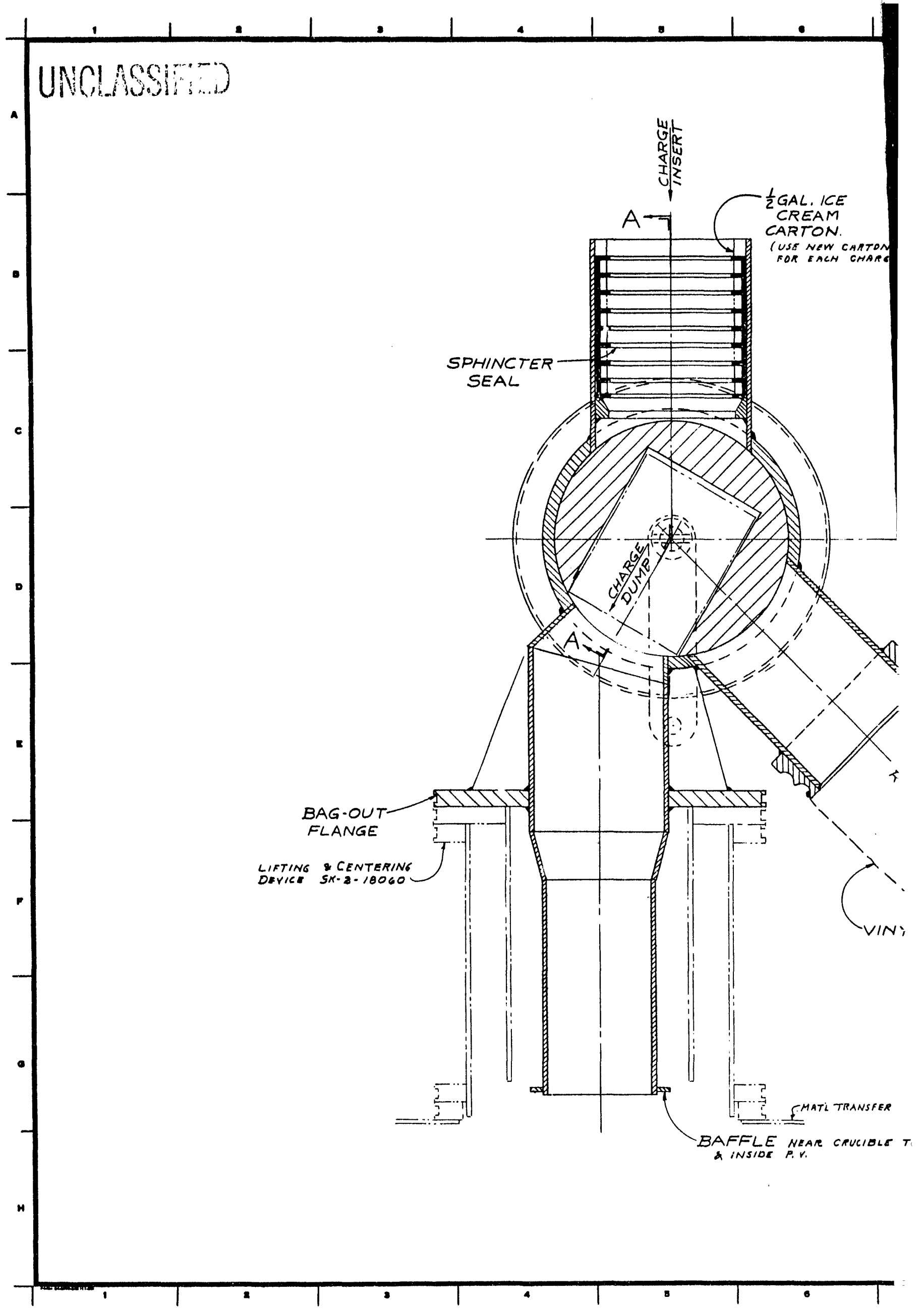




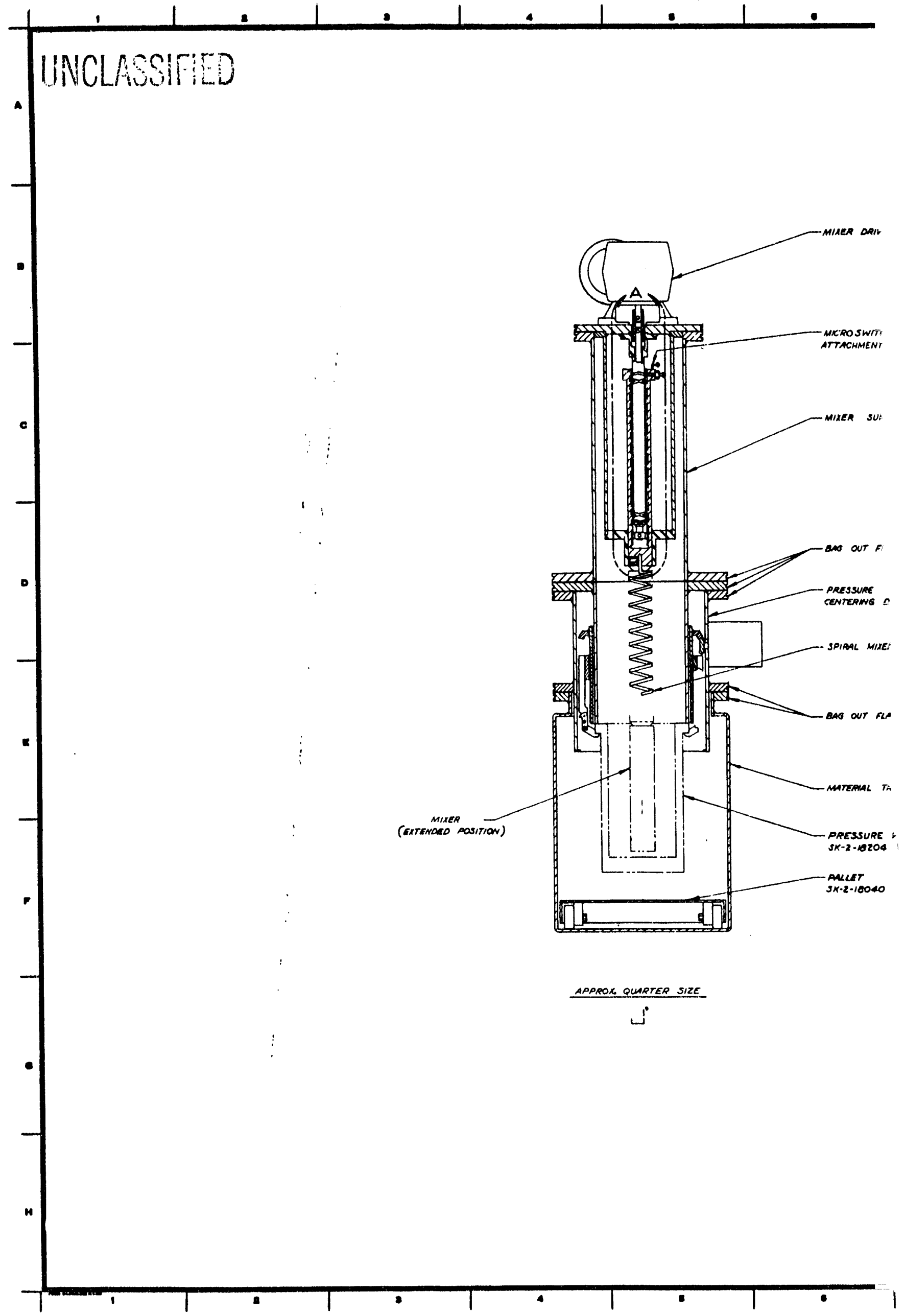


ORT

vees

3SRL. IFTHOS
VICE ST.2.10060

vice $5 x \cdot 2 \cdot 10060$

oes

NSFER TUEC

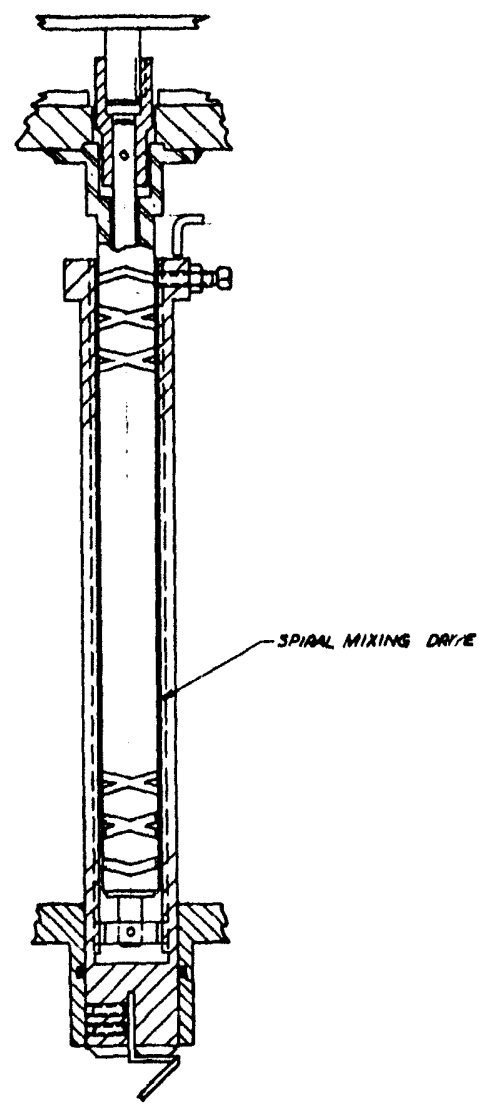

isset

VIEW $A$

$\frac{\text { Approx.male size }}{{ }^{i}}$

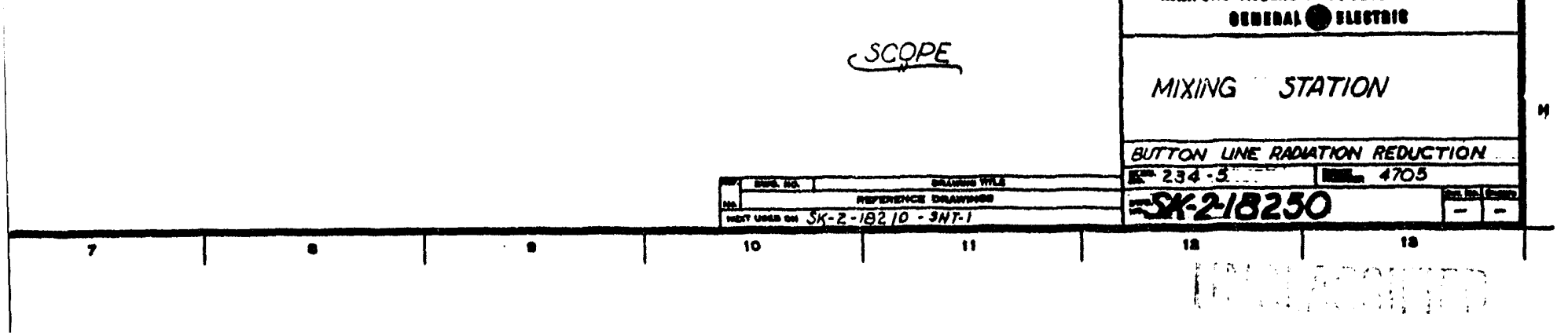




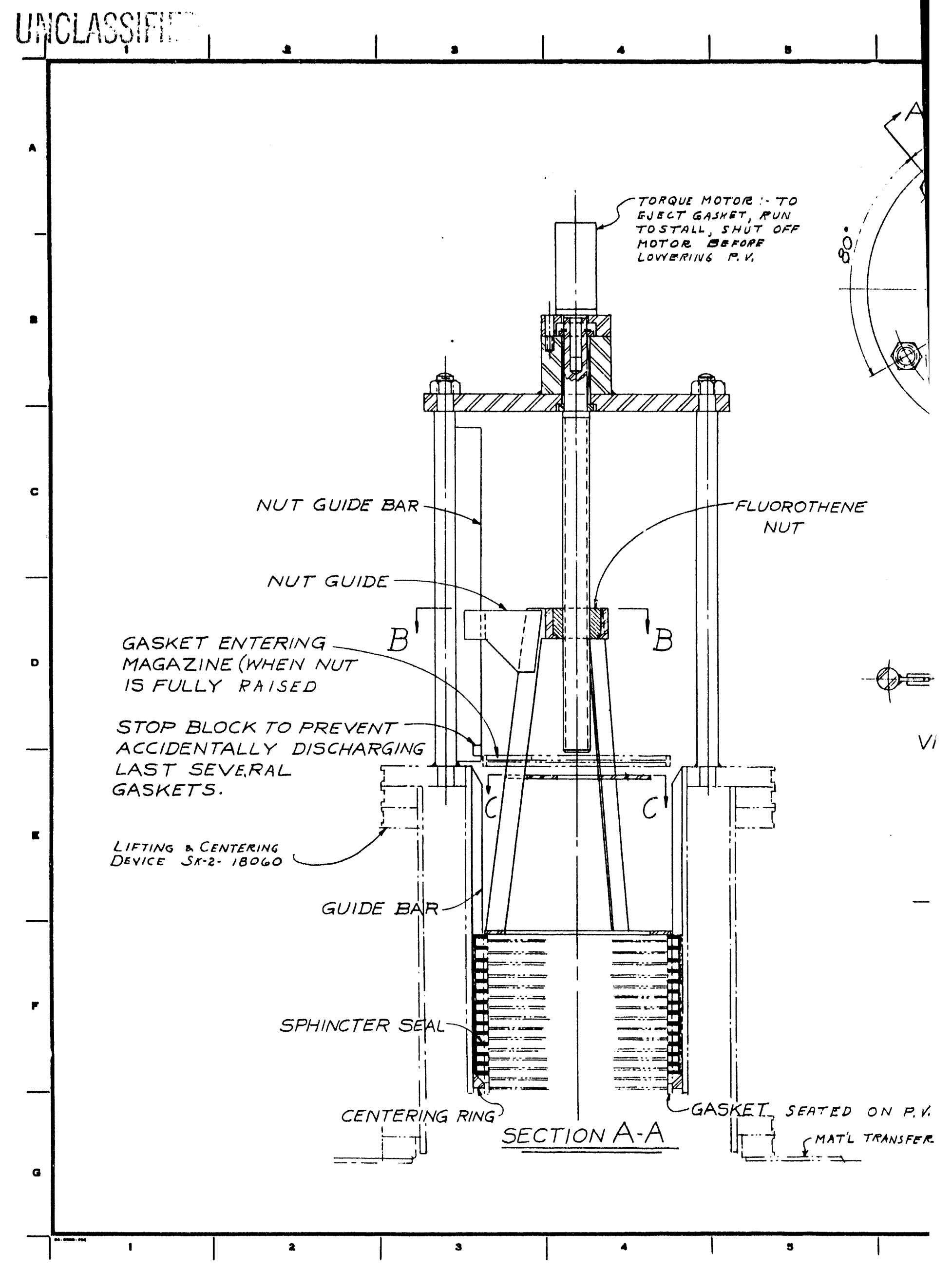




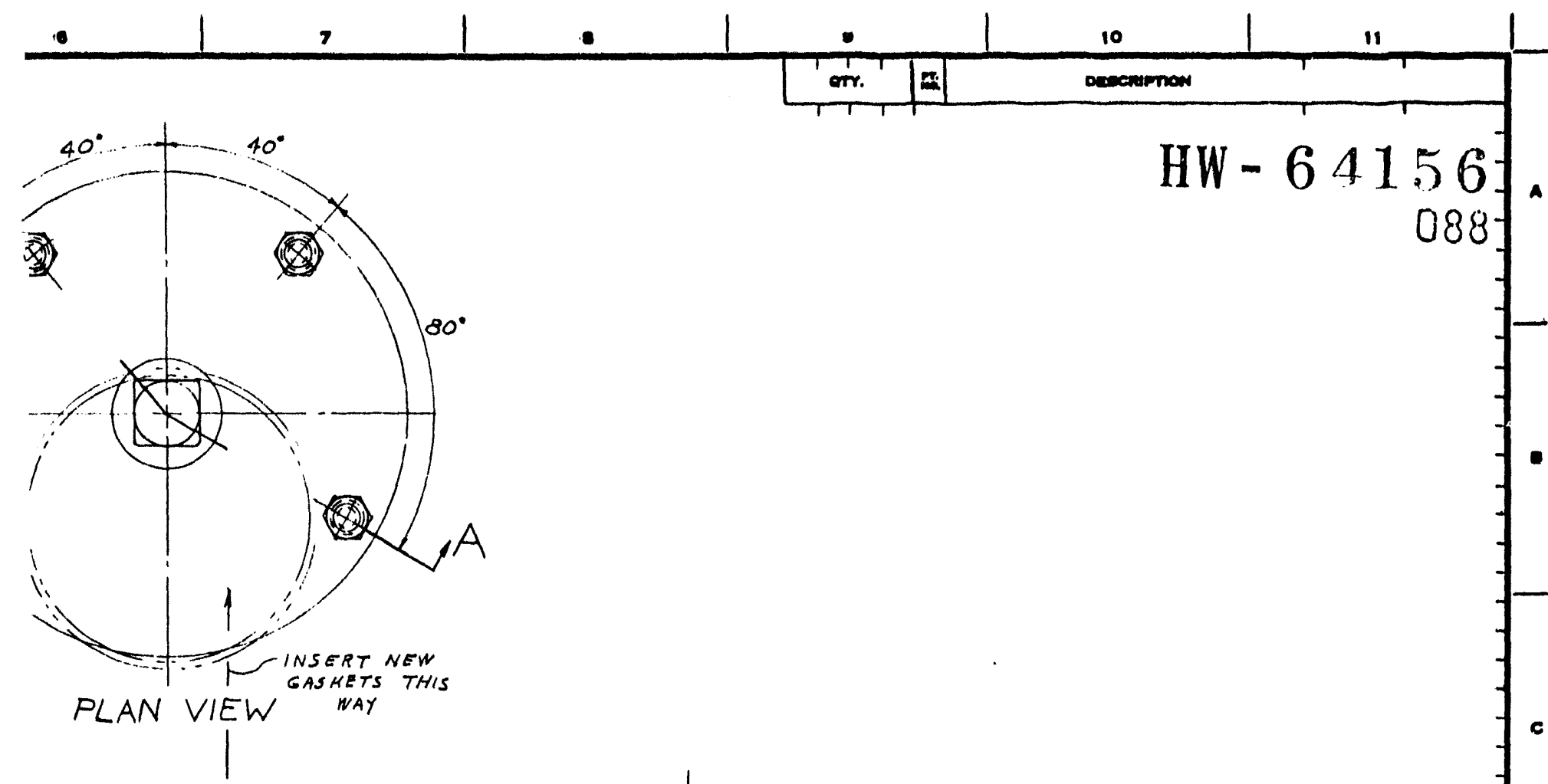

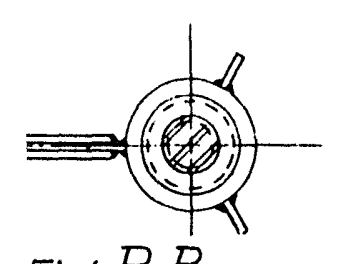

EW $B \cdot B$

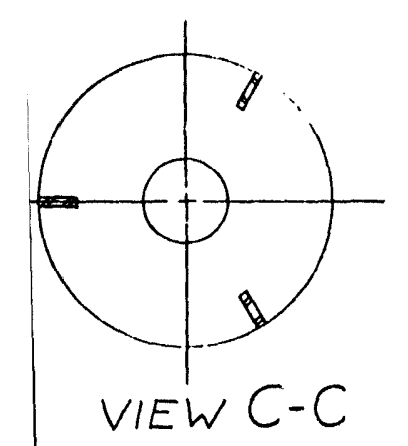

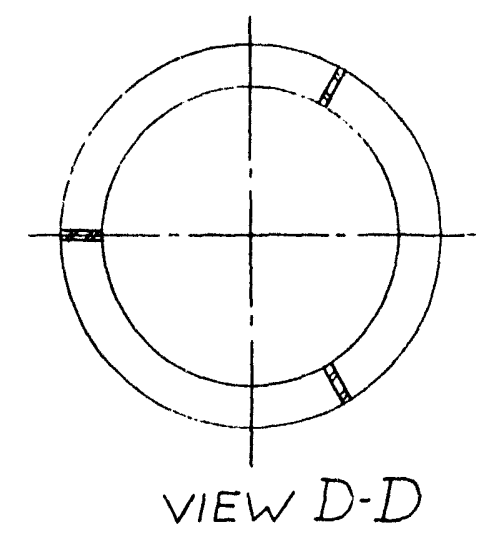

VIEW D-D

Joe roos
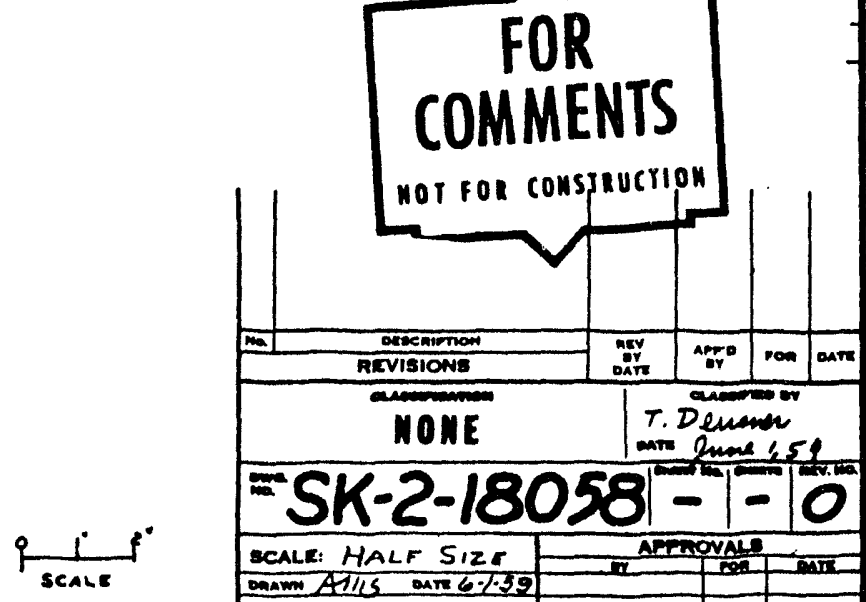

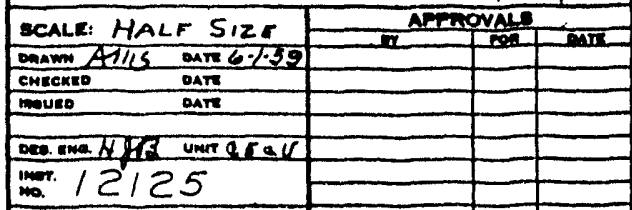

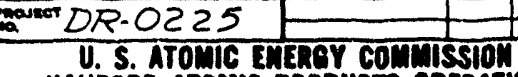
HAWFORD ATOMIC PRODUGTS OPERATION ozmenal Ellethie

GASKET DISPENSER STATION

Q 9 SCOPE

PROJ BUTTON LINE, RADIATION RED. $\frac{71 T 234-5 \quad 1 \mathrm{~L}-4701}{2}$

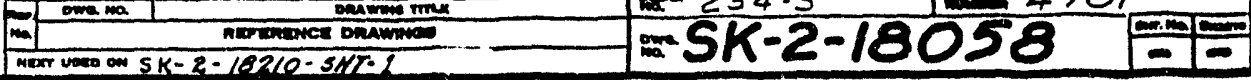




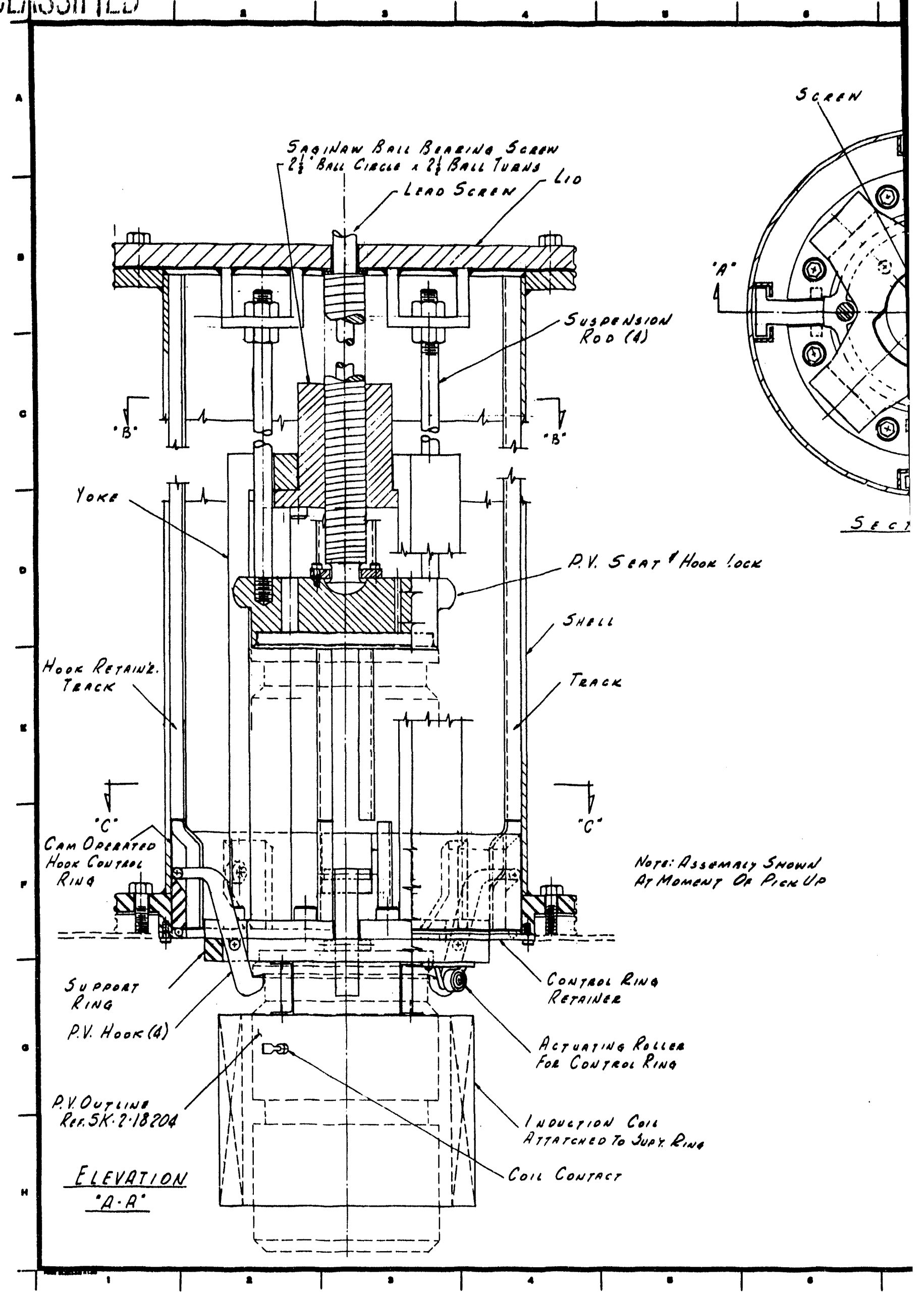



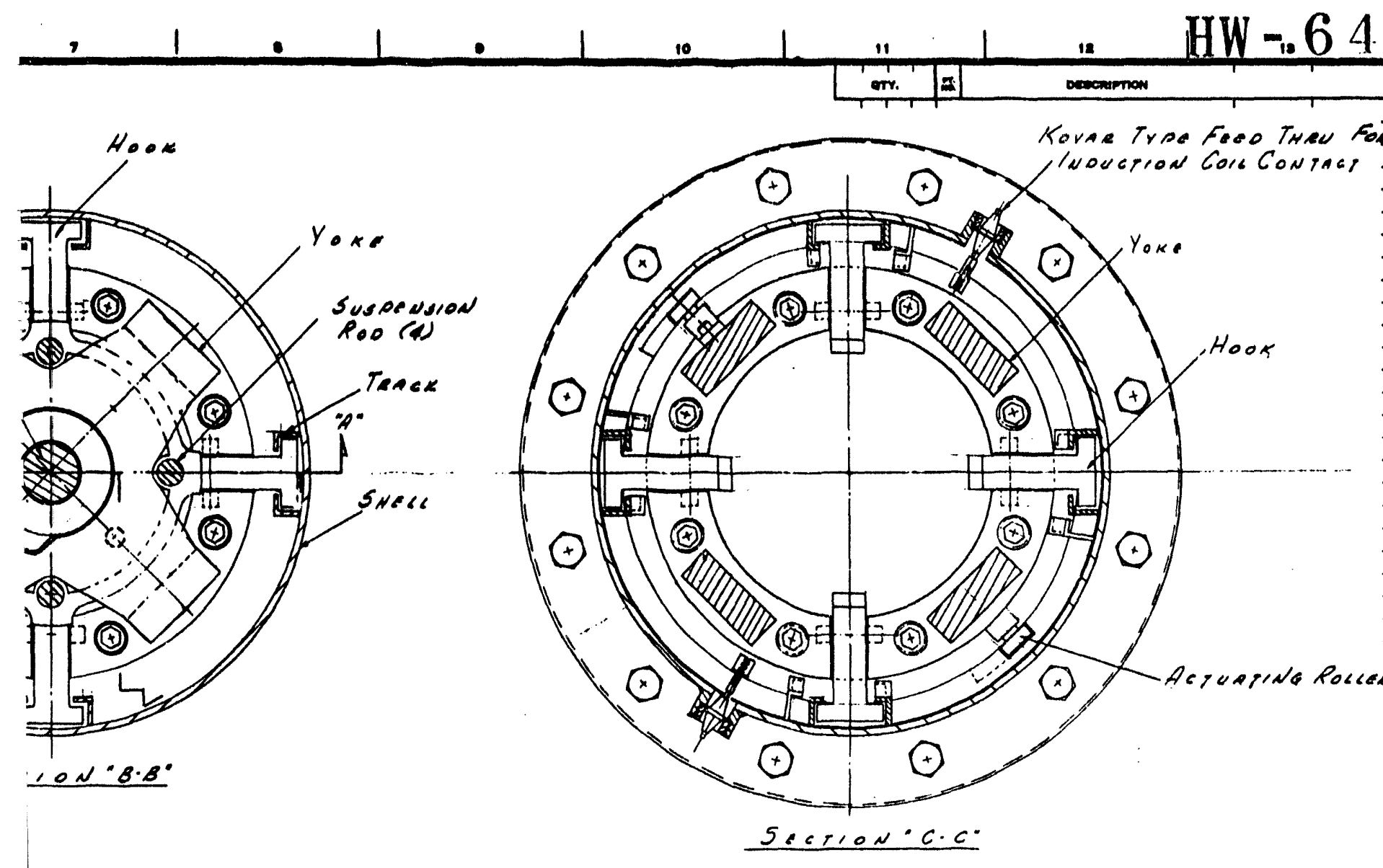

089
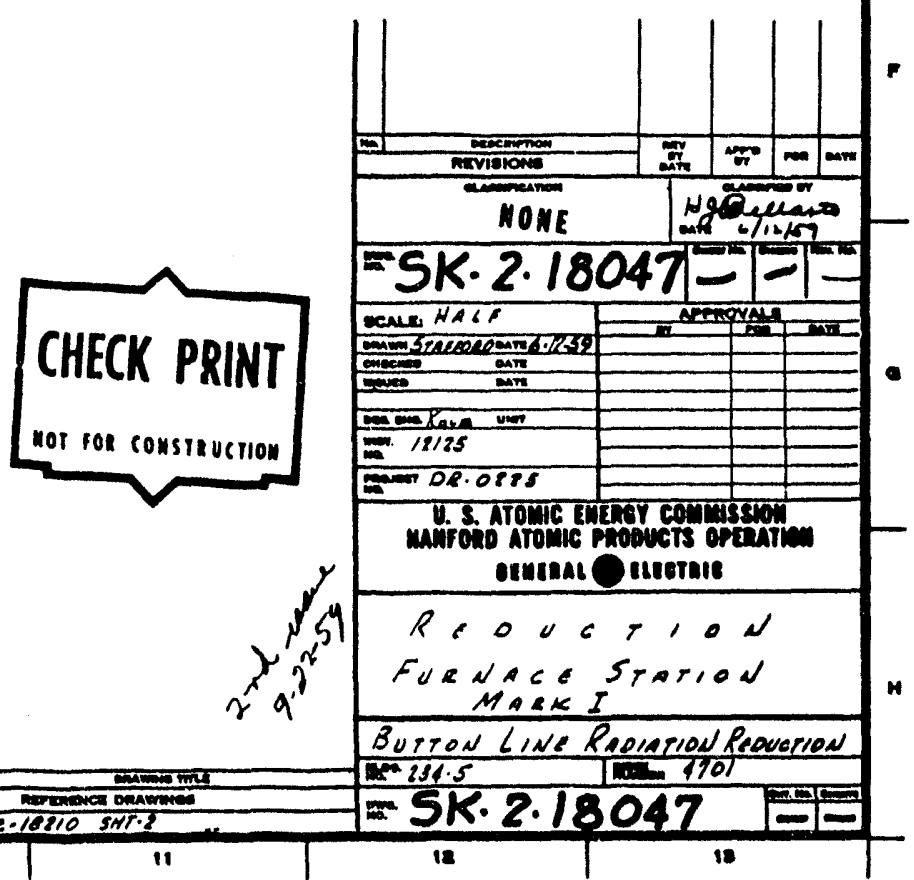

-SK.2.18047 $=$ 
Unutromition

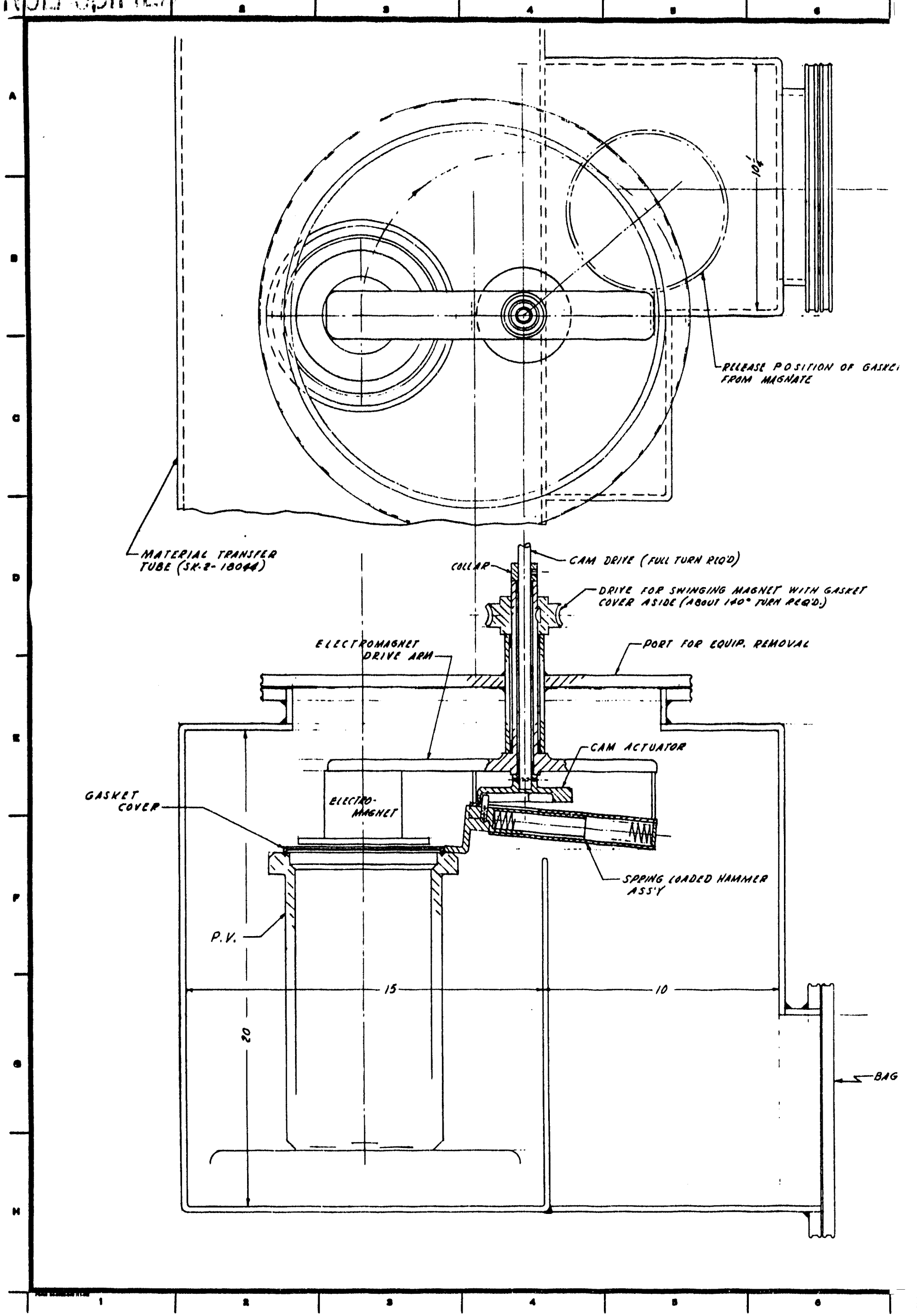




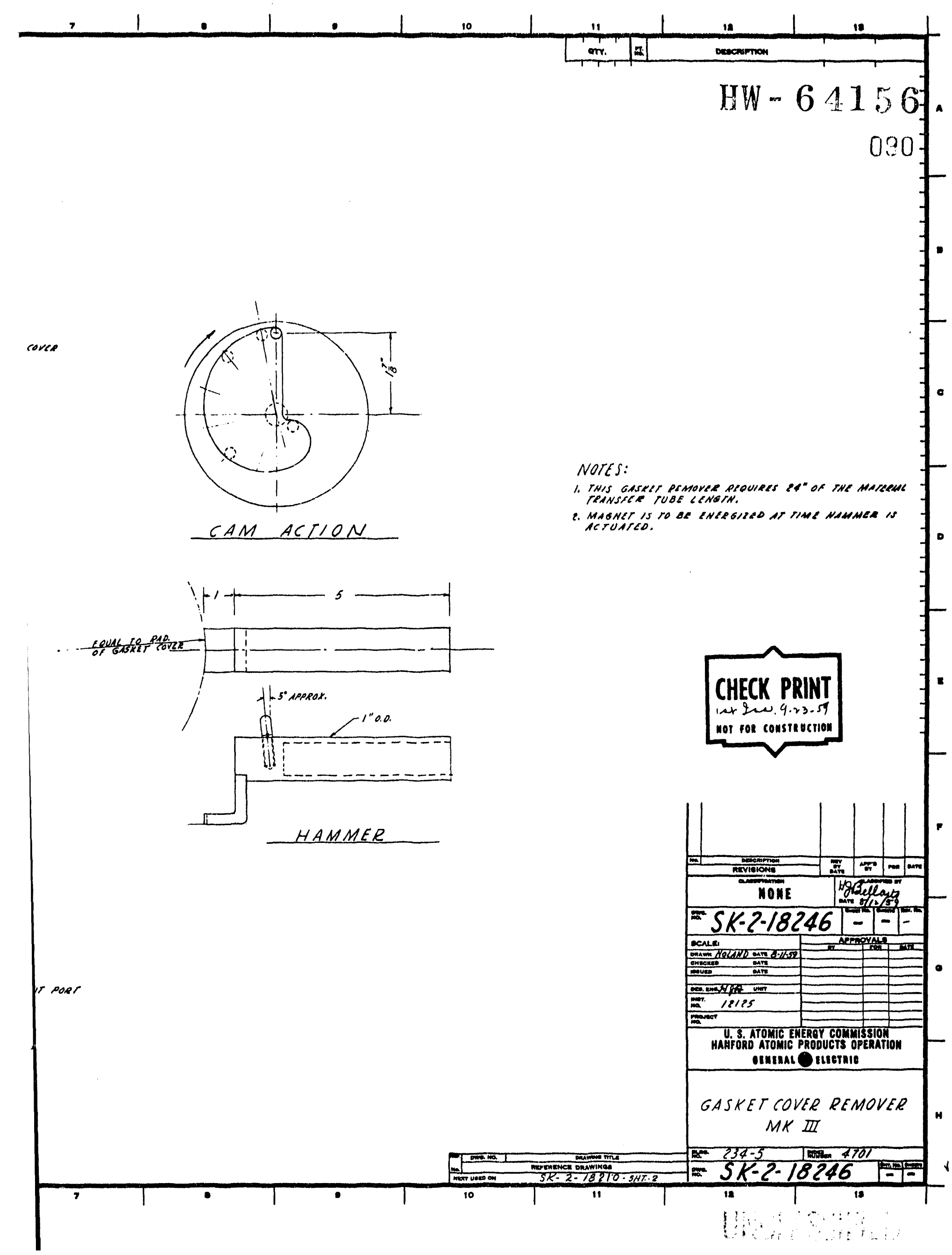




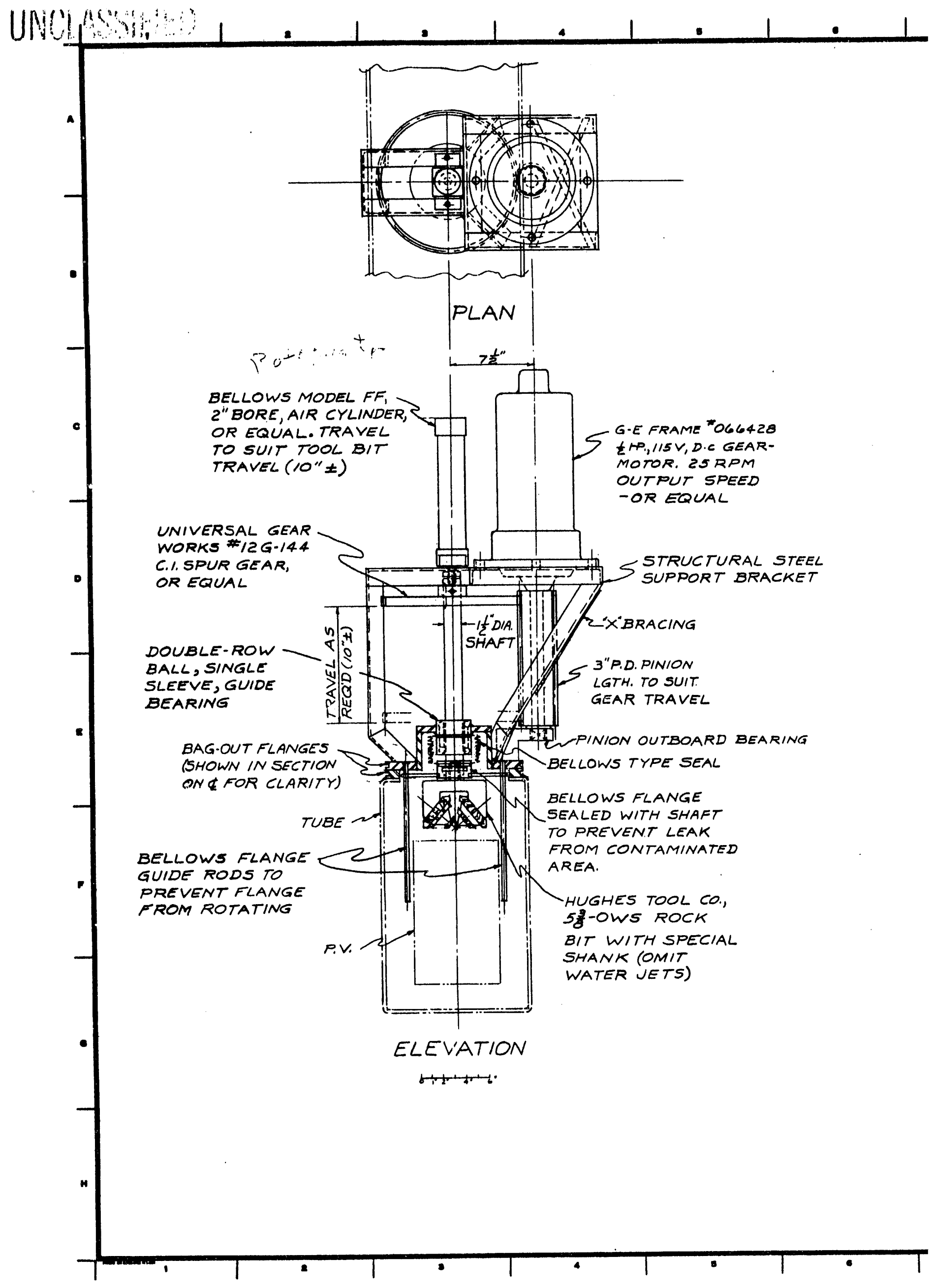




$+1.1 .1$

10

.

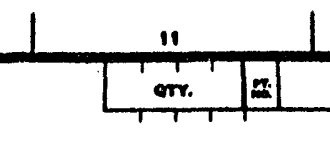

$\mathrm{HW}-64156$

091
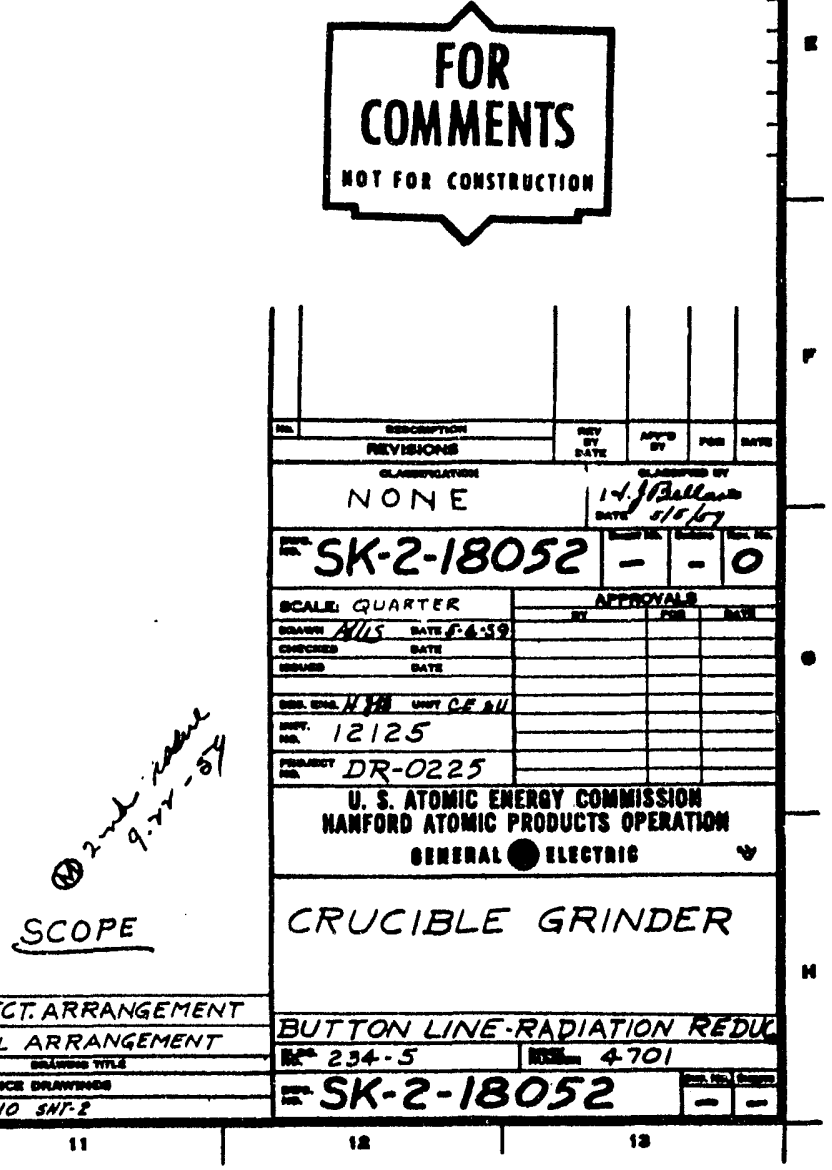

SK.2.18039 ARCHITECT. ARRANGEMENT \begin{tabular}{|l|l}
\hline SK.2.17972 GENERAL ARRANGEMENT \\
\hline
\end{tabular}

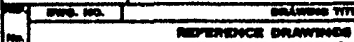




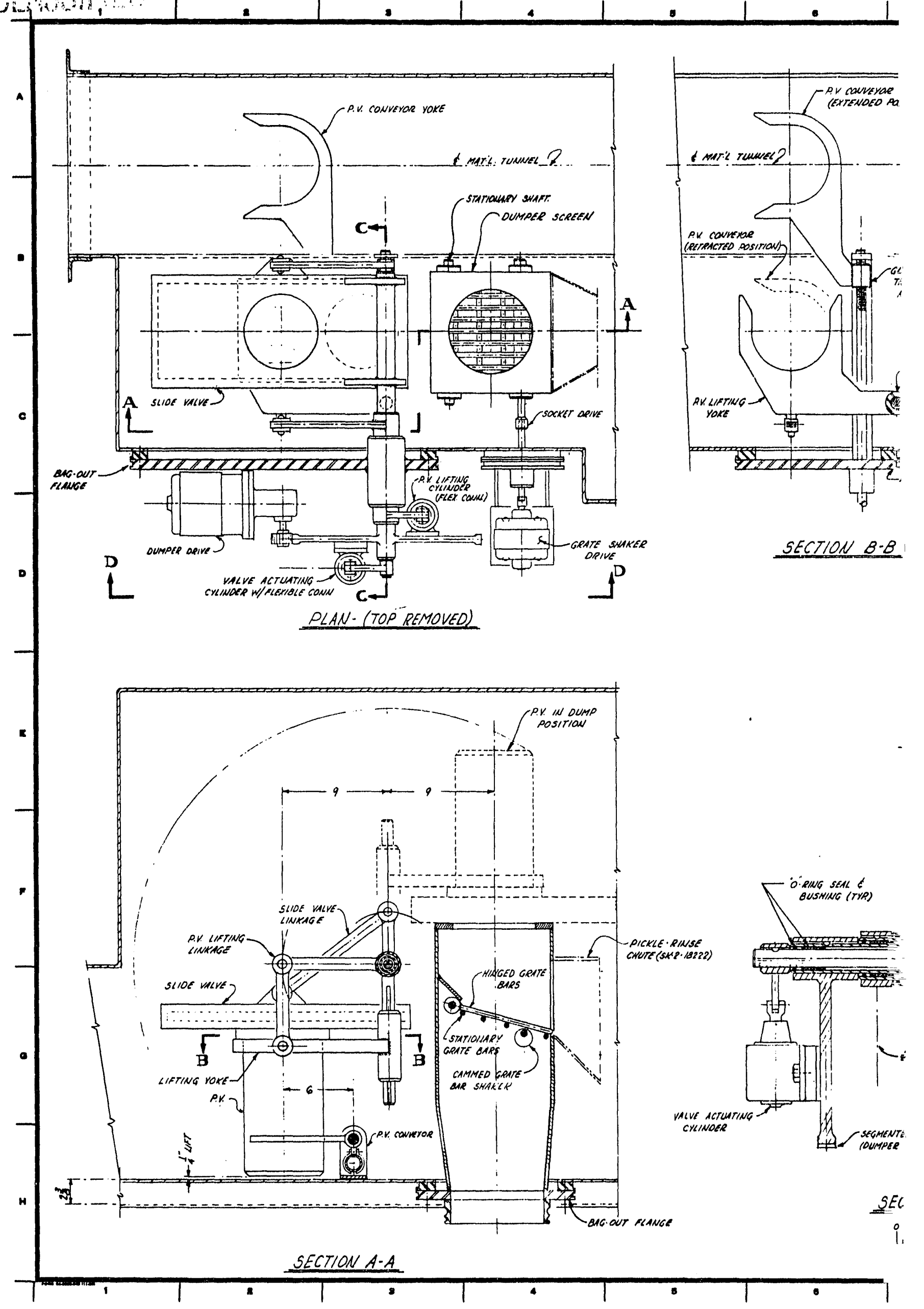




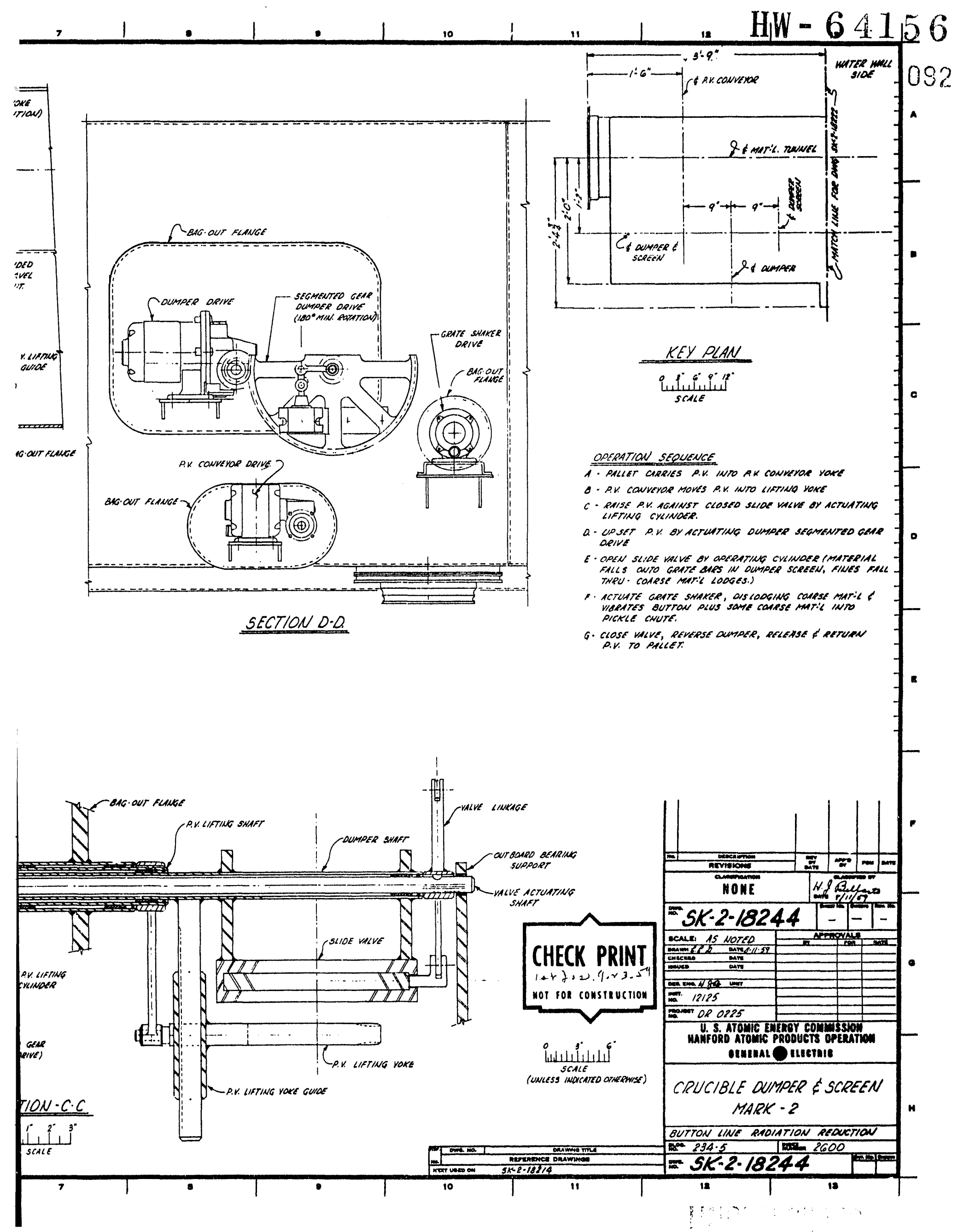




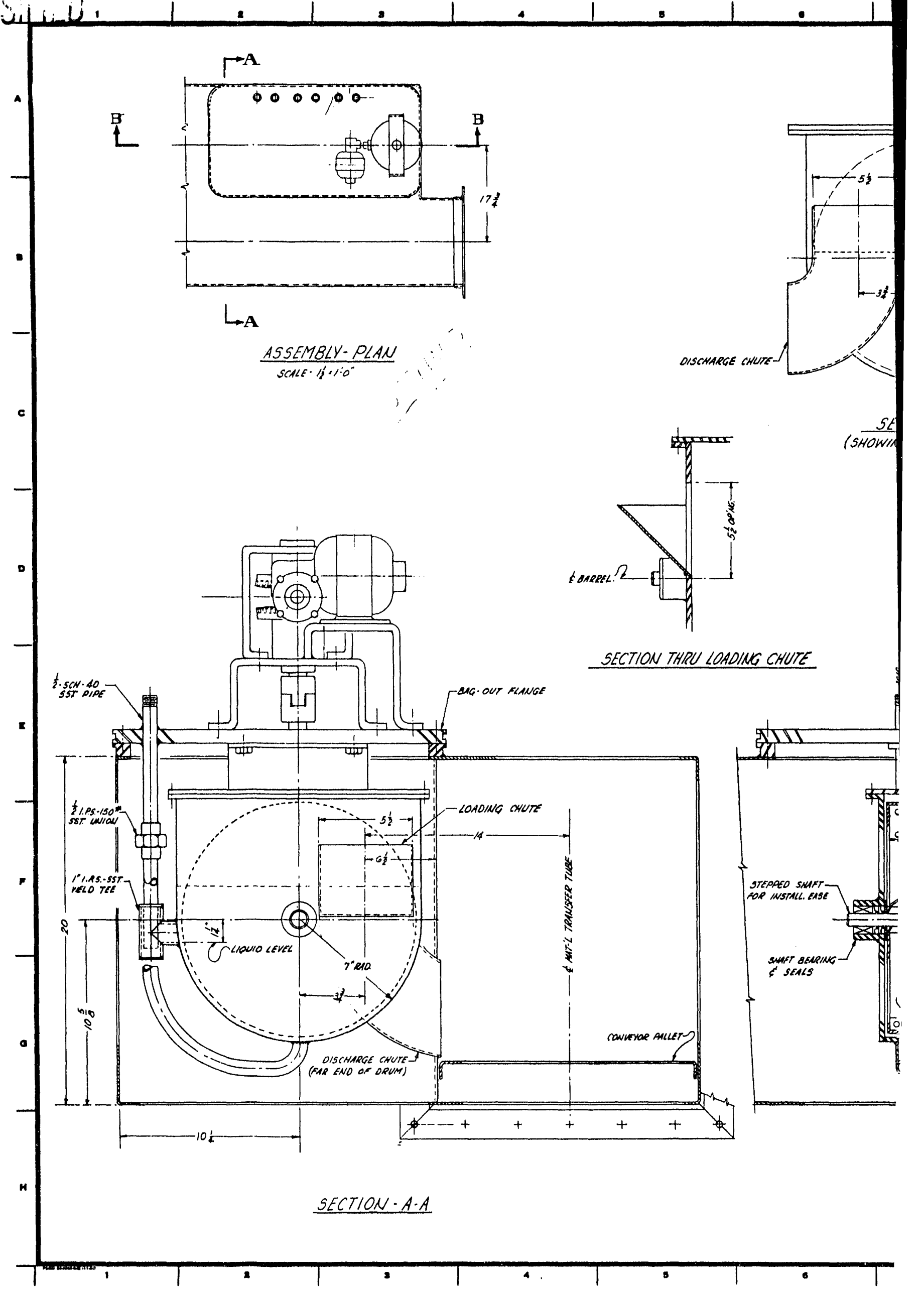



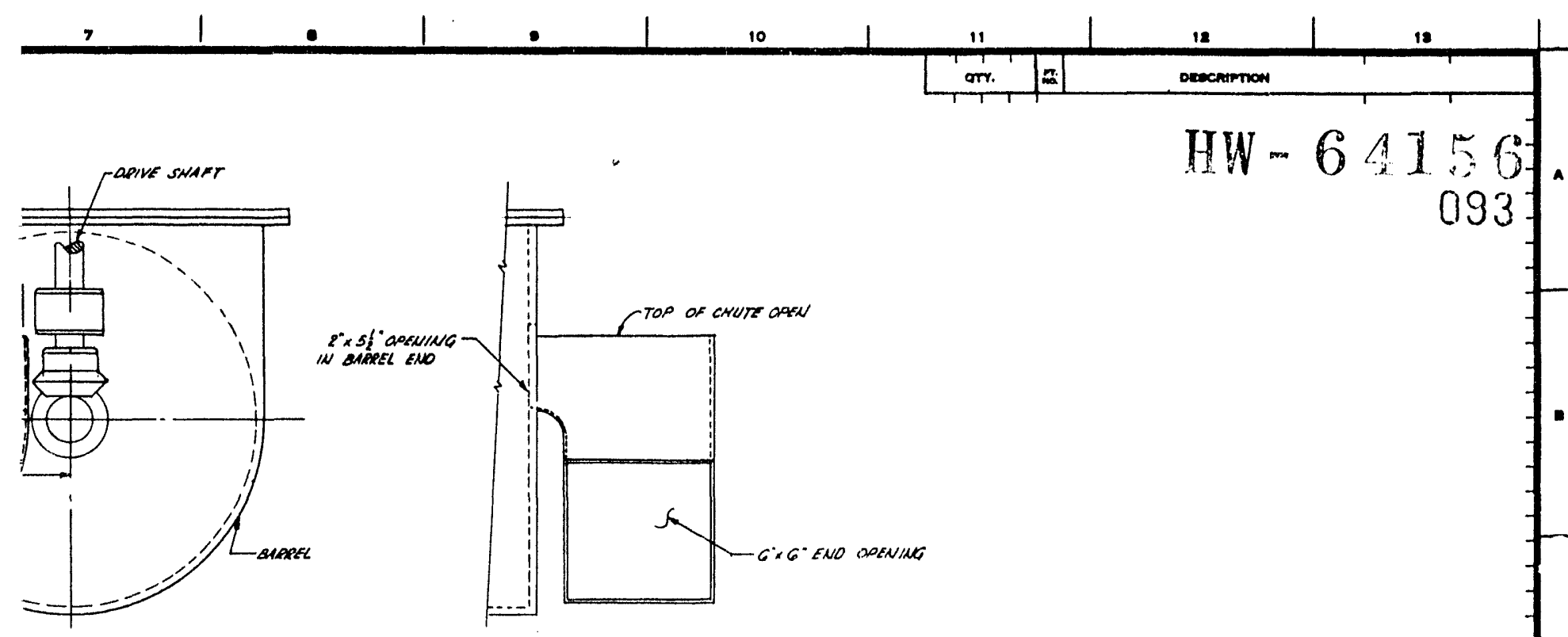

$H W-641560^{\circ}$

STION C.C

'G DISCHARGE CHUTE)

END VIEW-DISCHARGE CHUTE

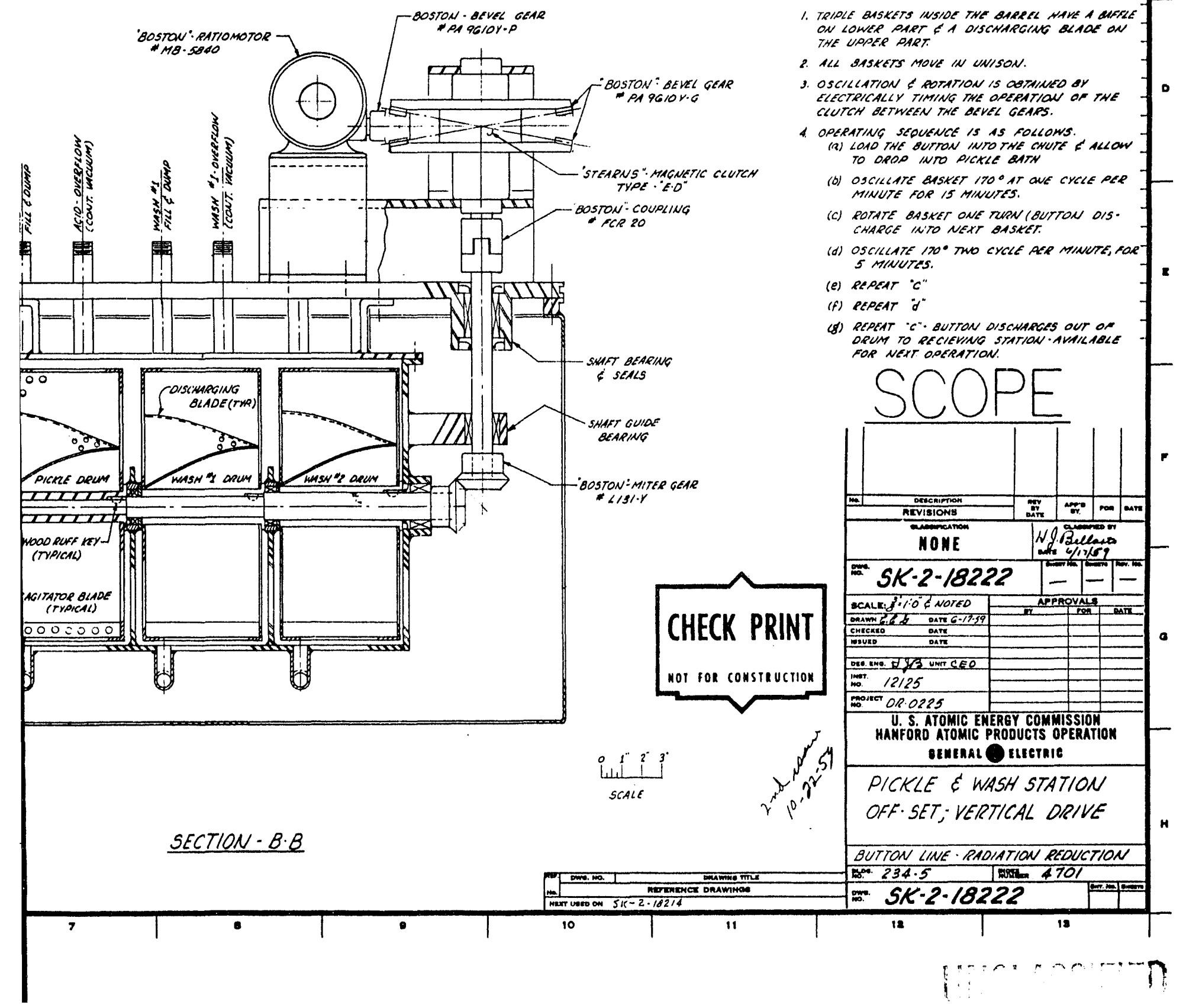




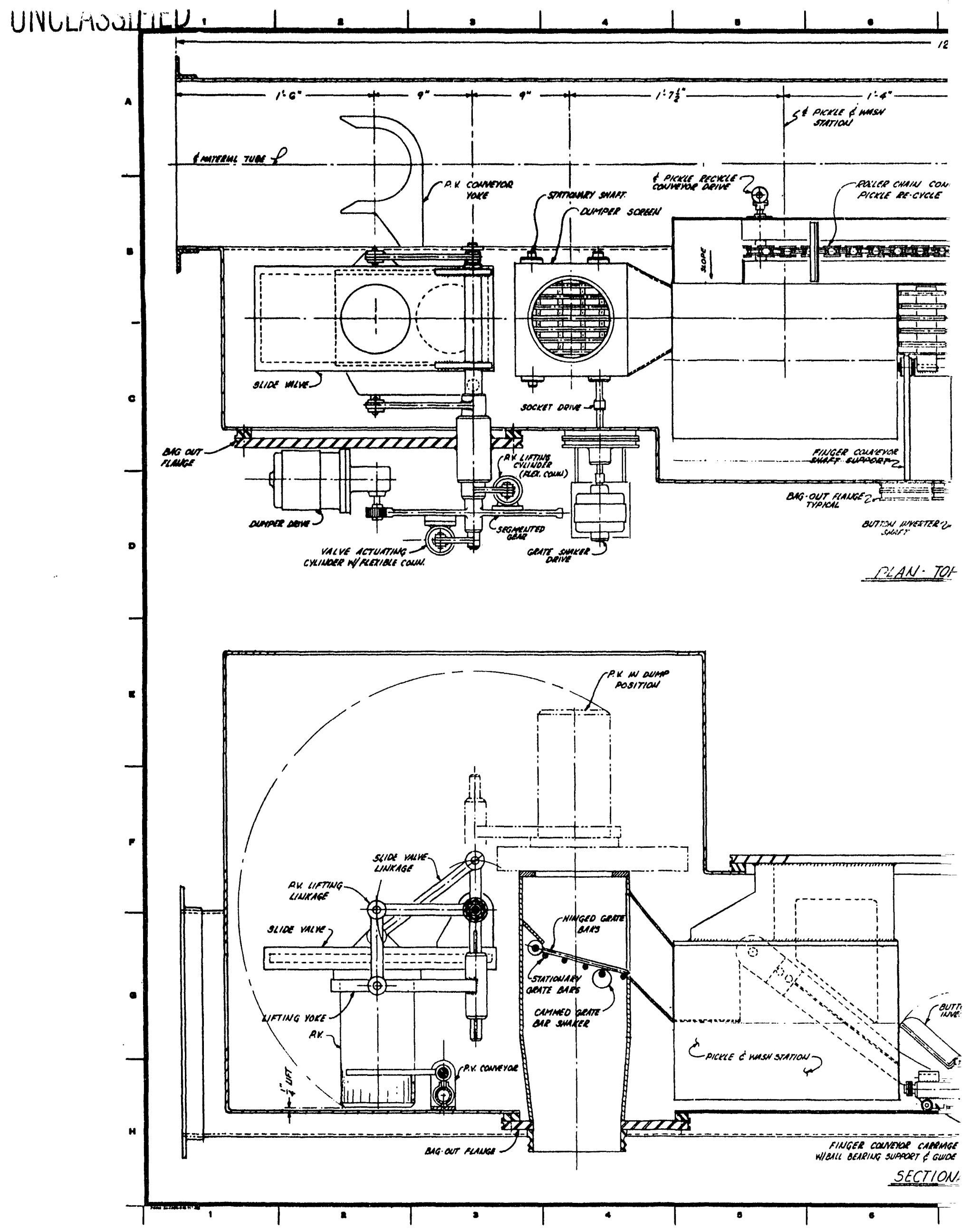




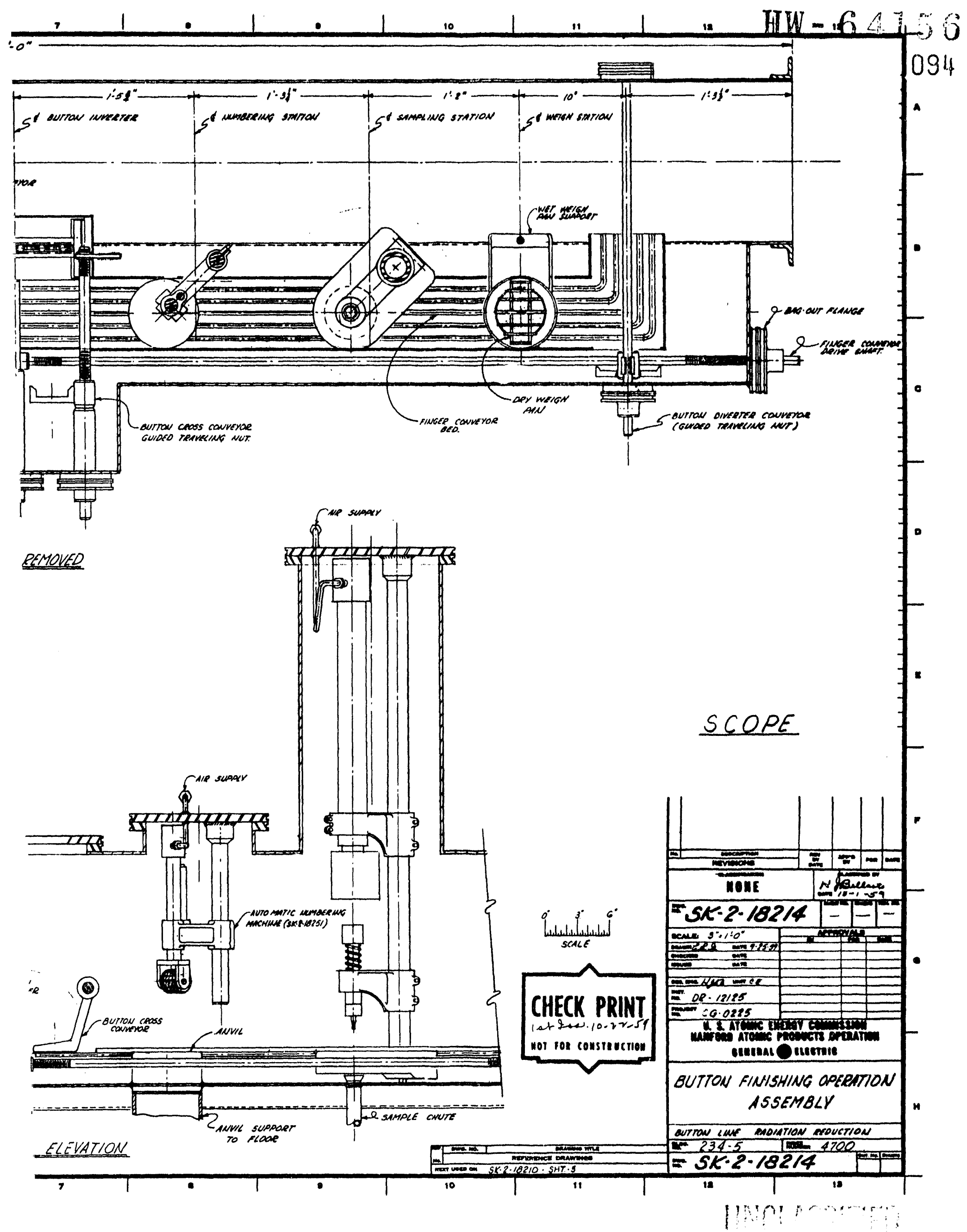




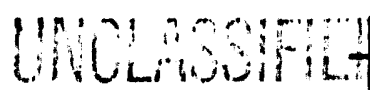

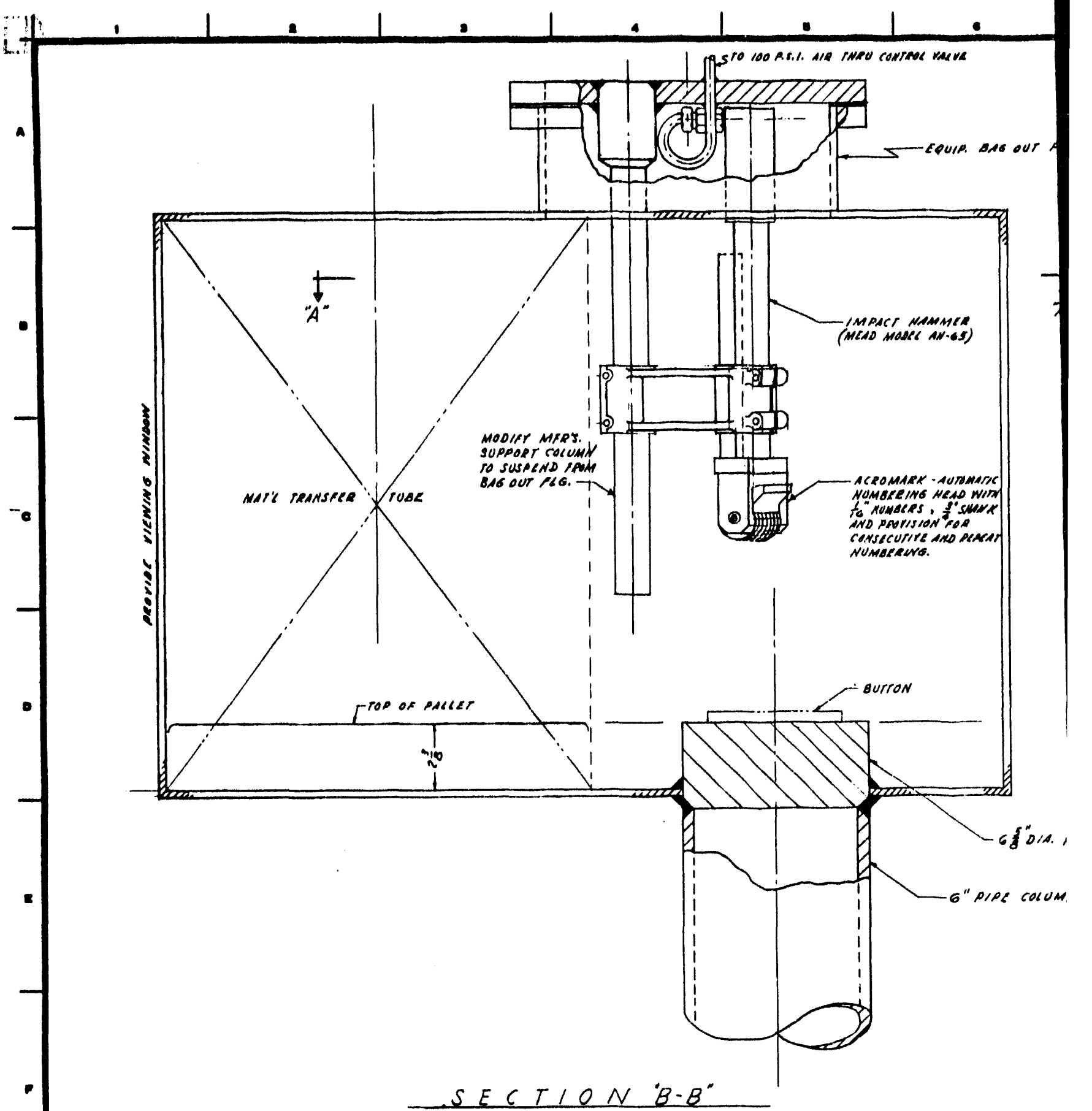

H

-

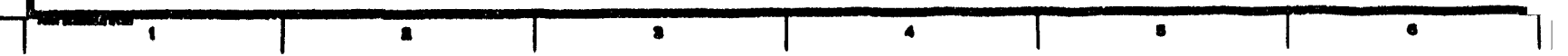




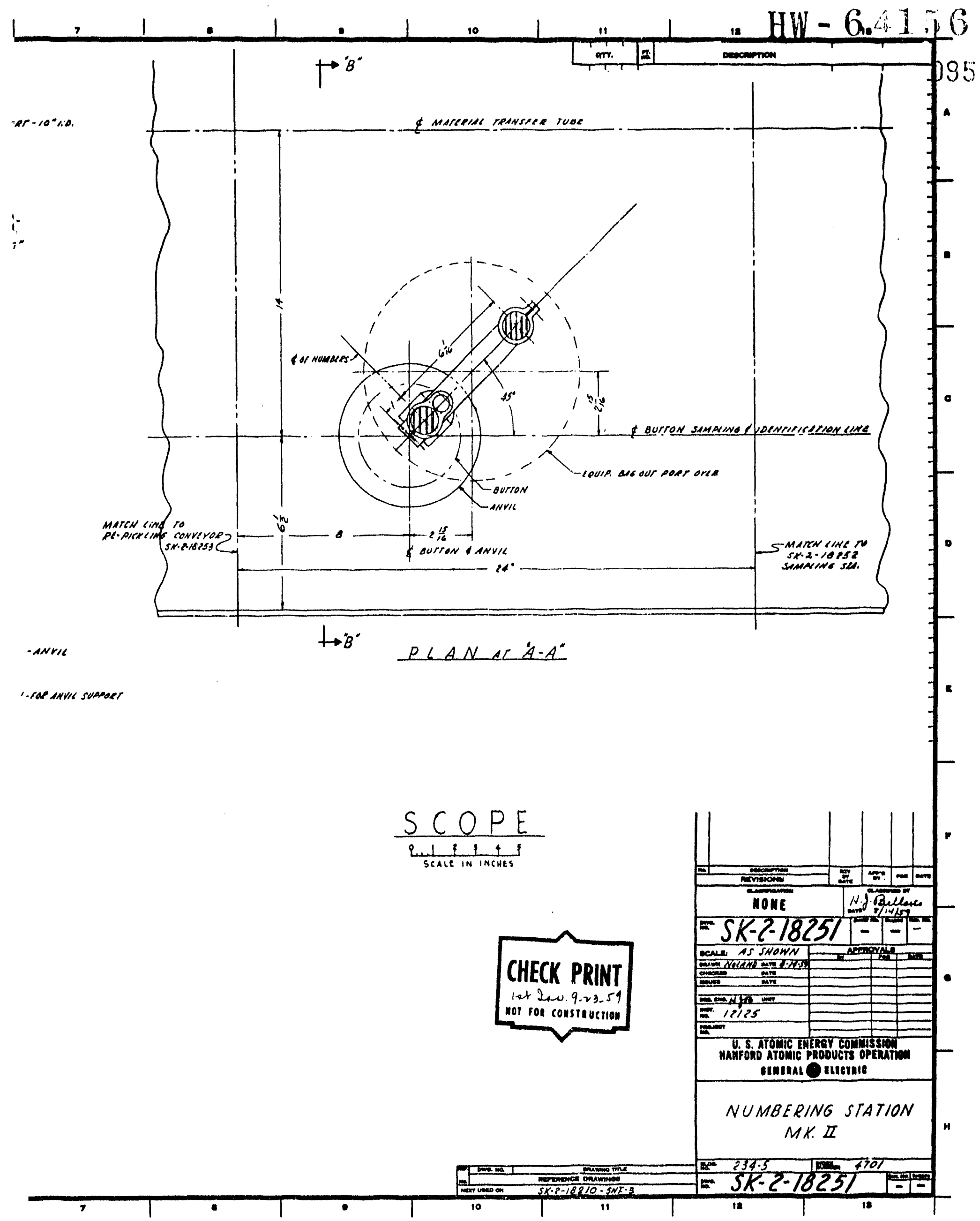


UNCI ROLIO

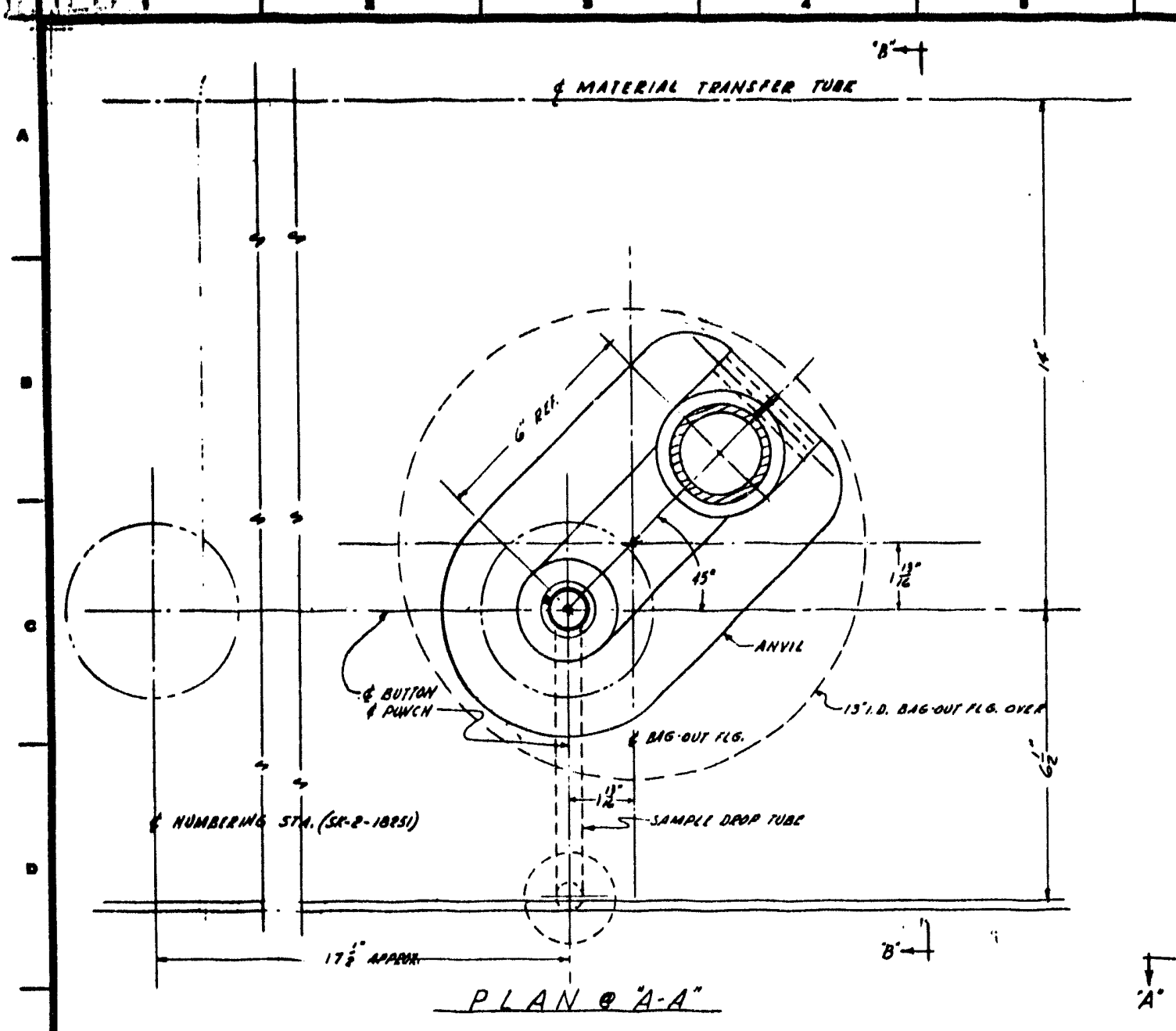

INPACI HAMNLE (NCAD MODL AN.95)
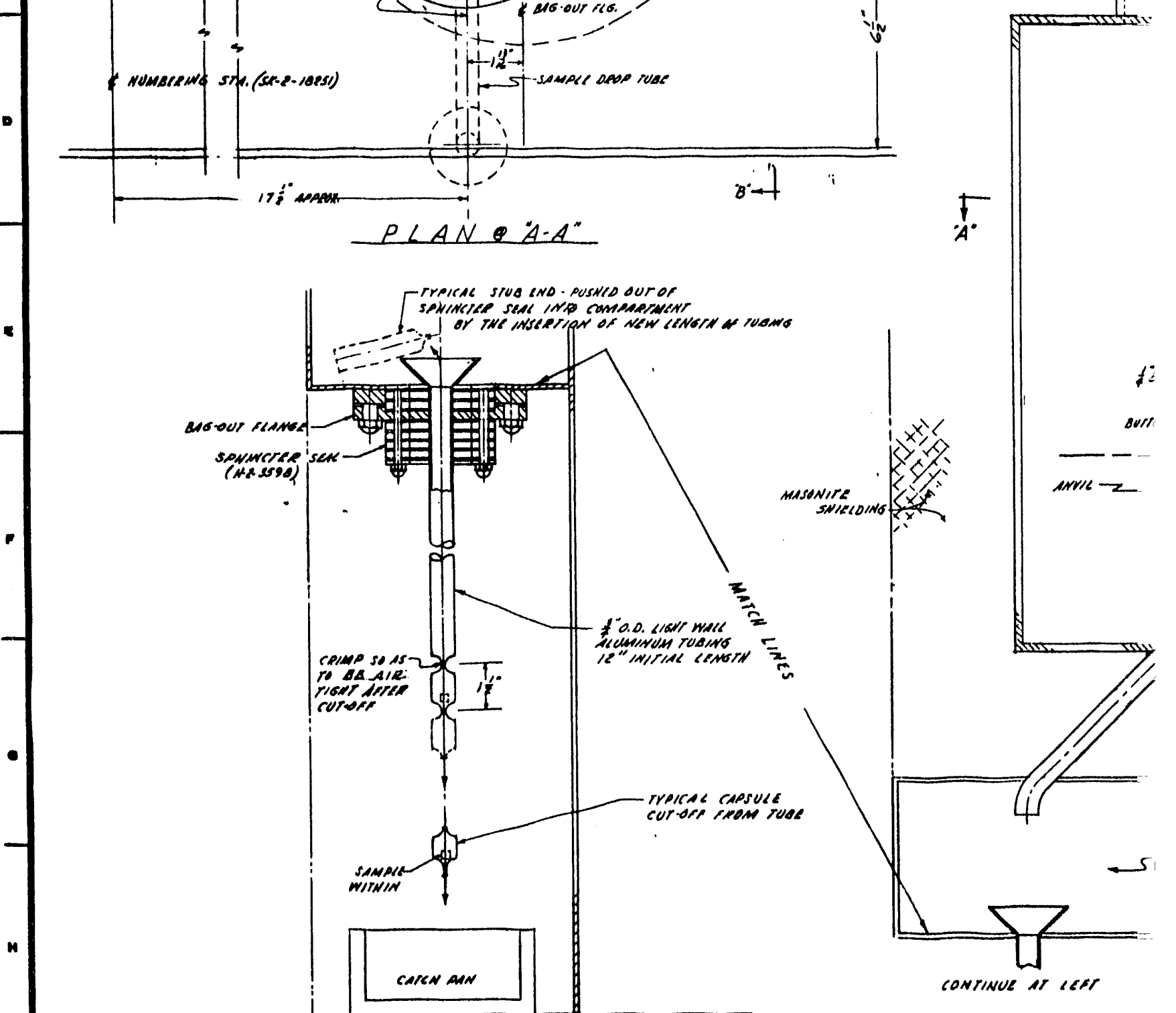

CONTINUE AT ILAP

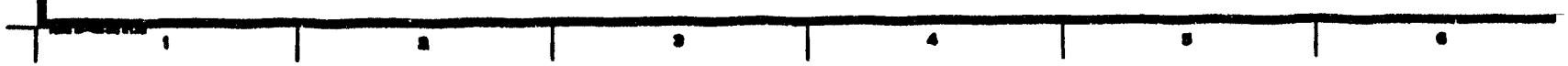




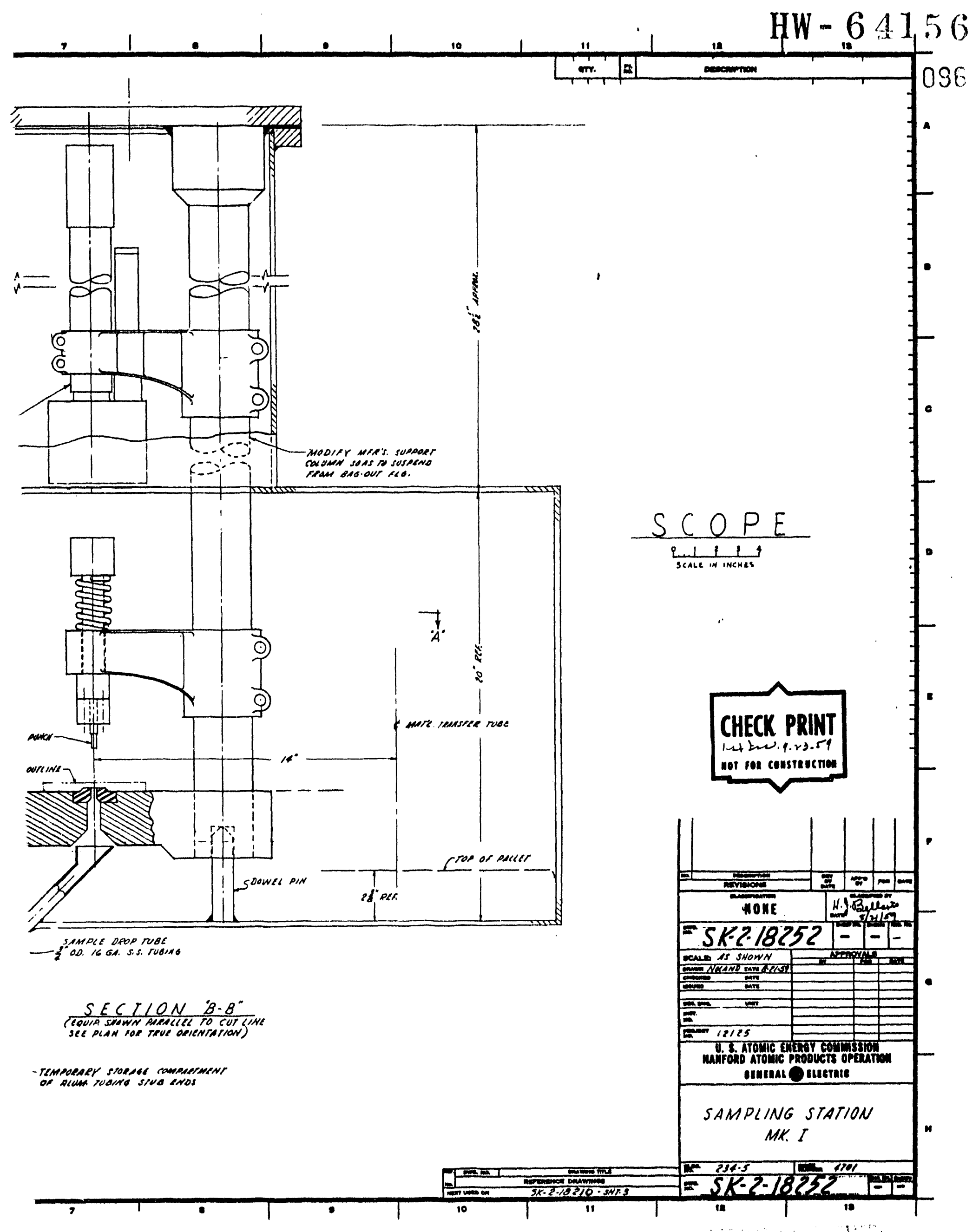




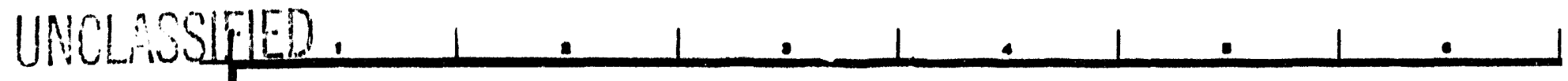

a

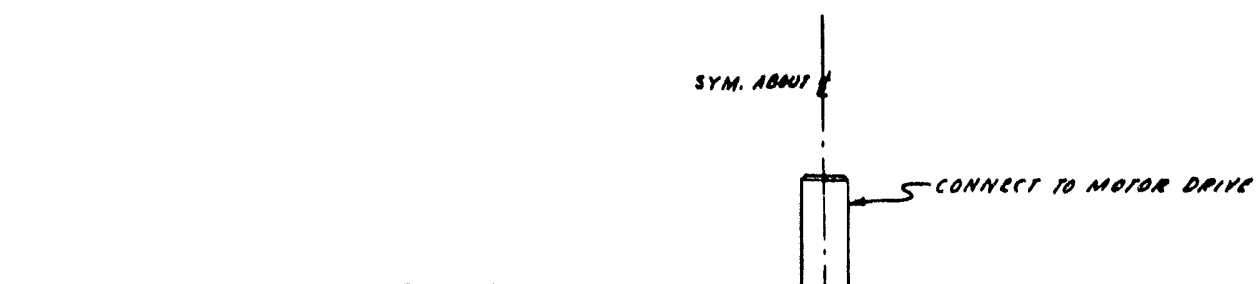

$\checkmark$

n

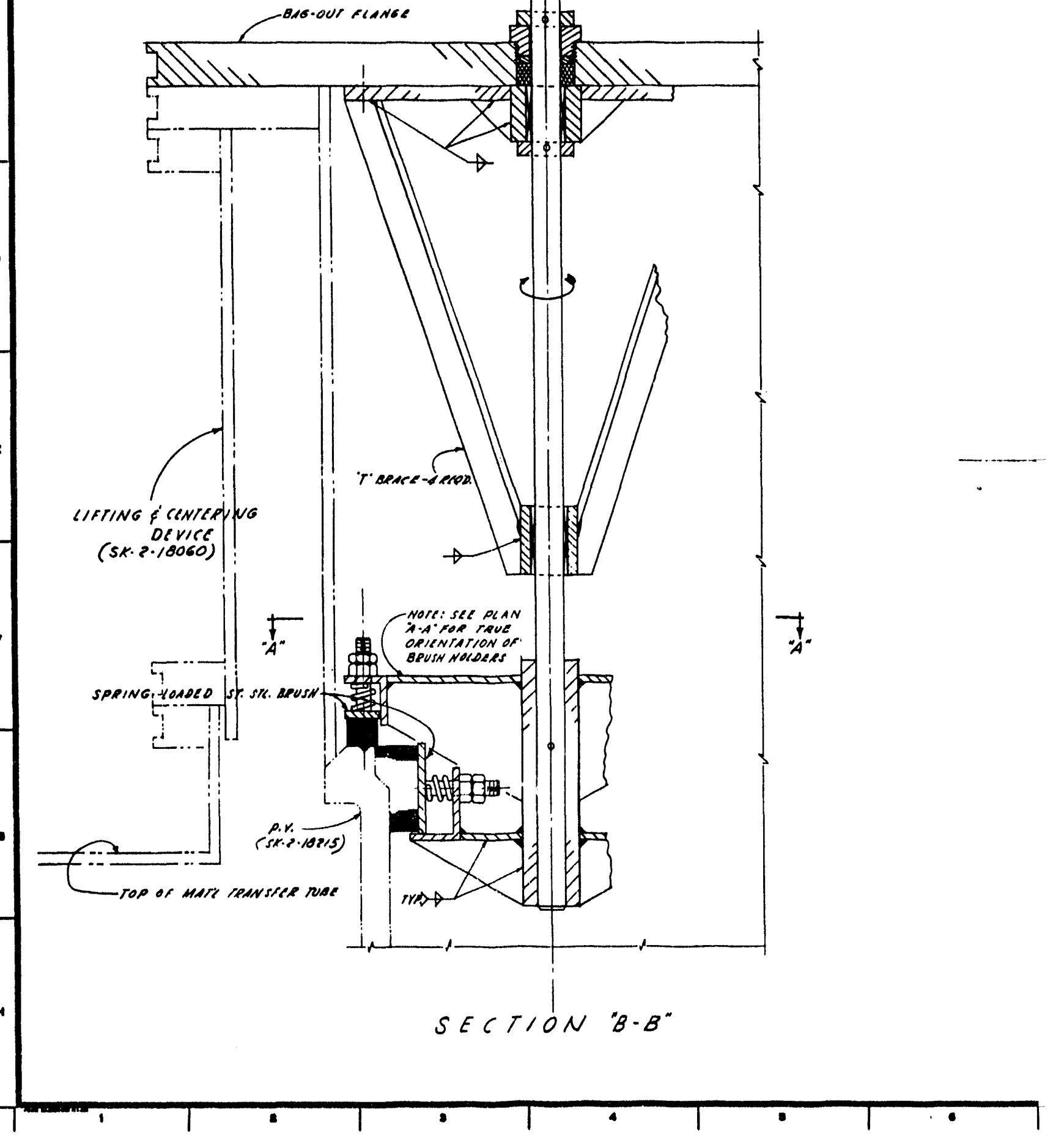



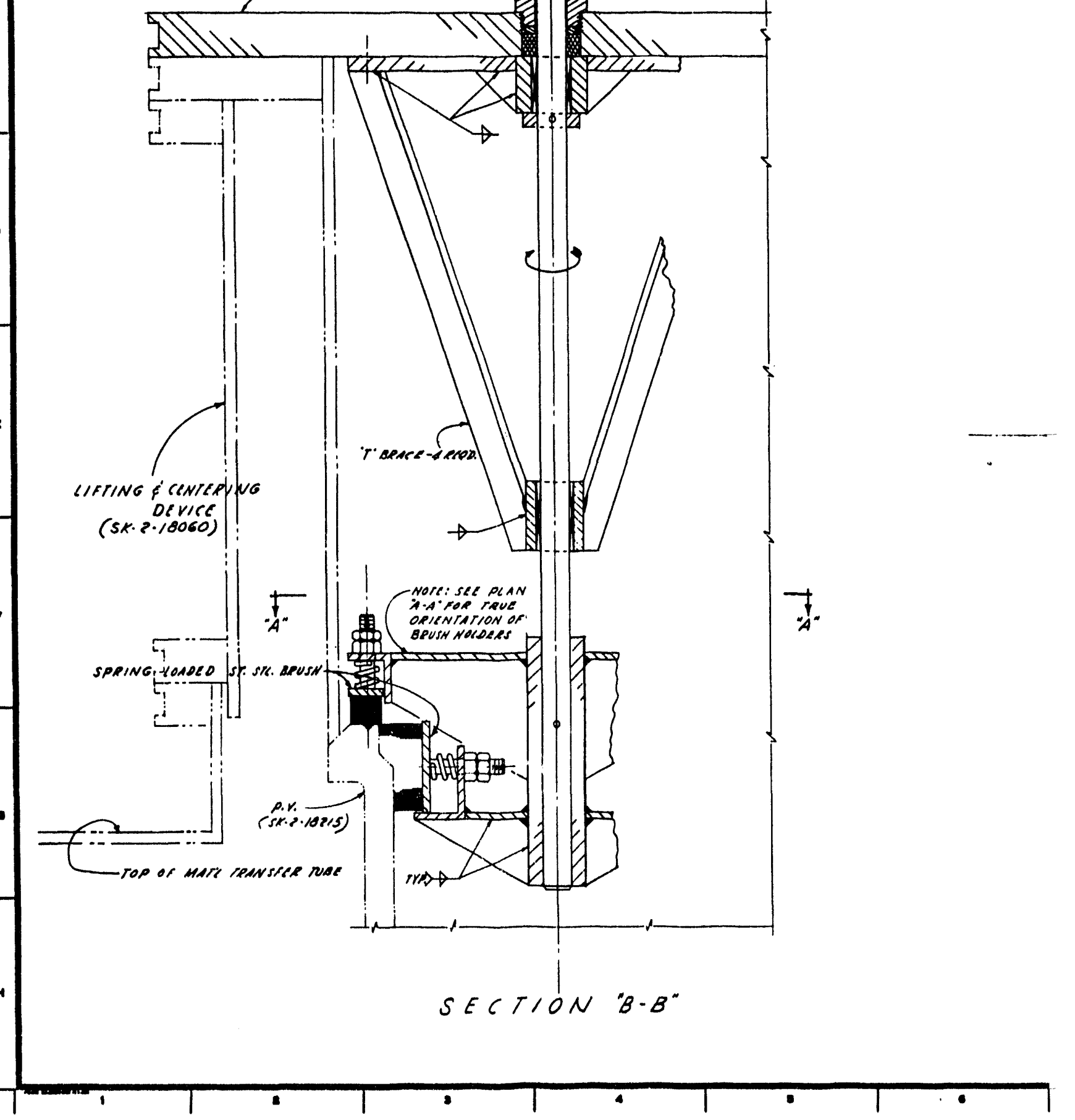

$$
\text { . }
$$

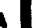

7 

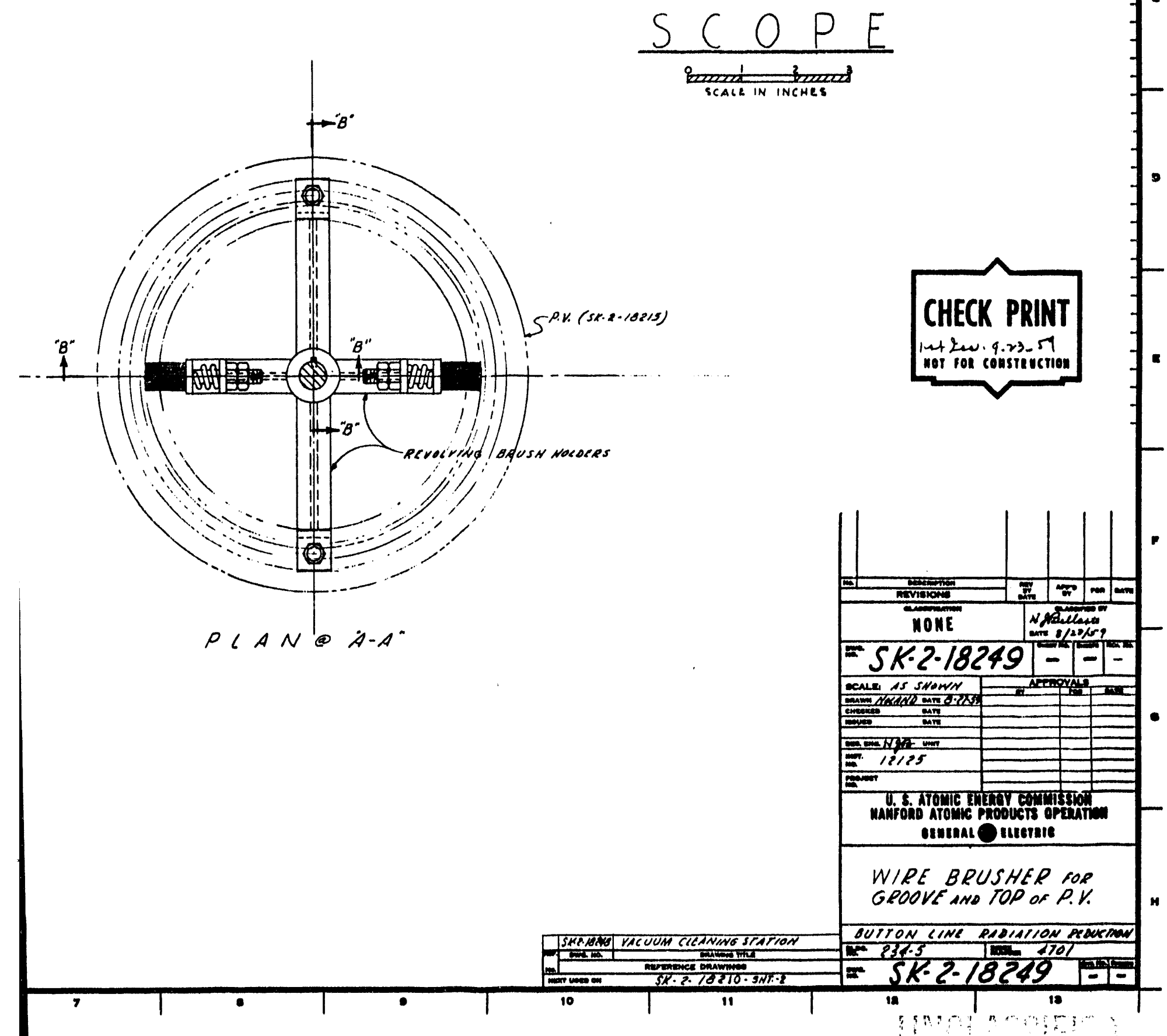


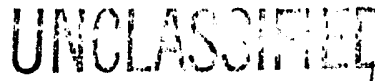

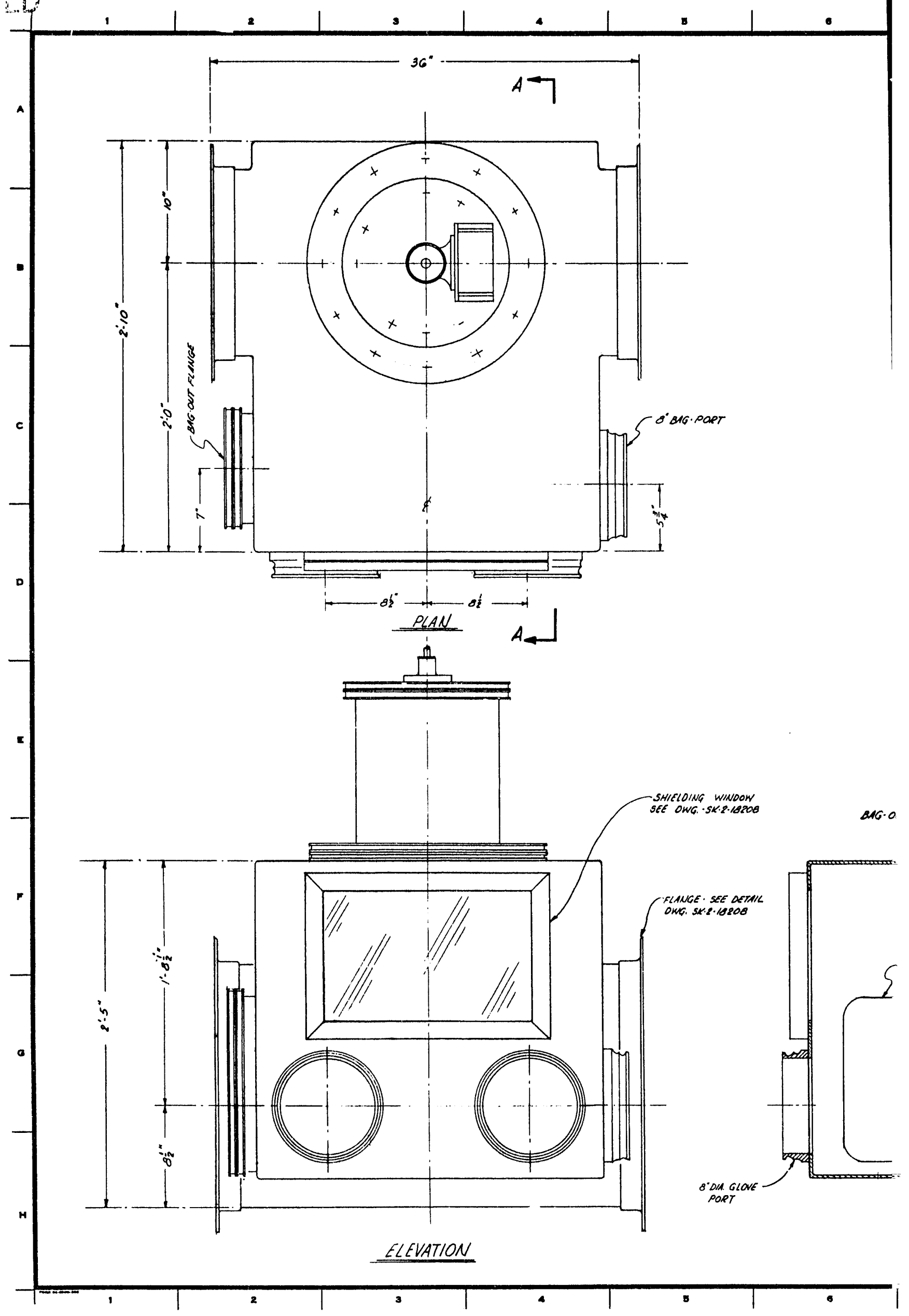


UNCLASSERED

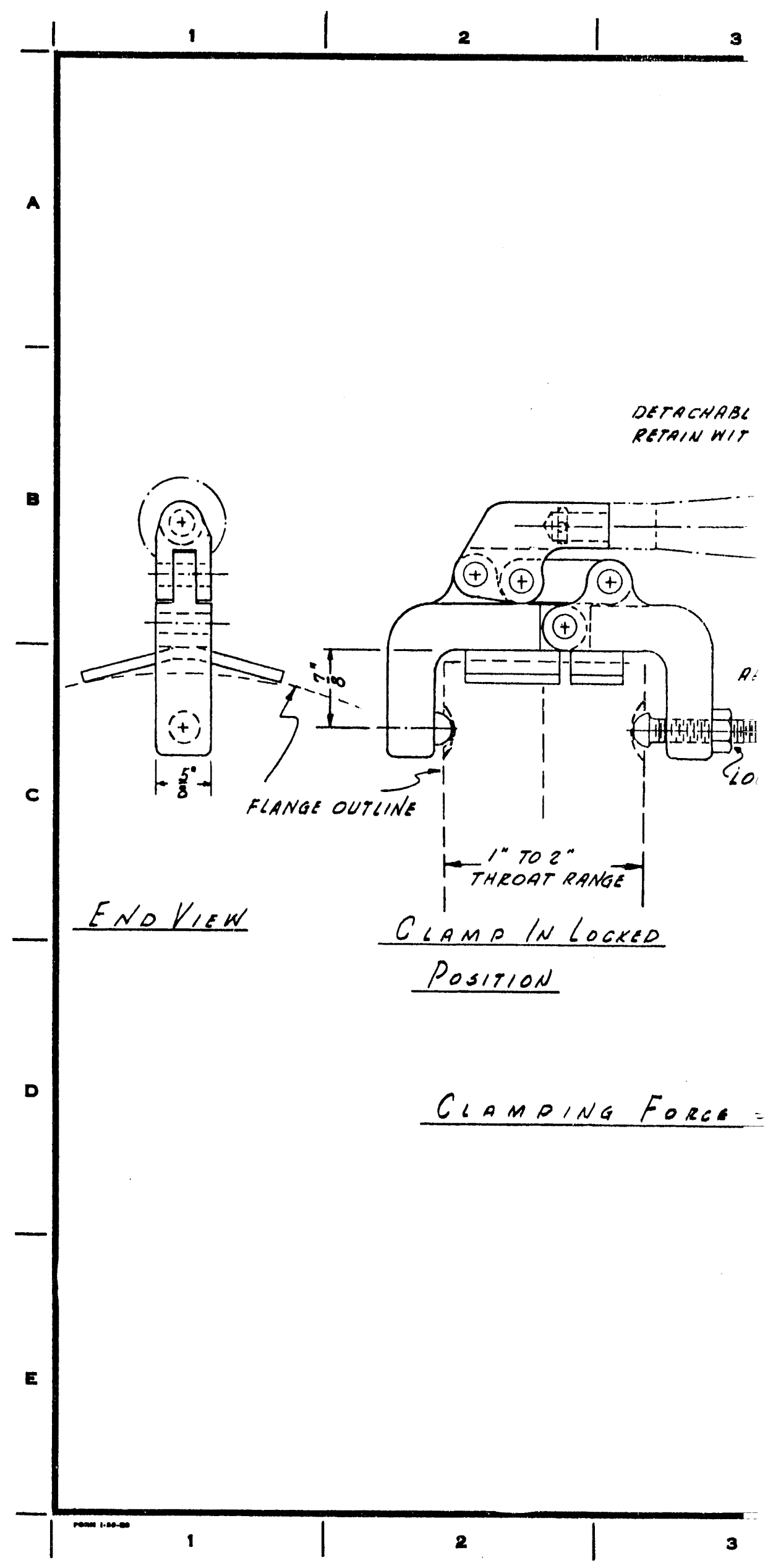




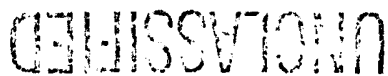

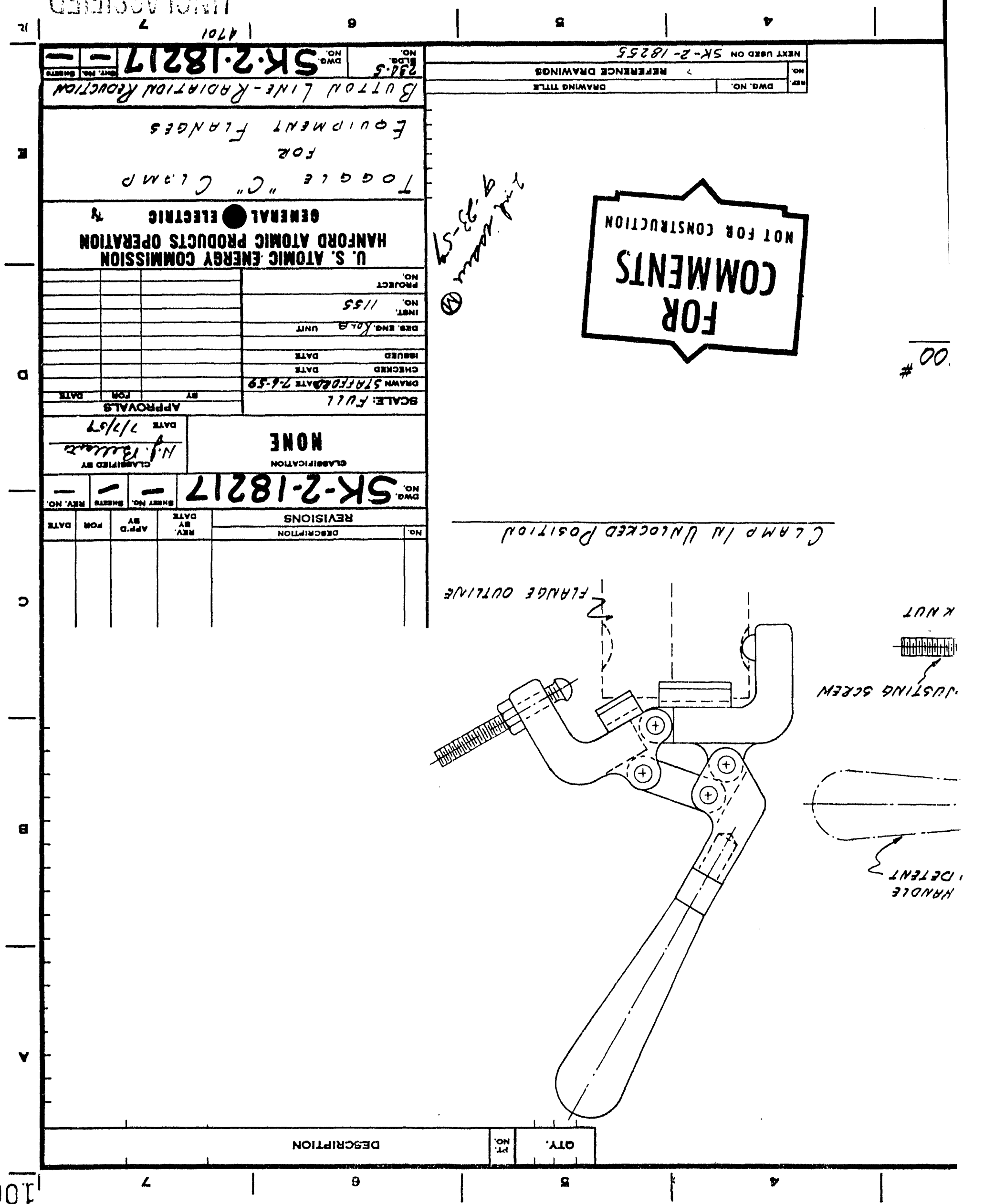

$9-\operatorname{ID} 9-\mathrm{MH}$ 


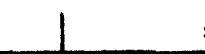

$\checkmark$
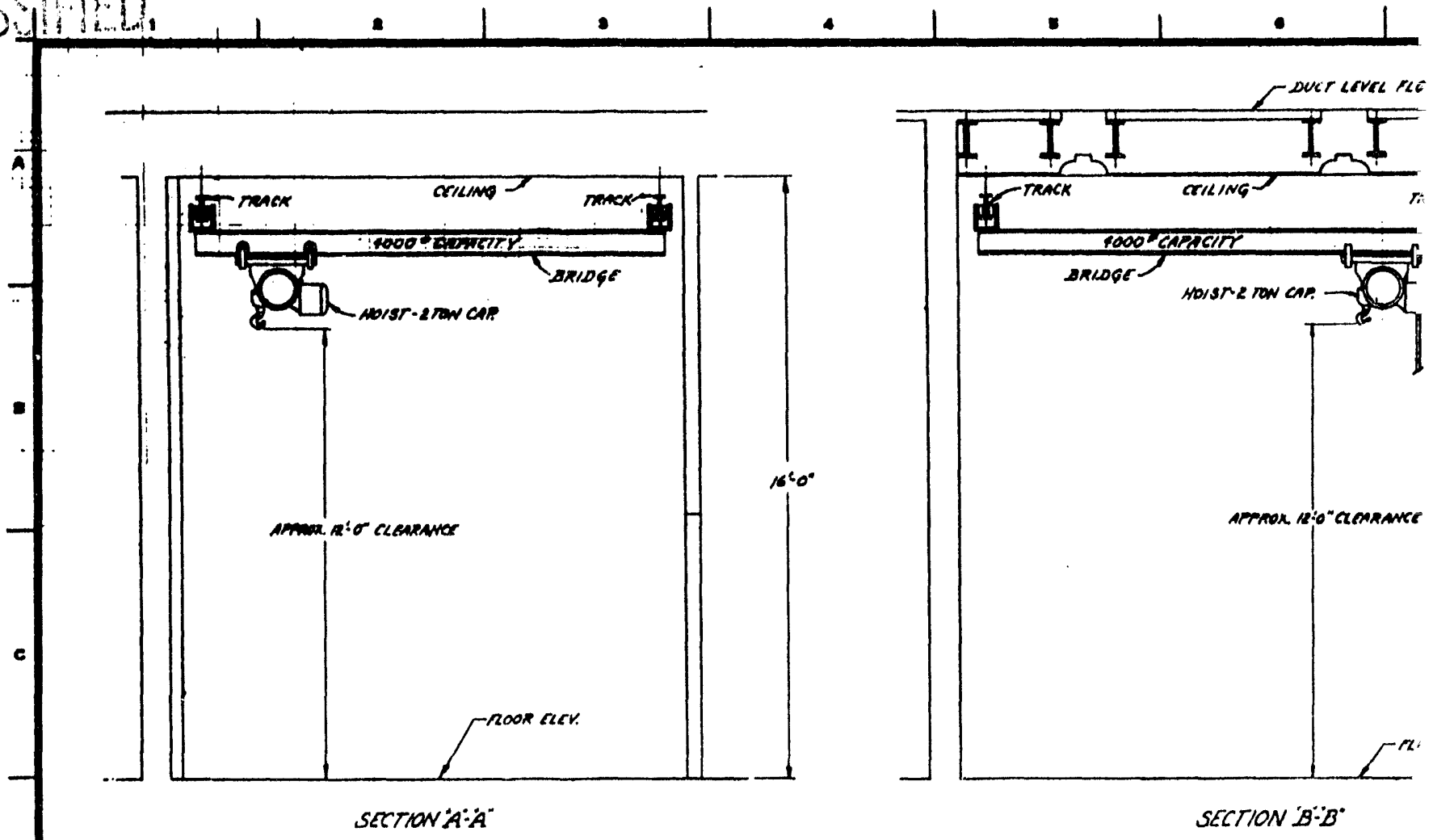

-

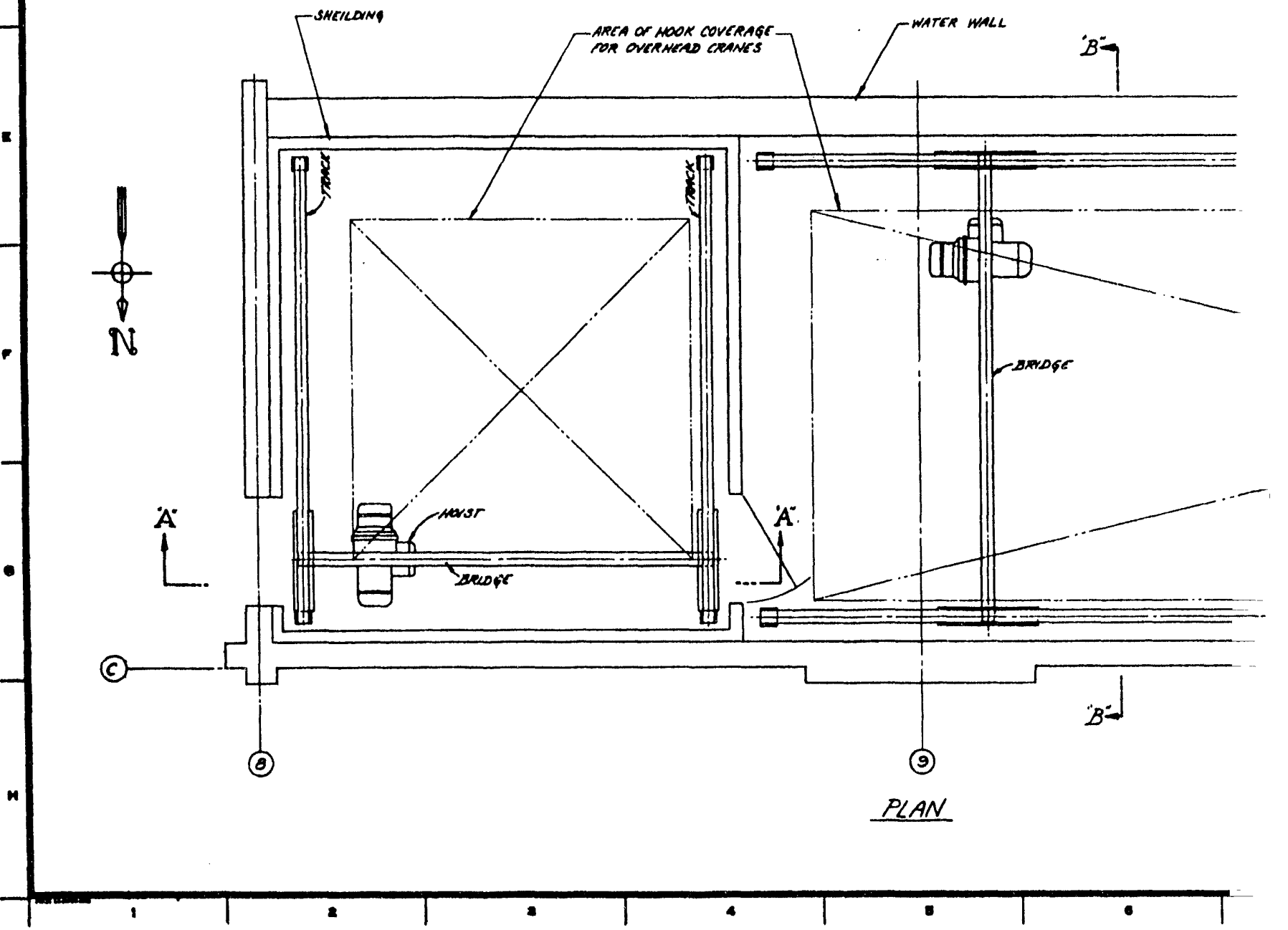




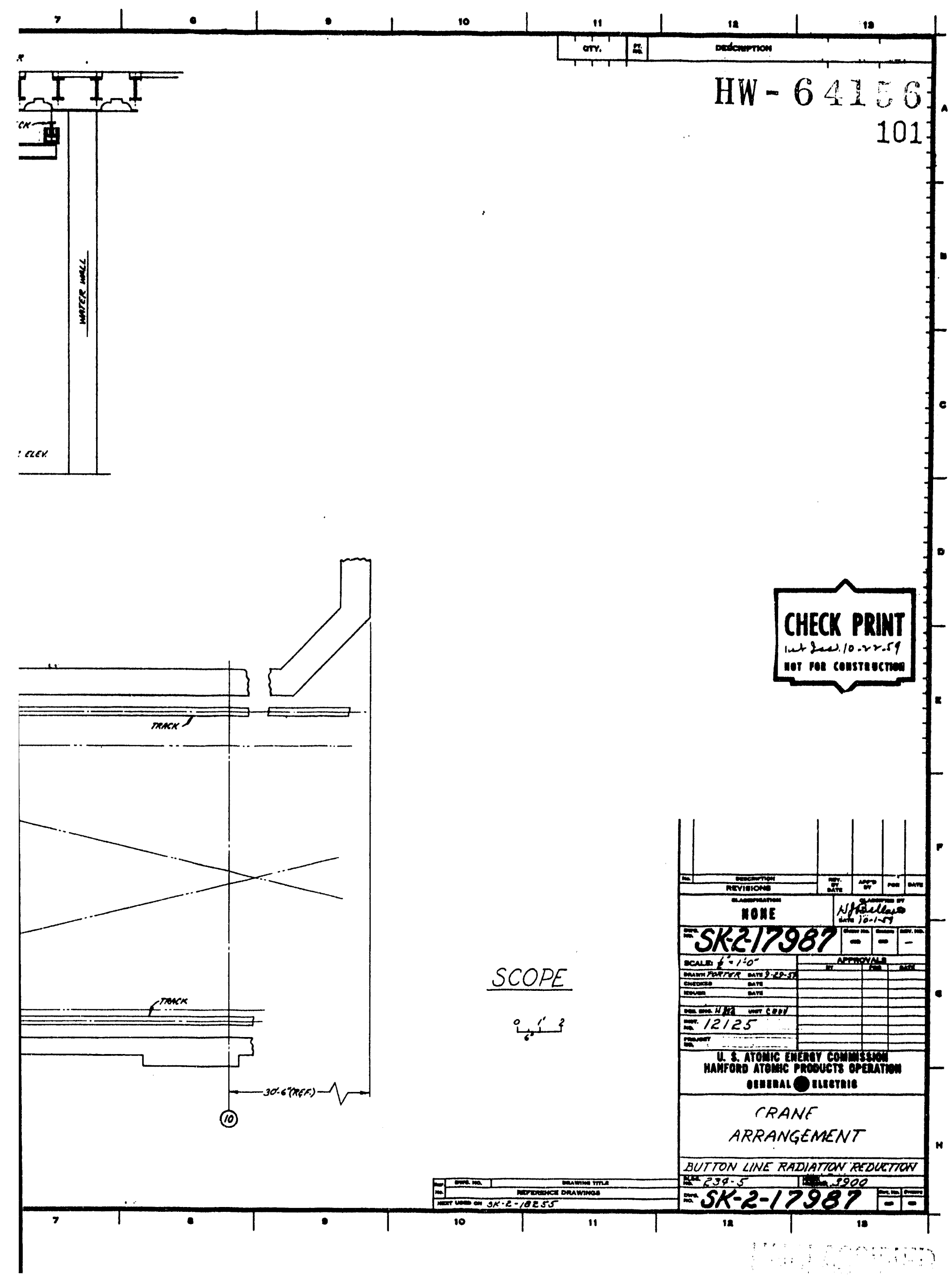



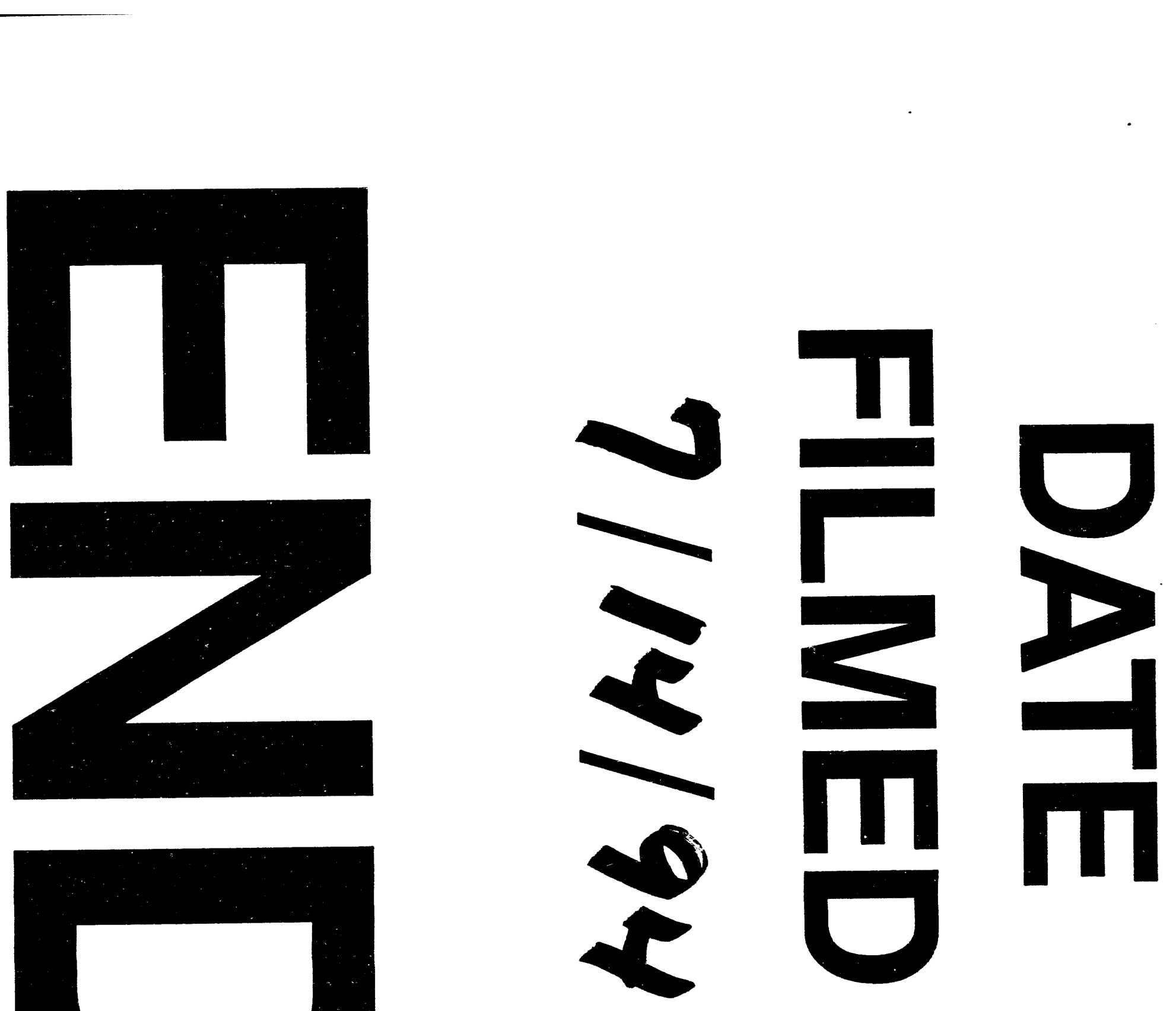

F

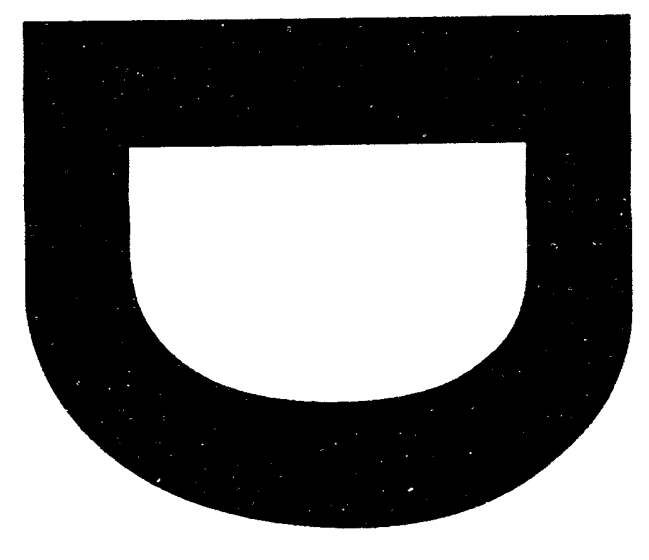




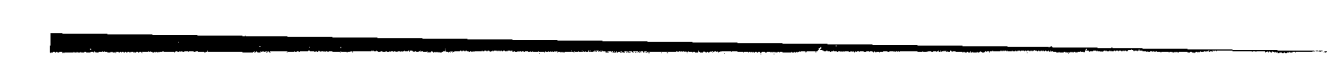

